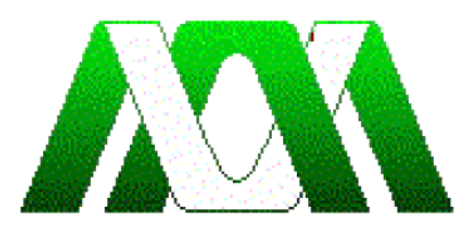

Casa abierta al tiempo

UNIVERSIDAD AUTÓNOMA METROPOLITANA

UNIDAD IZTAPALAPA

DIVISIÓN DE CIENCIAS SOCIALES Y HUMANIDADES

POSGRADO EN CIENCIAS ANTROPOLÓGICAS

El proceso político del Proyecto Tren Maya: narrativas y disputa por recursos (2018-2019)

Marco Enrique Almeida Poot

Tesina de Maestría en Ciencias Antropológicas

Directora: Dra. Ella Fanny Quintal Avilés

Asesores: Dr. Luis Bernardo Reygadas Robles Gil

Dr. Samuel François Jouault 


\section{El proceso político del Proyecto Tren Maya: narrativas y disputa por recursos}

(2018-2019)

Introducción 1

Capítulo 1. El Proyecto Tren Maya. .13

1.1 Programas y proyectos antecedentes. 13

1.2 Características principales del Proyecto Tren Maya............................25

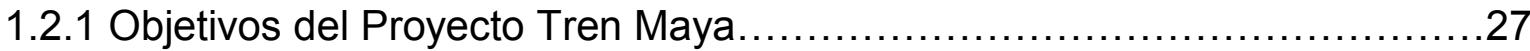

1.2.2 Ruta, paraderos, estaciones y comunidades sustentables....................28

1.2.3 Características técnicas del equipo e infraestructura ferroviaria...............38

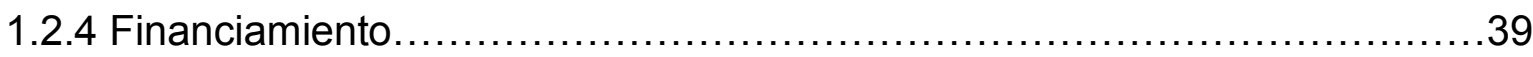

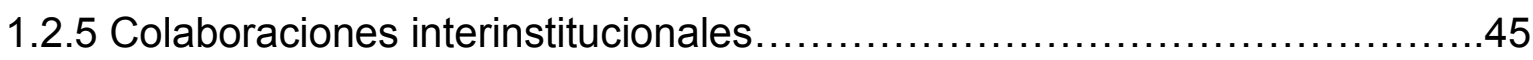

1.2.6 Estado actual de avance de la obra......................................49

1.3 Forma ideal y forma real del actuar gubernamental en el proceso político del

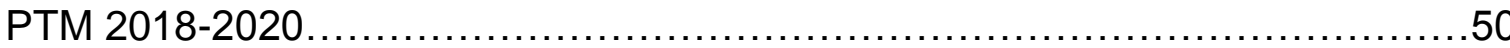

1.4 Continuidades y diferencias entre el proyecto Tren Maya y sus antecedentes.

\section{Capítulo 2. El drama social del Proyecto Tren Maya previo a su existencia}

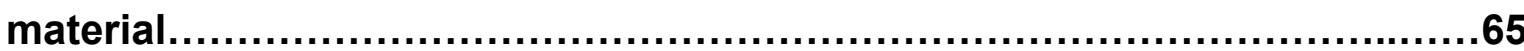

2.1 El procesualismo como teoría y el drama social como método...................66

2.2 Conceptos complementarios al procesualismo turneriano........................74

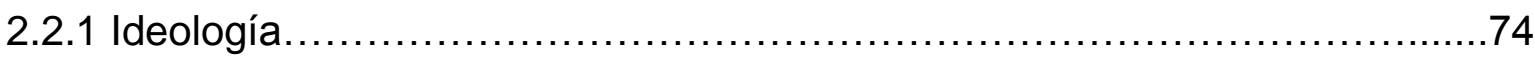

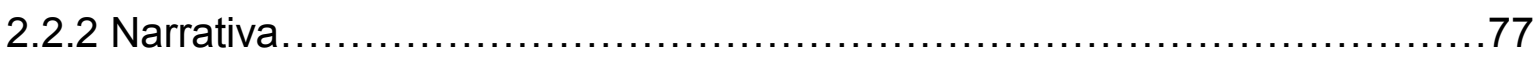

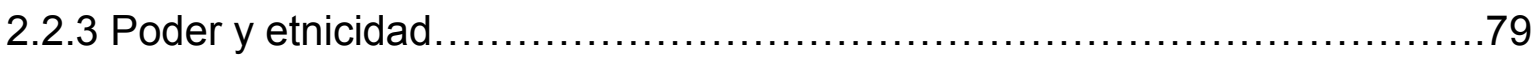

2.2.4 Mayanidad y mayanización..................................................... 81

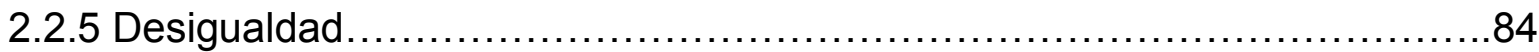

2.3 Conveniencia de analizar el Proyecto Tren Maya como un drama social.......89

2.4 Posibilidad de analizar el fenómeno del Proyecto Tren Maya como un drama

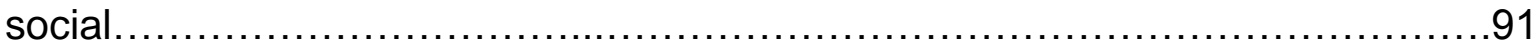

2.4.1 Actores del Campo Político del Proyecto Tren Maya...........................91

2.4.2 Significados y usos de los recursos en disputa: espacio geográfico, mayanidad

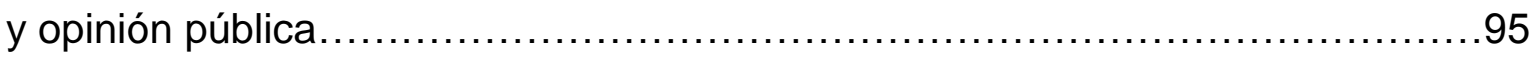

2.4.3 Fases del Drama Social del Proyecto Tren Maya...............................101 
3.1 Procesos políticos antecedentes del proyecto Tren Maya.

3.1.1 Dramas sociales cercanos espaciotemporalmente al drama social del Proyecto Tren Maya. 105

3.1.2 Dramas sociales lejanos espaciotemporalmente al drama social del Proyecto Tren Maya 107

3.1.3 La narrativa del despojo por megaproyectos/resistencia territorial indígena. 108

3.2 Fase 1: Ruptura. 113

3.2.1 El presidente electo AMLO anuncia a RJP como titular de FONATUR y a esta instancia como la encargada del PTM................................................114

3.2.2 Anuncio de la Consulta Nacional sobre los Programas Prioritarios. 115

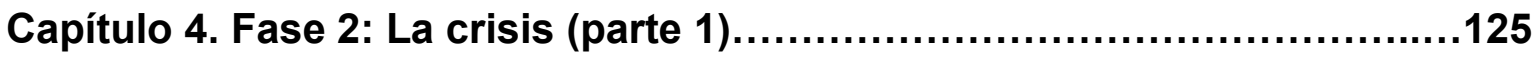

4.1 Consulta Nacional sobre los Programas Prioritarios.

4.2 Toma de protesta de la presidencia y entrega del bastón de mando de los pueblos indígenas. 132

4.3 Ritual de los Pueblos Originarios a la Madre Tierra para anuencia del Tren Maya. 145

4.425 Aniversario del inicio de la guerra contra el olvido (EZLN) .................155

4.5 FONATUR inicia búsqueda de alianzas intersectoriales......................170

4.6 Foro Maya Peninsular convocado por Gubernatura Nacional Indígena........171

Conclusiones.

Bibliografía. .205

ANEXO: Publicaciones escritas por académicos sobre el Proyecto Tren Maya. 209

Notas y referencias a pie de página. .212 


\section{Índice de tablas}

Tabla 1. Detalles sobre los tramos del Proyecto Tren Maya.............................35

Tabla 2. Vocación de los municipios del Tren Maya.......................................

Tabla 3. Instancias académicas colaboradoras en el Proyecto Tren Maya............45

Tabla 4. Agencias de la ONU colaboradoras en el Proyecto Tren Maya.................46

Tabla 5. Asesores técnicos del Proyecto Tren Maya ................................48

Tabla 6. Proceso ideal y proceso real del Proyecto Tren Maya 2018-2020 _..........51

Tabla 7. Sectores y actores sociales en el campo político del Proyecto Tren

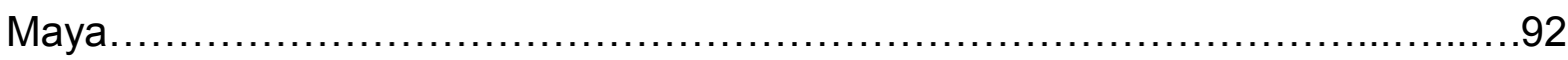

Tabla 8. Significados y usos de los recursos en disputa en el drama social del Proyecto

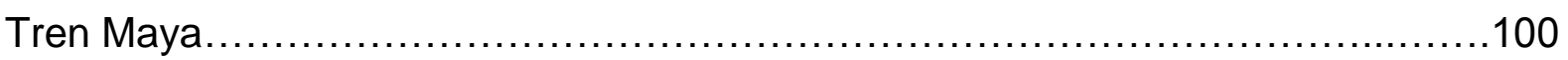

Tabla 9. Fases y eventos del drama social Proyecto Tren Maya.....................102

\section{Índice de imágenes}

Imagen 1. Circuitos del Mundo Maya. En amarillo circuito de aeropistas en la

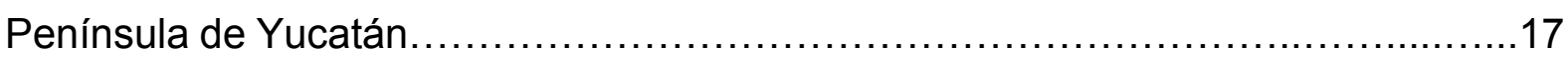

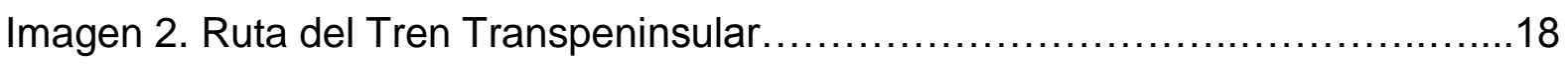

Imagen 3. Ruta del tren Chiapas-Mayab........................................... 19

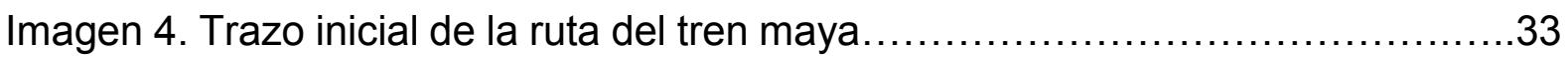

Imagen 5. Cambio de la ruta Valladolid-Cancún por la ruta Valladolid-Cobá-

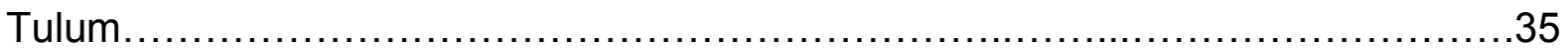

Imagen 6. Trazo actual de la ruta del Proyecto Tren Maya ..............................36

Imagen 7. Nombramiento de Rogelio Jiménez Pons como Titular de

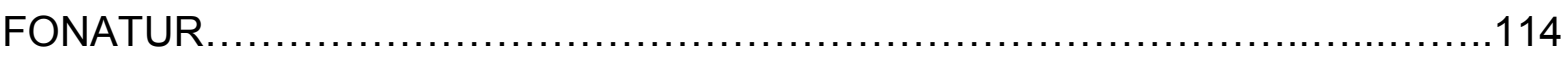

Imagen 8. Boleta de la Consulta Nacional sobre los 10 Programas

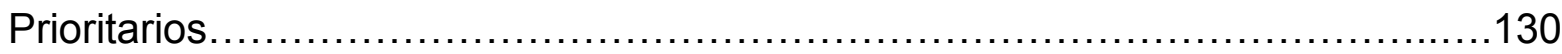

Imagen 9. AMLO en la toma de protesta de la presidencia de los Estados Unidos

Mexicanos

Imagen 10. Zócalo de la Ciudad de México el día que AMLO tomó protesta de la presidencia de la república mexicana.

Imagen 11. Saludando a los cuatro vientos durante la ceremonia de entrega del

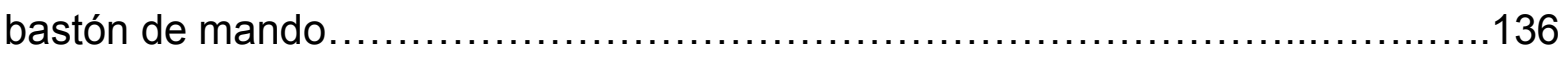

Imagen 12. AMLO recibe el bastón de mando de los pueblos indígenas............139 
Imagen 13. AMLO ostentando el bastón de mando entregado por representantes de organizaciones indígenas

Imagen 14. Hipólito Arriaga Pote, presidente de Gubernatura Nacional Indígena A.C. presentando el bastón de mando no entregado a AMLO.

Imagen 15. Miembros de Gubernatura Nacional Indígena tras serles negado

acercarse al escenario para la entrega del bastón de mando

Imagen 16. José Isabel Sulub Cimá en la ceremonia de entrega del bastón de mando a AMLO.

Imagen 17. Actores del sector gubernamental durante el ritual de los Pueblos

Originarios a la Madre Tierra para anuencia del Tren Maya.

Imagen 18. Ritual de permiso a la Madre Tierra en Palenque para construcción del

Tren Maya

Imagen 19. Jóvenes neozapatistas durante evento artístico en la celebración del 25

aniversario. 156

Imagen 20. Soldados del EZLN en la plaza cívica de La Realidad durante la celebración del 25 aniversario

Imagen 21. Mural en el caracol de La Realidad: Sobre las narrativas

contrapuestas.

Imagen 22. Filiberto Ku Chan cuando se presentaba como "dignatario maya" de GNI (derecha) e Hipólito Arriaga (con sombrero), presidente de GNI 172 Imagen 23. Organizadores del Primer Foro Peninsular Indígena Maya. Ku Chan al centro

Imagen 24. Tiburcio Can realizando una "ceremonia maya" antes del Foro Indígena Maya Peninsular. .173

Imagen 25. Mesa de funcionarios durante el Foro Indígena Maya Peninsular.......175 Imagen 26. Miembros del colectivo Úuchben Ch'i'ibal Túumben T'aan: Feliciano Sánchez Chan, Fidencio Briceño Chel, Marbella Casanova Calam, Elisa Chavarrea Chim y Pedro Uc Be. 182 


\section{Abreviaturas}

AMLO: Andrés Manuel López Obrador

ANP: Área Natural Protegida

APPO: Asamblea Popular de los Pueblos de Oaxaca

APTC: Alianza Peninsular para el Turismo Comunitario

BID: Banco Interamericano de Desarrollo

BM: Banco Mundial

BMV: Bolsa Mexicana de Valores

CAFS-CD: Comisión Asuntos Frontera Sur-Cámara de Diputados

CANACO-SERVYTUR Mérida: Cámara Nacional de Comercio, Servicios y Turismo de Mérida

CCMSS: Consejo Civil Mexicano para la Silvicultura Sostenible

CCRI-CGEZLN: Comité Clandestino Revolucionario Indígena-Comandancia General del EZLN

CCYTET: Consejo de Ciencia y Tecnología del Estado de Tabasco

CDI: Comisión Nacional para el Desarrollo de los Pueblos Indígenas

CDMX: Cludad de México

CEE: Comunidad Económica Europea

CICY: Centro de Investigaciones Científicas de Yucatán

CIDH: Comisión Interamericana de Derechos Humanos

CIEA: Centro de Investigación y Estudios Avanzados

CIESAS: Centro de Investigaciones y Estudios Superiores en Antropología Social

CIG: Consejo Indígena de Gobierno

CINVESTAV: Centro de Investigación y de Estudios Avanzados del IPN

CIP: Centro Integralmente Planeado

CMI: Corredor Multimodal Interoceánico

CMIC: Cámara Mexicana de la Industria de la Construcción

CNDH: Comisión Nacional de Derechos Humanos 
$\mathrm{CNI}$ : Congreso Nacional Indígena

CNI-CIG: Consejo Indígena de Gobierno del Congreso Nacional Indígena

CNT: Confederación Nacional Turística

CONACYT: Consejo Nacional de Ciencia y Tecnología

CONALEP: Colegio Nacional de Educación Profesional Técnica

CONCANACO-SERVYTUR: Confederación de Cámaras Nacionales de Comercio, Servicios y Turismo

COPARMEX: Confederación Patronal de la República Mexicana

CPTM: Consejo de Promoción Turística de México

CPPTM: Campo Político del Proyecto Tren Maya

CRIPX: Consejo Regional Indígena y Popular de Xpujil

CROC: Confederación Revolucionaria de Obreros y Campesinos

CRS: Ciudad Rural Sustentable

CTM: Confederación de Trabajadores de México

DEAS-INAH: Dirección de Etnología y Antropología Social del Instituto Nacional de Antropología e Historia

DNR: Derecho de No Residente

DSPTM: Drama Social del Proyecto Tren Maya

DS4T: Drama Social de la Cuarta Transformación

ECOSUR: El Colegio de la Frontera Sur

ENAH: Escuela Nacional de Antropología e Historia

EZLN: Ejército Zapatista de Liberación Nacional

FIBRA: Fldeicomiso de Infraestructura y Bienes Raíces

FONATUR: Fondo Nacional de Fomento al Turismo

GC-TTM: Grupo constituido por CONACYT para el análisis de riesgos en los territorios en los que está proyectado el Tren Maya

GNI: Gubernatura Nacional Indígena

IICA: Instituto Interamericano de Cooperación para la Agricultura 
IMCO: Instituto Mexicano para la Competitividad

INAH: Instituto Nacional de Antropología e Historia

INPI: Instituto Nacional de los Pueblos Indígenas

IPN: Instituto Politécnico Nacional

ITM: Instituto Tecnológico de Mérida

MIA: Manifestación de Impacto Ambiental

MIA-TMF1: Manifestación de Impacto Ambiental del Tren Maya Fase 1

MORENA: Movimiento Regeneración Nacional

NAIM: Nuevo Aeropuerto Internacional de México

NUM: Naciones Unidas México

ODS: Objetivos del Desarrollo Sostenible

OEA: Organización de Estados Americanos

OIT: Organización Internacional de Trabajo

OMT: Organización Mundial del Turismo

ONU: Organización de las Naciones Unidas

ONU-DH: Oficina del Alto Comisionado de la ONU para los Derechos Humanos

ONU-Habitat: Programa de las Naciones Unidas para los Asentamientos Humanos

OSC: Organización de la Sociedad Civil

PAN: Partido Acción Nacional

PEMEX: Petróleos Mexicanos

PIB: Producto Interno Bruto

PND: Plan Nacional de Desarrollo 2019-2024

PRI: Partido de la Revolución Institucional

PRIAN: Partido de la Revolución Institucional-Partido Acción Nacional

PTM: Proyecto Tren Maya

PYMES: Pequeñas y Medianas Empresas

RJP: Rogelio Jiménez Pons 
SCJN: Suprema Corte de Justicia de la Nación

SECTUR: Secretaría de Turismo

SEDENA: Secretaría de la Defensa Nacional

SEDESPI: Secretaría para el Desarrollo Sustentable de los Pueblos Indígenas

SEGOB: Secretaría de Gobernación

SEMARNAT: Secretaría de Medio Ambiente y Recursos Naturales

SHCP: Secretaría de Hacienda y Crédito Público

TLCAN: Tratado de Libre Comercio de América del Norte

TT: Tren Transpeninsular Mérida-Punta Venado

TTT: Tren Turístico Transpeninsular

UADY: Universidad Autónoma de Yucatán

UAM: Universidad Autónoma Metropolitana

UIMQROO: Universidad Intercultural Maya de Quintana Roo

UJAT: Universidad Juárez Autónoma de Tabasco

UNAM: Universidad Nacional Autónoma de México 


\section{Agradecimientos}

Este trabajo no hubiera sido posible sin el apoyo, colaboración y recomendaciones de muchas personas y las múltiples facilidades institucionales recibidas. En primera instancia, la realización de los estudios de maestría en Ciencias Antropológicas en la Universidad Autónoma Metropolitana Unidad Iztapalapa, cuyo resultado final es esta tesina, fue posible gracias a la beca del Programa Nacional de Posgrados de Calidad otorgada por el Consejo Nacional de Ciencia y Tecnología. Igualmente, la Rectoría de la Universidad Autónoma Metropolitana cumplió un papel importante en el financiamiento de esta investigación mediante el Apoyo Extraordinario para Estudiantes del Programa Nacional de Posgrados de Calidad 2020.

De manera particular agradezco a la directora de esta tesina, la Dra. Ella Fanny Quintal Avilés, del Instituto Nacional de Antropología e Historia-Yucatán, cuyas agudas observaciones y recomendaciones, así como el constante intercambio de información y el acompañamiento durante un par de eventos en trabajo de campo, nutrieron las reflexiones en torno al Proyecto Tren Maya y lo plasmado en este documento.

Agradezco también al Dr. Luis Reygadas Robles Gil del Departamento de Antropología de la Universidad Autónoma Metropolitana Unidad Iztapalapa, quien fue lector de este trabajo. Quisiera agradecerle ampliamente el haberme motivado a profundizar el análisis de los datos sistematizados. Las aportaciones del Dr. Reygadas han sido fundamentales para redondear varios aspectos del estudio.

Igualmente, aprovecho para agradecer al Dr. Samuel François Jouault, profesor-investigador de la Licenciatura en Turismo de la Universidad Autónoma de Yucatán. Como lector de esta tesina aportó valiosas observaciones que abonaron a mejorar la versión final. Igualmente, ha sido una influencia clave en mi interés sobre el estudio del turismo en la Península de Yucatán y el impulso del turismo comunitario en la región, como alternativa para disminuir las desigualdades sociales. Sobre todo le agradezco las facilidades otorgadas para la realización de parte del trabajo de campo, con cooperativas de turismo comunitario del oriente de Yucatán pertenecientes a la Co'ox Mayab y, a través de esta, a la Alianza Peninsular de Turismo Comunitario. 
Agradezco también a los profesores de la maestría en Ciencias Antropológicas de la UAM-I. Ha sido un placer y un privilegio haber tomado los cursos con la guía de tan buenos investigadores. Agradezco especialmente a aquellos con quienes tuve la fortuna de platicar sobre el tema de esta tesina, gracias a la Dra. María Ana Portal Ariosa, a la Dra. Ana Rosas Mantecón, a la Dra. Margarita Zárate Vidal, al Dr. Federico Besserer Alatorre, al Dr. Leonardo Tyrtania Geidt, al Dr. Ricardo Falomir Parker, al Dr. Héctor Tejera Gaona, al Dr. Pablo Castro y a la Dra. Natalia Radetich Filinich por las charlas donde me brindaron múltiples recomendaciones para la realización de este trabajo así como bibliografía pertinente. Gracias también al Dr. Esteban Krotz Heberle de la Universidad Autónoma de Yucatán y a la Dra. Xóchitl Leyva Solano del CIESASSureste por la constante compartición de información y las recomendaciones bibliográficas. Gracias también a Socorro Flores y Nancy Flores del Departamento de Antropología de la UAM-I por su invaluable apoyo en cuestiones administrativas.

Asimismo, agradezco a los socios y al equipo técnico de la articuladora de cooperativas de turismo comunitario Co'ox Mayab por las facilidades brindadas durante el trabajo de campo. Los socios optaron por mantener el anonimato en esta investigación, pero sépase que les estoy muy agradecido. Del equipo técnico quisiera agradecer de manera particular a Alejandro Montañez.

Aprovecho para agradecer a mi familia, especialmente a mis abuelos Alicia Salazar Campos y Enrique Poot Pech, a ustedes dedico este pequeño gran paso de mi formación profesional. Gracias también a Laura por el cariño, apoyo y las estimulantes conversaciones durante el proceso de elaboración de este trabajo.

Por último, quisiera agradecer a los compañeros de la generación 2018 de la maestría en Ciencias Antropológicas UAM-I. Ha sido un verdadero placer compartir cursos y caminos. Gracias especialmente a los pretextualistas Antonio Guerrero, Octavio Franco, Rodrigo Roque y Julieth Narváez. 


\section{Introducción}

El Proyecto Tren Maya (PTM) o Tren Turístico Transpeninsular (TTT) es un proyecto de infraestructura y reordenamiento territorial del sur-sureste mexicano basado en el turismo, el transporte de mercancías y la construcción o ampliación urbana planificada de localidades, denominadas "Comunidades Sustentables" o "polos de desarrollo". El PTM ha sido ideado y priorizado discursiva y presupuestalmente por el actual presidente de México, Andrés Manuel López Obrador (2018-2024).

El proyecto contempla la rehabilitación y construcción de vías férreas, estaciones, paraderos, nuevos desarrollos urbanos y la puesta en marcha de trenes de turistas, pasajeros locales y de carga en la región sur-sureste del país, conectando mediante un circuito ferroviario los estados de Chiapas, Tabasco, Campeche, Yucatán y Quintana Roo. Las obras iniciaron en mayo del 2020 y oficialmente se prevé que el Tren Maya inicie operaciones en 2024.

Como se verá en este trabajo, el PTM en sí no es tan innovador como el sentido desde el cual se propone realizarlo, pues retoma elementos de programas y proyectos de administraciones estatales y federales anteriores, refuncionalizándolos de acuerdo a los objetivos y valores de la Cuarta Transformación, la gran narrativa gubernamental -pretendidamente anti corrupción, no neoliberal y que prioriza a las clases popularesdesde la cual se propone el Tren Maya como vía para el desarrollo sostenible de la Península de Yucatán.

Dado que el PTM no es actualmente una realidad material, por ahora el estudio antropológico del fenómeno se acota al análisis de lo dicho y lo hecho en torno a los preparativos de su construcción. Desde el año 2018, múltiples actores sociales se han posicionado a favor y en contra del proyecto, tanto a nivel nacional como regional y al interior de las entidades federativas contempladas en el proyecto.

Estos actores pertenecen a variados sectores sociales como el gubernamental, empresarial, el de los poseedores legales de las tierras (ejidatarios o particulares), Organizaciones de la Sociedad Civil (OSC), academia, el activismo étnicoambientalista y el sector periodístico. Al interior de estos sectores y entre ellos han surgido alianzas y antagonismos, orientados a fortalecer a las facciones promovente 
y oponente del PTM. La facción promovente es encabezada por el sector gubernamental y la oponente es heterogénea y no centralizada. Asimismo, ha quedado en evidencia la diversidad de perspectivas al interior de los sectores sociales referidos.

Desde que el entonces presidente electo López Obrador nombró a Rogelio Jiménez Pons como titular del Fondo Nacional de Fomento al Turismo (FONATUR) y a esta instancia como la encargada del PTM -en agosto del 2018- los diversos actores sociales han generado tanto críticas y descalificaciones al proyecto y a sus promoventes, como propuestas de colaboración, observaciones y sugerencias para evitar o reducir los impactos sociales y ambientales negativos que pudiera desencadenar.

En este sentido, los actores sociales han realizado eventos para hacer públicos sus posicionamientos a favor o en contra. Se han llevado a cabo mítines políticos, supuestos rituales indígenas, mesas de trabajo, talleres, manifestaciones, coloquios, asambleas, mesas panel, proyectos de investigación en ciencias sociales y ambientales, publicaciones académicas, investigaciones periodísticas, comunicados, ruedas de prensa, cartas abiertas, amparos legales, webinarios, etcétera.

La reiteración de temas, estilos retóricos y opiniones en los discursos orales o escritos de los actores, devela la persistencia y conformación de narrativas particulares en torno al Tren Maya. Dichas narrativas tienen la función de conseguir la hegemonía para quienes las sostienen, tanto al interior de un sector como entre ellos, y para ganar la simpatía, aprobación o respaldo de la ciudadanía en general con respecto a la posición asumida ante el Tren Maya.

A lo largo de este trabajo se analizarán algunas de estas narrativas, como las de la turistificación-mayanización; la del despojo por megaproyectos y resistencia territorial indígena; la de la Cuarta Transformación; la del desarrollo; y las múltiples narrativas sobre la mayanidad activadas en torno al PTM, desde las cuales, por dar algunos ejemplos, la mayanidad es concebida como una identidad étnica para la movilización popular, como una marca comercial para generar valor agregado a productos y servicios o como patrimonio cultural a conservar y promover. 
En última instancia, la realización de eventos, el despliegue de narrativas, la conformación de alianzas y antagonismos, persiguen un fin común: conseguir o mantener el control sobre recursos o bienes significativos, sean materiales 0 inmateriales. En el caso del Proyecto Tren Maya, los recursos en disputa detectados y analizados en este estudio son tres: el espacio geográfico y su contenido de origen natural y humano; la mayanidad-indigeneidad y la opinión pública. En este sentido, se puede afirmar que estamos ante un proceso social conflictivo en el que hay bienes 0 recursos y sus significados en juego, es decir, se trata de un proceso político. De tal forma, considero posible y conveniente abordar el proceso político del Tren Maya desde la perspectiva procesualista de Victor Turner, recurriendo al método del drama social. Explico en párrafos más adelante los motivos de esta elección, antes es necesario hacer algunas precisiones.

Para la realización de este trabajo no se establecieron de antemano los recursos significativos en disputa. Tampoco se prejuzgó a los actores y sus narrativas, más bien se procuró mantener una mirada abierta y atenta a las constantes y particularidades para que fuera sobre la marcha del proceso político que se develaran por sí mismos los actores; las narrativas a las cuales recurren, abonan y promueven; los recursos o bienes en disputa y los significados y usos que les son dados.

En función de lo anterior, se puede afirmar que este trabajo se distingue de otros acercamientos al tema desde las ciencias sociales, pues no se partió de la idea de que el Proyecto Tren Maya es un megaproyecto para despojar del territorio a los pueblos indígenas de la región. Tampoco se dio por sentado que el PTM es un proyecto neoliberal que responde directamente a las órdenes del capital transnacional. No obstante, esto no quiere decir que se haya optado por los opuestos lógicos y políticos que conciben al PTM unidimensionalmente como un proyecto para el desarrollo -acaso sostenible- del sur de México. En este trabajo, las perspectivas como las referidas son tomadas como datos, como fenómenos mismos de la realidad social, como narrativas, y no como puntos de partida o llegada para la investigación antropológica.

Estos esquemas sobre-simplificadores -tendientes al esencialismo y al maniqueísmo- son escasamente útiles para comprender y explicar la realidad social. Sin embargo, representan estrategias para legitimar y deslegitimar agendas políticas 
a favor y en contra de proyectos como el Tren Maya que -debido a su complejidad y multidimensionalidad inherente- pueden ser objeto de múltiples lecturas. Dichos esquemas no se proponen comprender la realidad social, sino crear un piso común, una narrativa compartida, para dar sentido a una agenda, intención o creencia, un actuar e incluso una identidad personal o colectiva, un proyecto de vida o civilidad. De tal modo, es comprensible que desde ciertas facciones del sector académico frecuentemente con buenas intenciones- se opte por generar investigaciones que sirvan para dar sustento y validez científica a narrativas particulares, ya sean a favor o en contra de proyectos como el PTM, dependiendo de la subjetividad, trayectoria y circunstancia del investigador en el campo político.

Estos trabajos pueden ser poco o muy elaborados, con escasas o vastas referencias, con genealogías académicas rastreables o no, pueden corresponder a las corrientes hegemónicas o marginales de las discusiones disciplinarias, pueden ser aplaudidos o denostados por los colegas. Es decir, a pesar de que transversalmente pueden ser considerados justificaciones en extenso de un juicio a priori, unos pueden ser más verosímiles que otros o tener mayor respaldo que otros, dentro o fuera de la academia. No es algo nuevo afirmar que la academia es también un campo político y que la generación de conocimiento no es cultural ni políticamente neutral. Lo que me parece que no es común, es discutir sobre el falso dilema que la práctica de la justificación -benevolente, inercial o sumisa- de narrativas representa y suele tomarnos por asalto: ¡la verdad o la vida!

Planteo que es posible y necesario hacer investigaciones antropológicas que equilibren la generación de conocimiento científico sobre la realidad social y la incidencia positiva en la misma. Por un lado, considero que un científico social no debe engañarse/forzarse a sí mismo ni a otros intentando justificar alguna narrativa cuando es consciente de que lo es. Más bien, es imprescindible mantener en todo momento una postura crítica, autocrítica y velar por una vigilancia epistémica constante -que no ignore la mixtura de privilegios y desventajas que conforman cada subjetividad- que permita acercarse a una honesta pretensión de verdad.

Por otro lado, me parece que una de las vías para incidir positivamente en la sociedad estudiada, es a través de la atención a las desigualdades que presenta, ya sean de clase, étnicas, raciales, de género, sexo, etarias, por asimetrías 
centro/periferia, etc. En este trabajo se reflexiona principalmente sobre la dimensión étnica de las desigualdades en la sociedad peninsular, en concreto, sobre las mayanidades y sus usos, cuya consideración no fue punto de partida sino que se fue develando gradualmente. Este trabajo versa sobre mi sociedad y sobre el territorio con el cual me identifico, pues soy yucateco, meridano, hispanohablante, mayadescendiente y blanco-mestizo.

Para cuidar la vida, es decir, para comprometerse con los miembros de una sociedad -sobre todo con quienes viven las penurias de las desigualdades- es necesario comprenderla en sus propios términos. Pero ¿de quiénes son esos términos en realidad? ¿Cuándo son de quién? ¿Se debe comprometer el investigador de antemano con algún sector social? ¿Puede abonar a construir relaciones más equitativas si en sus puntos de partida considera a los actores como esencialmente diferentes y desiguales? ¿A quiénes sirve la romantización y estigmatización de los actores en las ciencias sociales? En este trabajo se considera que las desigualdades -aunque estructurales- son contingentes. $Y$ en vista de que cada actor puede priorizar su propia voz, el investigador sí podría aportar a la sociedad al "dar voz a los sin voz" -sin duda necesaria labor-, pero sería también de provecho si lograra comprender y explicar la polifonía y encontrara rutas de mediación de conflictos, organización y atención a las desigualdades, lo cual es menos frecuente tanto en logros como en intentos.

Este estudio, como acercamiento inicial al Proyecto Tren Maya, apunta a la segunda opción. No se partió de romantizar o estigmatizar a ningún actor, pues las desigualdades son construidas socialmente, es decir, todos estamos involucrados en su producción, reproducción y transformación. Es necesario conocer cómo se manifiestan, producen y reproducen las desigualdades sociales en las narrativas y en las disputas por recursos en el PTM -y en cualquier otro proceso político- para proponer rutas de incidencia social. Así pues, como se verá a lo largo del texto, el tipo de compromiso social presente en este trabajo antropológico fue construido a lo largo del mismo y no de antemano, se partió de un intento de escepticismo crítico.

Este posicionamiento personal no debe ser malinterpretado como una descalificación de los acercamientos académicos ya existentes al Tren Maya, tanto a favor como en contra, implicados o desde fuera, sin duda tengo mucho que aprender 
de sus ejecutores, quienes en su mayoría tienen más experiencia que yo en la investigación social. Tal vez por eso mismo, por la reiteración de resultados en sus indagaciones a lo largo de los años, sus puntos de partida y llegada pueden parecer justificaciones de juicios a priori, sin serlo tal vez. Coincido en que como sociedad nacional y peninsular aún arrastramos los lastres del despotismo de la clase política y el clasi-racismo estructural, pero apelo a que puede ser de otra manera y para construir alternativas pragmáticas hacen falta acercamientos alternativos a la realidad social. Con este trabajo inicial sobre el Proyecto Tren Maya pretendo sentar las bases de una investigación doctoral que permita ensayar otras rutas de indagación e incidencia social.

El primer paso fue explorar bibliografía que pudiera servir para analizar el fenómeno social del Proyecto Tren Maya (el llamarle proceso político vino después). Revisé trabajos sobre antropología de la infraestructura; territorio y geopolítica; megaproyectos en territorios indígenas; poder, política y movimientos sociales; etnicidad e identidades indígenas contemporáneas; narrativas territoriales; turismo en el área maya; racismo; mayanidad; desarrollo; decolonialidad; desigualdad, etc.

Cada uno de estos temas generales abría vetas interesantes para mirar el fenómeno, pero por separado parecían insuficientes. Al sistematizar la información generada sobre el Tren Maya al mismo tiempo que buscaba un enfoque teórico que sirviera para explicar el fenómeno, cada una de las vetas mencionadas era desbordada. Fue así que me propuse encontrar la forma de articularlas de manera coherente y pertinente para comprender y explicar el fenómeno del Tren Maya. Esto se logró sólo de manera parcial. A final de cuentas, es todo un reto retratar una realidad multidimensional con las herramientas lineales de la escritura, aunado a los límites institucionales de tiempo y extensión del documento. Asumo pues que el tema superó mi capacidad para conectar una vasta y creciente cantidad de eventos, microprocesos, epifenómenos, discursos y perspectivas sobre el Tren Maya. Acaso sólo es posible lograr esta tarea con un equipo de investigación. Es así que este trabajo puede considerarse como la exploración articulada de vetas de investigación abiertas, con resultados no concluyentes para ser profundizados en la tesis doctoral.

El Proyecto Tren Maya es un fenómeno complejo puesto que implica variables locales, estatales, regionales, nacionales y globales; políticas, económicas, sociales, 
(multi) culturales y ambientales; narrativas diversas sobre la realidad pasada, presente y las posibilidades utópicas y distópicas del futuro; a una diversidad de actores con variadas perspectivas sobre lo que el fenómeno del Tren Maya es, lo que representa y significa. El modo más prometedor que hallé para articular las dimensiones de análisis referidas fue mediante el método del drama social, propuesto por Victor Turner en su teoría procesualista, a la cual llegué a través de la obra de Rodrigo Díaz Cruz (2014) Los lugares de lo político, los desplazamientos del símbolo. Poder y simbolismo en la obra de Victor W. Turner.

El procesualismo como teoría y el drama social como método tienen varias ventajas para estudiar el Tren Maya, en comparación con otros posibles acercamientos aislados como los ya señalados, incluso permite articularlos de manera crítica. En el capítulo 2 de este documento expongo con mayor detenimiento las características del procesualismo, del drama social y los motivos por los cuales elegí esa ruta para realizar esta investigación; por ahora adelanto tres ideas. En primera instancia, el uso del drama social permite sondear la realidad y sus posibilidades de interpretación. Permite un "mapeo" de los actores, sus ideologías, narrativas, representaciones y discursos, valores, creencias, interacciones, alianzas, antagonismos, los recursos materiales e inmateriales por los que luchan y los recursos de los que disponen. Además, es una especie de síntesis historiográfica con perspectiva antropológica en tiempo real, pues se basa en el análisis de eventos concatenados.

En segundo lugar, considero que el método del drama social facilita la constante vigilancia epistémica. Al recolectar y ordenar la información se procura no imprimir juicios de valor propios, la atención está puesta en los juicios de valor, narrativas, discursos, acciones, etc. de los otros actores implicados en el campo, no para confirmar las ideas preconcebidas del antropólogo, sino para ofrecer una vista panorámica de la multiplicidad de perspectivas sectoriales con la intención de comprenderlas, analizarlas y explicarlas, considerando los modos en que se manifestaron en la realidad y el cómo interpelan la subjetividad del investigador y su marco teórico, necesariamente ubicados en el entramado de la construcción del sentido de la realidad social y sus significados. 
De tal modo, con una deliberada vigilancia epistémica, producto del espejeo constante con las otras perspectivas, el antropólogo podrá decantarse por alguna 0 algunas de las vetas de investigación e incidencia abiertas por la realidad misma y su discurrir en ella, sin haberla elegido a priori, lo que habitualmente -como ya se señalótermina por forzar la realidad para adecuarse a los prejuicios, sesgos y tendencias tanto del autor como de las discusiones antecedentes a las cuales busca interpelar o a la cuales intenta insertarse.

En tercer lugar, quisiera enfatizar, particularmente, la virtud teórica y metodológica que implica el uso de categorías flexibles espacial y temporalmente para el estudio de los fenómenos sociales, como las propuestas en el procesualismo turneriano. Tienen una ventaja sobre otras propuestas al poder establecer puentes entre las dimensiones macro y micro, intrasociales e intersociales (entendiendo a las sociedades como unidades abiertas), entre el pasado y el presente, entre lo material y lo simbólico, entre el tiempo, el espacio, la mente, la agencia, lo político y lo económico. Los símbolos, en tanto su eficacia y performatividad, (re)producen la realidad social. La configuración de los significados se traduce en el control de recursos, tanto materiales como inmateriales. En este sentido, se develan las relaciones de lo simbólico con lo político y lo económico. Con el procesualismo turneriano no se pretende generar una teoría omniabarcadora, lo relevante es la multiplicidad de dimensiones de la realidad social que evoca y permite conectar.

En este sentido, en función del eje teórico y el método elegido, este trabajo no parte de una hipótesis a comprobar o refutar, sino que se propone un objetivo de investigación: ofrecer un balance de la disputa por recursos materiales e inmateriales significativos en torno a la construcción del PTM, de agosto del 2018 a marzo del 2019, analizando las acciones, alianzas, antagonismos, narrativas y usos simbólicos desplegados por diversos sectores sociales, como son el gubernamental, empresarial, dueños legales de las tierras, académico, Organizaciones de la Sociedad Civil (OSC), activismo étnico-ambientalista y periodístico. Las preguntas que se busca responder con este objetivo de investigación a lo largo del documento, son:

1. ¿Qué es el Proyecto Tren Maya y en qué se parece y distingue de otros proyectos del Estado mexicano en administraciones anteriores?

2. ¿Quiénes son los actores que disputan recursos en torno al Tren Maya? 
3. ¿Cuáles son los recursos disputados y cómo son significados por los diversos actores?

4. ¿Qué acciones -simbólicas- emprenden los actores para lograr la hegemonía al interior de sus sectores y en el campo político amplio?

5. ¿Cuáles son las narrativas que utilizan los actores para justificar y explicar sus posicionamientos y acciones ante el Tren Maya?

6. ¿Cuáles son las características de dichas narrativas?

7. ¿Cuáles son las alianzas y antagonismos detectados?

8. ¿Qué facción tiene la hegemonía en el campo político y está más cerca de lograr sus objetivos, la promovente o la oponente?

9. ¿Cómo se manifiestan las desigualdades sociales en el campo político del Tren Maya?

10. ¿Qué desigualdades sociales puede producir o reproducir el Tren Maya en la región?

11. ¿Qué se puede hacer al interior del campo político del Tren Maya para disminuir las desigualdades sociales en la región?

La información necesaria para realizar el balance y responder estas preguntas fue obtenida mediante un seguimiento vía internet del fenómeno, considerando el sitio web y la cuenta oficial de Facebook del Tren Maya; las notas e investigaciones a profundidad generadas por la prensa nacional y extranjera; las declaraciones, comunicados, estudios y demás producciones escritas realizadas por los sectores OSC, activista y académico; así como las discusiones y mesas panel en redes sociales como Facebook, Twitter, Youtube y Zoom, que incrementaron desde fines de marzo del 2020 en el contexto de la pandemia de COVID-19. Igualmente tuve la oportunidad de participar en tres reuniones virtuales entre personal de FONATUR y ciudadanos de la Península en junio y julio del 2020, con el fin de resolver dudas y exponer inquietudes con respecto al PTM. He realizado este seguimiento en línea desde agosto del 2018 hasta la actualidad (noviembre del 2020).

Igualmente obtuve información mediante el trabajo de campo realizado entre los meses de febrero a abril del 2019, durante la huelga de la UAM. En este periodo asistí a foros y mesas panel sobre el turismo y sobre el Proyecto Tren Maya en Mérida, Yucatán; realicé observación participante en talleres sobre el turismo en Yucatán 
organizados por instancias gubernamentales; asistí a la asamblea semestral de una OSC articuladora de cooperativas de turismo comunitario en la que compartí avances preliminares de investigación para generar un diálogo; realicé entrevistas, encuestas y tuve pláticas informales durante el trabajo de campo en las localidades yucatecas de Chichén Itzá-Pisté, Valladolid, Izamal y Mérida, donde se contempla construir estaciones del PTM; y en Yokdzonot y Ek Balam que cuentan con cooperativas de turismo comunitario y son cercanas a Chichén Itzá y Valladolid respectivamente.

La información recabada y sistematizada, ya sea de primera o segunda mano, excedía por mucho las posibilidades de este acercamiento inicial al fenómeno, por lo que buena parte de los materiales serán analizados en la tesis doctoral. Se menciona la información sistematizada pero no analizada únicamente para abonar a la Idónea Comunicación de Resultados que estipula el Departamento de Antropología de la Universidad Autónoma Metropolitana-Unidad Iztapalapa.

En el "Capítulo 1. El Proyecto Tren Maya", se pretende responder a la pregunta ¿qué es el Proyecto Tren Maya y en qué se parece y distingue de otros proyectos del Estado mexicano en administraciones anteriores? Para ello, se presentan los programas y proyectos gubernamentales que pueden considerarse antecedentes del Tren Maya. Luego se exponen las características principales del PTM: los objetivos declarados del proyecto; la ruta y ubicación de los paraderos, estaciones y "comunidades sustentables"; las características técnicas del equipo e infraestructura ferroviaria; el financiamiento; las colaboraciones interinstitucionales para su realización; el estado actual de avance de la obra; un contraste entre las formas ideal y real del proceso del PTM desde el actuar gubernamental 2018-2020. Por último, se ofrece un balance de las continuidades y diferencias encontradas entre los objetivos del Tren Maya y los programas y proyectos gubernamentales antecedentes señalados.

En el "Capítulo 2. El drama social del Proyecto Tren Maya previo a su existencia material", expongo el marco teórico y conceptual de este estudio, basándome en la propuesta del procesualismo turneriano y complementando con propuestas de otros autores, sobre los conceptos de ideología, narrativa, la relación poder-etnicidad, mayanidad y mayanización, y desigualdad. Asimismo, argumento por qué el Proyecto Tren Maya y sus efectos en la sociedad pueden ser entendidos 
como un proceso político y por qué es posible analizarlo con el método del drama social. Para esto comparto información sobre los actores del campo político, los recursos en disputa y los principales eventos de la primera y parte de la segunda fase del drama social del Proyecto Tren Maya (DSPTM) -ruptura y crisis respectivamentedesde el anuncio de FONATUR como la instancia encargada del proyecto en agosto del 2018 hasta las reacciones al Foro Maya Peninsular sobre el PTM convocado por Gubernatura Nacional Indígena (GNI) en marzo del 2019.

En el "Capítulo 3. Fase 1: La ruptura", se presentan las características teóricas señaladas por Turner y una sucesión de los eventos correspondientes a la fase de ruptura. Cada evento es abordado a través de los principales discursos y acciones de sus protagonistas, así como las reacciones inmediatas -discursos y acciones- de otros actores sociales que forman parte del Campo Político del Proyecto Tren Maya (CPPTM). En este capítulo se aborda la formación de las facciones promovente y oponente mediante el análisis de dos eventos, el primero de ellos es el nombramiento de Rogelio Jiménez Pons como titular de FONATUR y encargado del Tren Maya; el segundo evento es el anuncio de la Consulta Nacional sobre los Programas Prioritarios.

En el "Capítulo 4. Fase 2: La crisis (parte 1)", se exponen las características teóricas de la fase de crisis señaladas por Turner y una primera parte de la relación de eventos correspondientes a dicha fase. Al igual que en el capítulo 3, cada evento es abordado mediante los principales discursos y acciones de sus protagonistas, seguido de las reacciones inmediatas de otros actores sociales que forman parte del Campo Político del Proyecto Tren Maya (CPPTM). Se aborda el devenir de las facciones y las narrativas desplegadas en el CPPTM mediante el análisis de seis eventos. El primero de ellos es la Consulta Nacional sobre Programas Prioritarios; el segundo, la toma de protesta de la presidencia y la entrega del bastón de mando de los pueblos indígenas a AMLO; el tercero, la realización del Ritual de los Pueblos Originarios a la Madre Tierra para anuencia del Tren Maya; el quinto es el inicio de la búsqueda de alianzas intersectoriales por parte de FONATUR; y el sexto y último, el Foro Maya Peninsular, convocado por Gubernatura Nacional Indígena.

En las conclusiones de este trabajo se aborda cómo las diversas narrativas desplegadas en el drama social del Proyecto Tren Maya han servido para disputar el 
control y significado de los recursos espacio geográfico, indigenidad-mayanidad y opinión pública. Se presta particular atención a las narrativas sobre la mayanidad y se presenta una clasificación de las mismas. El análisis y categorización de las narrativas de la mayanidad propuesto es un hilo conductor que permite ofrecer una síntesis de las posiciones de los actores principales del proceso político, en función de las desigualdades interétnicas alrededor del Proyecto Tren Maya. Asimismo, con base en el análisis de los resultados obtenidos, se brindan recomendaciones para que el Proyecto Tren Maya pueda reducir y no reproducir o profundizar las desigualdades interétnicas existentes en la región sur-sureste de México. Por último, se señalan posibles rutas de estudio para la investigación doctoral en ciencias antropológicas 


\section{Capítulo 1}

\section{EI Proyecto Tren Maya}

En este capítulo se pretende responder a la pregunta ¿qué es el Proyecto Tren Maya y en qué se parece y distingue de otros proyectos del Estado mexicano en administraciones anteriores? Para ello, se presentan los programas y proyectos gubernamentales que pueden considerarse antecedentes del Tren Maya. Luego se exponen las características principales del PTM: los objetivos declarados del proyecto; la ruta y ubicación de los paraderos, estaciones y "comunidades sustentables"; las características técnicas del equipo e infraestructura ferroviaria; el financiamiento; las colaboraciones interinstitucionales para su realización; y el estado actual de avance de la obra (septiembre 2020). Seguidamente, se contrastan la formas ideal y la forma real del proceso del PTM desde el actuar gubernamental del 2018 al 2020. Por último, se ofrece un balance de las continuidades y diferencias encontradas entre los objetivos del PTM y los programas y proyectos gubernamentales antecedentes señalados.

\subsection{Programas y proyectos antecedentes}

El turismo es una de las modalidades más importantes de desplazamiento de la población mundial en esta época de globalización del capitalismo tardío. Constituye por una parte un logro de las luchas obreras del siglo XX y a la vez un escenario de reproducción de las desigualdades políticas, económicas y sociales entre los países del Norte y los del Sur y al interior de los mismos (Castellanos Guerrero, 2012).

De acuerdo con el Ranking de Turismo Internacional de 2018 de la Organización Mundial del Turismo (OMT), México ocupó el séptimo lugar mundial en arribo de turistas internacionales y el decimosexto lugar en captación de divisas por la actividad turística (SECTUR, 2019¹). En 2018 esta actividad aportó el 8.7\% del Producto Interno Bruto (PIB) mexicano (Subsecretaría de Planeación y Política turística, 2019:1). Igualmente, fue la tercera fuente de entrada de divisas al país sólo después de la industria automotriz y las remesas ${ }^{2}$. Asimismo, en 2018 se reportaron alrededor de 2.3 millones de puestos de trabajo en la industria turística, lo que representa el 6\% de las ocupaciones remuneradas del país (INEGI, 2019:7). 
Ante este panorama geopolítico y macroeconómico, la regulación de la actividad turística es y ha sido progresivamente de mayor interés para el estado mexicano. Cada administración federal ha tenido sus proyectos y énfasis territoriales y discursivos particulares, no obstante, la visión que se tiene para el sur-sureste del país ha presentado continuidades fundamentales en los siete periodos presidenciales transcurridos de 1988 a la fecha ${ }^{3}$.

En concreto, mediante el uso gubernamental-empresarial de "lo maya", se ha sostenido durante las últimas tres décadas la propuesta de turistificación de los estados mexicanos de Chiapas, Tabasco, Campeche, Yucatán y Quintana Roo y de los países centroamericanos de Guatemala, Belice, Honduras y El Salvador, siendo la Organización Mundo Maya (OMM) la instancia intergubernamental clave para este fin (Secretaría Ejecutiva OMM, 1996; BID, 2000). Dicha organización se conforma por las secretarías de turismo o equivalentes de los cinco países del área maya. Surgió en 1988 por iniciativa de la Organización Mundial del Turismo (OMT) y la Comunidad Económica Europea (CEE) (Moreno Acevedo, 2018:105).

El 21 de junio del 2011, el entonces presidente de México Felipe Calderón (2006-2012) anunció la creación del "Programa Mundo Maya 2012" en el país, el cual fue una reformulación del Programa Mundo Maya creado en el 2000 por la OMM con patrocinio del BID4. El programa de Calderón tenía como propósito impulsar la actividad turística de Quintana Roo, Yucatán, Tabasco, Chiapas y Campeche con vistas a aprovechar económicamente las expectativas desplegadas en torno al 21 de diciembre del 2012. En esta fecha terminaría un baktún $n^{5}$ del calendario maya clásico, pero sería interpretada como el día del "fin del mundo" o del "inicio de una nueva era de conciencia" desde narrativas occidentales como las del movimiento espiritual New Age $^{6}$ y el de la "mexicanidad"7 (De la Peña, 2012), narrativas populares entre los turistas y prestadores de servicios turísticos en la porción de la costa quintanarroense denominada "Riviera Maya" (Elbez, 2017).

Cuando llegó el 21 de diciembre de 2012 ya había sido nombrado presidente Enrique Peña Nieto (2012-2018), quien le dio continuidad al programa de Calderón. En términos generales puede decirse que la iniciativa fracasó, pues se tenía previsto el arribo de 52 millones de visitantes en el denominado Mundo Maya mexicano y sólo se registraron 8 millones, según señaló el dirigente de la Confederación Nacional 
Turística (CNT), Jorge Hernández Delgado. Afirmó que fue un desacierto de la administración calderonista haber promovido circuitos turísticos sin tener productos consolidados $^{8}$.

La presencia en el campo político nacional e internacional, así como la intensidad de las labores de la OMM ha sido intermitente, pero sigue vigente hasta la fecha. A pesar de que los resultados de los programas gubernamentales en el marco de la Organización Mundo Maya pueden resultar cuestionables en términos económicos, sociales, ambientales, infraestructurales y de integración regional, la turistificación de la región mediante la marca comercial "Mundo Maya" se ha vuelto hegemónica durante los treinta años previos a la propuesta del Proyecto Tren Maya en 2018. Ese ha sido uno de sus mayores logros.

La noción "Mundo Maya" se ha vuelto una especie de sentido común o punto de partida para las políticas públicas y el emprendimiento social o convencional relacionados con el turismo. Como ejemplos tenemos el corredor turístico quintanarroense Riviera Maya; el programa gubernamental "Aldeas Mayas" a cargo de SEFOTUR Yucatán; la iniciativa de turismo comunitario Co'ox Mayab; la iniciativa de turismo rural Camino del Mayab; el Hotel Maya Yucatán en Mérida; el restaurante La Chaya Maya en Mérida; y un sinfín de agencias de viajes, tour operadoras, tiendas de artesanías y demás negocios vinculados al turismo que usan la marca comercial "Maya". Este es el contexto en el cual se nombró "Tren Maya" a un proyecto gubernamental de infraestructura y reordenamiento territorial basado en el turismo.

En consideración de lo anterior, es posible hablar de una narrativa gubernamental-empresarial de la turistificación-mayanización generada en el seno de la OMM y propagada en la región hasta desconocerse su origen, volviéndose un elemento cultural abierto a la resignificación constante y a múltiples usos, primordialmente económicos. Al ser una narrativa abierta, los usuarios de la misma pueden priorizar, combinar, resignificar y excluir algunos de los componentes originales de la narrativa a conveniencia. Los componentes fundamentales de la narrativa de la turistificación-mayanización original son: 
1. El Mundo Maya es un concepto turístico regional que une cultura, ecología y desarrollo para los pueblos del área (Secretaría Ejecutiva OMM, 1996:4);

2. Pretende la revalorización y aprovechamiento de los componentes [¿ambientales y/o culturales?] sin destruirlos (Secretaría Ejecutiva OMM, 1996:5);

3. Busca otorgar fuentes alternativas de ingreso para los habitantes pobres de la región y reducir la destrucción del bosque tropical de la región Maya (BID, 2000:2);

4. Concibe que el éxito dependerá en gran medida de las iniciativas privadas nacionales y locales (BID, 2000:2);

5. Apuesta por el diseño de proyectos de infraestructura y planes de adiestramiento para beneficio de las comunidades locales e inversionistas (BID, 2000:2);

6. Combina la narrativa indigenista estatal sobre la mayanidad con las narrativas del New Age sobre los "mayas galácticos" desde una perspectiva comercial, según quedó en evidencia con el Programa Mundo Maya 2012 de Calderón.

Aunado a lo anterior, resulta llamativo que desde 1996 la OMM ya tenía contemplado implementar un circuito turístico de aeropistas en la Península de Yucatán con un trazo muy similar al del PTM (ver imagen 1). Por lo anterior -y como se verá más adelante- puede afirmarse que el Proyecto Tren Maya se sirve y al mismo tiempo es una derivación de la narrativa gubernamental-empresarial de la turistificaciónmayanización, construida por la OMM y la Secretaría de Turismo (SECTUR) de México. Es así que la Organización Mundo Maya es un antecedente clave para entender el Tren Maya. 
Imagen 1. Circuitos del Mundo Maya. En amarillo circuito de aeropistas en la Península de Yucatán ${ }^{9}$

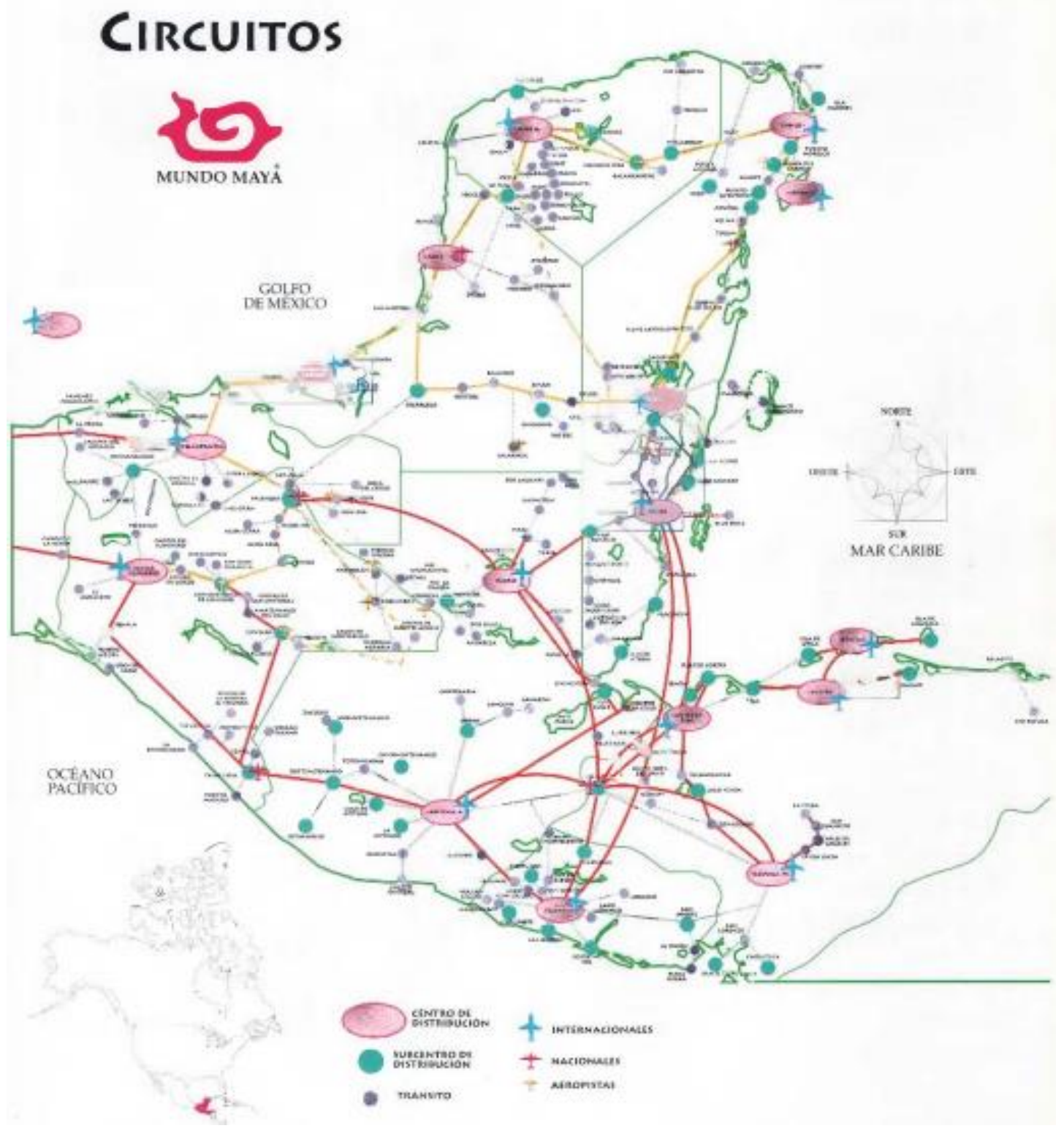

El Tren Maya no ha sido la única propuesta de tren turístico y de transporte de mercancías en la Península de Yucatán. EI PTM encuentra otro antecedente en el Tren Transpeninsular Mérida-Punta Venado (TT), conocido popularmente como el "Tren bala". Con este proyecto se pretendía conectar la parte media de Yucatán con el noreste de Quintana Roo mediante una vía férrea de 334.96 km (Dirección General de Transporte Ferroviario y Multimodal, 2012:9,11). El Tren Transpeninsular fue propuesto por la gobernadora de Yucatán Ivonne Ortega Pacheco (2007-2012) desde 
la campaña electoral. Al ganar la gubernatura, Ortega logró el visto bueno del entonces presidente de la República Felipe Calderón y posteriormente el proyecto contó con el respaldo de Enrique Peña Nieto (2012-2018).

Imagen 2. Ruta del Tren Transpeninsular ${ }^{10}$

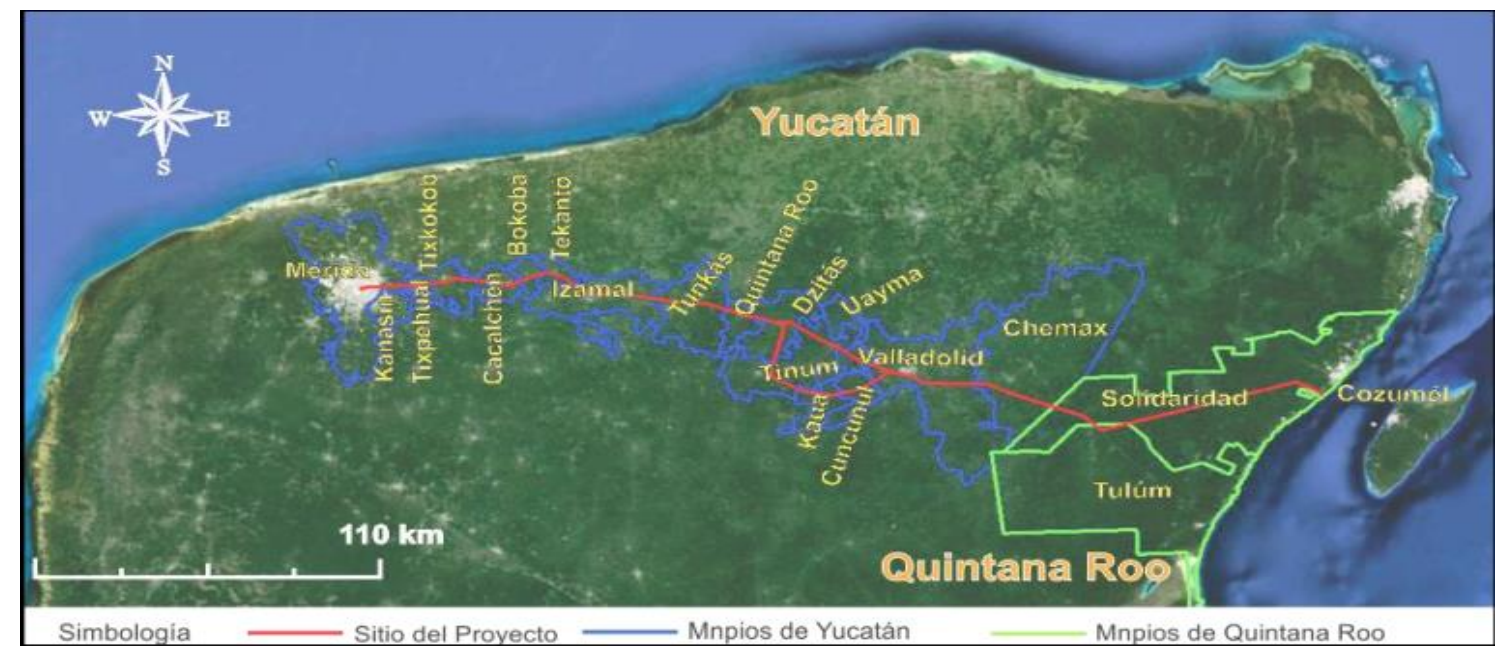

El TT contemplaba el traslado de mercancías y pasajeros a lo largo de la ruta, además de enlazar los principales puertos marítimos y aéreos de la Península de Yucatán con las diversas zonas arqueológicas y ciudades coloniales de la zona, atrayendo y fomentando el turismo a estas áreas a la par de la denominada Riviera Maya. Contemplaba la construcción de dos terminales, Mérida y Punta Venado; cuatro estaciones a corto plazo ubicadas en los municipios de Izamal, Chichén Itzá, Valladolid y Cobá; y cuatro estaciones a mediano plazo ubicadas en Tixkokob, Cacalchén, Tunkás y Aeropuerto Mérida (ver imagen 2) (Dirección General de Transporte Ferroviario y Multimodal, 2012:18). Sus objetivos -coincidentes en varios aspectos con los del Tren Maya- eran:

- Integración Ferroviaria de la Península de Yucatán a la República Mexicana;

- Aprovechamiento del derecho de vía existente, a nivel urbano y estatal con visión para impulsar la economía, el turismo y elevar la calidad de vida de la población;

- Creación de un eje Transpeninsular, que estructure en forma integral el transporte de pasajeros y carga;

- Impulso a las zonas arqueológicas: Tulum, Cobá, Chichén Itzá, Uxmal entre otras y a los pueblos coloniales: Izamal, Tekantó, Cacalchén, Tixkokob y Euán 
lo que ayudará a satisfacer la demanda creciente de turismo en busca de nuevos atractivos;

- Lograr un servicio de transporte ferroviario de pasajeros competitivo en velocidad, confiabilidad, confort y costo, en comparación con el autotransporte;

- Impulsar y ordenar el desarrollo a nivel urbano de los pueblos que coinciden con el trazo y restringir los desarrollos en aquellas zonas que por su naturaleza no sea recomendable (Dirección General de Transporte Ferroviario y Multimodal, 2012:10).

\section{Imagen 3. Ruta del tren Chiapas-Mayab ${ }^{11}$}

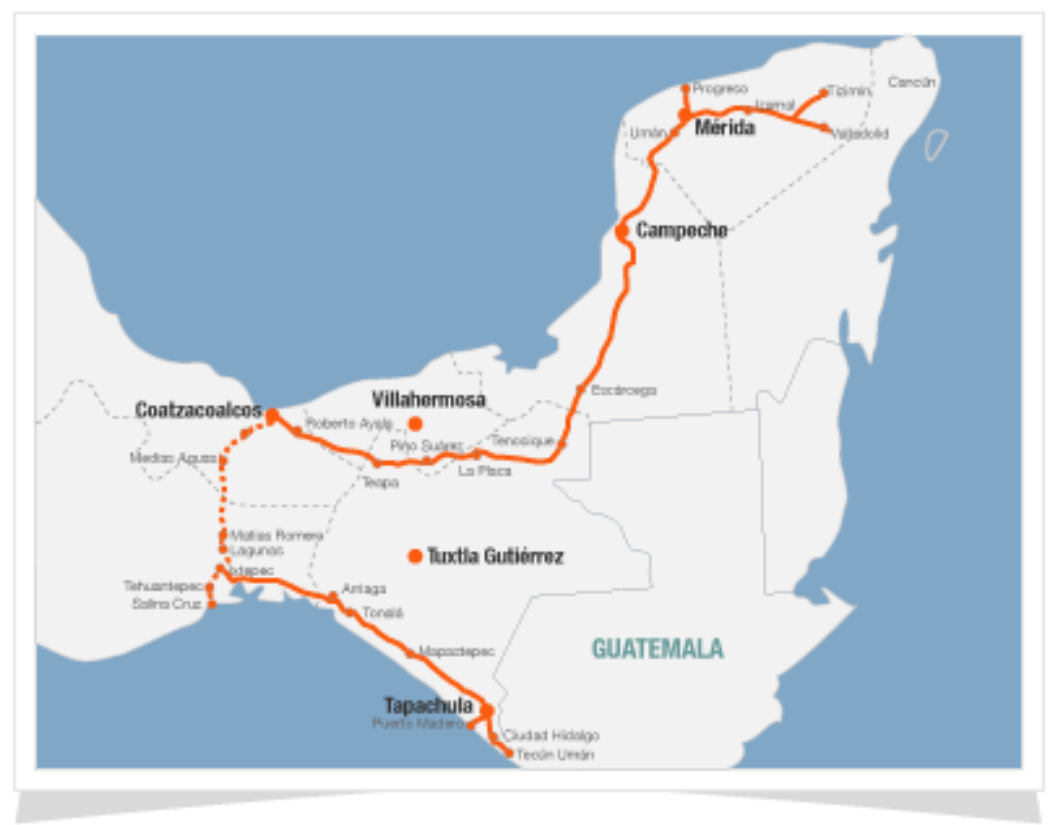

El Tren Transpeninsular fue cancelado en el año 2015 cuando aún se encontraba en planeación, como parte de una política de austeridad ante el bajo precio de los hidrocarburos y la volatilidad de los mercados, según expresó el entonces Secretario de Hacienda, Luis Videgaray ${ }^{12}$. Es decir, el TT no cuajó debido al desmantelamiento sistemático de PEMEX en el marco de la Reforma Energética de Peña Nieto que, aunado a la malversación de fondos públicos durante esa administración, se tradujo en la imposibilidad del Estado mexicano de financiar el proyecto.

A pesar de la cancelación del TT, el sector empresarial peninsular insistió en la rehabilitación de las antiguas vías férreas existentes de la ruta Chiapas-Mayab (ver imagen 3) para el transporte de mercancías ${ }^{13}$, acción que había sido anunciada por 
el Secretario de Comunicaciones y Transporte Gerardo Ruiz Esparza en 2014 ${ }^{14}$. Esto puede significar una justificación para la propuesta del Tren Maya.

En síntesis, el Tren Transpeninsular es el antecedente directo del Tren Maya en cuanto fue la primera propuesta en el siglo XXI de ampliación de vías férreas en la Península de Yucatán para el transporte de pasajeros locales, turistas y mercancías. El trazo propuesto era más modesto, pues sólo consideraba los estados de Yucatán y Quintana Roo. Es así que el Tren Maya retoma la idea de un tren en la Península pero considerando una ruta más amplia, un circuito peninsular muy similar al circuito de aeropistas propuesto por la OMM (ver imagen 1).

Otro antecedente del PTM en el ámbito ferroviario turístico, aunque de menor relevancia, es el tren turístico Expreso Maya, el cual operó entre los años 2002 y 2011 a lo largo de la ruta Chiapas-Mayab. Este tren constaba de cuatro vagones, privados y de lujo, y viajaba dos veces al mes en la ruta Palenque-Mérida $(571 \mathrm{~km})$ a una velocidad de 20 a $40 \mathrm{~km} / \mathrm{h}$. El viaje en tren formaba parte de un paquete "todo incluido" de 6 o 7 días de duración, hacía paradas en las principales ciudades e incluía el traslado a las zonas arqueológicas y sitios de interés cultural, el hospedaje en hotel y la alimentación en restaurantes o en la carroza-restaurante del tren. El precio era de entre 1,000 y 1,400 dólares según la clase (Gasparello, 2020:11).

Lo que vale la pena resaltar de esta iniciativa es que usó la marca comercial "maya" para nombrar a un proyecto ferroviario-turístico antes que el Tren Maya, e incluso resulta llamativo que un emprendedor del centro del país haya usado la mayanidad para promover este proyecto y no lo haya hecho así la gobernadora de Yucatán Ivonne Ortega, siendo el proyecto que propuso de mucho mayor envergadura.

Ahora bien, hay que recordar que el Tren Maya, además de ser un proyecto turístico y de transporte de mercancías y pasajeros locales, se propone el reordenamiento territorial de la región mediante la construcción de "ciudades sustentables" o "polos de desarrollo". Esta propuesta tiene un antecedente en el programa de Ciudades Rurales Sustentables (CRS) implementado en Chiapas durante el sexenio de Felipe Calderón (2006-2012) y la gubernatura de Juan Sabines (2006-2012). Asimismo, los Centros Integralmente Planeados (CIP) por el Fondo 
Nacional de Fomento al Turismo (FONATUR), en tanto propuestas de reordenamiento territorial y desarrollo inmobiliario basado en el turismo, también pueden considerarse antecedentes del Proyecto Tren Maya.

El proyecto de las CRS fue iniciado en el año 2010 en Chiapas en el marco del capítulo México del Plan Puebla Panamá (PPP). El objetivo fue crear centros urbanos intermedios en las zonas rurales del estado que provean todos los servicios públicos, sobre todo de infraestructura económica capaz de generar oportunidades de empleo permanente e ingresos bien remunerados, respetando la tenencia de la tierra y brindando un mejor lugar para vivir. Las CRS fueron concebidas como una estrategia de combate a la dispersión poblacional, situación que dificulta la dotación de servicios públicos a la población rural ${ }^{15}$, aunada a un ordenamiento territorial conducente a una explotación eficiente y sustentable de los recursos naturales (Gasparello, 2020:7475).

Actualmente las cuatro CRS construidas en Chiapas -Nuevo Juan de Grijalva, Santiago el Pinar, Ixtahuán y Jaltenango- son prácticamente pueblos fantasmas. Estas nuevas poblaciones fueron abandonadas debido a la mala calidad de los materiales de construcción, la falta de servicios públicos básicos como agua y electricidad, la lejanía de las tierras de cultivo, la inadecuación cultural de las viviendas y la falta de oportunidades de empleo en las mismas ${ }^{16}$ (Gasparello, 2020:76-77).

En este sentido, las principales lecciones del fallido proyecto de las Ciudades Rurales Sustentables al Tren Maya es que se debe priorizar la adecuación y pertinencia cultural de los desarrollos inmobiliarios, sobre todo en áreas donde la población es indígena y/o campesina. En caso contrario, se correría el riesgo de que sean abandonados y representen un desperdicio de dinero público cuyo único fin sería maquillar cifras. Además, otra de las experiencias a retomar es que se deben tener en orden los estudios de factibilidad, para asegurar la dotación de servicios y la calidad de los materiales de construcción.

La correcta ejecución de este tipo de proyectos depende en buena medida de la voluntad y ética de los agentes gubernamentales, lo cual está directamente vinculado al por qué llegaron a ser servidores públicos. Hay proyectos que desde el inicio son "elefantes blancos" o "pantallas de humo" y otros que se convierten en ello 
durante el proceso, debido a los malos manejos -corrupción- en cualquier eslabón de la cadena de planeación, administración y ejecución.

¿Cómo asegurar que el Tren Maya no vaya por el mismo camino que las CRS? Como se verá más adelante, la principal acción emprendida por la administración federal para que esto no ocurra es la planeación territorial participativa (con las poblaciones locales) realizada por ONU-Habitat en convenio con FONATUR. Adicionalmente, durante el trabajo de campo pude corroborar que entre los funcionarios del Tren Maya hay varios que tienen experiencia en el trabajo con las localidades mayas de la península en proyectos de desarrollo local a través de OSC nacionales e internacionales, como el Instituto Interamericano de Cooperación para la Agricultura (IICA) de la Organización de Estados Americanos (OEA). ¿Cuáles serán los resultados de esta suma de voluntades, perspectivas y capitales sociales y culturales del ámbito de las OSC al Estado mexicano? ¿Podrán captarse y materializarse las demandas y aspiraciones locales en las planeaciones territoriales participativas? Lo sabremos con el tiempo.

A su vez, los Centros Integralmente Planeados (CIP) son polos de desarrollo turísticos de sol y playa que se establecieron por iniciativa gubernamental en zonas del país consideradas marginales (Tulio Inda y Santamaría Gómez, 2015:38). Desde aquí puede notarse cómo no se problematizó desde el Estado mexicano la pertinencia sociocultural y ambiental de la noción de desarrollo y los programas y proyectos inspirados en ella. Esto es una constante hasta la fecha, pese al álgido periodo de crítica al desarrollo en las ciencias sociales en las décadas de 1980 y 1990.

Como resultado de este periodo de crítica al desarrollo, los organismos gubernamentales e intergubernamentales como la ONU, optaron por no desechar la noción de desarrollo, sino por adjetivarla y condicionarla mediante propuestas como la del desarrollo comunitario, desarrollo local, desarrollo sustentable, desarrollo sostenible, etc. desde las cuales se promueve el crecimiento económico pero no a costa del bienestar de la población y el medio ambiente presentes y futuros, siendo importante en algunas de estas variantes adjetivadas del desarrollo la participación local en la construcción de agendas de trabajo y el establecimiento de prioridades. 
Pero los CIP fueron propuestos en 1969, una década antes del inicio de la crítica al desarrollo, lo cual explica que en su concepción, planeación y ejecución no se consideraran relevantes el bienestar social y la conservación del medio ambiente. Se trataba de un periodo de crecimiento económico a toda costa, que prometía ser ilimitado si se administraba eficientemente, puede entenderse este periodo como una especie de proto-neoliberalismo heredero del Estado de bienestar.

La creación de los CIP se propuso por primera vez en 1969 durante el sexenio de Gustavo Díaz Ordaz (1964-1970) y comenzó su implementación en 1974 durante el sexenio de Luis Echeverría Álvarez (1970-1976), con financiamiento del BID -tras el rechazo del Banco Mundial (BM) - y bajo la coordinación de la instancia creada ex profeso, FONATUR (Tulio Inda y Santamaría Gómez, 2015:38).

Los CIP -nótese la normalización de la teoría desarrollista- surgieron con el objetivo de activar la economía de esas regiones, que hasta ese momento eran improductivas o de poca producción económica y que no contaban con alternativas para su desarrollo. Las primeras inversiones fueron realizadas por el Estado, mediante la adquisición y promoción de los terrenos, hasta la construcción de los primeros hoteles y el subsidio de asientos de avión; cuando la ocupación de éstos fue rebasada entonces la inversión privada se sumó al desarrollo de los proyectos (Tulio Inda y Santamaría Gómez, 2015:36).

La construcción de los CIP se dio en dos periodos, el primero durante las décadas de 1970 y 1980, y el segundo durante la década del 2000. Durante el primer periodo se construyeron los CIP de Cancún, Quintana Roo (1974), Ixtapa Zihuatanejo, Guerrero (1974), Los Cabos, Baja California Sur (1976), Huatulco, Oaxaca (1985) y Loreto, Baja California Sur (década de 1980). Durante el segundo periodo se fundaron los CIP de Bahía de Banderas, Nayarit (2004), Escuinapa, Sinaloa (2004) y Costa Lora, Tamaulipas (2009) (Tulio Inda y Santamaría Gómez, 2015:38).

A la par de las fuertes inversiones que han llegado a las regiones donde se han instalado los CIP, se han desatado conflictos sociales y ambientales, así como denuncias de malos manejos. Esto en gran parte se debe a que los CIP se desarrollan bajo modelos de políticas centralistas, que no consideran las características particulares de los territorios, como son: cultura e identidad, cuidado de los recursos 
naturales, los intereses y necesidades reales de las poblaciones en donde se establecen (Tulio Inda y Santamaría Gómez, 2015:42).

Al igual que las Ciudades Rurales Sustentables, las consecuencias negativas de los CIP provienen de la falta o infracción de los estudios de factibilidad pertinentes y de la exclusión de la población local -o regional en el caso de las zonas deshabitadas- en la construcción de los proyectos. No obstante, los CIP presentan una diferencia fundamental con respecto a las CRS, la entrada de grandes inversiones privadas e inyecciones de capital público de las arcas federales, ante los cuales es sabido que históricamente han quedado relegadas la sustentabilidad ecológica, la pertinencia social y la adecuación cultural de las regiones receptoras.

EI Proyecto Tren Maya está a cargo de FONATUR, la instancia creada para realizar los CIP, incluyendo Cancún. Esa ciudad, si bien es exitosa comercialmente en 2017 aportó el 7.1\% del PIB Turístico de México ${ }^{1718}$ - presenta graves problemas sociales y ambientales. Desde las primeras etapas de construcción del CIP no se respetaron las zonas de reserva y áreas verdes establecidas en el plan de desarrollo inicial. Igualmente, a la par del crecimiento de este megadesarrollo (en 1972 sólo lo habitaban decenas de personas y para 1975 ya lo hacían 25 mil) se formó una sociedad asimétrica con zonas marginadas como la colonia Puerto Juárez, la cual es habitada principalmente por inmigrantes que son atraídos por la oferta laboral que genera este puerto turístico. Esta zona carece de planeación urbana y en ella habitan hacinadas 600,000 personas que representan el 70\% de la población de Cancún, y como es de esperarse no cuenta con áreas verdes y deportivas, ni mucho menos con un buen servicio de transporte, todo ello ha contribuido a la formación de grupos delictivos (Villaseñor Palacios en Tulio Inda y Santamaría Gómez, 2015:42). En 2018 el municipio de Benito Juárez, donde se ubica Cancún, alcanzó una tasa de homicidios de 82 por cada 100,000 habitantes, lo cual estuvo cuatro veces por encima de la tasa nacional y diez veces arriba de la tasa mundial ${ }^{19}$.

Hasta aquí se ha mostrado que el Proyecto Tren Maya encuentra antecedentes en programas y proyectos implementados por el Estado mexicano desde la segunda mitad del siglo $X X$, podría decirse incluso que es la conjunción resignificada y refuncionalizada de los mismos. En el último apartado de este capítulo se profundiza el análisis de las continuidades y diferencias del Tren Maya con respecto a los 
antecedentes ya señalados. Para ello es necesario primero exponer las características del Tren Maya, tema de los apartados siguientes.

Para concluir este apartado, cabe mencionar que aunque este trabajo se centra únicamente en el PTM, hay que tener presente la complementariedad que tiene con el Corredor Multimodal Interoceánico (CMI), proyecto igualmente promovido desde el gobierno federal y manifiesto en el Plan Nacional de Desarrollo 2019-2024 ${ }^{20}$ (PND). El CMI tiene un objetivo propuesto y no logrado anteriormente por varias administraciones federales, modernizar la vía férrea que une actualmente el Golfo de México y el Océano Pacífico y crear un corredor industrial en la zona, consolidándose como una alternativa al Canal de Panamá para el tránsito interoceánico de mercancías para las potencias asiáticas, europeas y norteamericanas. En este sentido, sería conveniente considerar que el futuro del Istmo de Tehuantepec y el de la Península de Yucatán están mutuamente influidos y que ambos proyectos potencialmente insertarán a las regiones donde se asentarán en dinámicas globales más álgidas.

\subsection{Características principales del Proyecto Tren Maya}

Actualmente no existe un documento oficial público que explicite las características del Proyecto Tren Maya en su totalidad y a detalle. Hay dos documentos que son lo más cercano a ello. El primero, publicado en septiembre de 2019, es la Ficha Técnica del Tren Maya: Aspectos legislativos, ambientales, económicos y socio-culturales, realizado por la Comisión de Asuntos de la Frontera Sur de la Cámara de Diputados. En él se exponen los elementos técnicos generales del proyecto; información sobre los índices de rechazo y aprobación popular; además de algunos posibles impactos positivos y negativos en materia económica, sociocultural y ambiental, considerados por científicos de la región durante los cinco Foros Legislativo-Académicos celebrados en cada entidad contemplada en el PTM, durante los meses de marzo a agosto del 2019.

El segundo documento, publicado en junio de 2020, es la Manifestación de Impacto Ambiental del Proyecto Tren Maya Fase 1 (MIA-TMF1) elaborada por FONATUR, que contempla el trazo ferroviario, las estaciones y paraderos de Palenque, Chiapas a Izamal, Yucatán. Es decir, este documento no presenta 
información sobre el trazado férreo en su totalidad y tampoco contiene información sobre los polos de desarrollo o comunidades sustentables contemplados a lo largo de la ruta, denominados inicialmente por FONATUR "polos de desarrollo" y posteriormente "comunidades sustentables" por ONU-Hábitat.

Aunado a esto, en la página oficial del $\mathrm{PTM}^{21}$ se encuentra información general sobre el proyecto en su totalidad, con la aclaración de que puede cambiar. En su momento fue polémico que dicha página no presentara información detallada sobre el proyecto, situación que dejó de ser reprochable en junio de 2020, cuando se actualizó con vasta información, mucha de ella no contenida en la Ficha Técnica ni en la MIA-TMF1, publicada al mismo tiempo que la actualización ${ }^{22}$.

Cabe destacar un apartado denominado "Repositorio de documentos oficiales" 23 que cuenta con treinta y dos archivos, entre estudios y propaganda, sobre la consulta indígena, la dimensión ambiental, económica, legislativa y aspectos de ingeniería. Estos documentos fueron hechos en diferentes momentos, y con propósitos específicos diversos, a lo largo del periodo comprendido entre diciembre de 2018 y junio del 2020, por lo que se encuentran algunas inconsistencias comprensibles debido a la constante actualización de los datos. En este sentido, la crítica a la falta de información en la página ya no es vigente, aunque lo sigue siendo el cuestionamiento sobre la calidad, veracidad, coherencia interna y permanencia de la misma.

Hasta antes de la publicación de la Ficha Técnica, la MIA-TMF1 y la actualización de la página oficial, quien quisiera exponer de manera ordenada las características principales del proyecto sin ser trabajador de FONATUR, como quien escribe, tenía que armar el rompecabezas de documentos propagandísticos y declaraciones en prensa del titular de FONATUR, Rogelio Jiménez Pons (RJP). Estas declaraciones fueron tergiversadas en ocasiones por los medios, otras veces resultaban imprecisas y contradictorias por parte del enunciante, como es comprensible al inicio de un proyecto de la magnitud del PTM, que hasta ese momento sólo contaba con un Estudio de Prefactibilidad ambiental no público, como indica la MIA-TMF1 (FONATUR, 2020:I:9)24.

Considerando lo expuesto hasta ahora, es posible que la información presentada a continuación difiera de la manejada en el pasado y el futuro, siendo el 
Tren Maya un proyecto en construcción, tanto en sentido material como de concepción. Los siguientes apartados se basan principalmente en las fuentes oficiales más actualizadas y pertinentes para las necesidades de este trabajo, a saber, la Ficha Técnica y la página oficial actualizada del Proyecto Tren Maya.

\subsubsection{Objetivos del Proyecto Tren Maya}

Al revisar las declaraciones de objetivos del proyecto en diversos documentos oficiales, ya sean propagandísticos, legislativos o estudios ambientales o económicos, no se encontró una concordancia absoluta, pero sí una consistencia considerable. Es decir, los temas y rutas de incidencia son los mismos, aunque puedan variar en el número de objetivos por aglutinación, división y raramente por omisión; en el orden de su exposición; o en el verbo elegido al inicio de las oraciones, por ejemplo, "promover" en vez de "fomentar". A continuación se enlistan los objetivos del PTM tal como aparecen en la Ficha Técnica:

- Impulsar el desarrollo socioeconómico de la región sur-sureste y las comunidades locales;

- Fortalecer el ordenamiento territorial de la Península de Yucatán;

- Fortalecer la industria turística en México;

- Promover y resguardar las culturas indígenas locales;

- Fomentar la inclusión social y la creación de empleo;

- Proteger y rehabilitar las áreas naturales protegidas de la Península de Yucatán (CAFS-CD, 2019:7).

Ahora bien, la consecución de estos objetivos se pretende mediante el trabajo en cuatro ejes: económico, social, cultural y ambiental. Sobre cada eje hay información en la página actualizada, pero no existen objetivos particulares para cada uno ni una matriz de marco lógico o similar que muestre cómo el trabajo en cada eje abona al cumplimiento de los objetivos señalados en la Ficha Técnica y otros documentos. Resulta llamativo que en la página actualizada no hay un apartado sobre los objetivos del proyecto, como sí lo había en su versión anterior.

Por último y de manera complementaria, la página oficial previa a la actualización señalaba que el PTM promueve un "nuevo paradigma de turismo 
incluyente, en el que la riqueza se distribuye en la comunidad". Se indicaba que esto implica:

- Fomentar la inclusión social a partir del respeto a las etnias y el género para incorporar talento regional y local;

- Promover el respeto a los pueblos originarios;

- Detonar el crecimiento económico a partir del impulso a proyectos productivos agroecológicos y logísticos para crear nuevas cadenas de valor;

- Proteger los ecosistemas y los servicios ambientales que proveen;

- Evitar la sobreexplotación y crear mecanismos sociales para incentivar la conservación comunitaria;

- Definir los niveles máximos de carga -o límite de sostenibilidad- de los territorios, considerando factores económicos, ambientales, sociales y culturales de las regiones y los centros urbanos a desarrollar;

- Establecer el número máximo de visitas por destino, conociendo la capacidad de carga ambiental, de infraestructura o de servicios de cada sitio; tanto del entorno natural como de los sitios arqueológicos.

\subsubsection{Ruta, paraderos, estaciones y comunidades sustentables}

Como se ha señalado, el Tren Maya no se trata únicamente de la construcción de infraestructura ferroviaria, sino que se propone el reordenamiento territorial, incluyendo la ampliación de desarrollos urbanos. A estos inicialmente se les denominó "Polos de desarrollo" por parte de FONATUR, inspirándose en la teoría desarrollista en la que se basó dicho organismo en el siglo pasado para la construcción de los Centros Integralmente Planeados. Luego fueron llamados "Comunidades Sostenibles" por ONU-Hábitat, instancia que se valió de las terminologías propias de la ONU en el marco de los Objetivos del Desarrollo Sostenible (ODS). Finalmente, estas ampliaciones urbanas fueron denominadas "Comunidades Sustentables" por FONATUR. FONATUR definía su propuesta de "polos de desarrollo" de la siguiente manera: 
"Polo de Desarrollo es el territorio del área de influencia directa de las estaciones del Tren Maya donde se propiciará el ordenamiento urbano, bien gestionado como sub-centro o centro de vida urbana con calidad, que contribuye a reducir el rezago regional y local, con usos del suelo mixtos con espacios públicos, áreas verdes, movilidad sostenible, equipamiento, servicios e infraestructura, aprovechando la urbanización como motor impulsor de desarrollo económico, social sostenido e inclusivo de protección al medio ambiente, el acuífero, el patrimonio tangible e intangible de la cultura maya, que también permite la conectividad y articulación como un nuevo Sistema Urbano Rural de la península de Yucatán"25

En el marco de la planeación, FONATUR elaboró "Estudios de Preinversión para la construcción de Polos de Desarrollo a lo largo de la Ruta del Tren Maya". Según su descripción, consisten en realizar diversos estudios que permitan obtener datos suficientes para determinar cuáles serían, a lo largo de la Ruta del tren Maya, las comunidades factibles de desarrollo, considerando diferentes factores, como el ambiental, el legal, la disponibilidad de servicios, el potencial de desarrollo agropecuario, la búsqueda de atractivos turísticos, el cambio de vocaciones productivas fracasadas o débiles, todo ello en favor del desarrollo económico de la región sureste (CAFS-CD, 2019:17).

Posteriormente, los "polos de desarrollo" fueron renombrados por ONUHábitat como "Comunidades Sostenibles", en su carácter de instancia asesora en materia de reordenamiento territorial. FONATUR y ONU-Hábitat firmaron, el 21 de mayo de 201926, el convenio para ejecutar el proyecto denominado "Desarrollo Integral Territorial y Urbano de la Región Sureste de México - Corredor Regional Tren Maya". ONU-Hábitat señala en una entrada del 22 de mayo de 2019 en su página oficial $^{27}$ :

"ONU-Habitat proporcionará apoyo sustantivo y técnico al FONATUR en la definición de los parámetros y estrategias necesarios para construir una propuesta de desarrollo integral del sureste mexicano que creará bienestar, desarrollo y oportunidades para esta región como una forma de saldar una deuda histórica, reducir desigualdades, mejorar la calidad de vida, bajo la premisa fundamental de preservar el patrimonio natural y cultural de la región". 
Igualmente se señala que la colaboración se fundamenta en:

1. Crear un corredor regional basado en un esquema de ordenamiento del territorio;

2. Redefinir el sistema regional de ciudades;

3. Repensar y cambiar ventajas comparativas de las microrregiones;

4. Determinar los papeles de intermediación de algunas ciudades para articular zonas urbanas y rurales;

5. Evitar la generación de desigualdades en el territorio.

Adicionalmente, en un documento sobre la colaboración de instancias de la ONU y FONATUR se señala que:

"la participación de ONU-Hábitat en el Tren Maya responde a su compromiso con la Agenda 2030, especialmente con el Objetivo 11: Ciudades y Comunidades Sostenibles $^{28}$, para reducir la desigualdad y la pobreza en las comunidades y actuar por la acción climática y mejora del entorno urbano. En este sentido, ONU-Habitat quiere asegurarse de que el Tren Maya se convierta en motor inclusivo y asequible del crecimiento sostenible del sureste de México" (Naciones Unidas México, 2020:11).

Si prestamos atención a la fecha de publicación de los documentos referidos en este apartado podemos notar que durante el año 2019 se usaban de manera simultánea los términos "polo de desarrollo" y "comunidad sostenible". Actualmente, FONATUR ha optado por Ilamarles "Comunidades Sustentables", como se refleja en la página oficial actualizada del PTM y en la MIA-TMF1. En este sentido, es palpable la progresiva homologación de términos y de articulación de agendas y objetivos entre las instituciones involucradas. En la página oficial actualizada del PTM se puede encontrar información general sobre las "Comunidades Sustentables" ${ }^{29}$, cito en extenso:

"Las Comunidades Sustentables son la zona ${ }^{30}$ ubicada alrededor de las estaciones del Tren Maya, en donde se busca integrar los servicios y equipamientos carentes o demandados por las comunidades y con esto reducir paulatinamente el rezago local y regional existente. 
En estas zonas se intervendrá atendiendo y respetando la cultura local, y las necesidades y requerimientos de cada localidad. Contarán con infraestructura de salud y educación, vivienda, áreas comerciales y de servicios, espacios públicos y áreas verdes.

Las Comunidades Sustentables no son ciudades nuevas, son un reordenamiento urbano que responderá a las regulaciones locales para atender los rezagos de infraestructura de servicios y transporte para mejorar la conectividad y movilidad de la población local.

Las Comunidades Sustentables gestionarán el crecimiento urbano y comercial bajo estándares de densificación que favorecen comunidades compactas, conectadas y limpias.

En la planeación de estas Comunidades Sustentables, la protección al medio ambiente, los acuíferos y el patrimonio tangible e intangible de las culturas originarias es primordial. Se propiciará el ordenamiento urbano, bien gestionado como subcentro o centro de vida urbana con calidad, que contribuye a reducir el rezago regional y local.

Se buscará que propicien la vida comunitaria y el aprovechamiento racional y sustentable del suelo, para esto se atenderán los siguientes criterios de ocupación y aprovechamiento del suelo:

- Respetar las condicionantes naturales estableciendo una continuidad entre naturaleza y ciudad, con la mínima perturbación de los ecosistemas;

- El diseño urbano y de las infraestructuras será considerando las condiciones climáticas, naturales preexistentes, con uso y aprovechamiento eficiente del agua, la energía y el manejo integral de los residuos sólidos;

- Se propiciará un tejido urbano con mezcla y diversidad de usos, equipamientos básicos de proximidad, equipamientos regionales en caso de que se tenga carencia en la zona y áreas verdes que potencien 
la probabilidad de contacto, de intercambio y comunicación de la población, fortaleciendo la vida en comunidad;

- Se impulsarán actividades económicas detonadoras buscando el equilibrio entre éstas y las actividades de vida cotidiana, se buscará la congruencia con las expresiones sociales y culturales locales;

- Asegurar la conectividad y movilidad, priorizando la peatonal y no motorizada, así como la accesibilidad universal dentro del nuevo desarrollo y el resto del centro de población".

Ahora bien, han surgido críticas a la propuesta de las "comunidades sustentables" el argumento principal es que se trata de una propuesta exógena, vertical, culturalmente inadecuada y ambientalmente comprometedora. Es decir, a sabiendas o no, se teme que se repita la misma historia lamentable de las Ciudades Rurales Sustentables en Chiapas, o que se propaguen las desigualdades y violencias sociales -aunadas a la flagrante violación de los acuerdos de conservación natural- que se han podido observar a lo largo de los años en los Centros Integralmente Planeados, particularmente el de Cancún. En parte, este temor puede deberse a la información extraoficial -rumor del que no pude hallar la fuente- que circuló desde el inicio del proyecto, según la cual los entonces llamados "polos de desarrollo" consistían en la creación de nuevas ciudades de 50,000 habitantes alrededor de las estaciones, siendo particularmente sensible la zona de Calakmul ${ }^{31}$.

Retomando los elementos más importantes de lo dicho hasta ahora, cabe precisar las diferencias entre paradero, estación, y comunidad sustentable. En el Proyecto Tren Maya se concibe a los paraderos como lugares en los que la población local podrá acceder al servicio de transporte, pero que no consideran la ampliación y ordenamiento urbano alrededor del paradero. Por su parte, una estación lo será únicamente si cuenta con un desarrollo urbano planificado ex profeso para atender las necesidades preexistentes y generadas en la localidad a raíz del Tren Maya, es decir, una Comunidad Sustentable. En pocas palabras, los lugares donde pare el tren y no haya una comunidad sustentable serán paraderos, y donde sí haya una comunidad sustentable serán estaciones. 
Ahora bien, la ruta concebida del Tren Maya ha tenido modificaciones a lo largo de los meses. Cuando inició la promoción del proyecto por el entonces presidente electo AMLO en 2018, el trazo contemplaba 15 estaciones en los 5 estados incluídos en el proyecto: Palenque en Chiapas; Tenosique en Tabasco; Escárcega, Campeche y Calakmul en Campeche; Mérida, Izamal, Chichén Itzá y Valladolid en Yucatán; Cancún, Puerto Morelos, Playa del Carmen, Tulum, Felipe Carrillo Puerto y Bacalar en Quintana Roo (ver imagen 4).

Imagen 4. Trazo inicial de la ruta del tren maya ${ }^{32}$

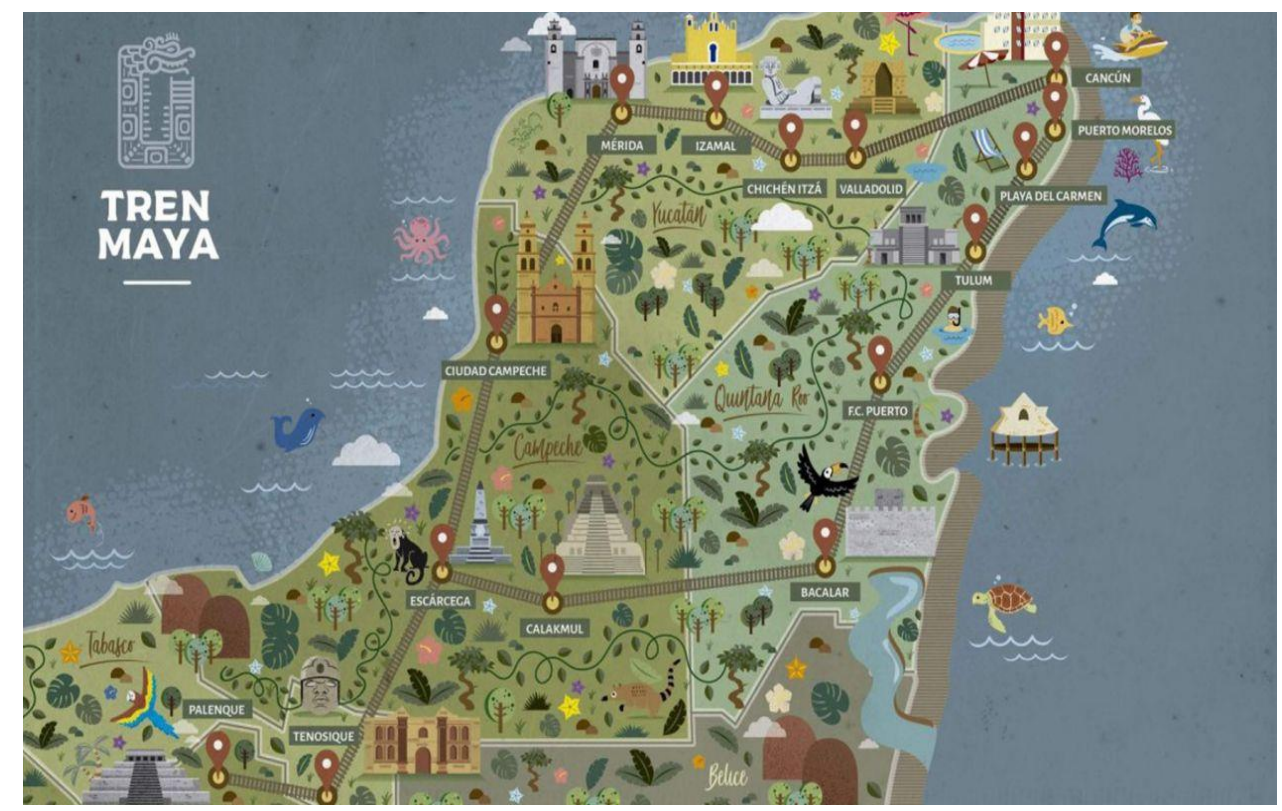

Durante el año 2019 hubo varias modificaciones. Las administraciones estatales y municipales, así como habitantes de los 5 estados, propusieron establecer estaciones adicionales. Algunas no procedieron, como la de Progreso en Yucatán, y otras sí, como las de Xpujil en Campeche y la de Chetumal en Quintana Roo. El municipio de Maxcanú en Yucatán fue considerado brevemente para tener una estación pero se resolvió que tenga un paradero, a pesar de ser la puerta de entrada a la Ruta Puuc, una importante ruta arqueológica de Yucatán.

Hubo un caso de especial interés en Campeche, donde se generaron cuestionamientos sobre la viabilidad ambiental de la construcción de una estación en Calakmul, mismas que devinieron en medidas legales para evitar no sólo la construcción de dicha estación sino de todo el proyecto. Actualmente el PTM está en 
marcha, no se prevé construir una estación cerca del sitio arqueológico de Calakmul, pero sí en la localidad de Xpujil, perteneciente al municipio de Calakmul.

\section{Imagen 5. Cambio de la ruta Valladolid-Cancún por la ruta Valladolid-Cobá-Tulum ${ }^{33}$}

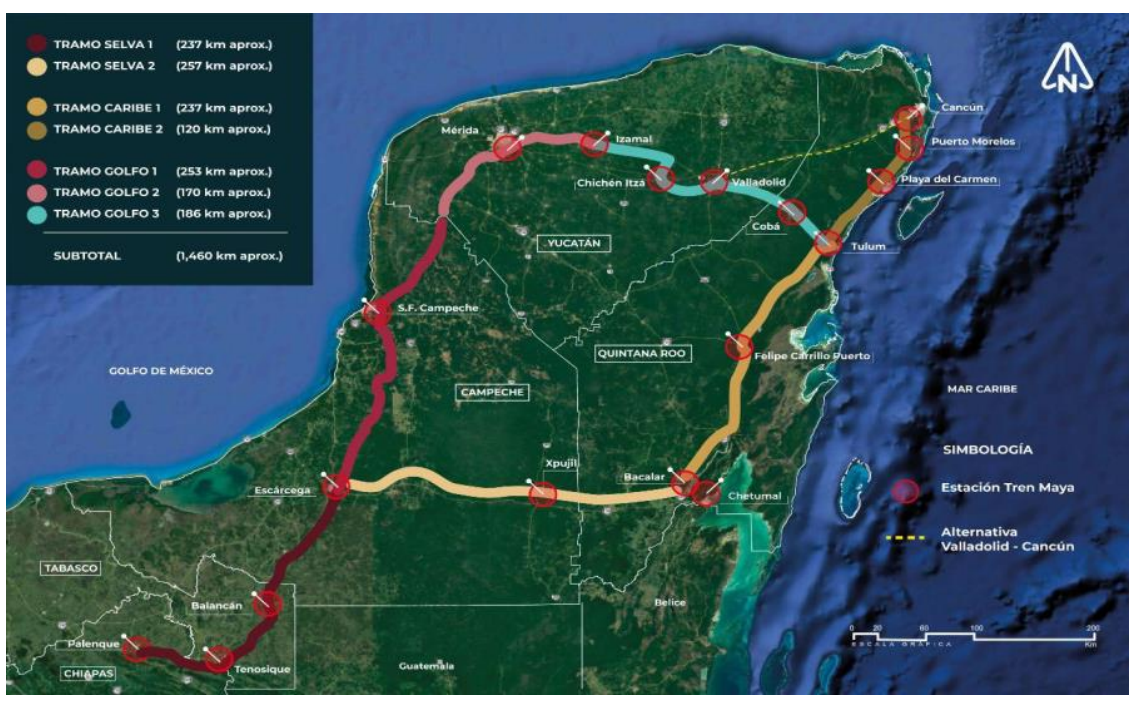

Otro hecho destacable es que, también en 2019, se consideró sustituir el tramo Valladolid-Cancún por el tramo Valladolid-Cobá-Tulum, más un ramal Tulum-Cancún (ver imagen 5). Al final esta idea no procedió debido a la alta densidad de cenotes y zonas arqueológicas reportados en el área circundante a Cobá, por lo que se volvió a la ruta original Valladolid-Cancún, más un ramal Tulum-Cobá.

Imagen 6. Trazo actual de la ruta del Proyecto Tren Maya ${ }^{34}$

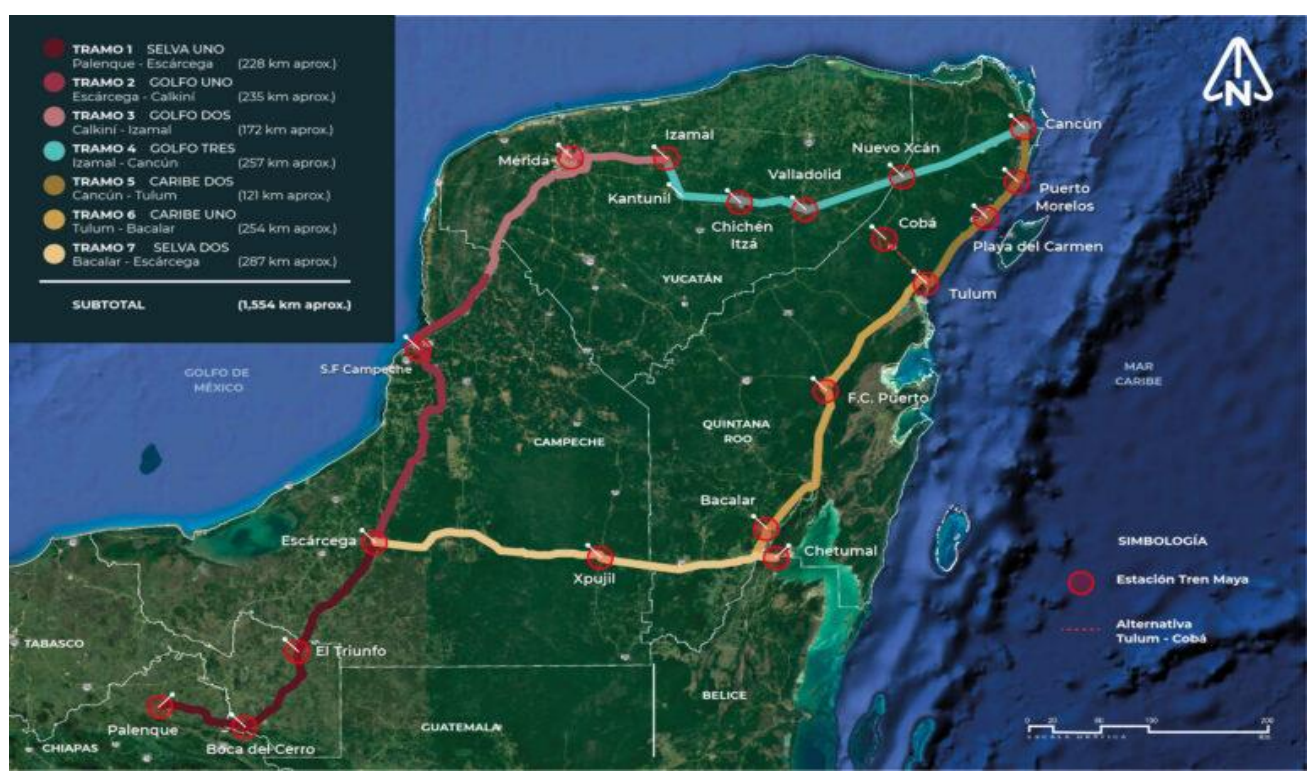


Actualmente, de acuerdo con la página oficial, se contempla rehabilitar y construir aproximadamente $1,554 \mathrm{~km}$ de vías férreas incluyendo 19 estaciones y 12 paraderos distribuidos en 7 tramos (ver imagen 6 y tabla 1), aunque no se descarta que puedan cambiar por consideraciones operacionales.

Tabla 1. Detalles sobre los tramos del Proyecto Tren Maya ${ }^{35}$

\begin{tabular}{|c|c|c|c|}
\hline Tramo & $\begin{array}{l}\text { Empresas } \\
\text { constructoras }^{36}\end{array}$ & $\begin{array}{l}\text { Estaciones/Polos } \\
\text { de desarrollo/ } \\
\text { Comunidades } \\
\text { sostenibles }\end{array}$ & Paraderos \\
\hline $\begin{array}{l}\text { I Selva: Palenque- } \\
\text { Escárcega } \\
\text { (228 km aprox.) }\end{array}$ & \begin{tabular}{|lr} 
Mota-Engil \\
México SAPI de \\
C.V. & en \\
convenio r con \\
China & \\
Communication \\
S Construction \\
Company & LTD, \\
Grupo & Cosh \\
S.A. de & C.,V \\
Eyasa y & Gavil \\
Ingeniería S.A.
\end{tabular} & $\begin{array}{l}\text { - Palenque, } \\
\text { Chiapas } \\
\text { - } \text { Boca del } \\
\text { Cerro, } \\
\text { Tabasco } \\
\text { - El Triunfo, } \\
\text { Tabasco } \\
\text { - Escárcega, } \\
\text { Campeche }\end{array}$ & $\begin{array}{l}\text { - Tenosique, } \\
\text { Tabasco } \\
\text { - Candelaria, } \\
\text { Campeche }\end{array}$ \\
\hline $\begin{array}{l}\text { Il Golfo: } \\
\text { Escárcega-Calkiní } \\
\text { ( } 235 \text { km aprox.) }\end{array}$ & \begin{tabular}{ll}
\multicolumn{2}{l}{ Operadora } \\
CICSA S.A. & de \\
C.V. & en \\
convenio r de \\
asociación & con \\
FCC & \\
Construcción \\
S.A.
\end{tabular} & $\begin{array}{l}\text { - San Francisco } \\
\text { de } \\
\text { Campeche, } \\
\text { Campeche }\end{array}$ & $\begin{array}{l}\text { - Tenabo, } \\
\text { Campeche } \\
\text { - Hecelchaká } \\
\text { n, } \\
\text { Campeche } \\
\text { - Calkiní, } \\
\text { Campeche }\end{array}$ \\
\hline $\begin{array}{l}\text { III Golfo: } \\
\text { Calkiní - Izamal } \\
\text { (172 km aprox.) }\end{array}$ & $\begin{array}{l}\text { Construcciones } \\
\text { Urales, en } \\
\text { asociación con } \\
\text { GAMI Ingeniería } \\
\text { e Instalaciones y } \\
\text { AZVI. }\end{array}$ & $\begin{array}{l}\text { - Mérida, } \\
\text { Yucatán }\end{array}$ & $\begin{array}{l}\text { - Maxcanú, } \\
\text { Yucatán } \\
\text { - Tixkokob, } \\
\text { Yucatán }\end{array}$ \\
\hline $\begin{array}{l}\text { IV Golfo: } \\
\text { Izamal - Cancún } \\
\text { (257 km aprox.) }\end{array}$ & $\begin{array}{l}\text { Grupo } \\
\text { Ingenieros } \\
\text { Civiles } \\
\text { Asociados }\end{array}$ & $\begin{array}{l}\text { - Izamal, } \\
\text { Yucatán } \\
\text { - Chichén Itzá, } \\
\text { Yucatán } \\
\text { - Valladolid, } \\
\text { Yucatán } \\
\text { - Nuevo Xcán, }\end{array}$ & $\begin{array}{l}\text { - Cancún, } \\
\text { Quintana } \\
\text { Roo }\end{array}$ \\
\hline
\end{tabular}




\begin{tabular}{|c|c|c|c|}
\hline & & Quintana Roo & \\
\hline $\begin{array}{l}\text { V Caribe: } \\
\text { Cancún - Tulum } \\
\text { (121 km aprox.) }\end{array}$ & 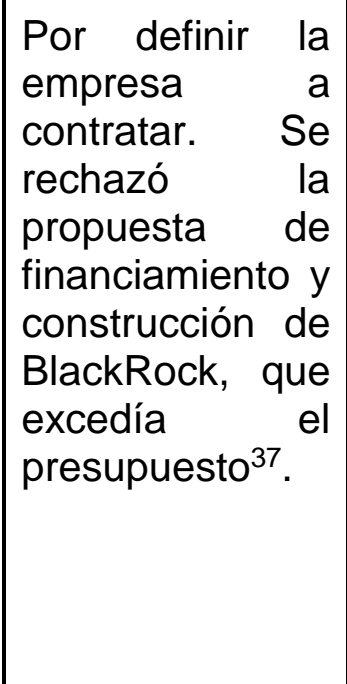 & $\begin{array}{l}\text { - Cancún } \\
\text { Centro, } \\
\text { Quintana Roo } \\
\text { - Cancún } \\
\text { Aeropuerto, } \\
\text { Quintana Roo } \\
\text { - Puerto } \\
\text { Morelos, } \\
\text { Quintana Roo } \\
\text { - Playa del } \\
\text { Carmen, } \\
\text { Quintana Roo } \\
\text { - Tulum, } \\
\text { Quintana Roo }\end{array}$ & $\begin{array}{l}\text { - Cobá, } \\
\text { Quintana } \\
\text { Roo } \\
\text { - Xcaret/Calic } \\
\text { a, Quintana } \\
\text { Roo } \\
\text { - Puerto } \\
\text { Aventuras, } \\
\text { Quintana } \\
\text { Roo } \\
\text { - Akumal, } \\
\text { Quintana } \\
\text { Roo }\end{array}$ \\
\hline $\begin{array}{l}\text { VI Caribe: } \\
\text { Tulum - Bacalar } \\
\text { (254 km aprox.) }\end{array}$ & $\begin{array}{l}\text { Secretaría de la } \\
\text { Defensa } \\
\text { Nacional }{ }^{38}\end{array}$ & $\begin{array}{l}\text { - Felipe Carrillo } \\
\text { Puerto, } \\
\text { Quintana Roo } \\
\text { - Bacalar, } \\
\text { Quintana Roo } \\
\text { - Chetumal, } \\
\text { Quintana Roo }\end{array}$ & \\
\hline $\begin{array}{l}\text { VII Selva: } \\
\text { Bacalar - Escárcega } \\
\text { (287 km aprox.) }\end{array}$ & $\begin{array}{l}\text { Secretaría de la } \\
\text { Defensa } \\
\text { Nacional }\end{array}$ & $\begin{array}{l}\text { - Xpujil, } \\
\text { Campeche }\end{array}$ & \\
\hline
\end{tabular}

Está contemplado que, el desarrollo del proyecto del Tren Maya, se lleve a cabo en tres etapas:

1. Primera Etapa, comprende el tramo que va de Palenque, Chiapas, a Izamal, Yucatán. Cabe mencionar, que en este tramo ya se cuenta con infraestructura ferroviaria instalada y en funcionamiento.

2. Segunda etapa, se pretende construir el tramo que va de Izamal, Yucatán, a Cancún, Quintana Roo.

3. Tercera etapa, comprende el tramo que va de Cancún, Quintana Roo, a Escárcega, Campeche. 
Los 1,554 km de vía se pretenden construir en cuatro años, para iniciar su operación en el quinto año (CAFS-CD, 2019:12-13). Es decir, se planea que la obra esté lista antes de terminar el sexenio de la actual administración federal.

De manera extraoficial, como señalan Gasparello et al. (2019:4), funcionarios de FONATUR difundieron un listado en agosto de 2019 en el que se indican las posibles vocaciones para las estaciones (ver tabla 2). Como puede notarse, la lista de las estaciones no está actualizada, por lo que, sumado a su carácter extraoficial, esta información debe ser tomada con cautela. Es probable que la vocación de los municipios actualmente y en el futuro sea otra.

Por el momento, remitiéndome a la información expuesta en la tabla 2, cabe resaltar que todos los municipios mencionados tenían asignada una vocación menos Izamal, Chichén Itzá y Valladolid en Yucatán, quizás con el propósito de contener la especulación sobre las tierras y la construcción, a la orden del día en la zona (FONATUR, 2020:III:181).

Tabla 2. Vocación de los municipios del Tren Maya ${ }^{39}$

\begin{tabular}{|l|l|}
\hline Municipio & Vocación \\
\hline Palenque & Subcentro urbano \\
\hline Tenosique & Subcentro urbano \\
\hline Balancán & Sólo estación \\
\hline Escárcega & Parque agroindustrial \\
\hline Campeche & Sólo estación \\
\hline Mérida & $\begin{array}{l}\text { *Estación y "Comunidad } \\
\text { sustentable" }\end{array}$ \\
\hline Izamal & Por definir \\
\hline Chichén Itzá & Por definir \\
\hline Valladolid & Por definir \\
\hline Cobá & Subcentro urbano \\
\hline Tulum & Subcentro urbano \\
\hline Playa del Carmen & Sólo estación \\
\hline
\end{tabular}




\begin{tabular}{|l|l|}
\hline Puerto Morelos & Subcentro urbano \\
\hline Cancún & Sólo estación \\
\hline Felipe Carrillo Puerto & Subcentro urbano \\
\hline Bacalar & Subcentro urbano \\
\hline Chetumal & Parque agroindustrial \\
\hline Calakmul & Comunidades autónomas \\
\hline
\end{tabular}

\subsubsection{Características técnicas del equipo e infraestructura ferroviaria}

Han habido varias versiones sobre las características de los trenes que utilizaría el Tren Maya, principalmente en cuanto a si serían de trenes de alta o media velocidad y respecto al tipo de energía usada para su funcionamiento, eléctrica, diésel, biodiésel o híbrida. Actualmente no se han abierto las licitaciones para la adquisición del material rodante, por lo que no es posible decir con certeza cómo serán los trenes.

No obstante, en algunos documentos oficiales se ha señalado las características esperadas del equipo. En un Anexo Técnico (s/f) probablemente anterior a marzo del 2020, puesto que contempla el descartado tramo ValladolidCobá-Tulum, encontramos lo siguiente:

"Se prevé disponer de un lote de aproximadamente 75 trenes de tracción Diesel- Eléctrica que circularán por la ruta para prestar el servicio de carga y pasajeros. La velocidad máxima que alcanzará el material rodante de pasajeros será de $160 \mathrm{~km} / \mathrm{hr}$ y de $120 \mathrm{Km} / \mathrm{hr}$ para el de carga.

- La composición de los trenes de pasajeros será de 5 a 7 vagones.

- Serán equipados con medios de información modernos para los pasajeros, que incluyen: pantallas de video, internet a bordo, servicio de cafetería para los servicios de largo recorrido, servicios sanitarios, aire acondicionado, ventanas panorámicas y asientos cómodos y con accesibilidad para personas con discapacidad. 
- La capacidad de transporte podrá ser de 300 a 500 asientos por tren (según la conformación del mismo)" (FONATUR, s/f:6).

Por otra parte, en la Manifestación de Impacto Ambiental de la Fase 1, publicada en junio del 2020, encontramos que se contempla el uso de locomotoras de biodiésel híbridas, acorde a la norma ambiental de California. Se señala también que el material rodante de pasajeros contempla trenes diésel-eléctricos con velocidad máxima de 160 $\mathrm{km} / \mathrm{h}$; mientras que los trenes de carga transitarán a 100 km/h (FONATUR, 2020:II:4). En el mismo documento se señalan las exigencias del material rodante de pasajeros:

"Como resultado de los estudio realizados, se debe considerar que el material rodante deberá estar basado en tracción diésel, aunque existe la posibilidad de considerar trenes duales, de tracción diésel y eléctrica, sin la instalación del equipamiento de tracción eléctrica en una primera fase de explotación diésel, pero disponiendo de una cierta pre-instalación eléctrica que facilite su introducción posterior, y desde luego disponiendo de todos los espacios necesarios, y que se podría implementar posteriormente cuando se decidiera la electrificación total o parcial de la línea" (FONATUR, 2020:Il:254).

A su vez, sobre las exigencias requeridas para el material rodante de carga se señala que:

"La explotación de los trenes de carga no es objeto de FONATUR, por tanto, no se pueden establecer unas características generales del tren que circulará por la línea dado que se desconocen los operadores que aprovecharán el Tren Maya para transportar sus mercancías" (FONATUR, 2020:II:256).

\subsubsection{Financiamiento}

De acuerdo con FONATUR, el Tren Maya, tiene un costo estimado de 120 a 150 mil millones de pesos (CAFS-CD, 2019:15). La forma de financiamiento del proyecto se ha transformado con el paso de los meses. Inicialmente se hablaba de un financiamiento $10 \%$ público y $90 \%$ privado $^{40}$ (CAFS-CD, 2019:15). Posteriormente se declaró que a largo plazo sería más caro el financiamiento mayoritariamente privado, por lo que la proporción pasó a ser $70 \%$ pública y $30 \%$ privada. Más adelante, en diciembre de 2019, AMLO declaró que la obra sería financiada al 100\% con recursos públicos ${ }^{41}$. Pero sólo se refería a las vías férreas y no incluía el material rodante ni las 
"comunidades sustentables", las cuales posteriormente se anunciaría que serían con financiamiento público y privado.

La pandemia de COVID-19 significó la caída de los precios del petróleo y la disminución drástica de la afluencia de turismo extranjero. Esto afectó directamente al plan de financiamiento del proyecto, pues se tenía previsto pagar el 50\% del Tren Maya a través del cobro del Derecho de No Residente (DNR) ${ }^{42}$ hasta 2024, el cual recauda normalmente 8 mil millones de pesos al año en promedio. Ante esta situación, FONATUR entregó un plan B a la Secretaría de Hacienda y Crédito Público (SHCP) en marzo del 2020, en la que no se descarta la participación de capital privado ${ }^{43}$. Según Rogelio Jiménez Pons, titular de FONATUR, el presupuesto asignado en 2020 al Tren Maya fue de 25 mil millones de pesos ${ }^{44}$

Con la asignación de recursos en el ejercicio fiscal 2020 para el proyecto del Tren Maya, se iniciaron las obras en los tramos 1, 2, 3 y 4 de la ruta establecida, se firmaron 12 convenios de colaboración con dependencias y entidades gubernamentales, así como con instituciones educativas públicas y organismos privados para apoyar el desarrollo del proyecto en los más diversos ámbitos (SHCP, 2020:116).

En septiembre del 2020 el ejecutivo federal presentó el Proyecto del Presupuesto de Egresos de la Federación para el 2021 a la Cámara de Diputados, la cual debe ratificarse a más tardar el 15 de noviembre. En esta partida presupuestal se propone asignar 36,288 millones de pesos al Proyecto Tren Maya (SHCP, 2020:195), lo que significa un aumento del 48\% en comparación con lo designado para esta obra durante el $2020^{45}$. Asimismo, el presupuesto para el sector Turismo del cual el Tren Maya se lleva el 94\%- tendría un aumento de casi el $700 \%$ en comparación con el año $2020^{46}$. Con este presupuesto se pretende continuar la construcción de los tramos 1, 2, 3 y 4; e iniciar la construcción de los tramos 5 y 6 , para con ello alcanzar 45\% del avance total de la obra (SHCP, 2020:117).

Asimismo, con este presupuesto se contempla la adquisición de material rodante que incluye 30 locomotoras y 180 carros de pasajeros; estaciones y talleres, y la adquisición del ancho de la franja de 40 metros por concepto de derecho de vía, dado que existen asentamientos irregulares a lo largo del recorrido de los tramos mencionados, aunado a la compra de riel que permita garantizar la interoperabilidad 
del material rodante que actualmente opera en el resto del sistema de infraestructura ferroviario mexicano (SHCP, 2020:99).

Para cubrir las necesidades de productos y servicios que implica el Proyecto Tren Maya, FONATUR lleva a cabo contrataciones bajo 4 modalidades: licitaciones públicas; invitación restringida a por lo menos tres personas; convenios entre entes públicos y adjudicación directa. FONATUR y sus filiales involucradas en la construcción del Tren Maya (Infraestructura y Tren Maya), han realizado 32 contrataciones para el proyecto por un monto de $\$ 39,620,995,385.46$ en el ejercicio $2020^{47}$.

Adicionalmente, la inversión requerida para la construcción de los tres tramos de la Fase 1 del proyecto es de \$44,284,810,090.21.M.N. Dicho capital será aportado por el Gobierno Federal de acuerdo al siguiente desglose: Tramo 1: $\$ 15,538,133,056.79 ;$ Tramo 2: $\$ 18,553,738,338.84$; Tramo 3: $\$ 10,192,938,694.58$ (FONATUR, 2020:II:59). Cabe recordar que la MIA-TMF1 contempla los primeros tres tramos, aunque ya se ha adjudicado (pero no formalizado) la concesión para construir el tramo 4 a ICA, por un monto de 27 mil millones de pesos ${ }^{48}$.

En cuanto a las estaciones y Comunidades Sustentables, en 2019 se declaró que serían financiados mediante un Fideicomiso de Infraestructura y Bienes Raíces, llamado "FIBRA Tren Maya" (CAFS-CD, 2019:15). Aunque en septiembre del 2020 el presidente de la República descartó este tipo de financiamiento, vale la pena señalar algunas de sus características, pues se trató de una propuesta que recibió muchas críticas por una parte del sector académico, por el sector del activismo étnicoambientalista, por una facción del sector de las OSC, y que sobre todo mereció la desaprobación de los propietarios legales de la tierra -ejidatarios o particulares- que mientras más conocían sobre los mecanismos de estos fideicomisos menos los aceptaban, pues no sólo no estaba garantizada la rentabilidad en su participación como socios del proyecto, sino que incluso corrían el riesgo de perder sus tierras de manera definitiva, pero legal. A esto, Violeta Núñez, investigadora del departamento de producción económica de la UAM-Xochimilco, lo calificó como un proceso de "despojo elegante"49.

Sobre el tema de los FIBRAS no hubo información oficial pública detallada. Sin embargo, Violeta Núñez abordó críticamente el asunto en diversas entrevistas, 
publicaciones en prensa y colaboraciones de difusión académica, en las que enfatiza la preocupación sobre el futuro de la propiedad y usufructo de las tierras ejidales de la región. A continuación comparto algunos datos expuestos por ella.

Según la Suprema Corte de Justicia de la Nación (SCJN), un fideicomiso es, de manera general, "un acto jurídico que debe constar por escrito, y por el cual una persona... destina uno o varios bienes... en beneficio de otra persona, encomendando su realización a una institución bancaria llamada fiduciaria, recibiendo ésta la titularidad de los bienes " (SCJN en Núñez Rodríguez, 2019:39).

De manera particular, un FIBRA, es un instrumento financiero que cotiza en los mercados de capital, para financiar proyectos inmobiliarios (CAFS-CD, 2019:16). De acuerdo con la Bolsa Mexicana de Valores (BMV) "son una opción de inversión en inmuebles, a través de un fideicomiso, cuyos títulos se negocian diariamente en la BMV, bajo la misma normatividad que cualquier otra acción" (BMV en Núñez Rodríguez, 2019: 39). En cuanto a los FIBRAS, de manera esquemática, la BMV señala los siguientes pasos:

1. La empresa aporta el (los) inmueble(s)

2. El fideicomiso recibe el (los) inmueble(s). Entidad administradora

3. El fideicomiso coloca los certificados en la BMV

4. Entrega de certificados a

4.1 Inversionistas institucionales

4.2 Público inversionista

5. Los recursos, producto de la emisión, son destinados al fideicomiso

6. El fideicomiso mantiene la propiedad.

7. La empresa recibe el dinero y/o los derechos fiduciarios (BMV en Núñez Rodríguez, 2019: 39).

En el caso específico del Tren Maya, los ejidatarios y propietarios particulares, concebidos como la "empresa", serían los que aportaran "los inmuebles", que en este caso sería la tierra, sobre la que se edificaría y construiría la infraestructura necesaria para las estaciones y comunidades sustentables. Sobre este punto, el director de TMSourcing, empresa que trabaja el tema de los fideicomisos junto a FONATUR, señala: "será un fideicomiso que tendrá como aportación tierra para desarrollar lo que se ha concebido como subcentros urbanos que convergerán con las (entonces) 15 
estaciones que tendrá el proyecto férreo... La tierra de aportación del FIBRA provendrá principalmente de ejidatarios y particulares". En este tipo de "asociación", la tierra antes ejidal o privada ahora pasa a ser del FIBRA, mientras "lo que está arriba va a ser del que construye o el que quiera hacer el negocio, y pagará una renta por usar la tierra" (Núñez Rodríguez, 2019:40).

Los FIBRAS son un instrumento híbrido de inversión, ya que se pueden tener beneficios mediante dividendos (renta fija) y mediante rendimientos (renta variable). En este último es donde existía el riesgo. De acuerdo con alguno de los principales grupos de la banca a nivel mundial, la renta variable "es un tipo de inversión en la que la recuperación del capital invertido y la rentabilidad de la inversión no están garantizadas, ni son conocidas de antemano. Además puede ocurrir que la rentabilidad sea negativa, pudiendo llegar incluso a perder el dinero invertido". Es en este sentido que la BMV señala que con la renta variable "el rendimiento puede generar utilidades si la plusvalía sube, y puede generar pérdidas si el mercado inmobiliario tiende a la baja". La rentabilidad de la renta variable "depende de distintos factores como pueden ser la evolución de la empresa en la que se invierte, su situación económica, el comportamiento de los mercados financieros, etc.". Así, como ya ha ocurrido en diversos mercados financieros, las ganancias y beneficios, o incluso todo lo invertido, pueden desaparecer de un momento a otro (Núñez Rodríguez, 2019:40).

Ahora bien, el lunes 7 de septiembre del 2020, AMLO señaló en conferencia de prensa matutina que no se utilizarían fideicomisos para el Tren Maya, tras haber sido cuestionado por una reportera del medio digital Pie de Página, en el sentido de que él mismo ha dicho que los fideicomisos son modelos que permiten la corrupción ${ }^{50}$. Esto se dio en el contexto de la cancelación de fideicomisos de varias instancias gubernamentales, entre ellas el CONACYT, desde el cual se destinaban fondos públicos a la investigación científica al servicio de grandes empresas transnacionales ${ }^{51}$. Aquí tenemos un claro ejemplo de cómo un evento del drama social de la $4 \mathrm{~T}$ repercutió en el drama social del Tren Maya, el cual, por supuesto, está contenido en el primero.

La declaración de AMLO fue reiterada por Rogelio Jiménez Pons el 22 de septiembre al señalar durante una Conferencia sobre Programas del Bienestar 
dedicado al Tren Maya, que FONATUR está trabajando con la Procuraduría Agraria para hallar un esquema de financiamiento similar, pero que garantice que los dueños originales no sean desplazados. Cito en extenso:

"Estamos buscando distintas [alternativas de financiamiento para las comunidades sustentables], el chiste que la figura fundamental que estamos buscando que sean mandatos legales que nos garanticen que los dueños originarios de la tierra no pueden ser desplazados, este es el principal planteamiento. Que no venga a generarse despojos y cosas de ese tipo. Ahora pueden venir muchas fórmulas de financiamiento ya distintas. Lo que es esencial, lo que es fundamentalmente, lo que es el derecho de vía, la estación en sí, la estación eso es patrimonio del gobierno. Es inversión pública, ya lo colateral tiene que ser fórmulas de asociación con distintos vehículos particulares. Porque vienen muchos, hay que hacer hoteles, hay que hacer restaurantes; hay que hacer centros comerciales, hay que hacer vivienda, ahí sí tenemos que abrir mucho. Pero siempre bajo un esquema que nos garantice que el dueño original de la tierra, esté bajo un esquema un mandato en que no se le desplace. Tampoco que se le pueda finalmente diluir en una sociedad. Y tenemos que buscar y en eso estamos trabajando con la Procuraduría Agraria, buscando una solución para ver cuál es la mejor alternativa. Se está buscando que no necesariamente sean los fideicomisos sino que sea algo semejante, que es un mandato a final de cuentas, y puede ser que nos puede servir como instrumento legal de asociación al final ${ }^{52}$.

En síntesis, el financiamiento para el Proyecto Tren Maya será público en lo respectivo a la construcción de las vías férreas y la adquisición del material rodante de pasajeros y turistas; mientras que el material rodante de carga será el utilizado por la iniciativa privada. Por otra parte, se ha definido que las estaciones y paraderos serán operadas por el Estado. A su vez, el esquema de financiamiento para las Comunidades Sustentables será público-privado, pero se ha descartado la opción de los Fideicomisos en Bienes Raíces (FIBRA), pues ponían en riesgo los intereses de los propietarios legales de las tierras, tanto ejidales como particulares, y aún no se define el modo en que se realizará, permitiendo que los propietarios originales no sean desplazados en el mediano y largo plazo. Igualmente, aún está en discusión en la 
Cámara de Diputados el presupuesto de egresos del 2021, en el cual el Tren Maya es prioritario.

\subsubsection{Colaboraciones interinstitucionales}

Desde el año 2019 FONATUR comenzó a establecer convenios y acuerdos de colaboración con múltiples universidades, instancias de investigación, colegios profesionales, organizaciones de la sociedad civil y empresas nacionales e internacionales. En las siguientes tablas se puede encontrar cuáles son y qué papel ocupan en la realización del Proyecto Tren Maya. Cabe mencionar que en el caso de las instancias de asistencia técnica la colaboración se basa en una prestación de servicios con orientación comercial. Con respecto a las dependencias de la ONU, excepto ONU-DH, también se ha establecido una relación de prestación de servicios, pero sin fines lucrativos, puesto que, según ONU-Habitat, todo el dinero recibido por parte de FONATUR se destinaría íntegramente a la ejecución de sus labores en el marco del PTM.

Tabla 3. Instancias académicas colaboradoras en el Proyecto Tren Maya ${ }^{53}$

\begin{tabular}{|c|c|}
\hline Instancia & Tipo de colaboración \\
\hline $\begin{array}{l}\text { Instituto } \\
\text { Politécnico } \\
\text { Nacional (IPN) }\end{array}$ & $\begin{array}{l}\text { Se firmó un convenio general que permite impulsar proyectos en } \\
\text { conjunto e incluir aportaciones de académicos, científicos y } \\
\text { técnicos de esta casa de estudios al proyecto Tren Maya. }\end{array}$ \\
\hline $\begin{array}{l}\text { El Colegio de la } \\
\text { Frontera Sur }\end{array}$ & $\begin{array}{l}\text { El acuerdo de colaboración tiene por objetivo de llevar a cabo } \\
\text { actividades conjuntas en materia de investigación científica, } \\
\text { desarrollo de tecnologías y diseño de estrategias que contribuyan } \\
\text { a fortalecer el proyecto del Tren Maya. }\end{array}$ \\
\hline $\begin{array}{l}\text { Universidad } \\
\text { Nacional } \\
\text { Autónoma de } \\
\text { México (UNAM) }\end{array}$ & $\begin{array}{l}\text { El marco de colaboración busca generar un estudio de impacto } \\
\text { socioeconómico y antropológico del Tren Maya a través de la } \\
\text { generación de una línea basal. Ésta medirá con objetividad } \\
\text { estadística los impactos que son atribuibles al proyecto }\end{array}$ \\
\hline $\begin{array}{l}\text { Foro Consultivo } \\
\text { Científico y } \\
\text { Tecnológico A. } \\
\text { C. }\end{array}$ & $\begin{array}{l}\text { Dicho convenio tiene entre sus objetivos, organizar seminarios, } \\
\text { simposios, cursos y reuniones académicas, nacionales e } \\
\text { internacionales de relevancia para el proyecto; intercambiar } \\
\text { conocimiento, publicaciones y materiales académicos, e impulsar } \\
\text { actividades que consideren de interés en relación al Tren Maya. }\end{array}$ \\
\hline $\begin{array}{l}\text { Consejo de } \\
\text { Ciencia y } \\
\text { Tecnología del }\end{array}$ & $\begin{array}{l}\text { A través de este convenio, FONATUR y el CCYTET llevarán a } \\
\text { cabo actividades académicas, de capacitación, investigación, } \\
\text { innovación, científicas, tecnológicas, socioeconómicas y }\end{array}$ \\
\hline
\end{tabular}




\begin{tabular}{|c|c|}
\hline $\begin{array}{l}\text { Estado de } \\
\text { Tabasco } \\
\text { (CCYTET) }\end{array}$ & culturales, incluyendo estudios de factibilidad. \\
\hline $\begin{array}{l}\text { Universidad } \\
\text { Autónoma } \\
\text { Metropolitana } \\
\text { (UAM) }\end{array}$ & $\begin{array}{l}\text { Convenio General de Colaboración para llevar a cabo actividades } \\
\text { académicas, de capacitación, investigación, innovación, así } \\
\text { como actividades científicas, tecnológicas, socioeconómicas y } \\
\text { culturales, relacionadas con el Tren Maya }\end{array}$ \\
\hline $\begin{array}{l}\text { Universidad } \\
\text { Juárez } \\
\text { Autónoma de } \\
\text { Tabasco } \\
\text { (UJAT) }\end{array}$ & $\begin{array}{l}\text { Se impulsa la participación en actividades académicas, de } \\
\text { capacitación, investigación, científicas, socioeconómicas y } \\
\text { culturales, incluyendo estudios de factibilidad y evaluación de } \\
\text { impacto, relacionadas al Tren Maya, así como en el desarrollo de } \\
\text { acciones de interés mutuo que serán acordadas mediante } \\
\text { convenios específicos. }\end{array}$ \\
\hline $\begin{array}{l}\text { Colegio } \\
\text { Nacional de } \\
\text { Educación } \\
\text { Profesional } \\
\text { Técnica } \\
\text { (CONALEP) }\end{array}$ & $\begin{array}{l}\text { Convenio de colaboración para desarrollar actividades de } \\
\text { capacitación y formación de capital humano. }\end{array}$ \\
\hline $\begin{array}{l}\text { Centro de } \\
\text { Investigación en } \\
\text { Ciencias de } \\
\text { Información } \\
\text { Geoespacial } \\
\text { A.C. }\end{array}$ & $\begin{array}{l}\text { El objetivo de este instrumento es llevar a cabo actividades } \\
\text { académicas, de capacitación, investigación, } \\
\text { innovación,científicas, tecnológicas, socioeconómicas y } \\
\text { culturales, incluyendo estudios de factibilidad y evaluaciones } \\
\text { relacionados con el proyecto ferroviario. }\end{array}$ \\
\hline
\end{tabular}

Tabla 4. Agencias de la ONU colaboradoras en el Proyecto Tren Maya ${ }^{54}$

\begin{tabular}{|c|c|}
\hline Instancia & Tipo de colaboración \\
\hline $\begin{array}{l}\text { Oficina de las } \\
\text { Naciones } \\
\text { Unidas de } \\
\text { Servicios para } \\
\text { Proyectos } \\
\text { (UNOPS) }\end{array}$ & $\begin{array}{l}\text { UNOPS trabaja junto con FONATUR brindando asistencia } \\
\text { técnica para garantizar el cumplimiento de los mejores } \\
\text { estándares y las buenas prácticas internacionales en temas de } \\
\text { gestión, licitaciones e infraestructura. UNOPS proporciona al } \\
\text { proyecto } \\
\text { del Tren Maya conocimientos especializados a través de sus } \\
\text { expertas y expertos internacionales en gestión de proyectos, } \\
\text { ingeniería ferroviaria e infraestructura pública, contrataciones de } \\
\text { obras, gestión ambiental, social y arqueológica, entre otras, a fin } \\
\text { de brindar las mejores prácticas internacionales a través de una } \\
\text { Gestión Pública Justa y Equitativa (GPJE). } \\
\text { La asistencia técnica de UNOPS en la Fase I para el Tren Maya } \\
\text { consiste en la revisión y aportación de recomendaciones a: }\end{array}$ \\
\hline
\end{tabular}




\begin{tabular}{|c|c|}
\hline & $\begin{array}{l}\text { - Estudios previos y del diseño conceptual y básico de ingeniería } \\
\text { relacionados con la construcción de las vías férreas, adquisición } \\
\text { de trenes y operación. } \\
\text { - Las bases de licitación del proyecto ejecutivo y construcción de } \\
\text { las vías férreas, adquisición de trenes y operación. } \\
\text { - El modelo de negocio y operación del Tren Maya. } \\
\text { UNOPS apoyará la Fase II de Tren Maya en los procesos de } \\
\text { licitación de los contratos del proyecto ejecutivo y obras de vías } \\
\text { férreas suministro de rieles de los tramos } 1 \text { al } 4 \text {; supervisiones de } \\
\text { obras; software de gestión de obras; estudio de impacto } \\
\text { ambiental; y obras complementarias. Mediante dichas acciones, } \\
\text { la UNOPS en México contribuye con resultados al cumplimiento } \\
\text { de la Agenda } 2030 \text {. Cabe destacar que la UNOPS incide en las } \\
\text { causas estructurales de la pobreza correspondiente al ODS } 1 \text {, } \\
\text { combatiendo las desigualdades y generando oportunidades para } \\
\text { mejorar la calidad de vida de la población en un marco de } \\
\text { desarrollo sostenible. } \\
\text { También tiene una incidencia con los ODS } 6,10 \text {, } 11 \text { y 16, } \\
\text { manteniendo los objetivos transversales de enfoque de género, } \\
\text { respeto al medio ambiente, respeto a los principios y valores de } \\
\text { rendición de cuentas y utilización eficiente de recursos, así como } \\
\text { la aprobación y fortalecimiento de capacidades nacionales. }\end{array}$ \\
\hline $\begin{array}{l}\text { Programa de } \\
\text { las Naciones } \\
\text { Unidas para los } \\
\text { Asentamientos } \\
\text { Humanos } \\
\text { (ONU-Habitat) }\end{array}$ & $\begin{array}{l}\text { ONU-Habitat proporcionará apoyo sustantivo y técnico al } \\
\text { FONATUR en la definición de los parámetros y estrategias } \\
\text { necesarios para construir una propuesta de desarrollo integral del } \\
\text { sureste mexicano que creará bienestar, desarrollo y } \\
\text { oportunidades para esta región como una forma de saldar una } \\
\text { deuda histórica, reducir desigualdades, mejorar la calidad de } \\
\text { vida, bajo la premisa fundamental de preservar el patrimonio } \\
\text { natural y cultural de la región. Esta colaboración se fundamenta } \\
\text { en: } \\
\text { - Crear un corredor regional basado en un esquema de } \\
\text { ordenamiento del territorio. } \\
\text { - Redefinir el sistema regional de ciudades. } \\
\text { - Repensar y cambiar ventajas comparativas de las } \\
\text { microrregiones. } \\
\text { - Determinar los papeles de intermediación de algunas } \\
\text { ciudades para articular zonas urbanas y rurales. } \\
\text { - Evitar la generación de desigualdades en el territorio. }\end{array}$ \\
\hline $\begin{array}{l}\text { Organización } \\
\text { de las Naciones } \\
\text { Unidas para la } \\
\text { Educación, la } \\
\text { Ciencia y la } \\
\text { Cultura } \\
\text { (UNESCO) }\end{array}$ & $\begin{array}{l}\text { El acompañamiento que la UNESCO en México propone a } \\
\text { FONATUR para la implementación del Proyecto Integral de } \\
\text { Desarrollo del Tren Maya contempla: } \\
\text { - Coordinación interinstitucional para velar por los valores } \\
\text { culturales y naturales de la zona desde una perspectiva } \\
\text { integral. } \\
\text { - Fortalecer la conservación del medioambiente, de los }\end{array}$ \\
\hline
\end{tabular}




\begin{tabular}{|c|c|}
\hline & $\begin{array}{l}\text { recursos naturales y el agua de manera comunitaria y } \\
\text { retomando conocimientos tradicionales y ancestrales. } \\
\text { - Detonar el potencial creativo de grupos y comunidades en } \\
\text { favor de un desarrollo económico inclusivo. } \\
\text { - Promover la interculturalidad a través del reconocimiento } \\
\text { de la diversidad cultural y del patrimonio cultural inmaterial } \\
\text { de la región. } \\
\text { - Estrategia de comunicación que propicie la participación } \\
\text { de la comunidad y ayude a la toma de decisiones } \\
\text { informadas. }\end{array}$ \\
\hline $\begin{array}{c}\text { Oficina del Alto } \\
\text { Comisionado de } \\
\text { la ONU para los } \\
\text { Derechos } \\
\text { Humanos } \\
\text { (ONU-DH) }\end{array}$ & $\begin{array}{l}\text { La ONU-DH fue invitada por el Instituto Nacional de los Pueblos } \\
\text { Indígenas (INPI), FONATUR y la Secretaría de Gobernación } \\
\text { (SEGOB) a observar los procesos de consulta en torno al } \\
\text { proyecto del Tren Maya, incluyendo la consulta realizada entre el } \\
15 \text { de noviembre y el } 15 \text { de diciembre de } 2019 \text {. } \\
\text { El trabajo de la ONU-DH en relación con el proyecto del Tren } \\
\text { Maya tiene como objetivo el respeto y protección de los derechos } \\
\text { humanos en línea con los estándares y recomendaciones } \\
\text { internacionales, así como impulsar la inclusión social, económica } \\
\text { y política de las personas y pueblos indígenas, y su acceso a la } \\
\text { información, en vinculación con los Objetivos de Desarrollo } \\
\text { Sostenible } 10 \text { para la reducción de las desigualdades y } 16 \text { para } \\
\text { la paz, la justicia e instituciones sólidas de la Agenda } 2030 \text {. }\end{array}$ \\
\hline
\end{tabular}

Tabla 5. Asesores técnicos del Proyecto Tren Maya ${ }^{55}$

\begin{tabular}{|c|l|}
\hline Instancia & Tipo de colaboración \\
\hline Steer Davies & $\begin{array}{l}\text { Steer Davies es una de las principales consultoras de } \\
\text { infraestructura de transporte del mundo. Se brinda asesoría } \\
\text { técnica para el Análisis de Demanda del Tren Maya }\end{array}$ \\
\hline Mextypsa & $\begin{array}{l}\text { Asesoría técnica en la evaluación de la Ingeniería Básica del } \\
\text { sistema. La ingeniería básica de la primera fase del Tren Maya } \\
\text { contempla: }\end{array}$ \\
& $\begin{array}{l}\text { - Inventario de vías e instalaciones } \\
\text { - Estudio de alternativas y definición del trazo } \\
\text { - Afectaciones a vialidades, ferrocarriones, carreteras y } \\
\text { - Caminos } \\
\text { - Obras inducidas y servicios afectados, impacto urbano } \\
\text { - Definición de talleres, patios y entorno de las estaciones } \\
\text { - Modelo de operación, de explotación, catálogos de } \\
\text { inversión inicial } \\
\text { - Plataforma y vía, material rodante, señalamiento, }\end{array}$ \\
\hline
\end{tabular}




\begin{tabular}{|c|c|}
\hline & $\begin{array}{l}\text { comunicaciones, seguridad, tracción y sistema eléctrico } \\
\text { - Cartografía y topografía }\end{array}$ \\
\hline Senermex & Asesoría técnica en el diseño de la ingeniería básica del sistema. \\
\hline Eclecsis & $\begin{array}{l}\text { Cuenta con amplia experiencia prestando servicios } \\
\text { administrativos, financieros, técnicos, de asesoría o consultoría, } \\
\text { así como, llevar a cabo programas de capacitación y desarrollo } \\
\text { e investigación a distintas dependencias de gobierno y empresas } \\
\text { privadas. } \\
\text { Sus áreas de negocio son: oferta de servicios de consultoría e } \\
\text { investigación, seguridad física, infraestructura tecnológica y } \\
\text { centro de datos, así como telecomunicaciones y redes. }\end{array}$ \\
\hline $\begin{array}{l}\text { Colegios De } \\
\text { Ingenieros Y } \\
\text { Arquitectos Del } \\
\text { Estado De } \\
\text { Tabasco }\end{array}$ & $\begin{array}{l}\text { El convenio busca establecer mecanismos de colaboración para } \\
\text { proyectos estratégicos del sector, incluyendo el Tren Maya, así } \\
\text { como efectuar el apoyo e intercambio de información, asesoría, } \\
\text { consulta y capacitación, en su caso. }\end{array}$ \\
\hline $\begin{array}{l}\text { Colegio De } \\
\text { Ingenieros } \\
\text { Civiles De } \\
\text { Yucatán A.C. }\end{array}$ & $\begin{array}{l}\text { El objetivo de esta alianza es que especialistas colegiados } \\
\text { participen y colaboren en la ejecución del proyecto del Tren } \\
\text { Maya. }\end{array}$ \\
\hline $\begin{array}{l}\text { Colegio } \\
\text { Yucateco De } \\
\text { Arquitectos A.C. }\end{array}$ & $\begin{array}{l}\text { El objetivo de este Convenio es que el Colegio Yucateco de } \\
\text { Arquitectos, A.C participe activamente en el diseño y planeación } \\
\text { urbana del proyecto, desde su competencia profesional, aporte } \\
\text { de información y asesoría para favorecer a su desarrollo. }\end{array}$ \\
\hline $\begin{array}{l}\text { CMS } \\
\text { Woodhouse } \\
\text { Lorente Ludlow }\end{array}$ & $\begin{array}{l}\text { Asesora sobre la estructuración y la implementación de los } \\
\text { concursos públicos, los acuerdos innovadores de financiamiento } \\
\text { tanto público como privado, y la garantía de que la infraestructura } \\
\text { ferroviaria cumpla con los estándares de calidad y } \\
\text { medioambientales. }\end{array}$ \\
\hline $\mathrm{PwC}$ & $\begin{array}{l}\text { Asesora en materia de sostenibilidad financiera del proyecto y su } \\
\text { Análisis Costo-Beneficio. }\end{array}$ \\
\hline
\end{tabular}

\subsubsection{Estado actual de avance de la obra}

Las obras de los primeros cuatro tramos del PTM, correspondientes a la Fase 1, iniciaron en mayo del 2020, tras el proceso de publicación, evaluación y adjudicación de licitaciones para cada tramo durante los meses de febrero a abril. Dicho proceso fue acompañado por UNOPS ${ }^{56}$. A partir del lunes 24 de agosto FONATUR ha presentado semanalmente un reporte de avances sobre la construcción del PTM, 
durante las conferencias de prensa matutinas del presidente AMLO. Se estima que el PTM se concluya en 157 semanas, a las cuales corresponderá respectivamente un reporte. A la fecha de escritura de este apartado (29 septiembre 2020), han transcurrido 6 semanas.

En términos generales, se ha avanzado en el desmantelamiento de las vías antiguas, liberación de los derechos de vía, fabricación de nuevos durmientes y preparación del suelo, ésta última con asistencia especializada en geofísica. También se ha avanzado en la determinación de los espacios donde se realizarán los pasos de fauna y en el salvamento arqueológico, utilizando fototrampeo y vuelos LIDAR respectivamente. Igualmente se ha iniciado la rehabilitación de 42 estaciones antiguas, las cuales funcionarán como centros de distribución. Asimismo, se ha continuado el diálogo con las comunidades locales para la planeación territorial participativa y la canalización de las demandas surgidas al Comité Interinstitucional, el cual está conformado por alrededor de 30 dependencias federales.

\subsection{Forma ideal y forma real del actuar gubernamental en el proceso político del PTM 2018-2020}

El Gobierno Federal ha cumplido más o menos en tiempo con los puntos señalados en su agenda para la realización del Tren Maya. No obstante, el proceso ha llevado un curso distinto al esperado idealmente, si se toman en cuenta los protocolos legales nacionales y el cumplimiento con convenios internacionales de los cuales participa el Estado mexicano. No obstante, independientemente del orden, la forma y la meticulosidad de cada acción, FONATUR ha "palomeado" los requisitos que el mismo Estado mexicano determina para iniciar una obra de este tipo.

A continuación se presentan en orden cronológico los eventos más importantes relacionados al desenvolvimiento del Proyecto Tren Maya por parte del Estado mexicano, tanto en su forma ideal (como debió ser), como en su forma real (como fue), de diciembre del 2018 a septiembre del 2020. Como puede notarse en la tabla 6 , todos los pasos que por ley deben seguirse, se siguieron, aunque no en el orden ideal. Asimismo, la forma real del proceso tuvo más pasos que la forma ideal. 


\begin{tabular}{|c|c|}
\hline $\begin{array}{l}\text { Forma ideal del proceso Proyecto } \\
\text { Tren Maya 2018-2020 }\end{array}$ & $\begin{array}{l}\text { Forma real del proceso Proyecto } \\
\text { Tren Maya 2018-2020 }\end{array}$ \\
\hline $\begin{array}{l}\text { 1) Reiteración del PTM en la toma } \\
\text { de protesta de la presidencia; } \\
\text { 2) Se anuncia a SCT o FONATUR } \\
\text { como la instancia encargada del } \\
\text { PTM; } \\
\text { 3) Realización y presentación de las } \\
\text { Manifestaciones de Impacto } \\
\text { Ambiental de todo el proyecto } \\
\text { ante SEMARNAT; } \\
\text { 4) Apertura a Consulta Pública de la } \\
\text { MIA; } \\
\text { 5) Realización y presentación de las } \\
\text { Evaluaciones de Impacto Social } \\
\text { de todo el proyecto; } \\
\text { 6) Realización y presentación de } \\
\text { estudios de viabilidad financiera y } \\
\text { Análisis Costo-Beneficio; } \\
\text { 7) Consulta Indígena previa, libre, } \\
\text { informada, culturalmente } \\
\text { adecuada y de buena fe (en caso } \\
\text { de que la resolución fuera } \\
\text { negativa el proyecto debía parar); } \\
\text { 8) FONATUR inicia búsqueda de } \\
\text { alianzas intersectoriales } \\
\text { (academia, colegios } \\
\text { profesionales, organizaciones de } \\
\text { la sociedad civil, dependencias de } \\
\text { la ONU); y adjudicación de } \\
\text { 9) Apertura y adjudicación de } \\
\text { licitaciones de asistencia ténica; } \\
\text { 10)Apertura y aciones de construcción de la } \\
\text { licitacionas } \\
\text { infraestructura; } \\
\text { 11) Banderazos de inicio de obras; } \\
\text { 12) Inicio de obras. }\end{array}$ & 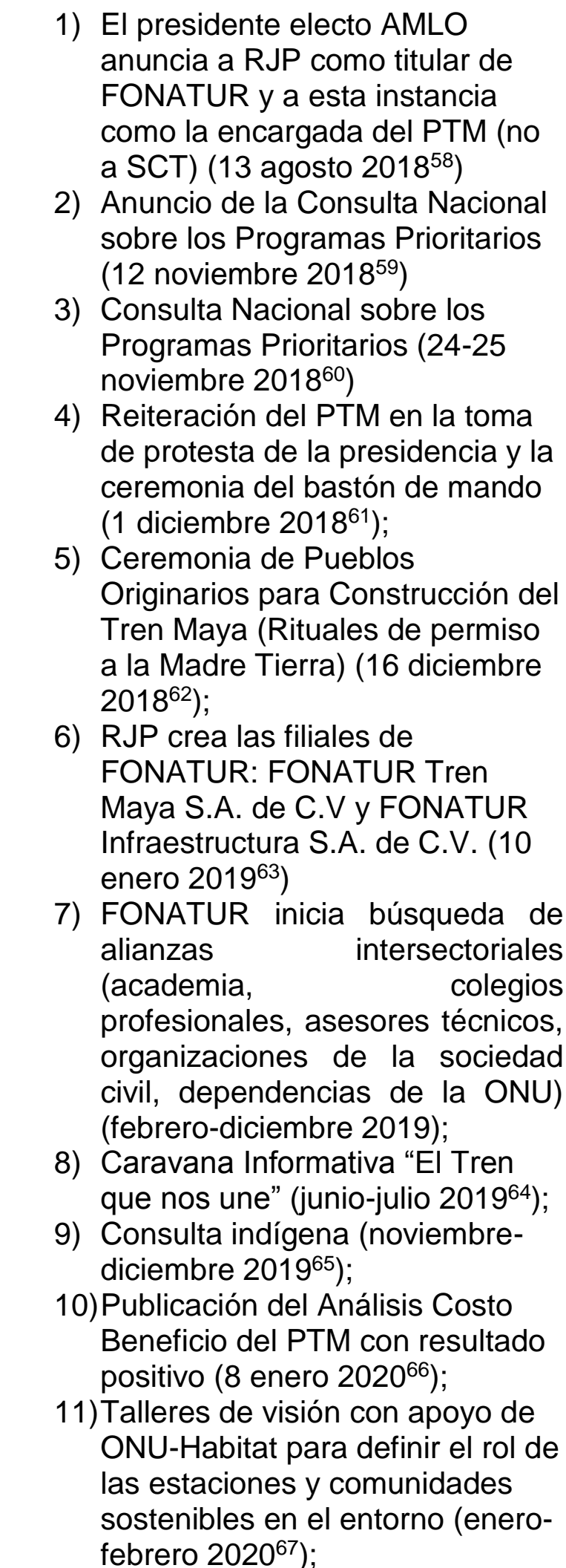 \\
\hline
\end{tabular}




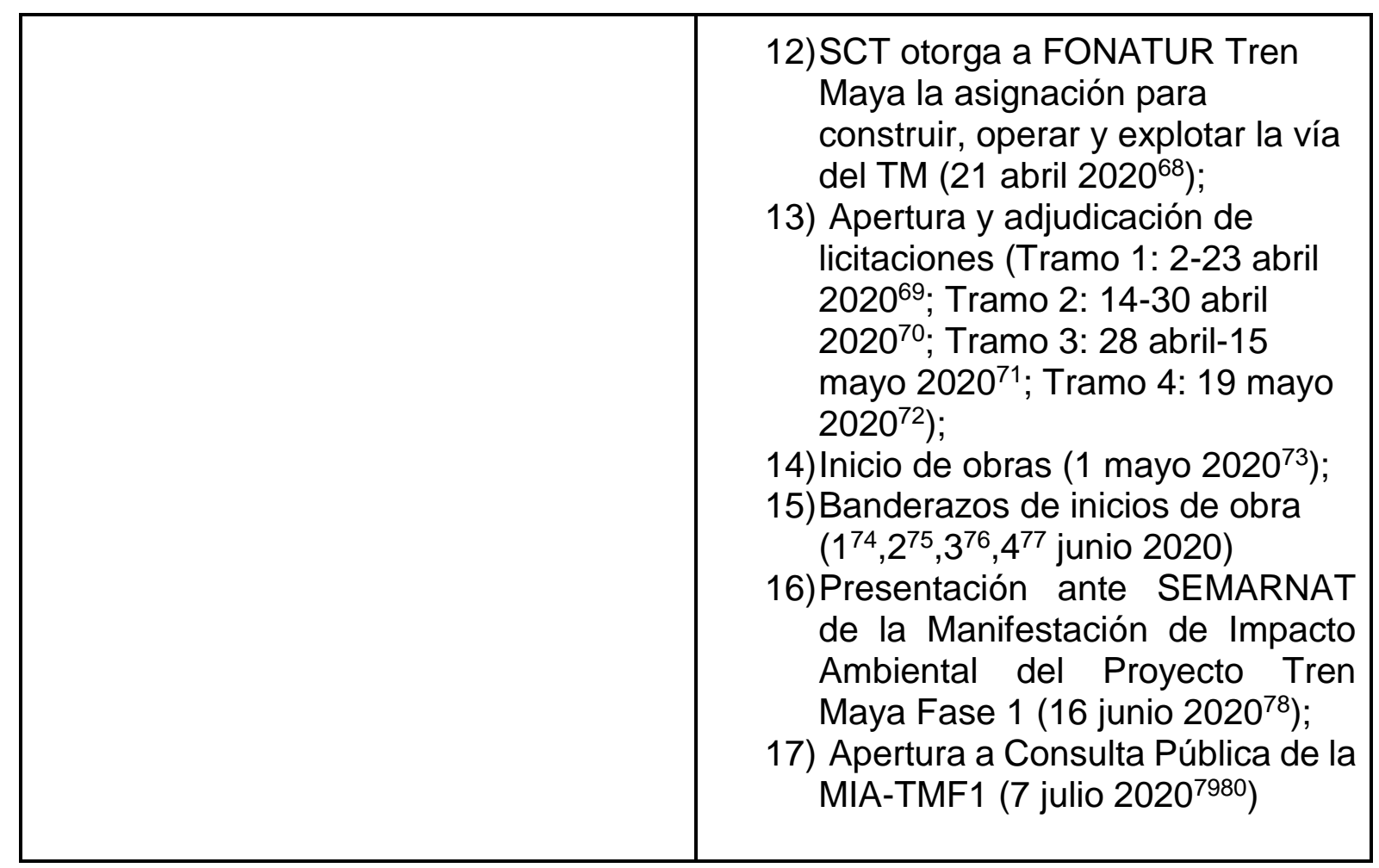

Ahora bien, ¿Por qué el proceso no fue ideal? ¿Por qué el proceso real tuvo más pasos que el proceso ideal? ¿Por qué no se siguió el orden ideal si se busca construir una sociedad ideal desde la $4 \mathrm{~T}$ ? Desde una perspectiva antropológica hay varias respuestas posibles a este conjunto de preguntas.

En primer lugar, las nociones sobre la implementación de procesos ideales tienden a considerar únicamente los aspectos legales -acaso burocráticos- de la realización de programas y proyectos públicos, sin considerar el contexto de las relaciones de poder alrededor del Estado. Desde esta perspectiva sólo hay una vía correcta para llevar a cabo un proyecto, la estipulada legalmente, para la cual el tiempo de consecución de cada uno de los pasos puede quedar en segundo término, pues lo importante es que se cumplan y en el orden establecido. Aunado a esto, los eventos políticos como el Ritual de Permiso a la Madre Tierra y los Banderazos de inicio de obras no tienen una función particular, incluso podrían ser percibidos como innecesarios.

En contraste, en los procesos reales se suele considerar los aspectos legales de manera subordinada a orientaciones pragmáticas en el contexto de relaciones y disputas por el poder alrededor del Estado. En este caso el objetivo es lograr que el Tren Maya esté listo antes de finalizar el sexenio de López Obrador, puesto que la 
visibilización de sus resultados puede ser la diferencia entre si esta obra sería percibida como un despilfarro sin precedentes del erario público o como la magna obra de desarrollo para el sur-sureste de México. En última instancia, es posible que en esta gran apuesta está en juego -en cierta medida- la permanencia o no de MORENA como partido hegemónico para el próximo sexenio y la continuidad de la agenda política de la Cuarta Transformación. Tal vez por ello la urgencia de avanzar lo más rápido posible.

Adicionalmente, en los procesos reales los eventos como el Ritual de Permiso a la Madre Tierra, los Banderazos de inicio de obras, etc. sí tienen una función. Con estos eventos -que desde el procesualismo turneriano pueden ser catalogados como rituales políticos o ceremonias definicionales- los actores muestran el poder que tienen o el que aspiran tener, evidencian su posición en las disputas por recursos, es decir, dejan en claro quiénes son o quieren ser en los campos políticos. Igualmente, aunque en términos burocráticos estos eventos pueden parecer irrelevantes, en términos políticos son fundamentales, pues la espectacularidad del poder es una vía importante para obtener el respaldo social de actores particulares, proyectos específicos o agendas políticas. Es así que se explica que los procesos reales tengan más pasos que los procesos ideales, pues se da importancia a los rituales políticos y ceremonias definicionales para mostrar e incrementar la influencia en el medio social. Como se verá en el capítulo 2, los rituales políticos sirven para ganar la opinión pública y las ceremonias definicionales para mostrar las fuerzas en momentos poco propicios.

Se puede afirmar que el proceso que ha seguido el Tren Maya no ha sido el ideal porque las condiciones del medio en el que se desenvuelve no son lineales ni controladas, son complejas y están atravesadas por múltiples relaciones de poder. En la realidad social hay de manera inacabada disputas por el poder y alrededor del mismo. Por este motivo, a veces los pasos a dar idealmente tienen que omitirse, apresurarse, hacerse con baja calidad o variar en orden, esto dependerá de las condiciones políticas, de los recursos y el tiempo con que se cuente. Aunque por supuesto, el Estado debe ser el primer actor en ser congruente con los modos ideales que se proponen desde el mismo.

En los procesos reales se aprovechan momentos de ventaja construida 0 casual y se está constantemente resolviendo problemas operativos, legales y de 
intereses interinstitucionales e interpersonales, así que en cierta medida se actúa cuando se puede, o cuando se debe, pero no en función de los requerimientos legales, sino de las posibilidades del campo político. Se opera estratégicamente para lograr los objetivos librando y reduciendo las múltiples trabas legales y operativas, ya sean orquestadas por los oponentes o consecuenica de la acción propia.

El punto de partida en los procesos reales es que se tendrá que hacer lo necesario para lograr un objetivo, lo que incluye -entre otras cosas- el cumplimiento de los aspectos legales. En algunos casos se puede recurrir incluso a prácticas paralegales o ilegales para palomear los requerimientos estipulados por la ley. En mi opinión -no especializada en el ámbito legal y basándome en la información a la que he tenido acceso- considero que para la realización del Tren Maya no se ha incurrido en prácticas ilegales o paralegales siguiendo la tónica anti-corrupción de la narrativa de la 4T, aunque ciertamente es cuestionable la calidad de algunos procesos, como la Consulta Indígena.

Esta última fue criticada por los oponentes del Tren Maya al no ser considerada previa, pues se avisaba que el Tren va, no se preguntaba si debía realizarse. Se señaló que tampoco fue libre, puesto que durante las asambleas de consulta los asistentes podían registrarse a programas sociales o externar sus necesidades individuales o colectivas. También se cuestionó que la consulta fuera informada, pues no se compartía información suficiente sobre la ubicación de las estaciones, paraderos, el tipo de financiamiento de las comunidades sustentables ni cómo se involucraría a los propietarios legales de las tierras en este último mediante los FIBRA, por lo que no había claridad sobre el destino de la propiedad y uso de las tierras que se proponía con el proyecto. Igualmente fue cuestionada la pertinencia cultural de la consulta, pues no hubo una labor de traducción suficiente hacia ambas vías. La suma de lo anterior hacía que los oponentes al PTM consideraran que la consulta tampoco cumplía con el requerimiento de ser de buena fe.

Para grupos de defensa de Derechos Humanos, actores del activismo étnicoambientalista, parte del sector académico y de las OSC, la Consulta Indígena constituye en cualquier proyecto una de las garantías para que sea en beneficio de la población, que no se atropellen o violen los derechos de las poblaciones locales, que 
no se implemente de manera autoritaria, y que se abran las rutas para negociaciones justas. Es decir, es uno de los puntos clave del proceso ideal.

No obstante, este aspecto ha sido históricamente un requisito a palomear en los procesos reales, al igual que las Evaluaciones de Impacto Social y las Manifestaciones de Impacto Ambiental. Con esto no quiero decir que es justificable ni mucho menos que estoy de acuerdo con que así sea. Es inaceptable en términos de justicia social que estos pasos tan fundamentales para garantizar la optimización de beneficios locales y la reducción de afectaciones sean considerados simplemente requisitos.

No justifico ni respaldo el proceder gubernamental con respecto a la Consulta Indígena, pero desde una perspectiva antropológica del poder es comprensible. El sector gubernamental hizo lo que tenía que hacer, cuando debía y como podía, en función del ambiente político y de los recursos de los que disponía, para lograr cuatro objetivos simultáneos: palomear el requisito legal; conocer las necesidades de la población local para usarlas a favor del proyecto; identificar a los líderes locales; y utilizar la Consulta -entendida como propaganda en el área de incidencia- con fines también propagandísticos y lograr la aprobación de la opinión pública local, nacional e internacional.

La forma no ideal en que se llevó a cabo la Consulta Indígena puede deberse a que el tiempo apremiaba, aunado a que no se puede cambiar la cultura política del asistencialismo en el corto plazo. Asimismo, es posible que no se haya brindado información de calidad durante las asambleas porque no se había generado, puesto que el proyecto estaba en una etapa temprana de construcción. Aún así, para seguir avanzando con el ritmo esperado se tenía que palomear el requerimiento de la Consulta Indígena. No obstante lo polémica que resultó, y reconociendo la calidad cuestionable de la misma, se llevó a cabo y se ha dado seguimiento a los resultados obtenidos mediante los aparatos de vinculación social de FONATUR, en coordinación con ONU-Hábitat y el Comité Interinstitucional, entre los que se encuentran el INPI, la SEMARNAT y el INAES. Insisto, no es ideal y está lejos de serlo, pero es un inicio para que lo ideal se vuelva real si progresivamente se esperan y exigen mejores resultados que el obtenido en esta ocasión, si la cultura política de la participación ciudadana logra romper el pacto de dominación basado en el asistencialismo. 
Es necesario convertir este punto clave de los procesos ideales en un elemento fundamental de las orientaciones pragmáticas de los procesos reales. Es decir, que la consecución de los objetivos del proyecto incluya desde el inicio la optimización de beneficios y la reducción de afectaciones sociales y ambientales, de manera culturalmente adecuada y en una actitud de respeto a las poblaciones locales. Esta propuesta -idealista- puede resultar absurda en el contexto cultural del neoliberalismoasistencialismo, pero no lo es tanto desde la propuesta de la Cuarta Transformación, que narrativamente revitaliza características del Estado Benefactor en el contexto cultural del capitalismo tardío, constituyendo una especie de neokeynesianismoneoindigenista-posneoliberal. La cuestión de fondo es: ¿Es posible o es posible hacerlo posible? Para responder a esta pregunta será necesario atender a los hechos de los próximos años y mantener una distancia crítica, para no incurrir en la justificación de fatalismos o utopismos a priori. Exploraré con mayor detenimiento esta idea en la tesis doctoral.

Queda por responder la pregunta ¿por qué no se siguió el orden ideal si se busca construir una sociedad ideal desde la 4T? En función de lo expuesto hasta ahora, puede decirse que el medio sociocultural y el campo político no han sido propicios. Se tendría que revertir primero dos condicionamientos que han echado raíces en las últimas décadas en la cultura política mexicana: el asistencialismo como eje de las políticas públicas y la cultura del neoliberalismo como la base de las relaciones sociales y como premisa del actuar político. Si se hubiera seguido el proceso ideal, probablemente el proyecto habría encontrado muchos más obstáculos y se hubiera puesto en riesgo la culminación del Tren Maya antes de finalizar el sexenio de López Obrador y la continuidad de la agenda política de la Cuarta Transformación.

Para finalizar este capítulo quisiera exponer un par de ideas más. Los modos ideales de realizar un proceso desde el Estado son guías para la acción de los agentes gubernamentales, y guías para la vigilancia del actuar gubernamental desde la sociedad civil. Pero al controlar los aparatos desde los cuales podrían ser sancionados, los actores gubernamentales pueden actuar con mayor holgura. E riesgo radica en que esta laxitud, sumada a las necesidades estratégicas del campo político, pueda devenir en un actuar no ético, de mala fe y que no vele por los intereses y bienestar de la sociedad en su conjunto. Es decir, se corre el peligro de que por una 
orientación radicalmente pragmática el bienestar de la sociedad se vea subordinado a la consecución del proyecto por sí mismo, limitando su relevancia meramente al ámbito narrativo, para la creación de discursos estratégicos. De este modo se abre la posibilidad de que los agentes gubernamentales puedan en el mediano o largo plazo disociar lo que dicen y lo que hacen.

En síntesis, una orientación radicalmente pragmática y operativa puede llevar a la incongruencia y la contradicción, así como una orientación radicalmente idealista puede llevar a la imposibilidad de articular el decir y el hacer en función de las condiciones reales de la sociedad. Así pues, los actores que quieran velar por el bienestar social, tanto en el Estado como fuera de él, necesitan tanto conocer las condiciones reales de la sociedad como mediar con prudencia, estrategia y vigilancia epistemológica el pragmatismo y el idealismo en su actuar y su decir.

\subsection{Continuidades y diferencias entre el Proyecto Tren Maya y sus antecedentes}

Después de haber abordado las características del Proyecto Tren Maya, ahora es posible ofrecer un análisis de las continuidades y diferencias que guarda con respecto a los antecedentes señalados en la introducción de este capítulo, que son la Organización Mundo Maya (OMM); el Tren Transpeninsular (TT); el Expreso Maya; las Ciudades Rurales Sustentables (CRS); y los Centros Integralmente Planeados (CIP). A continuación realizo un contraste considerando cada uno de los antecedentes.

En primera instancia, las similitudes/continuidades que guarda el Proyecto Tren Maya con respecto a la Organización Mundo Maya y sus programas son varias. Ambas se proponen promover el desarrollo económico de la región sur-sureste mexicano a través de un modelo de turismo que articule cultura, ecología y desarrollo a través de un producto multidestino. Igualmente, en los propósitos de la OMM y del PTM queda de manifiesto la intención de generar empleo para la población local, en una tónica de respeto a la población indígena; siendo esta última reforzada mediante Consultas Indígenas y actividades tendientes a la revalorización de sus culturas.

En el aspecto ecológico ambas propuestas se plantean proteger el medio ambiente generando productos turísticos sustentables/sostenibles que ayuden a 
reducir la destrucción de las selvas y bosques de la región por la tala clandestina. Este elemento ha servido como argumento para intervenir en los espacios del área maya, y es en este sentido que desde el activismo étnico ambientalista y desde organizaciones de derechos humanos se ha señalado que esta posición es una criminalización de la pobreza, pues los habitantes recurren a la tala clandestina por la necesidad de generar ingresos. La respuesta del sector gubernamental suele ser que esta misma crítica apoya el argumento de la necesidad de ampliar la oferta laboral en la zona, para que la población local no se vea en necesidad de incurrir en prácticas ilegales para obtener el sustento.

Igualmente, tanto la Organización Mundo Maya como el Proyecto Tren Maya han propuesto generar un circuito turístico en la Península de Yucatán financiado mediante asociaciones público-privadas, que consideran la construcción de infraestructura, la ejecución de programas, proyectos sociales y la restauración y promoción de los sitios arqueológicos de la región. Aunque, como ya se ha mencionado, el circuito turístico propuesto por la OMM contemplaba la construcción de aeropistas en el perímetro de la Península, con un trazo muy similar al del Tren Maya.

Por último, una concordancia fundamental entre la Organización Mundo Maya y el Proyecto Tren Maya es que ambas buscan generar un producto turístico multidestino en la región basado en la narrativa de la turistificación-mayanización, la cual, como se explicó en el primer apartado de este capítulo, fue generada en el seno de la OMM y propagada en la región hasta desconocerse su origen, volviéndose un elemento cultural abierto a la resignificación constante y a múltiples usos, primordialmente económicos.

Como ya se ha mencionado, al ser una narrativa abierta, los usuarios de la misma -sean conscientes o no de que la usan- pueden priorizar, combinar, resignificar y excluir algunos de los componentes originales de la narrativa a conveniencia, ya sea para legitimar proyectos económicos y políticos, evitar la crisis ontológica o identitaria. Los componentes fundamentales de la narrativa de la turistificaciónmayanización original son: 
7. El Mundo Maya es un concepto turístico regional que une cultura, ecología y desarrollo para los pueblos del área (Secretaría Ejecutiva OMM, 1996:4);

8. Pretende la revalorización y aprovechamiento de los componentes [¿ambientales y/o culturales?] sin destruirlos (Secretaría Ejecutiva OMM, 1996:5);

9. Busca otorgar fuentes alternativas de ingreso para los habitantes pobres de la región y reducir la destrucción del bosque tropical de la región Maya (BID, 2000:2);

10. Concibe que el éxito dependerá en gran medida de las iniciativas privadas nacionales y locales (BID, 2000:2);

11. Apuesta por el diseño de proyectos de infraestructura y planes de adiestramiento para beneficio de las comunidades locales e inversionistas (BID, 2000:2);

12. Combina la narrativa indigenista estatal sobre la mayanidad con las narrativas del New Age sobre los "mayas galácticos" desde una perspectiva comercial, según quedó en evidencia con el Programa Mundo Maya 2012 de Calderón.

Ahora bien, con respecto a las diferencias entre el PTM y los programas de la OMM, tenemos que el Tren Maya contempla la creación de Comunidades Sustentables y la OMM no ha tenido entre sus objetivos la creación o ampliación de asentamientos urbanos. Otra diferencia clave es que el Tren Maya no es un proyecto exclusivamente turístico, pues incluye el transporte de pasajeros locales, el transporte de mercancías y el reordenamiento territorial basado en la creación de Comunidades Sustentables.

Otra diferencia entre el Proyecto Tren Maya y la Organización Mundo Maya es que el primero se propone explícitamente evitar la generación de desigualdades en la región de incidencia. Esto puede deberse a la influencia de las agencias de la ONU con las que colabora FONATUR y sobre todo a las narrativas en boga para la elaboración de políticas públicas que corresponden a momentos diferentes, la OMM fue concebida en la época del desarrollismo no adjetivado y el PTM en la época del desarrollo adjetivado (sostenible, local, etc.) en el que se generaron los Objetivos del Desarrollo Sostenible, los cuales consideran la atención a las desigualdades sociales. 
En los documentos revisados con respecto a la OMM se habla de incluir a la población local en el desarrollo, mientras que en el PTM se habla de generar el desarrollo sustentable mediante la colaboración Estado-Sociedad.

Hay que destacar que la OMM y el trabajo a partir de ella han estado presentes en la agenda turística mexicana durante los últimos siete periodos presidenciales. Después de 30 años la marca comercial "Mundo Maya" sigue sin ser integral para la región de la OMM, pero forma parte del sentido común para la elaboración de las políticas públicas y las concepciones sobre la vocación turística de la zona y la configuración de las relaciones interétnicas e interculturales que implica la actividad turística: un modo particular de concebir lo maya produce un modo particular de actuar sobre-con-para-a pesar de lo maya en la región.

En síntesis, la narrativa de la turistificación-mayanización se vuelve hegemónica. Incluso las narrativas subalternas se ven obligadas a invertir tiempo en generar y exponer argumentos críticos y de oposición que en ocasiones son reflejos u opuestos lógicos de la misma narrativa hegemónica. Esa hegemonía es el gran logro de la OMM pese a no haber obtenido los resultados económicos, sociales e infraestructurales que se ha trazado. La vigencia de esta narrativa es evidente al recordar que en agosto del 2020, por iniciativa de la Secretaría de Fomento Turístico de Yucatán (SEFOTUR), los cinco estados mexicanos miembros de la OMM -e incluídos en el Proyecto Tren Maya- firmaron el convenio de colaboración "Alianza Mundo Maya México", para la reactivación conjunta del turismo después de la pandemia de COVID-1981.

Pasando al contraste con el segundo antecedente señalado, el Tren Transpeninsular propuesto por la ex gobernadora de Yucatán, Ivonne Ortega, tenemos que son similares primeramente en el nombre, pues inicialmente el Tren Maya fue promovido como Tren Turístico Transpeninsular. En segundo lugar, ambos proyectos plantean la construcción de nuevas vías férreas interestatales para el transporte de pasajeros locales, turistas y mercancías para favorecer el desarrollo económico de la región. Asimismo, uno de los puntos fundamentales para la oferta turística considerado en ambos proyectos es la oferta arqueológica. Igualmente, ambos proyectos plantearon la construcción de estaciones en varias localidades a lo largo de la ruta aprovechando el derecho de vía existente y ordenando el desarrollo 
urbano de las localidades. Por último, hay que mencionar que el esquema de financiamiento de ambos es mediante asociaciones público-privadas.

Por otra parte, entre las diferencias identificadas entre el Tren Maya y el Tren Transpeninsular tenemos que la ruta del Tren Maya contempla cinco estados Chiapas, Tabasco, Campeche, Yucatán y Quintana Roo- mientras que el Tren Transpeninsular sólo consideraba conectar Yucatán con Quintana Roo. Igualmente, el Tren Maya se propone proteger y rehabilitar Áreas Naturales Protegidas, lo que, hasta donde tengo conocimiento, no estuvo contemplado en el TT.

Otra diferencia fundamental entre el Proyecto Tren Maya y el Tren Transpeninsular es que en el segundo no apareció en ningún momento el tema indígena/maya, ni para promover el respeto a la población maya ni como marca comercial. Desconozco las razones de esta omisión, pero queda claro que el TT no surgió a partir de la narrativa de la turistificación-mayanización ni se interesó en utilizarla. Una explicación posible de esta ausencia es que el TT fue propuesto en el 2007, algunos años antes del "boom" de lo maya en el año 2012, momento en el que Calderón aprovechó para dar un nuevo aire a la turistificación-mayanización iniciada en el marco de la OMM. En síntesis, se puede afirmar que el Tren Transpeninsular es el antecedente directo del Tren Maya, pero que no procedió al ser una iniciativa a nivel estatal en un momento en que el poder federal no priorizaba la región sursureste, aunado al ambiente político de corrupción y desfalco a las arcas nacionales que imposibilitó el financiamiento del proyecto en la administración peñanietista.

Con respecto al tercer antecedente identificado del PTM, el Expreso Maya, la similitud principal es que ambos contemplan la ruta Palenque-Mérida y promueven los sitios arqueológicos y de interés cultural al visitante. Lo que vale la pena resaltar del Expreso Maya es que usó la marca comercial "maya" para nombrar a un proyecto ferroviario-turístico antes que el Tren Maya, e incluso resulta llamativo que un emprendedor del centro del país haya usado la mayanidad para promover este proyecto y no lo haya hecho así la gobernadora de Yucatán Ivonne Ortega, siendo el proyecto que propuso de mucho mayor envergadura.

Por otra parte, entre las diferencias identificadas tenemos que el Tren Maya se propone no sólo utilizar las vías existentes, sino rehabilitarlas y ampliarlas creando un circuito en la península. Esto, obviamente, es posible porque el Tren Maya tiene 
financiamiento federal mientras que el Expreso Maya era una iniciativa particular. De esto último se desprende que el Tren Maya no se limite únicamente al aspecto turístico, como ya se ha mencionado. La diferencia a destacar es que el Expreso Maya era una iniciativa privada con un presupuesto mucho menor al del Tren Maya, que buscaba primordialmente ser rentable, mientras que el PTM busca simultáneamente la rentabilidad y el beneficio social, al menos en lo que se ha declarado al respecto.

Hasta aquí se han abordado las similitudes y diferencias que el Tren Maya guarda con los proyectos y programas públicos y privados relativos al ámbito ferroviario-turístico y a la turistificación-mayanización. A continuación se contrasta el PTM con los antecedentes relativos al reordenamiento territorial. El primero de ellos, como se recordará, es el programa de las Ciudades Rurales Sustentables promovido en el estado de Chiapas durante la administración de Juan Sabines, durante el periodo presidencial calderonista.

Entre las similitudes que tiene el PTM con esta propuesta tenemos, en primera instancia, que el nombre dado a las ampliaciones urbanas alrededor de las estaciones del PTM denominadas Comunidades Sustentables, al igual que las Ciudades Rurales Sustentables, hacen patente la influencia de las terminologías de los organismos intergubernamentales como la ONU en ambos proyectos. Igualmente, los dos plantearon la creación de centros urbanos intermedios en las zonas rurales, facilitando las posibilidades de proveer servicios básicos a la población rural. También coinciden en la necesidad de construir infraestructura no sólo para proveer servicios sino también para generar empleos en la zona.

Por otra parte, entre las diferencias detectadas, tenemos que las Ciudades Rurales Sustentables no tuvieron el mismo nivel de aprobación popular -ni tanta propaganda- que el Proyecto Tren Maya. Igualmente, las CRS no fueron planeadas para el turismo, a diferencia de las Comunidades Sustentables del Tren Maya. Eso puede explicar en cierta medida el poco cuidado que se tuvo en la planeación de estos asentamientos en Chiapas, destinados a la población indígena, lo cual es un reflejo del racismo institucional. Aunado a esto, tenemos que las CRS han sido señaladas como proyectos culturalmente inadecuados, a diferencia de lo que se pretende con el Tren Maya mediante la participación comunitaria en la planeación a través de talleres liderados por ONU-Habitat. Claro, esto tampoco es una garantía, con el tiempo 
veremos los resultados. Adicionalmente, al no ser concebidas para el turismo las CRS no presentan la narrativa de la turistificación mayanización, esto lleva a preguntarnos ¿Es el turismo la única vía de visibilización y de atención a la población maya de la Península de consideración para el Estado?

El otro antecedente del Tren Maya con respecto al reordenamiento territorial es el de los Centros Integralmente Planeados. Entre las similitudes que guarda el Tren Maya con ellos tenemos que ambos están a cargo de FONATUR. Esto, como ya se ha señalado, incidió en que en un primer momento las ahora llamadas Comunidades Sustentables fueran primeramente denominadas Polos de Desarrollo, pues fue esta la nomenclatura dada a los CIP por FONATUR el siglo pasado, basado en las teorías del desarrollo aún sin adjetivar. Igualmente, tanto los CIP como las Comunidades Sustentables tienen el objetivo de impulsar el desarrollo económico a través del turismo. Asimismo, ambas iniciativas recurren a financiamientos mixtos, en los que primero el Estado aporta capital y posteriormente, cuando la inversión ya no es de riesgo, aporta la iniciativa privada. Por último, tanto los CIP como el PTM son iniciativas del gobierno federal y tienden al centralismo, aunque para el PTM, FONATUR ha buscado alianzas locales con actores clave, si bien esto no es garantía de descentralización u horizontalidad.

Por otra parte, entre las diferencias entre los Centros Integralmente Planeados y las Comunidades Sustentables del Tren Maya, tenemos que los CIP, particularmente Cancún (1972), no consideraron inicialmente la narrativa de la turistificación-mayanización -iniciada en 1988 por la OMM-, a diferencia del PTM que la considera fundamental desde el inicio. Sobre este último punto, cabría considerar que el éxito de Cancún y la expansión de la turistificación por la costa quintanarroense fue el detonante de la turistificación-mayanización en lo que se llegaría a denominar Riviera Maya.

Este es pues el contexto en que se ha propuesto el Proyecto Tren Maya. Es posible afirmar que el Tren Maya recupera y conjuga los objetivos, terminologías y narrativas de proyectos gubernamentales, intergubernamentales y de iniciativa privada de los últimos 50 años. No obstante, el PTM no es simplemente un refrito de propuestas previas, pues hay innovaciones importantes sobre todo en el aspecto narrativo, es decir, las propuestas tienen otros significados en el marco de la Cuarta 
Transformación. En síntesis, la narrativa de la 4T ha hecho que algunas propuestas, que en otro contexto político serían tomadas como afrentas, puedan ser concebidas como oportunidades.

Considero destacable el hecho de que desde la narrativa de la 4T esta propuesta de inversión, reordenamiento territorial y promoción del turismo ha tenido mayor aceptación que si el proyecto integral hubiera sido propuesto por las administraciones anteriores del PRI y del PAN. Probablemente un sector importante de los que ahora están colaborando para la correcta ejecución del Tren Maya estarían radicalmente en contra. Es decir, López Obrador puede cumplir desde su izquierda el sueño no logrado de la derecha -por incompetencia, corrupción, desaprobación popular- de integrar a la región sur-sureste de México cabalmente a la economía nacional y global.

En buena medida, es por las narrativas en torno al proyecto que ciertas facciones de la academia, de las OSC y de los propietarios legales de las tierras lo aceptan. Por otra parte, otros sectores del campo político del Tren Maya, como el del activismo étnico ambientalista y ciertas facciones de la academia y las OSC no creen en esta nueva narrativa y están atentos más bien a las acciones emprendidas por los funcionarios públicos de todos los niveles. Los hechos hablarán y veremos si la propuesta de la Cuarta Transformación logra generar una tendencia hacia la finalización de la cultura política del neoliberalismo-asistencialismo. Con la implementación del Proyecto Tren Maya veremos si se intenta -y si es posible- sentar las bases para la transición hacia una reelaboración del Estado Benefactor keynesiano. 


\section{Capítulo 2}

\section{El drama social del Proyecto Tren Maya previo a su existencia material}

En este capítulo se presentan las razones por las cuales resulta posible y también conveniente analizar el fenómeno social del Tren Maya como un proceso político usando el método del drama social. Para ello se presenta el marco teórico y conceptual de este estudio, basado en la propuesta del procesualismo turneriano, complementado con propuestas de otros autores sobre los conceptos de ideología, narrativa, la relación poder-etnicidad, mayanidad, mayanización y desigualdad. Asimismo, se presenta a los actores del campo político, los recursos en disputa y los principales eventos de la primera y parte de la segunda fase del Drama Social del Proyecto Tren Maya (DSPTM) -ruptura y crisis respectivamente- desde el anuncio de FONATUR como la instancia encargada del proyecto en agosto del 2018 hasta las reacciones al Foro Maya Peninsular sobre el PTM convocado por Gubernatura Nacional Indígena (GNI) en marzo del 2019.

Para la construcción del marco conceptual me baso principalmente en la obra de Rodrigo Díaz Cruz (2014) Los lugares de lo político, los desplazamientos del símbolo. Poder y simbolismo en la obra de Victor W. Turner. Dicho trabajo puede considerarse como una nueva lectura obligada para comprender y recuperar el legado turneriano, pues Díaz Cruz lo presenta de un modo sintetizado, integral y reflexionado desde las condiciones actuales de la antropología. Por lo anterior resulta conveniente para este trabajo partir de la síntesis de Díaz Cruz (2014).

Para explicar la posibilidad y conveniencia de estudiar el fenómeno del Proyecto Tren Maya como un drama social, comparto información sobre los actores del campo político, los recursos en disputa y los principales eventos de la primera y parte de la segunda fase del drama social del Proyecto Tren Maya (DSPTM) -ruptura y crisis respectivamente- desde el anuncio de FONATUR como la instancia encargada del proyecto en agosto del 2018 hasta las reacciones al Foro Maya Peninsular sobre el PTM convocado por Gubernatura Nacional Indígena (GNI) en marzo del 2019. Los siguientes dos capítulos de este trabajo están dedicados a abordar con mayor detenimiento las etapas 1 y 2 del drama social del PTM. 


\subsection{El procesualismo como teoría y el drama social como método}

Para empezar, cabe mencionar que las categorías de proceso y drama social, claves para este trabajo, fueron introducidas por primera vez en Schism and Continuity in an African Village [1957], resultado de la investigación doctoral de Victor Turner entre los ndembu de Zambia. Estos conceptos fueron puntos de partida de toda su obra posterior (Díaz Cruz, 2014:52).

La antropología procesualista de Turner está hecha sistemática y explícitamente de la convergencia del análisis de las relaciones de poder y del simbolismo. Una premisa del procesualismo que defendió, es que una antropología del poder que no tome en cuenta el análisis simbólico -la lucha por la inscripción y hegemonía de los sistemas de significados, representaciones y sus efectos- es una antropología ciega, y a su vez, la exploración de la dimensión simbólica de la vida que omita el esclarecimiento de las relaciones de poder es una antropología vacía (Díaz Cruz, 2014:19).

El procesualismo, en cuanto propuesta teórica, no ha pretendido ser una macro teoría social -al modo del neoevolucionismo o del marxismo- ni tampoco una microsociología -al estilo de la etnometodología-, pero desde luego nunca las ignoró. Antes bien ha procurado establecer puentes entre el análisis de las estructuras, los procesos y la agencia humana, entre la sociedad y la intención, entre la cultura y la subjetividad (Díaz Cruz, 2014:56).

Para Turner, el mundo social es un mundo en devenir, es un proceso antes que un sistema. Por esto los estudios de las estructuras sociales como tales son irrelevantes. Igualmente, considera que la vida social es agonística, es decir, la vida social está atravesada por el conflicto. Y los participantes no sólo hacen cosas, sino también muestran a otros lo que hacen, qué es lo que han hecho, o cómo quieren ser vistos. En este "modo agonístico primordial y perpetuo" las acciones son realizadas para sí y para los otros contendientes (Díaz Cruz, 2014:18,19).

Ahora bien ¿cómo investigar la vida social si está en constante flujo y movimiento, si es proceso y transición? ¿Cómo indagar en ella dado el carácter procesual del espacio y del tiempo? Turner encontró una forma en cierta clase de procesos sociales, una forma que es fundamentalmente dramática. De aquí que 
propusiera el concepto metodológico de "drama social" para describir a esa clase de procesos sociales, a saber, situaciones en crisis, conflictivas, no armónicas (Díaz Cruz, 2014:62).

Para Turner los dramas sociales son una unidad de descripción y análisis de procesos sociales en conflicto, esto es, de puesta en juego, operación y exposición de relaciones de poder. Por tanto, y en la medida que tal es su objeto de estudio, los dramas sociales no necesitan partir del supuesto de la existencia de culturas, sociedades, lugares o instituciones delimitadas (Díaz Cruz, 2014:62).

La noción de drama social se propone revelar, describir y analizar el carácter multidimensional de la vida: las contradicciones estructurales, las inconsistencias de y los conflictos entre las normas, los grupos, hombres y mujeres, las diferentes interpretaciones que todo conflicto necesariamente suscita, la forma en que se expresan las continuidades y cambios en las relaciones de poder, el poder de los símbolos y los símbolos del poder, los modos en que se ventilan los intereses divergentes (Díaz Cruz, 2014:63).

El drama social se propone también revelar el carácter individual, el estilo personal, la destreza retórica, las diferencias morales y estéticas, las narrativas en competencia que en él se van enunciando, la toma y ejecución de decisiones, la instrumentación de estrategias en situaciones conflictivas (Díaz Cruz, 2014:63).

Para Turner, los dramas sociales son una forma procesual prácticamente universal y poseen una estructura temporal, es decir, tienen un inicio, un medio y un final, análogo a las formas narrativas. Esta estructura puede fraccionarse en cuatro fases: 1) ruptura;2) crisis; 3) acciones y procedimientos de reajuste; y 4) reintegración o irremediable cisma. Cabe aclarar que este fraccionamiento tiene dos cláusulas: a) los desenlaces de los dramas sociales no pueden ser concluyentes; b) las fases no siempre siguen dicho orden, de la ruptura es dable encontrar conflictos que no sucumban a la crisis, sino que se remonten a la de acciones y procedimientos de reajuste (Díaz Cruz, 2014:114-115). A continuación se exponen las cuatro fases de los dramas sociales:

1) La fase de ruptura de las relaciones sociales regulares gobernadas por normas. Está indicada por la infracción -deliberada, espontánea, no 
intencional- de una ley, una regla, un contrato, un código de etiqueta (...) La ruptura puede deberse al seguimiento de otra ley, de otra regla, de otro contrato, otro código; de hecho cualquier otra regulación que modifique o altere una situación previa (...) Aparece en la superficie social un gesto, un "disparador" que suscita, que hace visible, que abre o posibilita la confrontación (Díaz Cruz, 2014:110);

2) La crisis puede seguir a la ruptura en la medida que otras personas o grupos tomen partido por, o se opongan a, quien(es) haya(n) provocado la ruptura (...) se crean nuevas facciones o se activan las viejas: distintos actores se comprometen con uno u otro contendiente, o son inducidos, seducidos, persuadidos, halagados o amenazados para adoptar una posición definida. Cada individuo o grupo hace acopio de recursos, recluta a sus seguidores y estigmatiza a los oponentes; se exigen obligaciones y lealtades. El clima de violencia física, verbal o simbólica se torna contagioso; los momentos cruciales, sean de peligro, suspenso, amenaza, solidaridad, sacrificio, se hacen inevitables (...) Se develan los patrones de las luchas faccionales entre los grupos; las contradicciones centrales de una estructura social; las ideologías y paradigmas de raíz que impulsan la acción de (y mueven a) los contendientes en ciertas direcciones y no en otras. En estas dos primeras fases se hace del todo relevante indagar respecto a las relaciones de poder tanto el sistema de diferenciaciones, que son al mismo tiempo condiciones y efectos del drama social, como el tipo de objetivos que lo están produciendo (Díaz Cruz, 2014:111);

3) Las acciones y procedimientos de reajuste, que pueden ser formales 0 informales, institucionales o ad hoc: "la amonestación y el arbitraje informal, la aplicación de la maquinaria jurídica formal, y, para resolver ciertas clases de crisis o legitimar otras vías para llegar a acuerdos [se recurre] a la realización de rituales públicos", algunos de los cuales requieren el "sacrificio", literal o moral, de un chivo expiatorio. Los procedimientos de reajuste varían en función de las modalidades instrumentales y formas de institucionalización de las relaciones de poder; de la profundidad y significado social de la ruptura, de la naturaleza de la crisis y del grupo social donde se gestó la ruptura, así como del grado de su autonomía en relación con un sistema más amplio o uno externo de relaciones sociales. En las sociedades complejas, por ejemplo, los 
antagonistas pueden llevar su disputa de una corte de baja jurisdicción a la Suprema Corte o incluso a una corte internacional. Los agentes de reajuste pueden ser jefes, ancianos, abogados, jueces, militares, sacerdotes, chamanes, adivinos, padres y madres, jurados, que disponen cada uno de sus propios instrumentos y dispositivos. La acción de reajuste puede ser una brutal y sanguinaria represión, la intervención de la metrópoli en una situación colonial, pero también, como en el caso de las revoluciones victoriosas, puede ser la creación de una institucionalidad que aspire a formas acaso más justas de convivencia social (Díaz Cruz, 2014:112).

4) Reintegración o irremediable cisma del grupo social o de los grupos sociales conmovidos: se acepta o reconoce ya sea el cisma irreparable entre las partes contendientes -señalado algunas veces por la separación espacial-, ya la subordinación, debilitamiento o derrota de una de las partes, ya su reintegración a partir de los mismos principios, de estos transformados o de otros. Esta fase suele delimitarse por ceremonias o rituales públicos que señalan la reconciliación, reintegración, fragmentación social o el palpable triunfo de uno de los contendientes. En este punto, y en función de sus acciones en el drama, algunos líderes habrán ganado legitimidad, mientras otros habrán perdido su fuente de autoridad; quizás las viejas alianzas se realinearan y hoy estén en bandos opuestos; las relaciones asimétricas se hayan vuelto igualitarias o viceversa, o bien la diferenciación se haya ahondado; acaso nuevas fuentes de poder se hayan canalizado a viejas autoridades, y la cercanía social se volviera distancia; tal vez las partes antes integradas se hayan segmentado y las previamente independientes se fusionaran; o bien, algunos actores dejaran de pertenecer al campo político en el que actuaban, y otros se incorporaran a éste; 0 las relaciones institucionalizadas se volvieran informales, las regularidades sociales se transformaran en irregularidades, las viejas normas se abrogaran. Desde el punto de vista del analista social estos cambios pueden ser observados, indagados, registrados y en algunos casos pueden ser incluso medidos y expresados en términos cuantitativos. Concluida esta fase, se puede analizar el continuum, el carácter temporal del drama; en qué medida alteró o no la estructura del campo político en el que se desplegó. En cualquier caso, las semillas de un nuevo drama social ya han sido sembradas: justo sobre los 
acuerdos -si los hubo-, la imposición o la violencia que a su modo resolvió la crisis. Los desenlaces de los dramas sociales no pueden ser concluyentes, como no lo son las oposiciones entre los grupos y entre los individuos; la vida social toda, incluso en sus momentos más apacibles, está preñada de dramas sociales: "debajo de la superficie los conflictos continúan; en realidad observamos reconfiguraciones de los grupos, realineamientos entre facciones, un nuevo conjunto de relaciones de poder, que se harán visibles en un nuevo drama social" (Díaz Cruz, 2014:113).

La fuerza de los dramas sociales también radica en que en ellos se producen, resultan y cristalizan símbolos dominantes o tipos simbólicos -personas, lugares, momentos, acciones- que contribuyen a legitimar un modo de existencia social y ofrecen referentes para la acción en el futuro. Los tipos simbólicos no están dados de una vez por todas: son temporales, ambiguos, recreados, negociados. Un símbolo dominante surgido de un drama social puede ser adoptado como emblema por un movimiento social en el futuro (Díaz Cruz, 2014:117), por ejemplo, el Zapata de la Revolución Mexicana retomado por el movimiento neozapatista de Chiapas ochenta años después.

Ahora bien, los dramas sociales no se dan en el vacío, forman parte de y se desarrollan en campos políticos. Victor Turner, Marc Swartz y Arthur Tuden en la introducción de Political Anthropology [1966] proponen el concepto de campo apoyándose en la obra del psicólogo social Kurt Lewin Field theory in social science [1951]. Con este concepto se propusieron compensar la rigidez de conceptos como sistema político o estructura política para dar cuenta de los procesos conflictivos que les interesaba explorar (Díaz Cruz, 2014:127).

Turner, Swartz y Tuden necesitaban una categoría analítica flexible que se expandiera y contrajera en el espacio, más allá incluso de las fronteras de una sociedad. Pero un campo político, a su juicio, no debe ceñirse sólo a elucidar las interacciones entre actores, conforma un continuum espacio-temporal -y no un sistema cerrado- con características sistemáticas. De tal suerte que los dramas sociales no necesariamente se despliegan en un solo campo; de hecho, conforme un conflicto se desarrolla incorpora y sobrepone distintos campos políticos -incluso, desde luego, campos transnacionales-, y el conflicto puede adquirir propiedades 
emergentes, pues puede involucrar a otros actores, otras relaciones, otras reglas, instituciones, metas, intereses, otros recursos escasos por los que se compite y a los que se busca controlar (Díaz Cruz, 2014:127).

Los actores de un campo, que desde luego no les impide participar en otros, pueden ser personas o grupos con sus metas, aspiraciones, formas peculiares de legitimarlas y búsqueda de beneficios singulares. Cuando Turner se refiere a la orientación de los actores nos remite: 1) a la competencia entre ellos por controlar premios y recursos escasos; de aquí que todo campo sea un campo de fuerzas; 2) a un interés compartido respecto a cada actor por salvaguardar o modificar una distribución particular de recursos; 3) a la voluntad de mantener o derruir un orden normativo específico, que puede ser el que rige a un grupo, un campo, una sociedad (Díaz Cruz, 2014:131).

Ahora bien, es necesario hacer una precisión. No es lo mismo un campo político que una arena política. La segunda es la "unidad espacial en la que antagonistas visibles y precisos contienden entre sí" (Díaz Cruz, 2014:125). Es decir, los campos políticos se manifiestan a través de y contienen arenas políticas. La existencia de un campo político se puede inferir a través de una serie de momentos de confrontación, ubicados espaciotemporalmente y relacionados entre sí por la permanencia de actores en pugna en torno a uno o más recursos escasos, sean estos materiales o simbólicos.

Con respecto a la dimensión simbólica de los procesos, siguiendo a Turner, se puede afirmar que las relaciones de poder implican también relaciones simbólicas, pues quien tiene poder intentará atribuir o fijar ciertos significados a los símbolos relevantes que controla, y quien no lo tiene intentará cambiar la situación a su favor. Las relaciones de poder suponen en consecuencia una intensa red entre actores humanos y objetos (Díaz Cruz, 2014:140).

En este sentido, los actores recurren a las prácticas performativas en la disputa por los significados. Estas son entendidas como un medio por el que los individuos y grupos se dan sentido a sí mismos y ante los otros, son actos de auto-reconocimiento y auto-definición frente a otros. El hombre es un animal auto-performativo, en tanto que sus actuaciones en la vida social son reflexivas, porque al representarse revela su yo y su nosotros a sí mismo y a los otros en los procesos sociales (Díaz Cruz, 
2005:106). Siguiendo a Turner, es posible encontrar dos tipos de prácticas performativas en los procesos políticos: los rituales políticos y las ceremonias definicionales.

Los rituales, en general, tienden a consagrar o legitimar posiciones o cualidades, naturalizan lo arbitrario, influyen en lo real actuando sobre la representación de lo real. Los rituales políticos, en particular, son además de transformatorios, actos de institución, constituyen ellos mismos procesos políticos impregnados de, y atravesados por, eficacia simbólica. Son actos persuasivos de dramaturgia política a la que se deben someter los diversos actores (Díaz Cruz, 2005:106).

El ritual político es entendido como un caso específico de acción simbólica, no es una máscara del poder o un instrumento que sólo expresa o camufla, sino que constituye un dispositivo de poder que instituye los centros activos del orden social y que produce efectos en todo sistema o estructura de poder (Díaz Cruz, 2005:105).

Cabe agregar que los rituales políticos fuertemente dramáticos no son el monopolio de una élite, aunque la gente con mayor poder está frecuentemente en la mejor posición de patrocinar tales rituales. Son también centrales tales dramatizaciones para los grupos que buscan cambiar las percepciones políticas populares, para ajustarse en el molde mítico apropiado, sin embargo, tales dramatizaciones requieren de un villano y de ricos símbolos de villanía (Zárate Vidal, 2012:18). Es decir, los actores que protagonizan un ritual político intentan posicionarse ante la opinión pública como "los buenos" representando a sus contendientes como "los malos".

Además, la ritualización involucra el uso repetitivo de símbolos emocionalmente cargados en lugares simbólicamente significantes en tiempos apropiados simbólicamente. Los símbolos tienen una historia de asociaciones cognitivas y emocionales. Los significados no se fijan eternamente, aunque nuevas sombras del significado son creadas continuamente y viejos significados se pierden a través de los intentos incesantes de los líderes políticos para manipular los símbolos (Zárate Vidal, 2012:19). 
Es importante agregar que el ritual político puede generar acción común sin necesitar creencias comunes. El comportamiento de la gente puede, en muchas circunstancias, ser mejor explicado como la reacción a presiones, más que como la manifestación de una creencia bien asentada (Zárate Vidal, 2012:20).

Por otra parte, si bien los rituales son transformatorios, las ceremonias son confirmatorias, enfatizan la situación o estado social en el que se celebran. Cabe destacar para el estudio de los procesos las ceremonias definicionales, aquellas en las que los individuos y los grupos se dan la oportunidad de volver a ser lo que una vez fueron; lo que nunca fueron pero quisieron haber sido; lo que quieren y aspiran a ser; o lo que se comprometen a ser. Se despliegan o activan cuando un grupo padece crisis de invisibilidad y es desdeñado por otros grupos más poderosos. Suelen estar saturados de símbolos presentacionales en situaciones de conflicto, estas ceremonias crean y mantienen alguna clase de subjetividad organizada en relatos más o menos consistentes (Díaz Cruz, 2005:107-108).

El simbolismo asociado a dichas ceremonias contribuye a erigir un mundo convincente e incuestionable, alienta el pensamiento, acciones y clasificaciones muchas veces esquemáticas y simplificadoras, por ejemplo, la oposición entre enemigos y héroes, entre fieles y herejes. Al estar cargadas de intensos climas emotivos y contagiosos, las ceremonias definicionales llegan a configurar las percepciones y creencias a tal grado que se sea incapaz de reconocer cualquier disonancia o anomalía, por ejemplo, negarse a reconocer que los enemigos y héroes, los fieles y herejes, no lo son tanto (Díaz Cruz, 2005:108).

Estas ceremonias inhiben el pensamiento crítico y suelen provocar una mayor atención a la información vívida y emocionalmente persuasiva: constituyen dispositivos para construir realidades políticas. Representan y dramatizan la cohesión y unidad del grupo con propósitos políticos, pero de aquí no se puede inferir por supuesto que el grupo que las celebra sea así. Cuando la idea de autenticidad del grupo y de sus principios se coloca como el emblema del centro activo al que se aspira y en el que se quiere participar, muchas reivindicaciones de la distinción y la identidad sucumben en la "razón arrogante": "una razón que con avidez no deja de desear más de lo mismo y nada de lo otro, se autoconfirma sin límites y con igual falta de límites desacredita, difama. Es una forma del espíritu sectario" (Pereda en Díaz Cruz, 
2005:109). Con otras palabras, pretende que los argumentos, demandas, principios, creencias, prácticas y valores de los grupos que celebran la ceremonia son verdades absolutas inmunes a la crítica.

Aunque en buena medida las ceremonias definicionales son utilizadas por grupos marginados, también son utilizadas por los detentores del poder político. Por ejemplo, un rey y un presidente de una república no están sometidos permanentemente a su propia transformación; una vez consumada ésta, debe reconocerse su investidura y diferencia social, ha de mantenerse la eficacia y legitimidad de aquel acto original que lo consagró, todo ello se realiza gracias al carácter confirmatorio de las ceremonias de que son objeto (Díaz Cruz, 2005:109).

\subsection{Conceptos complementarios al procesualismo turneriano}

Hasta aquí se han abordado los elementos principales de la teoría procesualista de Turner y el método del drama social. A continuación abordo los conceptos de ideología, narrativa, la relación poder-etnicidad, la mayanidad y mayanización, y la desigualdad. Considero que estos conceptos son complementarios y pertinentes para comprender y explicar la disputa por la fijación de significados, las estrategias que para ello despliegan los actores, y las asimetrías de poder y capacidades para influir en el campo político durante la disputa por recursos materiales e inmateriales en el rama Social del Proyecto Tren Maya.

\subsubsection{Ideología}

En primera instancia, hay que recordar que, desde el procesualismo turneriano, la antropología del poder debe tomar en cuenta el análisis simbólico, es decir, la lucha por la inscripción y hegemonía de los sistemas de significados, representaciones y sus efectos (Díaz Cruz, 2014:19). Para facilitar el análisis de esta lucha por la inscripción y hegemonía de los sistemas de significados resulta útil el concepto de ideología. En este sentido, cabe recordar que Díaz Cruz señaló que en las primeras dos fases del drama social se develan las ideologías y paradigmas de raíz que impulsan la acción de (y mueven a) los contendientes en ciertas direcciones y no en otras (Díaz Cruz, 2014:111).

Aquí no presento una discusión sobre las acepciones que el término "ideología" ha tenido a lo largo del tiempo en diversas propuestas sociológicas, antropológicas, 
filosóficas y políticas. De manera provisional (pensando que podré profundizar en la tesis doctoral) me limito a señalar algunas acepciones contemporáneas que considero útiles para el análisis del Drama Social del Proyecto Tren Maya. Me valgo de la obra de Iturriaga (2016) en la que recurre a Margulis [2009], Van Dijk [2003] y Thompson [1998].

Mario Margulis, en su obra Sociología de la cultura. Conceptos y problemas [2009], parte de la noción de ideología de Marx y reconoce la importancia de las relaciones de poder en el concepto, no obstante plantea que éstas no deben entenderse solamente desde el Estado y sus doctrinas, sino también desde lo simbólico, presente en la lucha por imponer significados sociales legítimos. Para Margulis, la ideología no es un conjunto de ideas propuestas por un grupo politizado específico, ni una forma de engaño deliberado (como muchas veces se utiliza el término), sino más bien una cualidad de la cultura, un nivel de significación que puede estar presente en los discursos y que puede ser puesto de manifiesto mediante un análisis crítico de los mismos (Iturriaga, 2016:50).

De este modo, el concepto de ideología es útil para dar cuenta de las relaciones de poder que están presentes en la producción social del sentido y el uso de los sistemas simbólicos. Como se verá más adelante, uno de los recursos inmateriales en disputa en el drama social del PTM es la opinión pública, por lo que el concepto de ideología puede ser útil para el análisis.

De manera complementaria, Margulis afirma que "las luchas sociales por la hegemonía son paralelas a la lucha por la imposición social del sentido" [2009:72]. La lucha por la producción social del sentido se manifiesta en los discursos sociales, en el lenguaje cotidiano -la forma en que nombramos o dejamos de nombrar las cosas-, la memoria, la historia oficial y en el sentido común (Iturriaga, 2016:51). Así, las disputas políticas son por el control de recursos y la hegemonía de la ideología que legitima esa distribución particular de controles y accesos desiguales.

Por su parte, Teun van Dijk enfatiza el aspecto identitario de la ideología en su obra Dominación étnica y racismo discursivo en España y América Latina [2003]. En ella señala que las ideologías son autodefiniciones compartidas grupalmente que permiten coordinar prácticas sociales hacia dentro del grupo y en relación con otros grupos. Éstas incluyen representaciones de criterios de pertenencia y acceso al 
grupo, acciones típicas, normas, valores, recursos sociales y posición en relación a otros grupos. De esta manera los contenidos ideológicos también funcionan como esquemas básicos de acción frente al otro (Iturriaga, 2016:51).

Por último, John Thompson [1998] en su obra Ideología y cultura moderna, propone que para estudiar la ideología se analicen las formas en que el significado sirve para establecer y sostener relaciones de dominación. Para dicho autor, la ideología moviliza el significado en el mundo social y sirve entonces para reforzar a los individuos y grupos que ocupan posiciones de poder. Igualmente, señala que caracterizar a los fenómenos simbólicos como ideológicos no implica tener que demostrar la falsedad o veracidad de las formas simbólicas. Lo importante es mostrar las maneras en que estas formas sirven, en circunstancias particulares, para establecer y sostener las relaciones de dominación. A diferencia de Marx que entiende las relaciones de dominación como relaciones de clase, Thompson considera que hoy en día no podemos hablar de relaciones de dominación sin incluir, además, las relaciones sociales estructurales entre hombres y mujeres, entre grupos étnicos o entre Estados-nación hegemónicos y periféricos (Iturriaga, 2016:51-52).

Ahora bien, rescatando elementos de las aportaciones de Margulis, van Dijk y Thompson, para los fines de este trabajo se entiende que una ideología es una autodefinición grupal que permite coordinar prácticas hacia dentro del grupo y con respecto a otros grupos, la cual proporciona y promueve normas, valores y esquemas básicos de acción frente al Otro, con la finalidad de imponer un orden simbólico que respalde y justifique los intereses del grupo en las disputas por recursos materiales e inmateriales. La ideología moviliza el significado en el mundo social y se manifiesta en los discursos, en el lenguaje cotidiano, la memoria, la historia oficial y en el sentido común. La ideología es un instrumento de dominación (política: étnica, cultural, de clase social, de género) y explotación (económica: distribución de la carga de trabajo y los beneficios resultantes) pero también puede ser un instrumento para la resistencia (política: étnica, cultural, de clase social, de género) y liberación (económica: distribución de la carga de trabajo y los beneficios resultantes), dependiendo de si el grupo en cuestión es hegemónico o subalterno y la agenda política que se haya trazado en un proceso o un conjunto de procesos políticos. Así, las disputas políticas pueden ser confrontaciones entre grupos que comparten una ideología o entre grupos con ideologías diferentes. 
De tal modo, los actores -sean hegemónicos o subalternos en procesos políticos específicos- activan o producen ideologías para legitimar o deslegitimar relaciones de poder y distribuciones generalmente desiguales de acceso y control sobre recursos materiales e inmateriales entre diversos grupos humanos. Es decir, a diferencia de las formulaciones de Thompson [1998] sobre el uso de la ideología para reforzar a los actores que ocupan posiciones de poder, considero que las ideologías no son monopolio de ningún grupo -ni siquiera el Estado- y pueden ser instrumentadas tanto por actores hegemónicos como subalternos, pues siguiendo a Turner, las ideologías se manifiestan también en los símbolos dominantes, estilos retóricos y narrativas presentes en los rituales políticos y ceremonias definicionales orquestados por los actores de un campo político, sobre todo en las fases 1 y 2 de los dramas sociales (Díaz Cruz, 2014:111).

Asimismo, aunque comparto la importancia que Thompson confiere a la interseccionalidad en la dominación estructural, no concuerdo con la propuesta de analizar las relaciones de poder y las desigualdades con esquemas que reducen el espectro de actores en díadas como hombres/mujeres, Estados hegemónicos/Estados periféricos u occidentales/indígenas, en los que se suele conferir todo el poder a uno de los polos y toda la razón moral al otro polo, cuando en la realidad tanto el poder y la razón moral (por llamarle de algún modo) se distribuyen por todo el entramado social, aunque ciertamente de manera desigual.

\subsubsection{Narrativa}

Como se mencionó en párrafos anteriores, el drama social se propone revelar las narrativas en competencia que en él se van enunciando (Díaz Cruz, 2014:63). Ahora bien, en antropología la narrativa es un recuento y una representación subjetiva continua y sostenida en el tiempo, cuyo propósito es explicar un evento, una historia o una cadena de acontecimientos, por parte de uno o más narradores a uno o más receptores. Pueden ser deliberadas o no, ficticias o verdaderas, académicas y científicas, sagradas o profanas, personales o colectivas, parte del folklore o la cultura, siendo esta última una especie de almacén del cual abrevan todas las narrativas (Villalobos Cavazos, 2016:75-76).

Construir narrativas ayuda a los actores a darle sentido al mundo. Como autoexplicaciones de la experiencia personal están presentes en la historia, las ciencias, 
las religiones, la cultura, el arte, la psicología y nuestra propia vida. Para las narrativas el mundo es entendido temporalmente, su objetivo es expresar coherencia a través del tiempo. Así, por medio de ellas el tiempo se humaniza e incorpora a la experiencia sociocultural, a la vez que temporalizan y estructuran los eventos, proveyendo una sensación de orden y significado a los relatos que describen. La secuencia del relato es importante en el significado de la narrativa, es esta secuencialidad la que distingue a la narrativa de otras formas de transmitir y aprehender información sobre el mundo. Es mediante la secuencialidad que la narrativa da a la experiencia humana una sensación de dirección y crecimiento (Villalobos Cavazos, 2016:76).

Ahora bien, existen narrativas para ofrecer orden que tienen los grupos que ostentan el poder, pero también hay narrativas que brindan versiones alternativas de orden para los mismos eventos. En este sentido, podemos hablar de narrativas dominantes o hegemónicas y de narrativas alternativas y subalternas, ya que una narración del mundo puede reprimir, reemplazar u oscurecer otras posibles narrativas precedentes o alternativas. Igualmente, como descripciones del mundo, las narrativas son también un sitio para la contestación y construcción de otros mundos (Villalobos Cavazos, 2016:76-77).

En síntesis, tanto las ideologías como las narrativas operan en el orden simbólico -en la construcción del sentido de la realidad social- y ambas son utilizadas por grupos hegemónicos y subalternos en procesos políticos particulares y en sucesiones de procesos interconectados, ya sea mediante símbolos dominantes 0 por recursos materiales e inmateriales específicos.

La diferencia entre ellas es que las ideologías sirven a los grupos humanos para autoidentificarse y justificar o descalificar un sistema de dominación y explotación; mientras que las narrativas sirven a los grupos humanos para autoexplicarse un evento, una historia o una cadena de acontecimientos, y otorgar un sentido al actuar presente en función del pasado.

En otras palabras, las narrativas sirven para darle sentido a la realidad social y las ideologías para crear identidades y justificar las agendas políticas de los grupos humanos en la realidad social. En este sentido, las ideologías contienen narrativas, ya sea por invención deliberada, por apropiación, cooptación, o porque una narrativa 
o una combinación de ellas haya devenido en una ideología a través del tiempo, a través de sucesiones de procesos políticos.

\subsubsection{Poder y etnicidad}

Como se ha mencionado, las ideologías y las narrativas surgen en los procesos políticos, los cuales son atravesados por relaciones de poder. En el caso del Proyecto Tren Maya han cobrado especial presencia las diversas narrativas sobre la mayanidad, de tal modo que se vuelve necesario considerar la relación entre poder y etnicidad para el presente estudio.

Gustavo Lins Ribeiro elabora su definición de poder recuperando las aportaciones de Richard Adams, Max Weber y Eric Wolf. Del primero retoma la idea de que el poder es el control que alguien posee sobre el ambiente de otro; del segundo, recupera la idea de que el poder es la capacidad de forzar a las personas a hacer lo que no quieren hacer; y del tercero enfatiza la capacidad que tienen las fuerzas y relaciones históricas de crear y organizar escenarios que constriñen las posibilidades de acción de las personas y de especificar la dirección y distribución de los flujos de energía. Entonces, el poder es la capacidad que tiene un sujeto de controlar su propio ambiente y destino, esto es, el curso de la acción y los eventos que harán que su vida permanezca como es o sea modificada. Asimismo, también es poder el impedir que las personas sean actores y tengan dicha capacidad sobre su ambiente y su destino (Zárate Vidal, 2008:5).

Adicionalmente, desde la óptica turneriana, el poder puede entenderse como un fenómeno de dos dimensiones. Por un lado, el control de recursos significativos, con el que se podrá controlar el ambiente y destino propio o de algún Otro. Por otro, como órdenes clasificatorios simbólicos que se vuelven hegemónicos, es decir, como narrativas e ideologías que justifican una particular distribución del control sobre recursos significativos y las relaciones de poder entre grupos humanos y al interior de los mismos, pudiendo ser entre grupos étnicos y al interior de ellos. Así, el análisis de la etnicidad y de las reivindicaciones étnicas debe hacerse en relación con esas dos dimensiones del poder (Llanes Salazar, 2016:7).

También es importante considerar que Occidente ha transformado los modos en que se politizan los conflictos sociales y en que los Estados y grupos que aspiran 
al poder persiguen sus objetivos políticos a escala mundial. Esto es una experiencia común de la modernidad -presente en el capitalismo tardío-, efecto de la articulación contemporánea de lo local y lo mundial (Gledhill, 2000). Aunado a esto, el modo en que la "etnicidad" se politiza en el mundo contemporáneo puede reflejar una sutil universalización en el Sur de algunos de los rasgos de la política de las sociedades del Norte, a pesar de las diferencias que sigue habiendo entre unidades territoriales y culturas políticas (Gledhill, 2000:35).

Aunado a lo anterior, cabe señalar que los líderes de movimientos "étnicos" y "regionalistas" son, en general, políticos profundamente "modernos" que compiten por el poder con otra facción de la élite que domina la maquinaria del Estado central, y los símbolos que suscita el apoyo popular a la causa son inventados o reinventados antes que primordiales (Hobsbawm y Ranger en Gledhill, 2000:35). Esto último remite al uso de los símbolos dominantes en los dramas sociales señalado por Turner. Tanto los medios como los fines del conflicto se centran en concepciones "modernas" de la organización política y económica: Estados, Autonomía, Derechos (Gledhill, 2000:35).

Ahora bien, las etnias no pueden compararse con especies naturales que sobreviven o desaparecen. La producción de la etnicidad debe analizarse como un fenómeno histórico que merece, caso a caso, una investigación particular. La identidad cultural no es fija, es una construcción, un proceso (Augé y Colleyn, 2004:58). Para entender los procesos de emergencia étnica primero es necesario precisar el concepto de etnicidad, esta es "la diferencia cultural movilizada por propósitos políticos, cuando los actores sociales a través de procesos de acciones sociales (re)crean narrativas de ascendencia común para responder al ambiente social cambiante" (Malesevic en Llanes Salazar, 2018:260).

Adicionalmente, es importante reconocer que como fenómeno histórico la etnicidad cobra distintas expresiones en épocas diferentes. Así, los antropólogos Jean y John Comaroff han propuesto el concepto de "etnicidad, S. A." para analizar cómo la etnicidad se está convirtiendo cada vez más en algo empresarial, mercantil, que tiene implicaciones económicas en la vida cotidiana. De acuerdo con los Comaroff, la "etnicidad, S. A." implica la conjunción de procesos de mercantilización de la cultura y de corporativización de la identidad (Llanes Salazar, 2018:260). 
Por otra parte, siguiendo la lógica de los Comaroff para el ámbito del derecho, el jurista César Rodríguez Garavito ha acuñado el concepto "etnicidad.gob" para analizar los procesos de judicialización de las reivindicaciones y demandas étnicas, y cómo la identidad étnica y los derechos indígenas se han convertido en una cuestión de gobernanza. Rodríguez concibe a la "etnicidad.gob" como un proceso paralelo a la "etnicidad, S. A." (Llanes Salazar, 2018:261).

Como se mencionó, la etnicidad es la identidad cultural -a menudo racializadapolitizada a través de narrativas particulares en la disputa moderna por el control de recursos significativos. De este modo, la etnicidad puede ser concebida como un tipo de ideología, pudiendo orientarse a la dominación y explotación o a la resistencia y liberación de los grupos humanos. Tenemos pues que las identidades étnicas en el capitalismo tardío son un recurso en disputa y para disputar otros recursos.

Es propia del capitalismo tardío la proliferación de movilizaciones étnicas desde la década de 1990, cuando comenzaron a aparecer en el escenario político planetario los denominados "movimientos globales", en los que tomó lugar central el papel de la cultura. Se plantearon demandas de reconocimiento étnico-cultural, sosteniendo que a las identidades hay que darles vida, no sólo reproducirlas, obteniendo derechos, comenzando por el derecho a existir como diferentes (Wieviorka, 2009).

\subsubsection{Mayanidad y mayanización}

Si tomamos en cuenta el carácter inacabado de la realidad sociocultural, la etnicidad maya, como todo fenómeno, dista de ser algo que simplemente ya está dado; además de ser una construcción histórica, se actualiza con las prácticas, que siempre son contingentes, es decir, que siempre pueden ser de otra forma (Llanes Salazar, 2016:231).

En la segunda década del siglo XXI, el "paisaje étnico maya" de Yucatán es sumamente diverso. En el estado encontramos organizaciones indígenas autodefinidas como mayas que se dedican a tareas de revitalización lingüística y al impulso de la educación intercultural; escritores, intelectuales y artistas mayas que reivindican su lengua y cultura; colectivos, organizaciones de la sociedad civil y redes neozapatistas que luchan a favor de la autonomía y autodeterminación del pueblo 
maya; jóvenes que a través de las nuevas tecnologías de información y comunicación buscan preservar, fortalecer y difundir expresiones culturales tradicionales y contemporáneas; fundaciones privadas con proyectos de desarrollo y de fortalecimiento de la identidad maya; trabajadores de la industria turística que "performan" una imaginada identidad maya prehispánica o antigua para atraer turistas y numerosos habitantes, tanto en comunidades rurales como en los centros urbanos del estado, que se identifican como "indígenas" —el 62.7\% de la población, según el conteo del Instituto Nacional de Estadística y Geografía de 2010 (Llanes Salazar, 2018:258).

El diverso paisaje étnico maya, apenas esbozado arriba en unas pocas líneas, no siempre ha existido en Yucatán. De hecho, la identidad étnica maya, en sus diferentes expresiones, se encuentra lejos de ser un fenómeno "tradicional", una "supervivencia", de una remota época prehispánica. Mucho menos se trata de un hecho "natural". Incluso, hasta hace un par de décadas, distintos estudiosos de la población mayahablante en Yucatán coincidían en la inexistencia de una identidad étnica maya o una conciencia étnica maya que aglutinara a todos los mayahablantes del estado (Castañeda, 2004; Gutiérrez, 1992; Mossbrucker, 1992; Restall, 1997; Mattiace, 2009 en Llanes Salazar, 2018:259).

Las evidencias históricas y etnográficas del argumento de la inexistencia de la identidad étnica maya en Yucatán es que los "indios" o "naturales", durante el periodo colonial, se identificaban principalmente con su cah (comunidad) y su chibal (linaje), no con una entidad más amplia equivalente a la idea de "pueblo maya" (Restall en Llanes Salazar, 2018:259). Otras pruebas, correspondientes a la época contemporánea, son que los habitantes de comisarías de la periferia de la ciudad de Mérida, capital del estado de Yucatán, evalúan la Conquista de América como un hecho positivo y la Guerra de Castas como uno negativo (Mossbrucker en Llanes Salazar, 2018:259); que los mayahablantes yucatecos conciben a los antiguos mayas como "otros", no como sus ancestros (Gutiérrez en Llanes Salazar, 2018:259), y que en el estado no existen las redes de organizaciones —religiosas, campesinas y de la sociedad civil- que funcionen como elementos facilitadores para la movilización étnica (Mattiace en Llanes Salazar, 2018:259). 
Los mayahablantes de Yucatán se llaman de muy diversas formas. En el siglo $\mathrm{XX}$, los mayahablantes de la península empleaban, además del término "mestizo", los etnónimos "masehual" (especialmente en el sur y oriente de Yucatán) y "mayero" (para quienes hablan la lengua maya) para referirse a sí mismos (Quintal Avilés, 2005). Cada vez más, el término "maya" es significativo ya no sólo para antropólogos y otros agentes externos a las comunidades yucatecas, sino también en la práctica de numerosos actores sociales en Yucatán. En este sentido, Llanes Salazar (2018) propone que se está dando un proceso de "mayanización del mestizo yucateco".

Por lo menos desde hace una década, los investigadores de la cuestión étnica en Yucatán han advertido el surgimiento de diversos actores que sí se identifican en términos étnicos y asumen una identidad maya, tales como escritores, organizaciones, intelectuales y miembros profesionistas de la clase media (Leirana, 2001; Gabbert, 2004; Quintal, 2005; Rosales y Llanez, 2003; López, 2011; Llanes, 2016 en Llanes Salazar, 2018:259).

Si bien las diversas expresiones de la etnicidad maya en Yucatán en la actualidad están redefiniendo las nociones hegemónicas de la "indigeneidad", un elemento importante a indagar es si estas transformaciones simbólicas sobre la indigeneidad y el ser maya están teniendo impacto en la distribución del poder y de los recursos materiales en el estado (Llanes Salazar, 2018:276).

Podemos argumentar que en el capitalismo tardío, lo "maya", en tanto símbolo, se ha convertido en un recurso significativo cuyo control sirve para obtener ganancias y con ellas ejercer poder. Asimismo, el nombre "maya" se encuentra inmerso en un orden clasificatorio hegemónico que remite a la antigua civilización maya, a la sabiduría, al misterio, al tiempo y a las profecías, a los paisajes pintorescos (narrativa Mundo Maya), pero también, y no de manera menor, al poder y a la obtención de ganancias a través del turismo (lo que denomino la narrativa de la turistificaciónmayanización). Por último, pero no menos importante, la versión alocrónica de la cultura maya, ciertamente magnífica y majestuosa, sirve al simbolismo del poder (Llanes Salazar, 2018:214). 


\subsubsection{Desigualdad}

Aunque la construcción de identidades y los resultados de procesos políticos siempre pueden ser de otra forma, los actores sociales y sus interacciones se dan en un contexto social marcado por la desigualdad en los accesos y controles -políticos, económicos, sociales y culturales- que pueden ejercer sobre recursos significativos, para producir o reproducir el modo de vida que consideran conveniente. Como señala Reygadas: "la desigualdad está sostenida en estructuras persistentes que se construyen y transforman como resultado de procesos en los que interviene la acción humana" (Reygadas, 2008:20).

Llevadas a un extremo las explicaciones estructurales tienden al determinismo. Es decir, pareciera que la desigualdad es una característica inherente al sistema y por lo tanto es imposible eliminarla o incluso reducirla. Se llega a reificar la desigualdad, como si fuera una cosa que existe al margen de las personas, de sus acciones, interacciones e interpretaciones. Ante esto, señala que la desigualdad, aunque tiene una dimensión estructural, también es creada y recreada en las interacciones cotidianas, de modo que no es algo fijo, sino que se modifica mediante las intervenciones de los actores (Reygadas, 2008:55). Ahora bien, no hay un actor social exclusivamente responsable de la generación de la desigualdad, ésta se produce tanto en el mercado, como en el Estado y la sociedad civil (Reygadas, 2008:39).

Igualmente, es importante señalar que existe una relación dialéctica entre la igualdad y la desigualdad. El grado de inequidad y el tipo de desigualdades que existen en una sociedad son resultado de las confrontaciones entre diversos agentes sociales, así como del entrelazamiento entre los procesos y mecanismos que producen mayor desigualdad y aquellos otros que la reducen o regulan (Reygadas, 2008:50).

Asimismo, la desigualdad no se limita a las cuestiones económicas, sino que atañe a todos los aspectos de la vida y afecta al conjunto de la experiencia social. La desigualdad es multidimensional porque las diferencias económicas entre las personas se encuentran estrechamente vinculadas con la clase social, el género, la etnia y otras formas de clasificación social (Reygadas, 2008:35,36). Es decir, las 
desigualdades operan en lo social, lo cultural, lo político y lo económico de manera simultánea.

En última instancia, la multidimensionalidad de la desigualdad está atravesada por el poder. Se vincula profundamente con las asimetrías en la distribución de recursos, capacidades diferenciales, acceso a la información y con las relaciones de poder que se establecen sobre la base de esas asimetrías (Reygadas, 2008:36,37).

De la mano de las relaciones de poder, los procesos simbólicos de significación cultural son un componente fundamental de la construcción de la igualdad y la desigualdad. Reygadas señala:

"La distribución de los bienes y servicios nunca sigue una lógica "racional" culturalmente neutra, ni se ajusta al funcionamiento de un mercado perfecto, sino que pasa por filtros de la cultura, cuyos procesos de valoración, clasificación, jerarquización, distinción, contra-distinción, equiparación y diferenciación inciden en la determinación de la cantidad y calidad de los beneficios que cada individuo y cada grupo recibe en una sociedad. Dentro de cada cultura, así como en las relaciones entre personas de diferentes culturas, existe una negociación constante con respecto al grado de desigualdad que es tolerable o deseable. Junto con los factores económicos y políticos, la cultura es un componente central de la desigualdad" (Reygadas, 2008:38).

Los umbrales de tolerancia a la desigualdad varían en cada sociedad y en cada época histórica. En función de lo anterior, los actores sociales emprenden acciones -según su sociedad y época- desde el sector gubernamental, empresarial y/o desde la sociedad civil para reducir las desigualdades. No obstante, los mecanismos diseñados para alcanzar la igualdad en un aspecto pueden provocar otras formas de desigualdad (Reygadas, 2008:48), por ejemplo, prácticas racistas en emprendimientos sociales, prácticas clasistas en programas gubernamentales de asistencia social, prácticas clasistas en organizaciones feministas, o prácticas machistas en organizaciones de reivindicación étnica. El riesgo existe para todos los mecanismos de compensación de desigualdades, por dos razones: 
"En primer lugar, porque seleccionan un determinado criterio de equiparación $y$, al hacerlo, excluyen otros. No es posible lograr al mismo tiempo la igualdad en todas las dimensiones, ya que los distintos tipos de igualdad se contraponen.

En segundo lugar, los dispositivos de compensación de las desigualdades redistribuyen recursos que son objeto de apropiación-expropiación: los intermediarios políticos pueden retener una parte de los apoyos destinados a los pobres, los grupos mejor organizados probablemente capturen porciones significativas de los apoyos estatales, el sistema financiero puede apropiarse de buena parte de las remesas enviadas por los migrantes a sus familias, etc." (Reygadas, 2008:49).

De ahí que sea crucial investigar los efectos, deseados y no deseados, de los mecanismos que una sociedad pone en marcha para promover la equidad (Reygadas, 2008:49), como el Proyecto Tren Maya que se propone disminuir la pobreza en la región sur-sureste y disminuir la asimetría en el desarrollo económico relativo de esta región en comparación al centro y norte de México. Por último, de acuerdo con el mismo autor, la desigualdad opera en distintas escalas:

- Individual: Diferencias en las capacidades y las dotaciones entre los diferentes sujetos;

- Institucional: Las relaciones sociales están marcadas por pautas inequitativas de interacción entre los géneros, las etnias, las culturas y las clases sociales;

- Estructural: Organiza distribuciones asimétricas de las ventajas y desventajas entre unidades económicas, grupos sociales y regiones dentro de un país;

- Global: Configura intercambios desiguales entre los países y las regiones del planeta (Reygadas, 2008:28).

Considerando lo recuperado del trabajo de Reygadas (2008), entiendo la desigualdad como la asimetría existente entre individuos o grupos humanos pertenecientes a una o diversas sociedades, en cuanto a los accesos y controles -políticos, económicos, sociales y culturales- que pueden ejercer sobre recursos significativos, para producir o reproducir el modo de vida, la distribución del trabajo y de los beneficios resultantes, que consideran convenientes. 
Aunado a esto, la desigualdad guarda una relación dialéctica con la igualdad. La producción de este continuum es multisectorial (Estado, empresas, sociedad civil), multidimensional (social, cultural, económica, política) y multiescala (individual, institucional, estructural, global). Se genera mediante procesos en los cuales actores con capacidades y acceso a la información desiguales -y marcados diferencialmente por género, sexo, clase y raza- operan en la sociedad, reproduciendo y transformando las condiciones de igualdad-desigualdad, en función del grado de tolerancia a la desigualdad que exista o quieren que exista en su momento histórico, o como parte de una agenda intergeneracional a mediano o largo plazo. Asimismo, los esfuerzos de los diversos sectores sociales por reducir la desigualdad no están exentos de reproducir desigualdades de otro tipo, por lo que es necesaria la reflexión transdisciplinaria y la colaboración intersectorial para mejorar los esfuerzos por reducir las desigualdades sociales de manera interseccional.

Antes de argumentar por qué considero conveniente y posible analizar el PTM como un drama social, se presenta un análisis de la relación entre las identidades sociales y el esencialismo, basado en los conceptos abordados en este apartado. En primera instancia, los actores no son esencialmente hegemónicos o subalternos, se ubican como tales en procesos políticos específicos, en el marco de distribuciones conflictivas particulares de accesos y controles sobre recursos. La reproducción histórica de las desigualdades entre los actores -organizados (o analizados) en grupos mayormente fluidos e interconectados- a través de sucesiones de procesos, no debe confundirse con la construcción y fijación de esencias. Lo que se construye son narrativas, las cuales devienen en ideologías que a su vez se manifiestan en organizaciones sociales y movimientos políticos que en conjunto ofrecen los universos simbólicos necesarios para producir identidades sociales específicas en momentos determinados, pero que se transformarán en el futuro.

Las identidades sociales no son esencias, sobre todo las identidades étnicas o culturales racializadas, pero tampoco son inherentes a los actores las identidades de clase, nacionales, regionales, laborales, políticas, religiosas, de género, etc. Si bien las identidades sociales condicionan a los actores en sus interacciones con los otros, no los determinan, y tampoco pueden las identidades sociales ser homologadas con las identidades psicológicas individuales confiriéndoles un carácter ontológico inmutable. 
Atribuir esencias identitarias a los actores (a uno mismo u otros) deviene en la producción y reproducción de estereotipos y prejuicios que promueven las discriminaciones, tanto negativas como positivas, que en la mayoría de las ocasiones tienden a buscar o construir correspondencias entre la ideología aceptada y la realidad social. Los actores construirán la realidad social que creen habitar y verán en ella los fundamentos de sus certezas. El esencialismo es un sustrato importante de la ideología, y esta a su vez es la base de los fundamentalismos, que pueden activar en los actores sentimientos, actitudes, agendas o acciones orientadas al supremacismo, el resentimiento o una combinación de ambos. Paradójicamente, el esencialismo identitario provoca crisis ontológicas y relacionales a los actores que a través de ello quieren darle sentido al mundo y su actuar en él.

El esencialismo identitario produce ideologías cercanas a los fundamentalismos. Señalaba Pereda (en Díaz Cruz, 2005:109) que existe un tipo de "razón arrogante", es aquella que "con avidez no deja de desear más de lo mismo y nada de lo otro: se autoconfirma sin límites y con igual falta de límites desacredita, difama. Es una forma del espíritu sectario". En este sentido, los esencialismos identitarios (nacionales, regionales, étnicos, laborales, de género, etc.) se basan en "razones arrogantes", independientemente de que tengan como propósito mantener, recrudecer o disminuir las desigualdades entre los actores.

Reconozco la urgencia de llenar un vacío conceptual, pues me parece cuestionable -incluso injusto- usar la misma etiqueta para analizar los motivos de actores que, sabiéndolo o no, mantienen o recrudecen las desigualdades, y para los motivos de actores que deliberadamente buscan disminuirlas. Ya sea que lo consigan puramente o que en sus intentos reproduzcan los contenidos ideológicos de la desigualdad que buscan erradicar o de alguna otra, por omisión, desconocimiento o limitación operativa para ofrecer una atención interseccional.

Para finalizar, sólo quisiera señalar que las identidades sociales son relacionales, circunstanciales y contingentes, son fluidas, pero su grado de fluidez dependerá de variables complejas como ideologías, narrativas, accesos y controles sobre recursos, expansión o contracción de sistemas sociales, emociones, azar, etc., por ello algunas identidades tienen más potencial de permanencia a lo largo de la vida 
de un actor o de transmitirse intergeneracionalmente que otras. Lo cultural es un proceso inacabado y universal, lo humano es devenir.

A continuación presento lo que considero son ventajas del método del drama social para la investigación antropológica en general. Posteriormente, expongo las razones por las que es posible estudiar el Proyecto Tren Maya como un proceso político mediante el método del drama social.

\subsection{Conveniencia de analizar el Proyecto Tren Maya como un drama social}

En primer lugar, considero que el uso del drama social permite sondear la realidad y sus posibilidades de interpretación. Permite un mapeo de los actores, sus ideologías, narrativas, representaciones y discursos, valores, creencias, alianzas, antagonismos, los recursos materiales e inmateriales por los que luchan y los recursos de los que disponen; además, es una especie de síntesis historiográfica con perspectiva antropológica en tiempo real.

En este sentido, los datos obtenidos mediante el mapeo y la síntesis historiográfica abren múltiples posibilidades de interpretación más allá de la teoría procesualista turneriana, es decir, pueden ser útiles para aportar a discusiones particulares que ya cuentan con bagajes conceptuales y metodológicos propios en la antropología y tal vez más allá de ella. Incluso puede desbordar el énfasis político, simbólico e histórico del procesualismo y develar pistas para el análisis de la repercusión de los procesos políticos en las dimensiones económica y cultural de las sociedades en cuestión.

En segunda instancia, considero que el método del drama social facilita la constante vigilancia epistémica. Al recolectar y ordenar la información se procura no imprimir juicios de valor propios, la atención está puesta en los juicios de valor, narrativas, discursos, acciones, etc. de los otros actores implicados en el campo, no para confirmar las ideas preconcebidas del antropólogo, sino para ofrecer una vista panorámica de la multiplicidad de perspectivas sectoriales con la intención de comprenderlas, analizarlas y explicarlas, considerando los modos en que se manifestaron en la realidad y el cómo interpelan la subjetividad del investigador y su marco teórico, necesariamente ubicados en el entramado de la construcción del sentido de la realidad social y sus significados. 
De tal modo, con una deliberada vigilancia epistémica, producto del espejeo constante con las otras perspectivas, el antropólogo podrá decantarse por alguna 0 algunas de las vetas de investigación (y acción) abiertas por la realidad misma y su discurrir en ella, sin haberla elegido a priori, lo que habitualmente termina por forzar la realidad para adecuarse a los prejuicios, sesgos y tendencias tanto del autor como de las discusiones antecedentes a las cuales busca interpelar o a la cuales intenta insertarse.

Por ejemplo, proyectos de investigación que se titularan "etnodesarrollo y reordenamiento territorial en el PTM" o "etnocidio y despojo territorial en el PTM", ya sabríamos más o menos de qué se tratan, cómo los autores miran o dicen mirar la realidad, qué buscan en ella, incluso podríamos tener una idea previa de los tonos narrativos y estilos utilizados en el texto. Ante todo, sabríamos que dichas investigaciones serían justificaciones en extenso de juicios a priori. Cabría esperar una pretensión de objetividad basada en la retórica emotiva o en la apología de narrativas hegemónicas o subalternas; o por el contrario, una negación políticamente estratégica de la objetividad, basada en la negación de la subjetividad del autor o en una presentación reducida o unidimensional de la misma. En toda investigación se corren estos riesgos, por eso es importante considerar desde el inicio estrategias que permitan la vigilancia epistémica. El método del drama social turneriano, debido a su inherente espejeo constante de perspectivas, es una buena opción.

Quisiera enfatizar, particularmente, la virtud teórica y metodológica que implica el uso de categorías flexibles espacial y temporalmente para el estudio de los fenómenos sociales, como las propuestas en el procesualismo turneriano. Tienen una ventaja sobre otras propuestas al poder establecer puentes entre las dimensiones macro y micro, intrasociales e intersociales (entendiendo a las sociedades como unidades abiertas), entre el pasado y el presente, entre lo material y lo simbólico, entre el tiempo, el espacio, la mente, la agencia, lo político y lo económico. Los símbolos, en tanto su eficacia y performatividad, (re)producen la realidad social. La configuración de los significados se traduce en el control de recursos, tanto materiales como inmateriales. En este sentido, se develan las relaciones de lo simbólico con lo político y lo económico. Con el procesualismo turneriano no se pretende generar una teoría omniabarcadora, lo relevante es la multiplicidad de dimensiones de la realidad social que evoca y permite conectar. 


\subsection{Posibilidad de analizar el fenómeno del Proyecto Tren Maya como un drama social}

Es posible analizar el Proyecto Tren Maya y sus repercusiones en la sociedad como un proceso político, mediante el método del drama social. El argumento principal es que existen correspondencias entre la realidad a estudiar y los principales elementos del procesualismo como teoría y del drama social como método. Encontramos actores en conflicto diacrónico por recursos significativos en arenas políticas particulares, mismas que en suma conforman el campo político del PTM, en el cual a su vez se llevan a cabo acciones simbólicas como el uso o establecimiento de símbolos dominantes mediante rituales políticos y ceremonias definicionales. A continuación se presentan los recursos en disputa, los actores del campo político y una clasificación de los eventos del proceso político del Proyecto Tren Maya acorde al método del drama social turneriano.

\subsubsection{Actores del Campo Político del Proyecto Tren Maya}

Encontramos una multiplicidad de actores en conflicto diacrónico de 2018 en adelante, pertenecientes a diferentes sectores del espectro indeterminado sociedad peninsular-mexicana-internacional, como son los sectores gubernamental, empresarial, los dueños de las tierras, las Organizaciones de la Sociedad Civil, la academia, el sector periodístico y el activismo étnico-ambientalista. En cada uno de estos sectores, que constituyen subcambos del campo político del PTM, hay una diversidad de actores que compiten simultáneamente por la hegemonía en el subcampo y por la incidencia en el campo político del PTM.

Es importante señalar que no se pueden establecer a priori los actores y los recursos que disputan en un proceso político. Es necesario observar y analizar el fenómeno durante un tiempo para que se vayan develando por sí mismos, especialmente durante la fase de crisis del drama social. En la siguiente tabla se presenta la clasificación de los actores detectados, después se aborda el tema de los recursos en disputa. 
Tabla 7. Sectores y actores sociales en el campo político del Proyecto Tren Maya

\begin{tabular}{|c|c|}
\hline Sector social & Actores \\
\hline Gubernamental & $\begin{array}{l}\text { - Presidente de la República: Andrés Manuel López } \\
\text { Obrador } \\
\text { - Fondo Nacional de Fomento al Turismo } \\
\text { (FONATUR): Rogelio Jiménez Pons (titular), } \\
\text { Aaarón Rosado Castillo (enlace territorial PTM } \\
\text { Yucatán) } \\
\text { - Secretaría de Medio Ambiente y Recursos } \\
\text { Naturales (SEMARNAT): Victor Toledo } \\
\text { (secretario) } \\
\text { - Instituto Nacional de los Pueblos Indígenas (INPI): } \\
\text { - Cdelfo Regino Montes (titular) } \\
\text { - de Disión de Asuntos de la Frontera Sur-Cámara } \\
\text { - Moedano (presidente) } \\
\text { - Gobiernos estatales de Yucatán, Campeche, } \\
\text { Quintana Roo, Chiapas y Tabasco } \\
\text { Gobiernos municipales de los cinco estados }\end{array}$ \\
\hline Empresarial & $\begin{array}{l}\text { - Empresas ganadoras de licitaciones de asistencia } \\
\text { técnica y legal: Steer Davies, Mextypsa, } \\
\text { Senermex, Eclecsis, CMS Woodhouse Lorente } \\
\text { Ludlow, PwC } \\
\text { - Empresas ganadoras de las licitaciones de } \\
\text { construcción de los tramos: 1) Mota-Engil México } \\
\text { SAPI de C.V. en convenio con China } \\
\text { Communications Construction Company LTD, } \\
\text { Grupo Cosh S.A. de C.,V Eyasa y Gavil Ingeniería } \\
\text { S.A.; 2) Operadora CICSA S.A. de C.V. en } \\
\text { convenio de asociación con FCC Construcción } \\
\text { S.A.; 3) Construcciones Urales, S.A. de C.V en } \\
\text { convenio de asociación con GAMI Ingeniería e } \\
\text { Instalaciones, S.A. de C.V y AZVI, S.A.U.; 4) } \\
\text { Grupo ICA } \\
\text { - Confederación de Cámaras Nacionales de } \\
\text { Comercio, Servicios y Turismo (CONCANACO- } \\
\text { SERVYTUR) } \\
\text { - Confederación Patronal de la República Mexicana } \\
\text { (COPARMEX) } \\
\text { - Cámara Nacional de Comercio, Servicios y } \\
\text { Turismo de Mérida (CANACO-SERVYTUR } \\
\text { Mérida) } \\
\text { - Cámara Mexicana de la Industria de la } \\
\text { Construcción (CMIC) } \\
\text { - Trabajadores del turismo y construcción } \\
\text { Pequeñas y Medianas Empresas (PYMES) del } \\
\text { ramo turístico }\end{array}$ \\
\hline
\end{tabular}




\begin{tabular}{|c|c|}
\hline & - Instituto Mexicano para la Competitividad (IMCO) \\
\hline $\begin{array}{l}\text { Propietarios legales de } \\
\text { la tierra }\end{array}$ & $\begin{array}{l}\text { - Comisarios ejidales } \\
\text { - Ejidatarios } \\
\text { - Propietarios particulares } \\
\text { - Vecinos en las vías del ferrocarril }\end{array}$ \\
\hline Académico & $\begin{array}{l}\text { - Instancias en convenio con FONATUR: UAM, } \\
\text { UNAM, IPN, INAH, ECOSUR, UJAT, CONALEP, } \\
\text { Consejo de Ciencia y Tecnología del Estado de } \\
\text { Tabasco (CCYTET), Foro Consultivo Científico y } \\
\text { Tecnológico A. C., Centro de Investigación en } \\
\text { Ciencias de Información Geoespacial A.C. } \\
\text { - A favor: Paloma Escalante Gonzalbo (ENAH), } \\
\text { Ildefonso Palemón Hernández Silva (Rector } \\
\text { UIMQROO), Karla Gruintal Lugo (UIMQROO), } \\
\text { Gilberto Avilez Tax (UIMQROO) } \\
\text { - Críticos: Articulación, Biólogos CICY; GT-TTM; } \\
\text { - En contra: Giovanna Gasparello (INAH), Felipe } \\
\text { Echenique March (INAH), Gilberto López y Rivas } \\
\text { (INAH), Violeta Núñez (UAM-X), Ana Esther } \\
\text { Ceceña (OLAG-UNAM) }\end{array}$ \\
\hline $\begin{array}{l}\text { Organizaciones de la } \\
\text { Sociedad Civil }\end{array}$ & $\begin{array}{l}\text { - } \text { Colegios profesionales en convenio con } \\
\text { FONATUR: Colegios De Ingenieros Y Arquitectos } \\
\text { Del Estado De Tabasco, Colegio De Ingenieros } \\
\text { Civiles De Yucatán A.C., Colegio Yucateco De } \\
\text { Arquitectos A.C., } \\
\text { - Gubernatura Nacional Indígena (GNI) } \\
\text { - Consejo Civil Mexicano para la Silvicultura } \\
\text { Sostenible (CCMSS) } \\
\text { - GeoComunes } \\
\text { - Unión de Ejidos de la Península } \\
\text { - Co'ox Mayab } \\
\text { - Alianza Peninsular para el Turismo Comunitario } \\
\text { - CoPTC) } \\
\text { - Instancivo Úuchben Ch'i'ibal Túumben T'aan } \\
\text { Habitat, UNOPS, UNESCO }\end{array}$ \\
\hline Periodístico & $\begin{array}{l}\text { - Prensa sensacionalista: Reforma, El Universal } \\
\text { - Prensa a favor: DOF, lopezobrador.org } \\
\text { - Prensa crítica: Proceso, Pie de Página, Animal } \\
\text { Político, Crónica, La Jornada } \\
\text { - Prensa extranjera: El País, BBC }\end{array}$ \\
\hline $\begin{array}{l}\text { Activista étnico- } \\
\text { ambientalista }\end{array}$ & $\begin{array}{l}\text { - Ejército Zapatista de Liberación Nacional } \\
\text { - Congreso Nacional Indígena-Concejo Indígena de } \\
\text { - Gobierno } \\
\text { - Múuch Xíinbal }\end{array}$ \\
\hline
\end{tabular}


- Consejo Regional Indígena y Popular de Xpujil

- U kúuchil k Ch'i'ibalo'on

- Indignación

Cada uno de estos actores despliega narrativas y discursos específicos para activar o sostener una ideología, establece alianzas y antagonismos estratégicamente, para disputar recursos significativos, pudiendo ser estos materiales o inmateriales. En el periodo analizado en este trabajo -agosto del 2018 a marzo del 2019- no se manifestaron todos los actores mencionados. La relación de los actores identificados comprende hasta septiembre del 2020, momento en el cual cada uno de los actores ya habría aparecido en escena en el campo político del Tren Maya. Queda pendiente el análisis de los meses posteriores para la tesis doctoral.

Uno podría preguntarse dónde está la población maya en esta clasificación. La respuesta sería que está en todos los sectores, no es posible hablar de un sector maya homogéneo, delimitado, con narrativas, ideología y una agenda política compartida. La población maya-hablante o mayadescendiente (no necesariamente identificada como maya) no está ausente en este esquema, más bien está presente en todo él, distribuida en todos los sectores del campo político del Tren Maya, engrosando las filas tanto de la facción proponente como de la facción oponente del proyecto.

Si bien hay sectores compuestos mayoritaria o prioritariamente por actores que reivindican su identidad como mayas -tal es el caso del sector del activismo étnico ambientalista-, es dado encontrar actores maya-hablantes o mayadescendientes en todo el campo político del Tren Maya. Los hay funcionarios públicos, empresarios convencionales o sociales, ejidatarios y propietarios particulares de tierras, académicos, miembros de OSC, periodistas. Los hay urbanos y rurales, dedicados a una gran variedad de actividades económicas, con ingresos bajos, medios y altos, con distintos grados de escolarización, conocimiento y control de otras lenguas y otros códigos culturales.

En todos los sectores sociales las relaciones interculturales son sostenidas. Es en ellas que se negocian, ganan y pierden ventajas, derechos, control sobre recursos. Al interior de cada sector hay relaciones de poder interétnicas e interacciones interculturales que pueden estar orientadas tanto al recrudecimiento como a la 
disminución de las desigualdades sociales estructurales basadas en la etnicidad, tanto a nivel regional, nacional o global.

Es posible que algunos actores operen en función de comunidades imaginadas que no existen pero las dan por sentadas o que proponen construirlas. También puede que otros actores no quieran o puedan reconocer las similitudes con otros actores que los llevarían a la creación de una identidad maya aglutinante. Incluso podría haber quienes se opongan a la construcción de alguna identidad de este tipo, ya sea porque la consideran innecesaria desde una perspectiva economicista neoliberal del mérito individual o porque la consideran anacrónica como resultado de la asimilación de variantes neocoloniales y racistas de las narrativas del desarrollo.

Así como no existe un sector social maya homogéneo tampoco existe un posicionamiento maya homogéneo a favor ni en contra del Tren Maya. Por ello, si se quisiera responder a la pregunta de qué opinan los mayas del Tren Maya se tendría primero que aclarar qué mayas serían representados. No considero prudente clasificar a los actores a nivel ontológico porque se corre el riesgo de esencializarlos y sesgar todo el análisis posterior, por ello la clasificación que propongo en este estudio se basa en la posición desde la cual se disputan recursos. La clasificación por sectores sociales, por supuesto, también es necesariamente un sesgo, la diferencia a favor radica en que a partir de ella se puede saber dónde están los actores sin proponer ideas sobre lo que son los actores. Estos son los motivos por los que en este estudio no se habla de "los mayas" sino de narrativas de la mayanidad activadas en diversos sectores sociales, en los cuales participan actores que pueden reconocerse a sí mismos, o pueden ser reconocidos por otros, como mayas.

\subsubsection{Significados y usos de los recursos en disputa: espacio geográfico, mayanidad y opinión pública}

Después de un análisis de los discursos y acciones emprendidas por los actores del campo político del Proyecto Tren Maya durante el periodo de tiempo referido, es posible afirmar que los recursos en disputa son tres: 1) El espacio geográfico y su contenido de origen natural y humano; 2) la mayanidad-indigeneidad; y 3) la opinión pública. De estos el primero es un recurso material y los otros dos son recursos inmateriales. 
Ahora bien, con fines analiticos, estos recursos por sí mismos son considerados significantes a los cuales los actores les otorgan significados particulares para usarlos de maneras específicas. Cabe añadir que la selección de los significados y los usos tienden a la acción en alguna dimensión social específica, como son la política, la económica y la cultural. Estas no son excluyentes de ninguna forma, pero se enfatiza alguna de ellas al momento de significar o usar estratégicamente un recurso. También es necesario señalar que el control de un recurso permite disputar otros, en este sentido, todos los recursos están en disputa para disputar. Esto parece algo enredado, pero en realidad no lo es tanto, vamos por partes.

Pensemos en el recurso material "espacio geográfico y su contenido de origen natural y humano". Una definición básica de espacio ofrecida por Giménez (2005), resultado de un ejercicio de revisión y síntesis de literatura geográfica, señala que éste comprende una porción cualquiera de la superficie terrestre considerada anterior a toda representación y a toda práctica. Aunado a ello, se le considera un recurso escaso debido a su finitud intrínseca, y por lo mismo, constituye un objeto en disputa permanente dentro de las coordenadas del poder. El espacio entonces es inherentemente político.

El espacio es la condición propia del ejercicio del poder, es a través de él que nuestra especie ordena su vida social y política. La ocupación del espacio precede a todo derecho y no existen ideas políticas sin un espacio al cual sean referibles, ni espacios a los que no correspondan ideas políticas (Velázquez Ramírez, 2013:64, 65). El espacio ha sido formado y modelado por elementos históricos y naturales; pero esto ha sido un proceso político. El espacio es político e ideológico. Es un producto literalmente lleno de ideologías (Lefebvre en Oslender, 1999:5).

Adicionalmente, definiciones recientes de territorio en la geografía humana, señalan que es el espacio apropiado por un grupo social para asegurar su reproducción y la satisfacción de sus necesidades vitales, que pueden ser materiales o simbólicas. Dicha apropiación del espacio podría ser predominantemente utilitaria y funcional o predominantemente simbólico-cultural (Raffestin; Di Meo; Scheibling; Hoerner en Giménez, 2005). Además, el territorio es multiescalar, a continuación, se presenta la clasificación de escalas expuesta por Giménez (2005): 
- Casa;

- Territorios próximos: pueblo, barrio, municipio, ciudad (prolongación del cuerpo, afección y apego, vida social de base) (Hoerner en Giménez, 2005);

- Territorios intermedios: región (entre lo local y el "vasto mundo") (Moles y Rohmer en Giménez, 2005);

- Estado-nación: espacio de legitimidad del Estado-nación; territorio-signo, espacio cuasi-sagrado metonímicamente ligado a la comunidad nacional (Giménez, 2005);

- Territorios supranacionales: Ejemplo, el Mundo Maya, la Unión Europea;

- Territorios de la globalización: Ejemplo, Zonas Económicas Especiales, paraísos fiscales, superpuesta a formas tradicionales de territorialidad, trascendiéndolas y neutralizando sus efectos regulativos y restrictivos en el plano económico, político y cultural. Se configuran en forma de redes, cuyos nodos serían las "ciudades mundiales" diversamente jerarquizadas y distribuidas por el mundo (Giménez, 2005).

Considerando lo anterior, vale decir que el espacio geográfico y sus contenidos de origen natural y humano -con fines políticos- puede ser significado como "territorio" por diferentes actores que se proclaman dueños legítimos (pudiendo o no ser propietarios legales de tierras) o voceros de los mismos, pertenecientes a los sectores gubernamental, activista étnico-ambientalista, propietarios legales de la tierra, academia y OSC, entonces le denominarán "territorio nacional", "territorio maya", "territorio peninsular", "Mundo Maya”, según sea el caso, según el momento, según el interlocutor o el público. Habiéndolo significado de alguna de estas formas lo usarán para producir o reproducir una cultura y un estilo de vida particulares, considerados ideales por los actores en cuestión, que le imprimen su ideología o lo activan estratégicamente desde alguna narrativa de su elección (en caso de que tengan opciones para elegir), o como consecuencia de las narrativas y valores apropiados inconscientemente.

Por otra parte, este mismo recurso, "espacio geográfico y su contenido de origen natural y humano", con fines económicos puede ser significado como "tierras/terreno" por actores de los sectores gubernamental, empresarial y terratenientes, con el fin de negociar las condiciones de usufructo o los términos de 
compra-venta. Igualmente con un fin económico, puede ser significado dicho recurso como "recurso natural", para el cual su uso es su explotación o no explotación.

A su vez, con fines culturales, el referido recurso puede ser significado como "patrimonio natural” y "patrimonio cultural (arqueológico, histórico)", por parte de actores del sector académico, gubernamental, OSC, activista, para incentivar la conservación y/o promoción de dichos recursos. Cabe mencionar que los modos de concebir la conservación y la promoción varían dependiendo de la narrativa que se active $o$ de la cual se parta.

Pasemos a los recursos inmateriales en disputa. El primero de ellos es la "mayanidad-indigeneidad". Con fines políticos puede ser significado como "identidad étnica" por actores del sector activista étnico-ambientalista y por una parte del sector académico, quienes estudian el papel de la etnicidad en los procesos políticos o pretenden incidir en los procesos políticos en los que la etnicidad es relevante o se procura su relevancia. Esta significación puede ser usada como un capital simbólico que al activarlo políticamente puede devenir en la movilización social. Este tipo de significación puede ser eclipsada de manera casual o deliberada por actores de otros sectores, al darle los significados y usos propios de ideologías que priorizan las dimensiones económica y cultural, como veremos a continuación.

El recurso "mayanidad-indigeneidad" puede también ser significado con fines económicos como una "marca comercial" -Mundo Maya, por ejemplo- por actores de los sectores gubernamental, empresarial, OSC y ciertas facciones del sector académico. El uso que se le da es como "capital simbólico-económico" que al activarlo puede generar valor agregado a un producto comercial. Ejemplo de ello es el nombre mismo del proyecto "Tren Maya”, pensado desde el sector gubernamental.

Por supuesto, el uso comercial del recurso "mayanidad-indigeneidad" no es exclusivo de actores que no se reconocen a sí mismos como indígenas, existen pequeñas y medianas empresas, con una visión convencional o social del emprendimiento, que son operadas por actores que se reconocen a sí mismos como indígenas y activan el capital simbólico-económico de su propia "identidad étnica". Ejemplo de ello son las cooperativas de turismo comunitario operadas por personas que se reconocen como mayas. 
Actualmente no son esfuerzos aislados, pues encontramos instancias articuladoras a nivel estatal y peninsular. En Yucatán se encuentra la red de cooperativas de turismo comunitario Co'ox Mayab; en Campeche está el Consejo de Turismo Rural de Campeche; y en Quintana Roo tenemos la organización Caminos Sagrados Kili'ch bejo'ob. Estas tres redes de cooperativas están actualmente articuladas en la Alianza Peninsular de Turismo Comunitario (APTC) ${ }^{83}$, instancia a través de la cual los miembros de las cooperativas han procurado el acercamiento a los sectores gubernamental, empresarial, OSC y académico (es decir, buscan alianzas intersectoriales) para maximizar los beneficios económicos, culturales, sociales y ambientales de sus propuestas comerciales, en las cuales la mayanidad asociada a lo natural, rural y/o comunitario- tiene un papel importante.

Una última forma identificada de significar el recurso inmaterial "mayanidadindigeneidad" es la derivada de una orientación cultural. En esta, actores pertenecientes a los sectores gubernamental, OSC, académico y activista étnicoambientalista le confieren el significado de "patrimonio cultural", para emprender acciones de conservación y/o promoción. Al igual que en la patrimonialización de los recursos materiales ya comentada, en este caso también las concepciones de lo que es conservación y promoción dependerán de las versiones sectoriales de la realidad priorizadas por los actores.

Con respecto al segundo recurso inmaterial en disputa referido, la "opinión pública", las cosas ocurren de un modo peculiar. Este es el recurso en disputa y para disputar otros recursos por excelencia. Quien controle la opinión pública tiene las condiciones a su favor para lograr los objetivos propuestos en su agenda política. En este sentido, la orientación a la acción aquí corresponde al continuum políticoeconómico-cultural, es decir, se alude integral e indeterminadamente a las tres dimensiones que condicionan la significación y los usos de los demás recursos materiales y simbólicos en disputa.

El significado que se le da al recurso "opinión pública" es el mismo para todos los sectores: es la legitimidad de su ideología, narrativas y de los significados y usos dados o propuestos para los recursos en disputa. Ahora bien, se usa la opinión pública para construir la opinión pública, esto se da mediante la promoción de la aprobación o rechazo del PTM a través de procesos legales, propaganda, mítines, asambleas, 
foros, talleres, conferencias, mesas panel, manifestaciones y actividad en redes sociales digitales. En la siguiente tabla se presenta una síntesis de lo expuesto sobre los significados y usos de los recursos en disputa.

Tabla 8. Significados y usos de los recursos en disputa en el drama social del Proyecto Tren Maya

\begin{tabular}{|c|c|c|c|c|}
\hline $\begin{array}{l}\text { Recursos en } \\
\text { disputa }\end{array}$ & Significante & Significado & Usos & $\begin{array}{l}\text { Dimensión } \\
\text { social } \\
\text { predomina } \\
\text { nte en la } \\
\text { orientación } \\
\text { de la } \\
\text { acción }\end{array}$ \\
\hline \multirow[t]{3}{*}{ Materiales } & \multirow[t]{3}{*}{$\begin{array}{l}\text { Espacio } \\
\text { geográfico y } \\
\text { su contenido } \\
\text { de origen } \\
\text { natural y } \\
\text { humano }\end{array}$} & $\begin{array}{l}\text { Territorio } \\
\text { (maya, } \\
\text { peninsular, } \\
\text { nacional, } \\
\text { transnacional- } \\
\text { Mundo Maya) }\end{array}$ & $\begin{array}{l}\text { Producción o } \\
\text { reproducción } \\
\text { cultural y del estilo } \\
\text { de vida }\end{array}$ & $\begin{array}{l}\text { Política- } \\
\text { Cultural }\end{array}$ \\
\hline & & $\begin{array}{l}\text { Tierras/terreno } \\
\text { Recurso(s) } \\
\text { natural(es) }\end{array}$ & $\begin{array}{l}\text { Usufructo y/o } \\
\text { compra-venta } \\
\text { Explotación }\end{array}$ & $\begin{array}{l}\text { Económica } \\
\text {-Política }\end{array}$ \\
\hline & & $\begin{array}{l}\text { Patrimonio } \\
\text { natural } \\
\text { Patrimonio } \\
\text { cultural } \\
\text { (arqueológico, } \\
\text { histórico) }\end{array}$ & $\begin{array}{l}\text { Conservación y/o } \\
\text { promoción }\end{array}$ & $\begin{array}{l}\text { Cultural- } \\
\text { Política }\end{array}$ \\
\hline \multirow[t]{3}{*}{ Inmateriales } & \multirow[t]{3}{*}{$\begin{array}{l}\text { Mayanidad- } \\
\text { Indigeneidad }\end{array}$} & Identidad étnica & $\begin{array}{l}\text { Capital simbólico- } \\
\text { político: legitimador } \\
\text { y/o movilizador } \\
\text { social }\end{array}$ & $\begin{array}{l}\text { Política- } \\
\text { Cultural }\end{array}$ \\
\hline & & $\begin{array}{l}\text { Marca } \\
\text { comercial }\end{array}$ & $\begin{array}{l}\text { Capital simbólico- } \\
\text { económico: } \\
\text { generador de valor } \\
\text { agregado }\end{array}$ & $\begin{array}{l}\text { Económica } \\
\text {-Política }\end{array}$ \\
\hline & & $\begin{array}{l}\text { Patrimonio } \\
\text { cultural }\end{array}$ & $\begin{array}{l}\text { Conservación y/o } \\
\text { promoción }\end{array}$ & $\begin{array}{l}\text { Cultural- } \\
\text { Política }\end{array}$ \\
\hline
\end{tabular}




\begin{tabular}{|l|l|l|l|l|}
\hline $\begin{array}{l}\text { Opinión } \\
\text { pública }\end{array}$ & $\begin{array}{l}\text { Legitimidad de } \\
\text { la ideología, } \\
\text { narrativas y del } \\
\text { significado y } \\
\text { uso de los } \\
\text { recursos en } \\
\text { disputa }\end{array}$ & $\begin{array}{l}\text { Construir la opinión } \\
\text { pública mediante la } \\
\text { promoción de la } \\
\text { aprobación o } \\
\text { rechazo del PTM a } \\
\text { través de procesos } \\
\end{array}$ & $\begin{array}{l}\text { Política- } \\
\text { económica- } \\
\text { cultural }\end{array}$ & \\
& legales, \\
propaganda, \\
mítines, \\
asambleas, foros, \\
talleres, \\
conferencias, \\
mesas panel, \\
manifestaciones, \\
actividad en redes \\
sociales digitales.
\end{tabular}

\subsubsection{Fases del Drama Social del Proyecto Tren Maya}

Ahora bien, como se ha mencionado, las disputas que establecen los actores por los recursos no ocurren en el vacío, sino en campos políticos. Básicamente, la sucesión de arenas políticas, rituales políticos y ceremonias definicionales en un campo político determinado constituyen el proceso político, el cual puede ser analizado como un drama social.

En la siguiente tabla se puede ver un listado en orden cronológico de los principales eventos o situaciones protagonizados por diferentes actores del campo político del PTM, de agosto del 2018 a marzo del 2019. En estos es posible encontrar algunos que cumplen con las características del ritual político señalado por Turner, como el ritual de permiso a la Madre Tierra; otros son ceremonias definicionales como el Foro Indígena Maya Peninsular organizado por Gubernatura Nacional Indígena (GNI). Aunado a esto, se ha dado el uso de símbolos dominantes surgidos de dramas sociales anteriores, como la remembranza de Jacinto Canek por actores del sector activista étnico-ambientalista o Benito Juárez por el presidente de la república, ambos indígenas del pasado (siglos XVIII y XIX respectivamente) significados por actores del siglo XXI con ideologías y narrativas disímiles, acaso opuestas en puntos primordiales, en fin, en contienda. 


\begin{tabular}{|c|c|}
\hline $\begin{array}{l}\text { Fase del drama } \\
\text { social }\end{array}$ & $\begin{array}{l}\text { Principales acontecimientos en torno al Proyecto Tren } \\
\text { Maya }\end{array}$ \\
\hline $\begin{array}{l}\text { 1) Ruptura de } \\
\text { las relaciones } \\
\text { sociales } \\
\text { regulares } \\
\text { gobernadas por } \\
\text { normas }\end{array}$ & $\begin{array}{l}\text { 1. El presidente electo AMLO anuncia a RJP como titular } \\
\text { de FONATUR y a esta instancia como la encargada del } \\
\text { PTM (13 agosto 2018); } \\
\text { 2. Anuncio de la Consulta Nacional sobre los Programas } \\
\text { Prioritarios y reacciones del sector académico y del } \\
\text { activismo étnico-ambientalista (12 noviembre 2018) }\end{array}$ \\
\hline 2) Crisis & $\begin{array}{l}\text { 3. Consulta Nacional sobre los Programas Prioritarios (24- } \\
25 \text { noviembre 2018) } \\
\text { 4. Reiteración del PTM en la toma de protesta de la } \\
\text { presidencia y la ceremonia de entrega del bastón de } \\
\text { mando (1 diciembre 2018); } \\
\text { 5. Ritual de los Pueblos Originarios a la Madre Tierra para } \\
\text { anuencia del Tren Maya (16 diciembre 2018); } \\
\text { 6. } 25 \text { Aniversario del inicio de la guerra contra el olvido (1 } \\
\text { enero 2019) } \\
\text { 7. RJP crea las filiales de FONATUR: FONATUR Tren } \\
\text { Maya S.A. de C.V y FONATUR Infraestructura S.A. de } \\
\text { C.V. (10 enero } 2019 \text { ) } \\
\text { 8. FONATUR inicia búsqueda de alianzas intersectoriales } \\
\text { (academia, colegios profesionales, asesores técnicos, } \\
\text { organizaciones de la sociedad civil, dependencias de la } \\
\text { ONU) (febrero-diciembre } 2019 \text { ); } \\
\text { 9. Foro Maya Peninsular convocado por Gubernatura } \\
\text { Nacional Indígena (2 marzo 2019). }\end{array}$ \\
\hline
\end{tabular}

Hasta aquí se han presentado las características principales del procesualismo turneriano como teoría y del drama social como método, así como los conceptos complementarios pertinentes. Igualmente se han argumentado los motivos por los que es conveniente y posible estudiar el Proyecto Tren Maya como un proceso a través del drama social. En este ejercicio se señalaron los actores del campo político, los recursos en disputa y los principales eventos del drama social del PTM, a través de cuyo análisis es posible afirmar que el DSPTM se encuentra actualmente en la fase 2, la de crisis. En los dos capítulos siguientes se presenta una relación de los principales eventos del drama social del Proyecto Tren Maya previo a su existencia material, suscitados entre agosto del 2018 y marzo del 2019, agrupados en dos de las cuatro fases del drama social propuestas por Turner: ruptura y crisis 


\section{Capítulo 3. Fase 1: La ruptura}

Este capítulo tiene como objetivo develar los motivos que desencadenaron el conflicto a partir del cual se inauguró el proceso político del Proyecto Tren Maya. En este sentido, se rastrean los eventos que detonaron la formación de la facción oponente y la facción promovente del Tren Maya, a la cual los distintos actores del campo político se irían alineando sobre la marcha. Esta primera fase del Drama Social del Proyecto Tren Maya (DSPTM), la ruptura, es abordada mediante el análisis de los eventos referidos en el capítulo anterior. Cada evento es abordado a través de los principales discursos y acciones de sus protagonistas, así como las reacciones inmediatas discursos y acciones- de otros actores sociales que forman parte del Campo Político del Proyecto Tren Maya (CPPTM).

Antes de comenzar con el análisis de dichos eventos, es necesario hacer algunas precisiones sobre los procesos políticos que influyeron en la conformación del campo político, las narrativas e ideologías presentes en el proceso político del Tren Maya. Se analizan a continuación, a modo, algunos procesos políticos del pasado cercano y lejano que inciden en el fenómeno aquí estudiado. Asimismo, se abordan la conformación y componentes principales de otra de las narrativas presentes en el proceso político del Tren Maya, la narrativa del despojo por megaproyectos/resistencia territorial indígena, la cual se ha manifestado en los procesos políticos antecedentes abordados en los siguientes párrafos.

\subsection{Procesos políticos antecedentes del proyecto Tren Maya}

En primer lugar, cabe recordar que el drama social es una unidad de análisis de la realidad social. Como tal, un drama social es la forma de comprender un proceso político que puede ser parte de procesos políticos mayores, y a su vez puede contener procesos políticos menores, considerando el tamaño de la red de actores, espacialidades y temporalidades involucradas en el proceso político. En este sentido, al elegir estudiar un proceso político mediante el método del drama social es posible comprenderlo en interacción con otros dramas sociales, como parte de dramas sociales mayores y compuesto por dramas sociales menores.

De tal modo, el proceso político del Proyecto Tren Maya puede considerarse como parte del proceso político de la Cuarta Transformación, y ambos procesos 
pueden ser analizados como dramas sociales. Así, el drama social del PTM forma parte del drama social de la Cuarta Transformación, a la vez que puede contener dramas sociales menores como el de la polémica estación del Tren Maya en las inmediaciones de Calakmul, considerado patrimonio mixto de la humanidad por la UNESCO, o los concernientes a cualquier otra estación.

La segunda precisión es que la temporalidad de este estudio se limita a una parte de los acontecimientos previos a la posible existencia material del PTM. No obstante, en caso de que el proyecto se construya y opere en los próximos años, eso constituiría la fase final de este drama social, la de reintegración o irremediable cisma. Con ello se sentarían las bases -es decir, las relaciones de poder en el campo políticopara los procesos políticos y sociales desencadenados en el contexto de la existencia material y operación del PTM, los cuales podrían ser analizados también mediante el método del drama social. O sea, es necesario distinguir el drama social previo a la existencia material del Tren Maya del posible drama social iniciado con su inauguración.

En tercera instancia, cabe recordar que, siguiendo a Turner, los dramas sociales suelen ser procesos inacabados a la vez que resultado de dramas sociales anteriores. Con respecto al DSPTM se han identificado dos tipos de dramas sociales previos de los cuales se nutre:

1. Dramas sociales cercanos espaciotemporalmente. Correspondientes al pasado cercano, incidieron en la configuración del Campo Político del Proyecto Tren Maya (CPPTM), en cuanto a la presencia de ciertos actores, las narrativas, ideologías y símbolos dominantes manifiestos en sus discursos y a las relaciones de poder entre ellos;

2. Dramas sociales lejanos espaciotemporalmente. Correspondientes a un pasado más distante en el que los actores ya no viven y/u ocurrieron en lugares ajenos al área de incidencia del Tren Maya. Estos dramas sociales sirven para evocar símbolos dominantes -sean personas, momentos o acciones- y así constituir narrativas que respalden propuestas políticas e ideologías en el presente. 


\subsubsection{Dramas sociales cercanos espaciotemporalmente al drama social del Proyecto Tren Maya}

Como ejemplo del primer tipo tenemos el drama social de la elección presidencial del 2018, del cual resultó electo presidente Andrés Manuel López Obrador (AMLO), quien nombró a Rogelio Jiménez Pons (RJP) como titular de FONATUR y responsable del Proyecto Tren Maya, y a Victor Toledo como titular de la SEMARNAT, entre otros. De este drama social cabe también mencionar la dicotomización del campo político manifiesta en la oposición "PRIAN-Mafia del poder/MORENA", la cual se expresa en la actualidad como "conservadores/Cuarta Transformación (4T)". Igualmente, jalando un poco más los hilos de la historia hay que recordar que AMLO había sido candidato presidencial en las elecciones de 2006 y 2012, ambos procesos políticos pueden ser comprendidos mediante el método del drama social, los cuales fueron configurando el campo político de la elección presidencial del 2018.

En este sentido, el legado de este drama social electoral y sus antecedentes es la presencia de actores y la relación de fuerzas, alianzas y antagonismos entre ellos en el CPPTM. También influyeron en las orientaciones discursivas desde el sector gubernamental, el cual tiende a leer la crítica como oposición, cuando no en todos los casos sea así. Esta es una estrategia comprensible durante una campaña electoral, pero puede ser contraproducente para el ejercicio democrático una vez en el poder, sobre todo porque podría resultar en una equiparación de actores con perspectivas, objetivos, críticas y propuestas diferentes en un sólo concepto: la "oposición".

Otro ejemplo del primer tipo es el relativo al Festival Independiente de la Cultura Maya Cha'anil Kaaj realizado en Yucatán durante el 2013, surgido en respuesta al Festival Internacional de la Cultura Maya, organizado por el gobierno del estado de Yucatán utilizando el etnónimo "maya" pero sin dar cabida a artistas mayas, ni considerar actividades fuera de la capital estatal. Las demandas de este festival eran de carácter predominantemente cultural, se pretendía sobre todo abonar al reconocimiento del Pueblo Maya, de su lengua y creación artística, por lo que la confrontación directa al poder y sus agendas no era parte sustancial, aunque ya se avisoraban indicios (Llanes Salazar, 2016 ${ }^{84}$ ). 
En este sentido, el DSPTM se nutre de los logros obtenidos en cuanto al reconocimiento por parte de los actores que llevaron a cabo el Cha'anil Kaaj, por lo que puede considerarse como una extensión de las demandas del Pueblo Maya del ámbito cultural al ámbito político, dado que ahora está en el centro la disputa por recursos con el Estado y el sector empresarial. El legado de este drama social al DSPTM es la "mayanización" de ciertos actores del sector activista yucateco, lo cual devino en la activación política de la etnicidad (Llanes Salazar, 2016).

Esta activación política de la etnicidad maya coincidió con -y fue potenciada por- el inicio del proyecto gubernamental-empresarial de instalar parques eólicos y fotovoltaicos en Yucatán, a la par de la construcción de mega granjas porcícolas y el cultivo de grandes extensiones de soya transgénica en Campeche y Quintana Roo.

En este contexto se desarrolla un último ejemplo de este primer tipo de dramas sociales que influyeron en el DSPTM. Se trata del drama social de los megaproyectos energéticos en la Península de Yucatán iniciado en el 2016. Este drama social aunado a los demás ya referidos- reconfiguró el significado conferido a los espacios geográficos y sus contenidos, dado el incremento de su valor comercial, lo que devino en disputas de todo tipo, desde la exigencia de pagos justos a los ejidatarios hasta las afirmaciones de territorialidad maya, desde las que se propone que la tierra no se vende ni se renta, sino que se trabaja y se defiende.

De este drama social surgió la Asamblea de Defensores del Territorio Maya Múuch Xínbal -que sería más adelante un actor del sector del activismo étnicoambientalista del DSPTM- el cual logró mediante amparos la cancelación de algunos parques de energías alternativas que ponían en riesgo al territorio maya. Igualmente conformó una serie de alianzas con otros actores activistas como el CNI y con actores predominantemente académicos como la Articulación Social de Energía Sustentable de Yucatán (Articulación Yucatán), asociación conformada por investigadores del CINVESTAV, INAH, CICY, etc. Es decir, este drama social también abonó a la preparación de las orientaciones discursivas y las alianzas de actores del sector del activismo étnico-ambientalista y académico en el campo político del Proyecto Tren Maya a nivel del estado de Yucatán. 


\subsubsection{Dramas sociales lejanos espaciotemporalmente al drama social del Proyecto Tren Maya}

Con respecto al segundo tipo de dramas sociales relacionados al DSPTM, tenemos el drama social de los parques eólicos en Oaxaca iniciado en el año 2000, mismo que nutrió al ya referido drama social de los megaproyectos energéticos en Yucatán, mediante la transferencia-adopción de la narrativa del "despojo por megaproyectos/resistencia territorial indígena", presente en sectores importantes de la prensa, el activismo y la academia. Se aborda esta narrativa en el siguiente apartado.

Este drama social, llevado a cabo en un pasado no tan distante pero en otra espacialidad, fue tomado como un referente para la comprensión de lo que pasaba en la Península de Yucatán con respecto a los megaproyectos energéticos y de otros tipos, lo que incluiría posteriormente al PTM. También fue un referente para la acción, pues devino igualmente en las estrategias de bloqueo legal mediante amparos y apelación a los derechos indígenas por parte de la Asamblea Popular de los Pueblos de Oaxaca (APPO) y el CNI, camino seguido principalmente por la ya mencionada Múuch Xíinbal.

Otro ejemplo de este segundo tipo de drama social que influyó en el PTM, cuya lejanía es temporal, es el de la rebelión maya de Cisteil en contra de la dominación española, en la entonces Capitanía General de Yucatán de la Nueva España en 1761, la cual fue liderada por Jacinto Canek. Dicho movimiento fue suprimido y su líder y allegados fueron torturados y asesinados por los colonos españoles y criollos. Cabe agregar que el mismo Canek, llamado originalmente Jacinto Uc de los Santos, tomó el nombre de Kaan Ek (serpiente negra, serpiente de la estrella o cielo estrellado), inspirado en el nombre recurrente de los gobernantes o jalach uinic de los itzáes, quienes constituyeron el último reducto de la población indígena que resistió a la conquista española hasta finales del siglo XVII, en Tayasal, en las inmediaciones del lago Petén Itzá.

En una tónica similar se ha recurrido a los líderes indígenas de la Guerra de Castas (1847-1901), Cecilio Chi, Jacinto Pat y Manuel Antonio Ay. No obstante, el símbolo dominante más recurrente es Jacinto Canek, al cual incluso se le asocia en el imaginario colectivo con la Guerra de Castas, a pesar de que esta ocurrió casi un 
siglo después de su muerte, pero de la que fue considerado probablemente un antecedente por Chi, Pat y May.

Considerando lo expuesto, Jacinto Canek es un símbolo dominante que significa la rebeldía indígena maya ante la dominación exógena, es decir, ante las imposiciones políticas de grupos Otros que los subordinan política, económica, social y culturalmente, privándolos del control sobre recursos significativos y de la capacidad de decidir sobre su propio destino. Jacinto Canek ha sido tomado en épocas recientes como símbolo dominante por actores del sector del activismo étnico ambientalista de Yucatán como la ya referida Asamblea de defensores del territorio maya Múuch Xíinbal.

Un último ejemplo del segundo tipo es el drama social de las Leyes de Reforma, impulsadas por el presidente Benito Juárez y consolidadas en la Constitución de 1857 por el presidente Sebastián Lerdo de Tejada. De este drama social se vale el actual presidente para tomar a Benito Juárez como símbolo dominante, exaltando su origen humilde e indígena y su papel en la transformación de la relación de fuerzas entre el Estado mexicano, el clero, las fuerzas armadas y las potencias imperiales extranjeras. En este sentido, recurre al símbolo de Benito Juárez como alguien de "abajo" que cambió el aparato de poder en su conjunto, lo que se corresponde discursivamente con las intenciones declaradas de lo que propone sea la "Cuarta Transformación" (4T) del Estado mexicano.

\subsubsection{La narrativa del despojo por megaproyectos/resistencia territorial indígena}

Como ya se ha mencionado, algunos dramas sociales previos que incidieron en el DSPTM han sido explicados por algunos actores mediante la narrativa del "despojo por megaproyectos/resistencia territorial indígena". En este apartado analizo brevemente algunos elementos sobre su origen y sus principales componentes. Es importante comprenderla, puesto que aparece reiteradamente en el proceso político del Tren Maya. Puede considerarse que es la narrativa rival directa de la narrativa de la turistificación-mayanización ya explicada en el capítulo 1.

La narrativa del despojo por megaproyectos/resistencia territorial indígena se nutre de lo sucedido y lo construido discursivamente sobre diversos episodios de disputa por recursos entre grupos con grandes asimetrías de poder en los que se 
manifestaron variados grados de violencia. Convencionalmente, al interior de esta narrativa se ha clasificado a los actores en dos sectores antagónicos. Por un lado, las sociedades "occidentales" -que se asumen europeas; mestizas o eurodescendientes en América- y por otro, los grupos denominados "indígenas", inicialmente llamados así por el primer sector y posteriormente por sí mismos, como una estrategia de reivindicación étnico-política.

En algunas variantes de la narrativa del "despojo por megaproyectos/resistencia territorial indígena" -presentes en el activismo étnico ambientalista y en algunas facciones de la academia- se asocia la identidad indígena con la naturaleza, mientras que el no indígena sería caracterizado como lejano a la naturaleza; al indígena se le asociará con lo colectivo y al no indígena con lo individual; al indígena con el origen y al no indigena con el final, acaso catastrófico, de la civilización. En síntesis, se asume al indígena como bueno y guardián de la naturaleza, y al no indígena como malo y destructor de la naturaleza. Siguiendo a Turner, esta narrativa sirve para establecer los moldes míticos apropiados para la constitución de ideologías útiles para competir por recursos durante los procesos políticos.

Aunado a lo anterior, en algunas variantes de la narrativa se asocia al capitalismo con la destrucción de la naturaleza, entonces, por definición, ser indígena -o la forma correcta de serlo- es siendo anticapitalista, lo que consecuentemente implica ser anti-Estado y anti-colonial. De este modo, las obras de infraestructura de gran calado suelen ser interpretadas como la conjugación del mal: el capital, el Estado y la colonialidad. En última instancia se considerará a estas iniciativas como proyectos de muerte, a los cuales los guardianes de la vida -los indígenas y/o activistas étnico ambientalistas- deben oponerse.

La narrativa "despojo por megaproyectos/resistencia territorial indígena", en la cual el indígena es asociado con la naturaleza y se le atribuye una esencia anticapitalista, encuentra resonancias a lo largo y ancho de América-Abya Yala y es un elemento clave en la configuración de las identidades y luchas indígenas contemporáneas de América Latina y de la sociedad global (Brysk, 2009), las cuales analíticamente deben ser entendidas como construcciones modernas por parte de actores modernos y contemporáneos que activan estratégicamente la identidad étnica 
vinculada a interpretaciones particulares del pasado, la lengua, la tradición y la naturaleza (Gledhill, 2000).

Esta narrativa se generó a finales del siglo $X X$ con incidencia clave del EZLN y el CNI, organizaciones que por una parte se presentan como herederas de los movimientos sociales indígenas previos $y$, por otra parte, son reconocidos como fuente de inspiración y fortaleza moral para muchos movimientos sociales basados en las identidades étnicas no occidentales y campesinas en el continente y el mundo. Igualmente, han sido actores clave en la conformación de nichos académicos más o menos actuales como la antropología comprometida y la teoría decolonial, entre otras. Asimismo, fueron nutridos por corrientes de pensamiento de las décadas de 1970 y 1980 como la teología, filosofía y pedagogía de la liberación, la teoría de la dependencia, el marxismo, el maoísmo, el etnomarxismo, la Investigación Acción Participativa, etc.

Es claro entonces que la relación entre actores del activismo étnicoambientalista y la academia cuenta con un nutrido intercambio en ambas vías y diversidad de episodios en su acervo narrativo que se extiende por toda América/Abya Yala y por todo el tiempo desde la Conquista-Invasión a la fecha. Esto se presenta entonces como una comunidad paradigmática o ideológica que desde fuera de esas facciones del activismo étnico-ambientalista y la academia de izquierdas, puede interpretarse como un fundamentalismo, pero, como ya se ha esbozado, es más complejo que eso.

Como causa y efecto de esta narrativa encontramos propuestas políticas diversas a lo largo del continente, algunas endógenas, otras exógenas y apropiadas; algunas con el Estado y otras al margen, en contra o a pesar de él; unas localistas y otras panindigenistas y/o "glocales". La gran mayoría con diversos grados de alianza y asesoría de actores no indígenas, de las cuales algunas incurren en prácticas que reproducen la dominación colonial. Otras tratan de invertirlo sublimando a los indígenas, lo que puede devenir en una competencia estéril por quién puede romantizar más lo indígena y a los indígenas, acaso cargada de un racismo velado. Mientras que otras iniciativas hacen un uso estratégico y pragmático, honesto o corrupto, de los privilegios de unos y de las discriminaciones positivas de otros, para 
navegar las complejidades sociopolíticas actuales en búsqueda de la reducción de las desigualdades sociales.

La realidad social no puede ser explicada en su complejidad mediante esquemas reduccionistas como el de la narrativa en cuestión, no obstante, es cierto que muchos grandes proyectos de intervención en los territorios indígenas son exógenos y están pensados para la obtención de beneficios para fortunas y poblaciones de otras latitudes. Históricamente se ha repetido este patrón de dominación que profundiza diacrónicamente las desigualdades interétnicas y esta narrativa ha constituido un referente moral para la disputa, es por esto que ante la propuesta del Tren Maya se han activado las alertas y la significación de la memoria propias de esta narrativa. Es, por así decirlo, una especie de Cruz Parlante panindígena que ha hablado en la Península mediante voceros mayas y no mayas.

A pesar de que la narrativa del despojo por megaproyectos/resistencia territorial indígena no sirve para explicar la realidad social en su complejidad, dada su composición esquemática y su alto condicionamiento ideológico, a partir de ella, la identidad indígena ha abierto para muchos actores la posibilidad de empatizar con otros en situaciones similares de desigualdad estructural y proponer rutas de liberación, abolición o disminución de las desigualdades sociales. Incluso la plataforma de la lucha ante las desigualdades interétnicas ha abierto caminos para la reflexión y colaboración ante otro tipo de desigualdades, como las de clase, género, sexo, raciales, etc. Ha abonado a la reflexión interseccional de las desigualdades sociales. Es decir, desde esta narrativa y afines se disputa el sentido común y los valores de las sociedades donde se activan, promoviendo paulatinos cambios culturales, no exentos de contradicciones e incongruencias, como todo proceso social, por ejemplo la romantización y folklorización de lo indígena.

Asimismo, la narrativa referida ha promovido la solidaridad, la cooperación y ha potenciado la reflexión sobre los privilegios estructurales, por lo que esta narrativa no es exclusiva de los sectores subalternos de la sociedad, sino que es popular entre muchos actores privilegiados de una u otra forma por la estructura social desigual, ya sea en los sectores gubernamental, empresarial, académico, OSC, periodístico u otros convencionalmente no asociados con la subalternidad. Permitiendo incluso, desde una tónica de justicia social y/o discriminación positiva solidaria o estratégica, 
que estos sectores sociales se abran a los actores indígenas. Lo importante de esta narrativa no es pues su potencia explicativa sino su potencia organizativa.

Esta narrativa, en tanto que es producida, reproducida y apropiada por actores indígenas y no indígenas, es una variedad de narrativa intercultural que se enriquece multidireccionalmente. Resulta llamativo que algunos actores simpatizantes de esta narrativa y de los proyectos políticos consecuentes, se indigenizan para caber en el molde mítico apropiado, mediante un redescubrimiento de las raíces genealógicas y/o mediante la búsqueda de la aculturación, es decir, mediante la apropiación cultural.

Para finalizar este apartado, valga reiterar que esta narrativa no sirve para explicar la realidad en las ciencias sociales, por lo que no debe ser considerada como punto de partida o de llegada ante un fenómeno complejo como suelen ser los procesos políticos. En este sentido, la labor del antropólogo no debe ser intentar justificar o denostar esta o cualquier otra narrativa con un tono científico, sino comprenderla como un fenómeno social contingente y en transformación, se debe pues intentar comprender las particularidades de su activación y manifestación en procesos políticos concretos, como el del Proyecto Tren Maya en este caso.

Habiendo realizado las precisiones anteriores, que recuerdan características fundamentales del método del drama social, ubican históricamente y develan algunos rasgos importantes de los elementos simbólicos, narrativos y discursivos del DSPTM, se abordan a continuación los principales eventos de la primera fase del Drama Social del Proyecto Tren Maya previo a su existencia material. Se presentan las características teóricas señaladas por Turner y una sucesión de los eventos correspondientes. Cada evento es abordado a través de los principales discursos y acciones de sus protagonistas, así como las reacciones inmediatas -discursos y acciones- de otros actores sociales que forman parte del Campo Político del Proyecto Tren Maya (CPPTM).

En algunas ocasiones las reacciones a los eventos se darán de manera inmediata y realizadas explícitamente como una respuesta, por lo que se incluirán en el desarrollo del apartado correspondiente al evento. En otras ocasiones se dará respuesta a eventos anteriores en uno nuevo -protagonizado por otros actores- en el cual la respuesta puede o no ser central en el nuevo evento y no ocurrirá de manera inmediata, pudiendo manifestarse un posicionamiento sobre algún evento concreto 
con meses de distancia, incluso en otra fase del DSPTM. Esto significa que en los siguientes apartados se encontrarán eventos aparentemente sin reacción en otros sectores del CPPTM, pero que en el desarrollo de otros eventos obtendrán algún tipo de respuesta, ya sea a modo de discurso o de acción. Cuando sea el caso se señalará si los eventos pueden ser comprendidos como rituales políticos, ceremonias definicionales o si conforman arenas políticas. Igualmente, se indicará cuando algún elemento discursivo sea un símbolo dominante.

\subsection{Fase 1: Ruptura}

Como se expuso en el capítulo anterior, la primera fase de los dramas sociales es la de ruptura de las relaciones sociales regulares gobernadas por normas. Está indicada por la infracción -deliberada, espontánea o no intencional- de una ley, una regla, un contrato, un código de etiqueta. La ruptura puede deberse al seguimiento de otra ley, de otra regla, de otro contrato, otro código; de hecho cualquier otra regulación que modifique o altere una situación previa. Aparece en la superficie social un gesto, un "disparador" que suscita, que hace visible, que abre o posibilita la confrontación (Díaz Cruz, 2014:110).

La ruptura de las relaciones sociales regulares se da al cambiar el partido en el poder como resultado de las elecciones presidenciales del 2018 culminadas el 2 de julio, que como ya se mencionó puede tomarse como un drama social inmediato anterior que incide directamente en el DSPTM y en la constitución de su campo político. Este fue un evento de relevancia histórica en la medida de que el Movimiento Regeneración Nacional (MORENA), fundado por AMLO en 2014, consiguió la hegemonía en las instancias legislativas a nivel federal y la presidencia de la república. Desbancando así a los dos partidos hegemónicos en la historia moderna del país, el Partido de la Revolución Institucional (PRI) y el Partido Acción Nacional (PAN), de los que muchos de sus miembros en cargos públicos habían sido acusados de corrupción y desvíos millonarios del erario público, lo que los condujo a elevados niveles de desaprobación popular. De este modo, la victoria presidencial de AMLO, la cual sostiene le había sido robada en las dos elecciones presidenciales previas, significó para muchos mexicanos -al menos el $53.1936 \%$ que votó por él ${ }^{85}$ - la oportunidad de hacer política y ejercer cargos públicos de otro modo, acaso mejor. 
Aunado a lo anterior, AMLO ha sido promotor de otros acuerdos nacionales que contrastan con los de las administraciones anteriores. Uno de ellos es atender prioritariamente a los estados del Sur-Sureste del país para nivelar el desequilibrio en su desarrollo con respecto a los estados del Centro y Norte. Por este motivo se encuentran en el Plan Nacional de Desarrollo 2019-2024 Proyectos Prioritarios como el Proyecto Tren Maya en la Península de Yucatán, el Corredor Multimodal Interoceánico en el Istmo de Tehuantepec y la Refinería en Dos Bocas, Tabasco.

En este contexto, ocurrieron dos eventos vinculados directamente con el PTM que pueden considerarse en conjunto como constitutivos de la Fase 1 del Drama Social del Proyecto Tren Maya. El primero de ellos es el anuncio de Rogelio Jiménez Pons como titular de Fonatur y encargado del PTM; y segundo es el anuncio de la consulta nacional ciudadana sobre los 10 Programas Prioritarios. A continuación se analizan las acciones y discursos de los actores protagonistas de estos eventos, así como las reacciones suscitadas en el campo político del naciente drama social del Proyecto Tren Maya.

\subsubsection{El presidente electo AMLO anuncia a RJP como titular de FONATUR y a esta instancia como la encargada del PTM}

Imagen 7. Nombramiento de Rogelio Jiménez Pons como Titular de FONATUR ${ }^{86}$

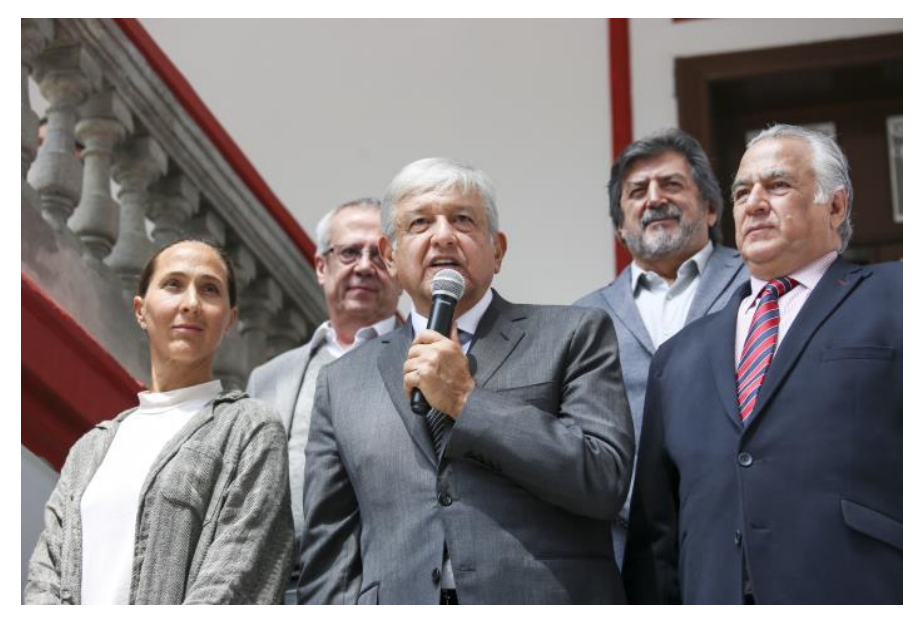

El 13 de agosto del 2018 el presidente electo Andrés Manuel López Obrador anunció en conferencia de prensa a Rogelio Jiménez Pons como titular del Fondo nacional de Fomento al Turismo ${ }^{87}$ y a Gabriela Cámara como titular del Consejo de Promoción Turística de México (CPTM). Estuvieron presentes también los entonces futuros secretarios de Turismo, Miguel Torruco, y de Hacienda, Carlos Urzúa. De igual 
manera, AMLO comentó que FONATUR sería la instancia encargada del Proyecto Tren Maya, del cual señaló que se realizaría con inversión pública y privada y conectaría los cinco estados del Sur-Sureste ya referidos.

Ante los comentarios emitidos en esta conferencia de prensa no hubo mayores reacciones de otros actores que conformarían el campo político del PTM. Esto puede deberse a que aún se estaba en el despliegue de acciones confirmatorias de la victoria electoral de AMLO y de su gabinete y los demás actores estaban a la expectativa de los giros actitudinales y discursivos del ex candidato convertido en presidente electo, lo que incluye las prioridades en la agenda. Iniciaba apenas el periodo de reajuste del panorama político nacional. Este evento puede interpretarse como un ritual político, pues se invistió oportuna y públicamente a Rogelio Jiménez Pons como titular de FONATUR y responsable del Tren Maya, produciendo así efectos concatenados en la estructura de poder.

\subsubsection{Anuncio de la Consulta Nacional sobre los Programas Prioritarios ${ }^{88}$}

Ahora bien, el "disparador" que abrió paso a la confrontación ocurrió el 12 de noviembre cuando AMLO anunció la Consulta Nacional sobre los Programas Prioritarios $^{89}$. Posterior a una reunión de trabajo en Mérida, Yucatán con gobernadores en funciones y electos de las entidades involucradas en la construcción del Tren Maya, comentó a la prensa:

"Informo a ustedes que los días 24 y 25 de este mes vamos a llevar a cabo una amplia consulta ciudadana para preguntarle a los mexicanos, no sólo a los habitantes del sureste, sino a todos los mexicanos, su opinión sobre este proyecto del Tren Maya. Vamos a aprovechar para preguntar acerca de la construcción de la nueva refinería [Dos Bocas, Tabasco], y sobre el proyecto del Istmo de Tehuantepec. Vamos a aprovechar para preguntarle a la gente si está de acuerdo en el apoyo a los adultos mayores, a las personas con discapacidad, si están de acuerdo en que se convierta en un derecho el recibir una beca si se estudia en la preparatoria, es decir, todos los programas sociales, vamos a preguntar sobre 10 programas".

Esta acción tuvo reacciones en la sociedad mexicana que pueden interpretarse como el inicio de la configuración del Campo Político del Proyecto Tren Maya (CPPTM), en 
el sentido de que empezaron los pronunciamientos en contra del PTM en específico, justo en el momento en que dejaba de ser sólo una promesa de campaña. Entre los pronunciamientos en contra de mayor relevancia tenemos dos casos, uno protagonizado por el sector académico con simpatizantes del medio artístico y del sector OSC; y otro protagonizado por el sector del activismo étnico ambientalista con actores del sector OSC. Ambos pronunciamientos fueron mediante respectivas cartas dirigidas al presidente electo y a la opinión pública.

Con respecto a la reacción del sector académico tenemos una carta con fecha del 15 de noviembre ${ }^{90}$, firmada por una centena de científicos, artistas, miembros de OSCs, etc. del país, por convocatoria del Taller por la Defensa de los Territorios de la Dirección de Etnología y Antropología Social del Instituto Nacional de Antropología e Historia (DEAS-INAH) ${ }^{91}$ y la investigadora independiente Cristina Barros.

En esta carta, los firmantes instaron a AMLO a no realizar la consulta sobre el PTM y el proyecto en el Istmo de Tehuantepec y menos iniciar las obras. También ofrecieron al presidente electo sus conocimientos y trabajo para lograr la justicia social y un desarrollo armónico con la naturaleza, señalando que creen tanto en la necesidad de resolver los problemas sociales y económicos que afectan al país como en que el verdadero desarrollo y el progreso no pueden derivar de la destrucción de la naturaleza ni del atropello al respeto elemental de los derechos de los pueblos.

Los principales argumentos que presentaron para no llevar a cabo la consulta y no iniciar las obras de los referidos proyectos son: 1) priorizar el cuidado de la biodiversidad y del agua; 2 ) no se deben realizar proyectos de este tipo sin las previas evaluaciones de impacto ambiental, social y arqueológico, las cuales no deben ser "a modo" como en las administraciones de los últimos 30 años; 3) no se deben realizar este tipo de proyectos sin una Consulta Indígena previa, libre informada, culturalmente adecuada y de buena fe, como indica el Convenio 169 de la Organización Internacional del Trabajo (OIT), la cual no puede ser sustituida por una Consulta Nacional o ejercicios similares; 4) el colapso de la civilización maya pudo deberse a la sobreexplotación del entorno natural, sería imperdonable no aprender de la historia y cometer los mismos errores, cuyas consecuencias podrían ser tan o más graves que en el pasado ${ }^{92}$. 
Ante esta carta hubo reacción de AMLO. En entrevista en el programa radiofónico de Carmen Aristegui ${ }^{93}$, con fecha del 19 de noviembre, entre otros temas, se abordó el de la carta y el amplio y diverso grupo de personas al que caracterizaría como los "abajo firmantes". En síntesis, vale recuperar de la entrevista los siguientes datos: 1) AMLO comentó que los “abajo firmantes” no tienen información sobre el proyecto y posiblemente muchos de ellos no conozcan la región de impacto del PTM y sólo hayan firmado por petición de conocidos; 2) Ofreció información que opina haría ver el proyecto desde otra perspectiva, que en la mitad del tramo hay vía de ferrocarril de propiedad pública, que en la mayoría del trazo se cuenta con los derechos de vía y que no se deforestaría sino que al contrario se sembrarían hectáreas de árboles maderables y frutales con el programa Sembrando Vida; 3) Se da la primera equiparación por parte de AMLO de los términos "abajo firmantes", "críticos" y "conservadores".

A continuación transcribo partes de la entrevista para ampliar los puntos señalados. El presidente electo dijo que quienes elaboraron la carta "no tienen información", argumentando que:

"a lo mejor hay algunos de ellos que ni siquiera conocen el sureste (...) a lo mejor no tienen la información, de que el Tren Maya significa un recorrido de mil 500 kilómetros, mil 500 kilómetros y la mitad ya está la vía (...) Es una vía de ferrocarril que se inició desde antes, desde el gobierno del general Lázaro Cárdenas, se inició la construcción del ferrocarril del sureste y se terminó con Miguel Alemán, en efecto... entonces de Palenque a Escárcega, de Escárcega a Campeche, de Campeche a Mérida, de Mérida a Valladolid,. estamos hablando de 750, 800 kilómetros, ya existe el tren, pero desde hace... (...) Cuando yo me enteré de que esa vía del tren era pública, fui muy feliz, pero muy feliz (...) Vamos a seguir a la segunda parte, eso va a ayudar mucho a aclarar: de Valladolid a Cancún el tren va, el trazo del tren va por la Autopista Mérida-Cancún, bueno; de Cancún a Playa del Carmen, a Tulum, el tren va por las líneas de la Comisión Federal de Electricidad, por las líneas grandes que se van a convertir en líneas subterráneas en algunas partes. Hacia adelante va por la carretera, que ya está hecha, te estoy hablando de Tulum (...) A Bacalar, sí, Bacalar, pero a Xpujil, es donde está la entrada, la entrada a 
Calakmul, o sea no va el tren a pasar por la reserva de Calakmul (...) No va a pasar, pasa por la carretera (...) Que ya está hecha desde hace 50 años"

Adicionalmente, Aristegui señaló que "hay quien dice que ese proyecto lo que va promover también es la explotación masiva de los recursos naturales del sureste, precisamente con la asociación de la palabra devastación”, a lo que AMLO respondió:

"Sí, eso no tiene ningún sentido, al contrario, en todo el sureste se van a sembrar ya desde diciembre, va iniciar el programa para sembrar, sólo en el sureste 500 mil hectáreas, 200 mil empleos, ¿sabes dónde se van a sembrar las 500 mil hectáreas? En ejidos que han estado abandonados, en pequeñas propiedades, en comunidades donde vive la gente más humilde (...) La gente más pobre, sí. Lo que queremos es que ya no siga la migración para que no se pierdan valores, para que no se pierdan...culturas (...) o sea, por eso te digo: los abajo firmantes, con todo mi respeto (...) ¿Sabes cuál es la mecánica para elaborar esos documentos? (...) Hay cien ó 200 ó 300 que firman, pero lo hacen cinco (...) por cierto son como clubes, existen, ¿no? Entonces: "Oye, estarías dispuesto, porque es gravísimo lo que está queriendo hacer Andrés Manuel, va a afectar el medio ambiente en el sureste, va a afectar las reservas ecológicas, va a construir el tren y todas esas cosas" "Claro que firmo" (...) Pero no tienen la información completa. Entonces, qué bien que todo eso se está analizando, pero además otra cosa, Carmen, que hay aquí también en el fondo... (...) ¿Sabes qué? Ya también es el tiempo y hay que avisarles a algunos,"Ya cambió el país, ya también cuentan los ciudadanos, los de abajo, no nada más elites. Porque un error que se comete es que lo importante es lo que opinan los de arriba, la llamada sociedad política, la llamada sociedad civil y ¿qué pasa con el pueblo, qué acaso el pueblo no tiene información? ¿Qué acaso el pueblo no sabe lo que quiere? Entonces cuidado con eso, o sea, el cambio significa también tomar en cuenta a los de abajo (...) Con información”.

Aristegui señaló que el término "abajo firmantes" puede resultar peyorativo, a lo que AMLO respondió pidiendo disculpas si fue mal interpretado, asegurando que no lo volvería a utilizar. Posteriormente, la entrevista discurrió sobre otros temas, hasta llegar AMLO nuevamente a mencionar el término "abajo firmantes", esa vez equiparando el término a "críticos" y "conservadores": 
"Estamos comprando petróleo crudo. O sea, nunca había sucedido eso en la historia. Entonces, dónde están, ya no voy a decir abajo firmantes, ¿dónde están los críticos que apoyaron la reforma energética, ahora que hay elementos suficientes, datos, que esto no es ...(...) De ocurrencias o subjetivo, sino datos para demostrar que fue un rotundo fracaso la reforma energética. ¿Cuándo en la prensa conservadora se ha hecho un análisis y una autocrítica...(...) a la política que ellos apoyaron? Bueno, entonces regresamos, no hay control...".

Antes del último tema de la entrevista surgido de una digresión no relacionada con el Tren Maya, Aristegui le pidió cerrar con un mensaje:

"AMLO: Creo que, que fuimos al fondo, a la sustancia, que no nos anduvimos por las ramas, que hablamos con claridad. Que me da mucho gusto estar aquí contigo, que nos vamos a seguir encontrando, vamos a seguir platicando, conversando; que yo estoy dispuesto ¿no? a defender mis argumentos y a respetar los argumentos de otros.

CA: Les dices a los abajo firmantes, porque están reclamando varios.

AMLO: Ya no les quiero llamar abajo firmantes.

CA: Cristina Barros mandó un mensaje.

AMLO: Sí.

CA: ¿Qué le dirías a Cristina y a los que se sintieron ofendidos?

AMLO: Que los quiero mucho.

CA: No, pero no es suficiente.

AMLO: y que los respeto y que se bate y que...

CA: ...y que los vas a escuchar.

AMLO: Y que sí los voy a escuchar.

CA: Y que vamos a discutir el Tren Maya. 
AMLO: Y qué claro, claro sí. Son mensajes de ida y vuelta... y que ellos tienen toda la libertad"

Hasta este momento del drama social podemos ver cómo empiezan a perfilarse los actores en el naciente Campo Político del Proyecto Tren Maya. Por una parte, el sector gubernamental va ordenando el aparato institucional para la ejecución del proyecto, principalmente por la declaración de priorizar y cumplir la promesa de campaña y nombrar a RJP como responsable general del PTM. Por otra parte, se nota el primer disenso público relacionado al PTM protagonizado por un conjunto de actores del sector académico como reacción al anuncio de la Consulta Nacional. Esto último es considerado el "disparador" del drama social.

Ahora bien, el resultado de este primer desencuentro fue que la petición de no realizar la consulta nacional fue desoída por el presidente electo, además de la creación de la etiqueta de "abajo firmantes" para referirse inicialmente a actores del sector académico, que sería intercambiable por las etiquetas de "críticos" y "conservadores".

De esto último es posible inferir un mensaje implícito que detona la conformación de bandos. Desde el sector gubernamental, como principal promotor del proyecto, se sugiere que los demás actores podrán estar a favor o en contra del PTM, siendo que al estar a favor se aceptan sin miramientos los argumentos desde el sector promovente; mientras que el ser crítico de esos argumentos significa estar en contra. Del mismo modo, se propone que aceptar el PTM implica aceptar la Cuarta Transformación, por lo que rechazar el PTM significa rechazar la transformación del país, lo que por un uso retórico de la lógica formal significa ser "conservador", pues si no se quiere transformar algo es porque se quiere conservar como está. Así la crítica se equipara narrativamente a la oposición y el conservadurismo en los dramas sociales de la $4 \mathrm{~T}$ y del PTM.

Por otra parte, la segunda reacción al anuncio de la Consulta Nacional fue protagonizada por actores del sector del activismo étnico-ambientalista en colaboración con actores del sector OSC de Campeche. El 16 de noviembre, un día después del anuncio de la Consulta Nacional, se hizo pública una carta abierta ${ }^{94}$ dirigida al presidente electo, firmada por la Coordinación Unir Fuerzas para la Defensa 
del Territorio ${ }^{95}$ encabezada por el Consejo Regional Indígena y Popular de Xpujil (CRIPX).

El sentido y el tono de dicha carta difieren del ánimo colaborativo y mesurado de la carta del sector académico ya referida, el contenido apunta una detracción no negociable, como puede inferirse por las declaraciones al final: "No a una consulta nacional sobre el Tren Maya", "No a una Consulta sin haber sido planeada y organizada por los pueblos originarios de la península", "No a los Megaproyectos que solamente destruyen y nos despojan de nuestros territorios", "Por la Defensa de nuestro territorio".

Ahora bien, los principales argumentos expuestos son: 1) Rechazan la consulta y cualquiera que sea su resultado porque ninguna persona de fuera de la Península de Yucatán puede decidir lo que se puede hacer o dejar de hacer en sus territorios; 2) Pidieron a AMLO la prohibición total y absoluta de cualquier tipo de subasta, autorización, permiso de cambio de uso de suelo o licencia para el establecimiento del proyecto de servicios, sin haber obtenido primero el consentimiento de los pueblos indígenas por los que pasaría el proyecto; 3) Aseguraron que el proyecto no traería beneficios ni desarrollo regional sino sólo perjuicios, porque no está planeado para la gente común sino que es un proyecto turístico que sólo beneficiaría a los pudientes y a los extranjeros.

Igualmente hicieron una serie de demandas y declaraciones que sintetizo a continuación: 1) que en todos los proyectos en territorios indígenas se realicen consultas indígenas previas; 2) la consulta no es un fin en sí mismo, sino parte del proceso de toma de decisión en el marco del derecho a la libre determinación; 3) la consulta debe ser previa, libre, informada, culturalmente adecuada y de buena fe; 4) rechazan las simulaciones o consultas a modo para garantizar el consentimiento; 5) la MIA debe realizarla un organismo independiente de la empresa constructora con una Misión de Observación como la Oficina del Alto Comisionado de la ONU, CNDH o CIDH y con una proyección a 40 años; 6) Rechazan cualquier tipo de diagnóstico de tipo forestal o faunístico sin la participación de las comunidades indígenas; 7) Rechazan la propuesta de construir ciudades en el municipio de Calakmul, pues descompondría a las comunidades indígenas e impactaría a todo el estado de Campeche y a la Península; 8) Piden mesas de trabajo por estado y una peninsular 
para garantizar el cumplimiento de sus derechos territoriales; 9) Piden facilidades económicas y logísticas para la realización de un "Plan Regional del Buen Vivir Maya", emanado de mesas de trabajo comunitarias, estatales y regionales.

Aunque esta carta causó cierto revuelo en un sector de la prensa crítica no fue contestada por AMLO de manera directa ni pública. Sin embargo, no por falta de atención del sector gubernamental este evento no tiene importancia, de hecho es la aparición en el CPPTM del CRIPX, instancia que más adelante implementaría una serie de acciones legales en contra del PTM en la zona de Calakmul y Xpujil.

Igualmente, es relevante en tanto que se explicita por primera vez la disputa por el recurso espacio geográfico y su contenido significado por estos actores como "territorio maya de la Península de Yucatán", vinculándolo con la idea de que se vulnera su uso para la reproducción cultural y del estilo de vida en la región, puesto que consideran al PTM como un proyecto pensado para "los pudientes y extranjeros". Con esto aparece por primera vez en el drama social la narrativa del despojo por megaproyectos/resistencia territorial indígena.

También es importante destacar que proponen una alternativa a lo que pudiera denominarse "desarrollo exógeno y vertical" mediante la implementación de un "Plan Regional del Buen Vivir Maya”, emanado de mesas de trabajo comunitarias, estatales y regionales, es decir, una especie de "Buen Vivir endógeno y horizontal", que podría considerarse el opuesto lógico de lo que desde la narrativa del despojo por megaproyectos/resistencia territorial indígena es la posición gubernamental.

Hasta aquí se han expuesto las apariciones iniciales de algunos actores que conformarían el Campo Político del Proyecto Tren Maya, concretamente de los sectores gubernamental, académico, activismo étnico-ambientalista y OSC. Con los eventos abordados queda inaugurado el drama social del Proyecto Tren Maya, pues constituyen el disparador del conflicto e inician la creación de las facciones promovente y oponente del proyecto.

La facción promovente es encabezada, por supuesto, por el sector gubernamental. $Y$ la facción oponente se conformará por los actores que presenten críticas puntuales al proyecto o que lo rechacen en su totalidad. Esto es llamativo pues en el caso de la carta generada en el INAH y firmada por otros actores 
principalmente del sector académico, la intención era generar un canal de diálogo y colaboración para atender preocupaciones puntuales. Esta intención fue rechazada, dejando en claro que el proyecto no sería negociable en términos generales y que la participación ciudadana sería promovida pero con ciertos límites.

Esta negación de la crítica puede ser interpretada como un modo de posicionar el proyecto como un tema serio en la agenda política. Si se mostraba demasiada apertura en una etapa tan incipiente ante las críticas, posiblemente la potencia de la propuesta se hubiera desvanecido y se hubieran abierto las puertas a que otros actores, tal vez sin las buenas intenciones de los académicos, hubieran aprovechado para sacar ventaja política. Se trató pues de una reacción gubernamental lamentable pero quizás estratégica, no justificable pero comprensible. En términos turnerianos, los "abajofirmantes" fueron el sacrificio simbólico que realizó el sector gubernamental para decir "conmigo o en mi contra", generando la ruptura de las relaciones sociales previas.

Aunado a lo anterior, la facción oponente se inauguró por actores que intentaron negociar en sus propios términos y no en los del sector gubernamental. Es decir, fueron declarados oponentes por la facción promovente. A su vez, los actores que firmaron la carta del CRIPX pueden considerarse como opositores desde el inicio; ellos no fueron negados por la facción promovente sino que negaron a la facción promovente y su proyecto. Así pues, en términos de conformación de las facciones, se dejó entrever que la única forma de incidir en el Tren Maya y en la Cuarta Transformación era sumándose a lo que desde el sector gubernamental se propusiera sin cuestionamientos. Esto explicaría quizás la criticada postura complaciente de la Dra. Paloma Escalante del INAH, tal vez fue la forma más inmediata y estratégica de lograr un espacio en la mesa de negociación.

Insisto, este posicionamiento tan tajante del sector gubernamental puede haber sido meramente estratégico, López Obrador aún debía afianzar su imagen como presidente, la de su agenda política de la Cuarta Transformación y la del Proyecto Tren Maya. Como se verá más adelante, algunos meses después FONATUR iniciaría la búsqueda de alianzas formales con instancias académicas, OSCs, empresas, etc. exigiendo, como propone Turner, lealtades incondicionales. Aunado a esto, aprovecharía el clima de control de la situación para proponer la participación 
comunitaria, en la que se darían por sobreentendidos los límites de las propuestas de la sociedad civil.

Es necesario hacer un recordatorio antes de pasar a la fase 2 del Drama Social del Proyecto Tren Maya. No hay que olvidar que un sector no puede ser representado totalmente por uno o algunos actores ni un proceso por un momento. Esto vale tanto para el sector gubernamental como el académico, el activismo étnico-ambientalista y OSC referidos en este capítulo sobre la formación de facciones en el marco de la fase 1 del drama social. Aunado a esto, el juego de significados y discursos es un flujo en el que hay cambios constantes y también se puede recurrir con fines del momento a discusiones -resignificadas- de fases previas. 


\section{Capítulo 4.}

\section{Fase 2: La crisis (parte 1)}

El objetivo de este capítulo es analizar una primera parte de los eventos que constituyen la segunda fase del Drama Social del Proyecto Tren Maya, la crisis. Es la primera parte porque se analizan eventos llevados a cabo hasta marzo del 2019 y a la fecha de escritura de este párrafo (noviembre del 2020) la fase 2 aún continúa. Al igual que en el capítulo anterior el análisis de esta fase se basa en las acciones y discursos de los actores protagonistas de los eventos, así como en las reacciones que éstos suscitaron en otros actores del campo político del PTM.

Como se señaló en el segundo capítulo de este trabajo, la fase 2 de un drama social es la crisis. Esta puede seguir a la ruptura en la medida que otras personas 0 grupos tomen partido por, o se opongan a, quien(es) haya(n) provocado la ruptura. Se crean nuevas facciones o se activan las viejas: distintos actores se comprometen con uno u otro contendiente, o son inducidos, seducidos, persuadidos, halagados o amenazados para adoptar una posición definida. Cada individuo o grupo hace acopio de recursos, recluta a sus seguidores y estigmatiza a los oponentes; se exigen obligaciones y lealtades. El clima de violencia física, verbal o simbólica se torna contagioso; los momentos cruciales, sean de peligro, suspenso, amenaza, solidaridad, sacrificio, se hacen inevitables. Se develan los patrones de las luchas faccionales entre los grupos; las contradicciones centrales de una estructura social; las ideologías y paradigmas de raíz que impulsan la acción de (y mueven a) los contendientes en ciertas direcciones y no en otras (Díaz Cruz, 2014:111). A continuación se presentan las correspondencias entre las características de la fase 2 del drama social propuestas por Turner y los eventos posteriores al anuncio de la Consulta Nacional sobre los Programas Prioritarios, evento con el que finalizó la fase 1.

En la fase anterior, la de ruptura, se da la creación de dos facciones en torno al PTM que pueden ser caracterizadas como la "facción promovente" -el sector gubernamental-, y la "facción oponente", conformada por algunos actores del sector académico y del activismo étnico-ambientalista. En esta segunda fase podemos observar a través de un seguimiento de los principales eventos, cómo otros actores y sectores se van alineando a estas dos facciones en torno al PTM, lo que conformaría 
progresivamente el Campo Político del Proyecto Tren Maya. Se pronunciarán en una u otra facción -compleja y fluida- actores pertenecientes a los sectores empresarial, los propietarios legales de la tierra, organizaciones de la sociedad civil, y actores del sector periodístico.

Igualmente, podremos notar cómo se generan las primeras disputas intrasectoriales. Por una parte, algunos actores del sector académico se posicionarán a favor y otros en contra mediante distintos mecanismos de agrupación, algunos serán invitados al serle convenientes al sector promovente, como es el caso de las instituciones académicas que firmaron convenios de colaboración con FONATUR: UAM, UNAM, IPN, UJAT, INAH y CONALEP.

Otros serán inducidos por la facción promovente o se aprovechará su posicionamiento -libre y/o estratégico- para crear un contrapeso en instituciones cuyos miembros tenderían a simpatizar con la facción oponente. Ejemplo de ello es el posicionamiento a favor del Tren Maya de la Dra. Paloma Escalante Gonzalbo, profesora-investigadora de la ENAH, opuesto a la opinión que tienen sobre el PTM otros investigadores del INAH como el Dr. Felipe Echenique March, el Dr. Javier Guerrero, el Dr. Gilberto López y Rivas, la Dra. Giovanna Gasparello, etc.

Algunos más serían convocados por el sector gubernamental para escuchar sus opiniones y propuestas, las cuales resultarían alineadas al sector promovente 0 al sector oponente, como ocurrió en dos eventos de esta fase: los Foros LegislativoAcadémicos sobre el PTM y lo acontecido en torno al informe sobre el PTM de un grupo de trabajo convocado por CONACYT ${ }^{96}$.

Por último, tenemos la aparición de proyectos, publicaciones académicas y escritos no académicos escritos por académicos de manera individual y colaboraciones en torno al PTM (ver anexo 1) ${ }^{97}$. En ellos se analiza la realidad social, cultural y ecológica a considerar en la implementación o rechazo del PTM, orientados la mayoría a lo segundo, o bien tomados como tales por otros sectores (sector promovente, grupos anti-AMLO/4T) por reflejar una postura crítica. Dichos trabajos críticos incluyen o no recomendaciones con diversos grados de viabilidad, si tomamos en cuenta la complejidad de las variables polisémicas a considerar (de índole política, económica, social, cultural, ambiental, operativa), la superposición de procesos regionales, nacionales e internacionales y los condicionamientos estructurales que 
producen y reproducen las desigualdades sociales. Cabe mencionar que la mayoría de las publicaciones sobre el PTM son posteriores a marzo del 2019, fecha de corte de este primer acercamiento al tema, por lo cual no son discutidos en este estudio.

Por otra parte, la estrategia del sector gubernamental para crear contrapeso en un sector que predeciblemente estaría en contra, como el gremio antropológico del INAH -considerando la reiterada oposición personal y gremial a los megaproyectos en territorios indígenas- se extiende a las organizaciones indígenas. En el país las hay de la más diversa índole, pues la activación política de la identidad étnica indígena como recurso inmaterial da un amplio margen de acción y generación de discursos tendientes a metas particulares y divergentes. Un ejemplo a contrapelo es la asociación civil de cuño prísta llamada Gubernatura Nacional Indígena (GNI), que intentó alinearse a la facción promovente pero fue rechazada. Los eventos en los que aparece la GNI son la ceremonia de entrega del bastón de mando, la ceremonia de permiso a la Madre Tierra en Chichén Itzá y el Foro Maya Peninsular, convocado este último por dicha A.C., y al cual asistieron representantes del sector gubernamental, incluyendo al titular de FONATUR, y "se acarreó" a comisarios ejidales de la Península, siendo esta la primera aparición del sector de los propietarios legales de las tierras.

Otros posicionamientos desde la etnicidad indígena están alineados a la facción oponente del PTM inaugurada por CRIPX y otros mediante la carta referida en la fase 1. Se trata pues de la aparición de los actores que conformarían el sector del activismo étnico-ambientalista del CPPTM, los cuales protagonizarían y reaccionarían a eventos sucedidos en esta segunda fase del DSPTM.

Entre ellos destacan a nivel nacional el Ejército Zapatista de Liberación Nacional (EZLN) y el Congreso Nacional Indígena y su Consejo Indígena de Gobierno (CNI-CIG), históricamente emanado de convocatorias del EZLN. No obstante, no hay una vinculación orgánica entre ambas organizaciones aunque hay actores individuales y colectivos que participan en las dos. También hay una diferencia fundamental entre el EZLN y el CNI, este último utiliza recursos legales como amparos para intentar detener proyectos que consideren atentan contra los derechos territoriales indígenas, mientras que el EZLN rechaza cualquier tipo de recurso legal 
y negociación con el Estado desde lo que consideran fue la traición a los Acuerdos de San Andrés Sakamch'en o Larraínzar firmados en 1996.

A nivel peninsular destacan la Asamblea de Defensores del Territorio Maya Múuch Xímbal de Yucatán, el Centro Comunitario U kúuchil k Chỉibalo'on de Quintana Roo y el Consejo Regional Indígena y Popular de Xpujil (CRIPX) de Campeche. Hay una orientación política más o menos compartida entre estas organizaciones que convergen en el CNI, siendo por extensión herederas de las narrativas, símbolos dominantes, estilos retóricos y estética particular del neozapatismo.

Estamos ante una comunidad ideológica, es decir, una comunidad de sentido con orientación política, ética, estética y narrativa, fluida y con contradicciones, pero activa y comprometida en la práctica. Con raíces -genealógicas y narrativas- en la historia de los movimientos obreros, campesinos e indígenas del país, herederos directos de la activación política de la identidad étnica indígena más influyente del siglo XX a nivel internacional, el neozapatismo. Al ser un sector definido en el campo político nacional anterior a los dramas sociales de la 4T y el PTM, es probable que se transforme en función de los mismos, pero que los trascienda.

Ahora bien, todos los actores referidos hasta ahora, alineados a las facciones promovente $\mathrm{u}$ oponente del PTM, tendieron a la estigmatización estratégica consciente o no- de sus adversarios. Por su parte, la facción promovente calificó a la facción oponente como desinformada y conservadora, incluso a los actores que se asumen y presentan a sí mismos como de izquierda radical. Mientras que desde la facción oponente se calificó a la promovente como etnocida, ecocida, racista, clasista y desinformadora. El uso de estos calificativos por ambas facciones fue elevando el clima de violencia en el CPPTM. El objetivo de dichas declaraciones -acompañadas por argumentos con diversos grados de fundamentación, veracidad y honestidad- era disputar el recurso inmaterial de la opinión pública y formar así bases sociales para sus propuestas políticas, es decir, disputaban la hegemonía en la opinión pública.

Por último, los actores del sector periodístico fungieron de diversos modos en esta fase y a lo largo del proceso -con o sin intención, representándose a sí mismos o al medio en que trabajan, con diversos grados de involucramiento con el fenómeno o actores específicos- como comunicadores hacia la sociedad en general, mediadores 
del conflicto, como respaldo propagandístico de alguna de las partes o como buscadores-creadores de contenido sensacionalista. En este trabajo no se realiza un análisis de los discursos de los periodistas y otros tipos de comunicadores como tales, pero se recurre a sus textos, fotografías y videos, como ya se ha notado, para analizar eventos concretos. Aprovecho para agradecer ampliamente a aquellos periodistas que ejercen su labor con profesionalismo y por vocación.

Hasta aquí se han expuesto de manera general las correspondencias entre las características de la fase 2 del drama social propuestas por Turner y los eventos del Drama Social del Proyecto Tren Maya. Ahora bien, el resto del capítulo trata sobre los eventos ocurridos entre noviembre del 2018 y marzo del 2019, los cuales considero la primera parte de la crisis sólo por la extensión permitida para este trabajo, pues ahora (noviembre del 2020) no se avizora el final de la fase 2. De tal modo, es posible que no se reflejen cabalmente la fase 2 del DSPTM y el CPPTM, pero se sientan las bases para un análisis más profundo en la investigación doctoral.

\subsection{Consulta Nacional sobre los Programas Prioritarios}

La Consulta Nacional sobre los 10 Programas Prioritarios del Gobierno Federal electo fue llevada a cabo del 24 al 25 de noviembre, participaron 925 mil 168 votantes y se instalaron 1,097 mesas de votación en 538 municipios del país, según datos de la Fundación Arturo Rosenblueth, responsable de su implementación ${ }^{98}$. La consulta constó de 10 preguntas a las que se podía responder sí o no, sobre programas y proyectos prioritarios de la nueva administración federal, entre las que se incluye el Tren Maya (Ver Imagen 8).

Los resultados de esta consulta reflejaron un amplio respaldo popular a los Programas Prioritarios. Por el Tren Maya se pronunciaron en favor $89.9 \%$; $6.6 \%$ en contra, y $3.6 \%$ de los votos fueron anulados. Los demás proyectos estuvieron por encima del $90 \%$ de aprobación ${ }^{99}$.

Ahora bien, este evento no estuvo exento de reacciones. Entre las principales críticas a este ejercicio se señaló que este tipo de consultas no tienen sustento legal, que no son representativas debido al bajo número de participantes y que no debe consultarse a todo el país por un proyecto localizado regionalmente y en territorio 
indígena. Igualmente se mantuvo el señalamiento, ya hecho por CRIPX, de que esta consulta no puede sustituir a la Consulta Indígena.

Imagen 8. Boleta de la Consulta Nacional sobre los 10 Programas Prioritarios ${ }^{100}$

\section{consulta 10 Programas NAAIONAL 10 Prioritarios}

\footnotetext{
EI próximo Gobierno Federal propone llevar a cabo los siguientes proyectos prioritarios.

Instrucciones: Se deberá marcar Sí en caso de estar de acuerdo, o NO en caso de estar en desacuerdo en cada uno de los proyectos.
}

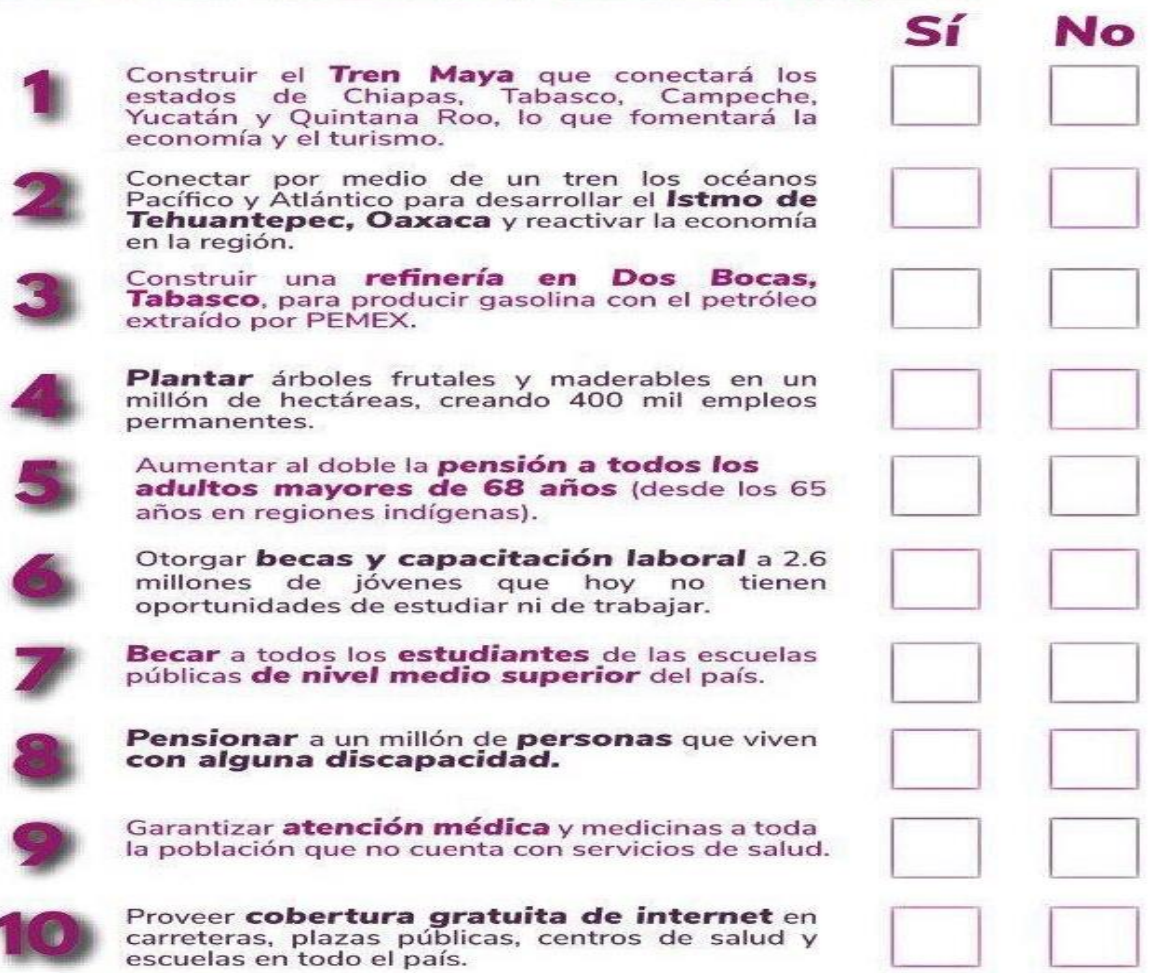

Con respecto al sector del activismo étnico-ambientalista, encontramos la crítica de Russell Pebá, miembro de Múuch Xíinbal, publicada el 8 de diciembre ${ }^{101}$ intitulada "El tren maya: Rodando entre celdas solares y aerogeneradores". En este escrito Pebá señala, como vocero de la Asamblea:

"Las actividades del Tren Maya inician el 16 de diciembre y para justificarlo se realizó una consulta nacional ( 24 y 25 de noviembre) donde se preguntó si la po-blación general estaba de acuerdo con el tren, cuando a quienes se nos debe preguntar primero es a nosotros que vivimos en estas tierras. 
(...) Desde nuestro pensamiento los mayas comprome-tidos con la defensa de nuestro territorio conside-ramos que este proyecto no nos va a dejar beneficios reales quienes habitamos en estas tierras. Sólo respon-de a intereses empresariales y compromisos de cam-paña. El circo mediático llamado consulta ciudadana ha servido para justificar el proyecto.

Defenderemos el lugar donde vivimos y que nues-tros abuelos y abuelas nos han dejado, no permitiremos que se cometan más injusticias y abusos en nuestro nombre. Rechazamos cualquier proyecto que tenga como finalidad el despojo de nuestro territorio y la des-trucción del medio ambiente.

Como parte de la asamblea de defensores del terri-torio maya Múuch' Xíinbal, levantamos la voz para recor-darle al gobierno en turno que existe una deuda históri-ca con nosotros por tantos años de abusos, discrimina-ción y políticas de exterminio en nombre del desarrollo. Hoy vemos con tristeza que los ojos del capitalismo verde están puestos en nuestros recursos naturales. Si nuestro territorio está siendo invadido por parques so-lares, parques eólicos, granjas de cerdos, plantación y comercialización de transgénicos que con sus agroquí-micos matan las abejas y contaminan el agua, suelo y aire, ahora nos anuncian que seremos los beneficiarios del Tren Maya sin claridad alguna sobre este proyecto prioritario. Por eso le decimos al gobierno de la Cuarta Transformación: No vamos a permitir más abusos con-tra nuestros pueblos".

Por otra parte, con respecto al sector empresarial, el 26 de noviembre el presidente de la Confederación Patronal de la República Mexicana (COPARMEX), Gustavo de Hoyos Walther, escribió en Twitter:

"La llamada Consulta Nacional sobre los 10 Programas Prioritarios, constituye un fraude a la Ley Federal de Consulta Popular. La \#SegundaTraición de @lopezobrador_a la verdadera democracia participativa. Que empeño en perder, tan rápido, credibilidad y confianza"102.

Cabe señalar que de Hoyos habría mostrado una actitud crítica hacia López Obrador desde la campaña electoral por la presidencia de la república, proceso en el cual se le asoció como simpatizante del candidato del PAN ${ }^{103}$. Es importante señalar que de Hoyos ha sido reelegido como presidente de COPARMEX anualmente desde el 2016 
hasta la actualidad (2020) y ha mantenido su postura crítica hacia AMLO y sus proyectos, con episodios de hostilidad y conciliación.

\subsection{Toma de protesta de la presidencia y entrega del bastón de mando de los pueblos indígenas}

Andrés Manuel López Obrador tomó protesta de la presidencia de la República el 1 de diciembre del 2018 en el Palacio Nacional. Este evento es un ritual político en el sentido turneriano, en vista de que es una dramatización transformatoria que confiere a AMLO nuevas atribuciones, poderes y responsabilidades a la vez que anuncia a la diversidad de actores el proceso de transformación iniciado en la estructura de poder. Se reiteraron la corrupción, el neoliberalismo y sus ejecutores en las administraciones previas, como símbolos de villanía transfigurados en "los conservadores" a los cuales la Cuarta Transformación y el presidente se opondrían. También se usó la figura de Benito Juárez como símbolo dominante. Este ritual fue hecho según el protocolo del Estado mexicano y estuvo dirigido a la ciudadanía, con énfasis en los funcionarios del Estado entrantes y salientes, actores político-partidistas, el sector empresarial y la opinión internacional, pues asistieron representantes de países de América, Europa, Asia y África.

Inmediatamente después, en el Zócalo de la Ciudad de México, se realizó la ceremonia de entrega del bastón de mando por parte de representantes de organizaciones indígenas, convocados por Adelfo Regino Montes, titular del ahora Instituto Nacional de los Pueblos Indígenas (INPI). Mediante este ritual político se dieron a AMLO atribuciones y responsabilidades simbólicas con respecto a los pueblos indígenas en particular y con las clases populares en general.

Con estos rituales políticos se proclaman dos cambios relevantes en la estructura de poder. El primero de ellos es la propuesta de gobernar para todos, pero priorizando a los sectores poblacionales sistemáticamente ignorados, como la población indígena. El segundo, es que se propone al Estado como la vía de participación política de y hacia los pueblos indígenas del país, lo que implica subordinar o suprimir otras vías.

A continuación abordo los aspectos relacionados con el Drama Social del Proyecto Tren Maya de ambos sucesos, considerados un sólo evento dada su 
complementariedad y sucesión inmediata. Posteriormente expongo las reacciones a este evento en el Campo Político del Proyecto Tren Maya.

Imagen 9. AMLO en la toma de protesta de la presidencia de los Estados Unidos Mexicanos

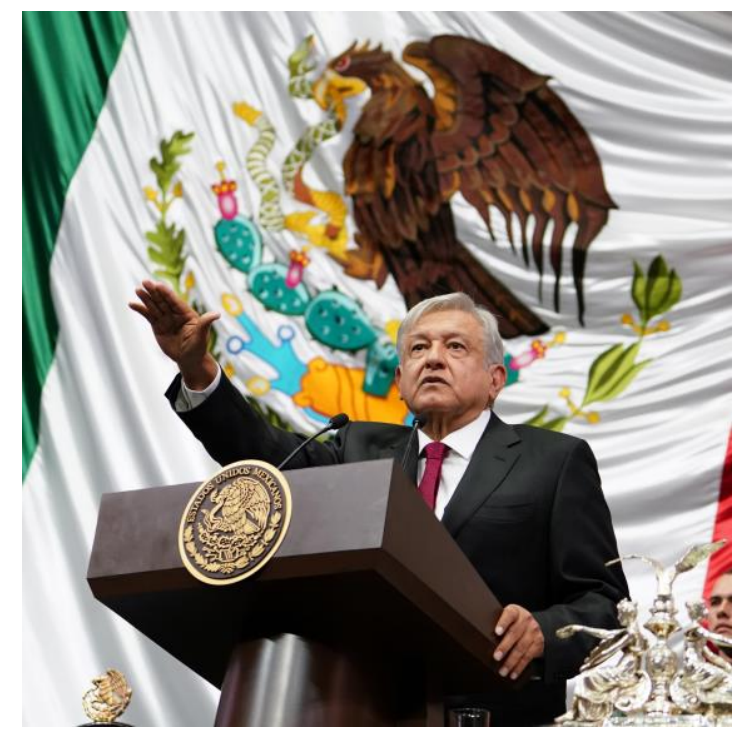

En primera instancia, hay que recordar que el DSPTM se da en el contexto de un proceso político más amplio, que puede ser comprendido como el drama social de la Cuarta Transformación (DS4T). López Obrador reitera durante su discurso ${ }^{104}$ en la toma de protesta de la presidencia algunos puntos de la narrativa de la 4T:

“(...) Si definimos en pocas palabras las tres grandes transformaciones de nuestra historia, podríamos resumir que en la Independencia se luchó por abolir la esclavitud y alcanzar la soberanía nacional, en la reforma por el predominio del poder civil y por la restauración de la República. Y en la Revolución nuestro pueblo y sus extraordinarios dirigentes lucharon por la justicia y por la democracia.

Ahora, nosotros queremos convertir la honestidad y la fraternidad en forma de vida y de gobierno. No se trata de un asunto retórico o propagandístico, estos postulados se sustentan en la convicción de que la crisis de México se originó, no solo por el fracaso del modelo económico neoliberal aplicado en los últimos 36 años, sino también por el predominio en este periodo de la más inmunda corrupción pública y privada.

(...) En cuanto a la política económica aplicada durante el periodo neoliberal, de 1983 a la fecha, ha sido la más ineficiente en la historia moderna de México. 
En este tiempo la economía ha crecido en 2 por ciento anual, y tanto por ello como por la tremenda concentración del ingreso en pocas manos, se ha empobrecido a la mayoría de la población hasta llevarla a buscarse la vida en la informalidad, a emigrar masivamente del territorio nacional o a tomar el camino de las conductas antisociales".

Hasta aquí se va perfilando en la narrativa de la 4T al neoliberalismo, la corrupción y sus ejecutores como símbolos de villanía a los cuales se opondrá la nueva administración federal. AMLO señala el modo en que procederá su administración ante estos "villanos", posicionándose en el molde mítico apropiado, como un mandatario simultáneamente benevolente y pragmático:

“(...) Pero al contrario de lo que pudiera suponerse, esta nueva etapa la vamos a iniciar sin perseguir a nadie porque no apostamos al circo ni a la simulación. Queremos regenerar, de verdad, la vida pública de México. No habría juzgados ni cárceles suficientes, y lo más delicado, lo más serio, meteríamos al país en una dinámica de fractura, conflicto y confrontación, y ello nos llevaría a consumir tiempo, energía y recursos que necesitamos para emprender la regeneración verdadera y radical de la vida pública de México, la construcción de una nueva patria, la reactivación económica y la pacificación del país".

Más adelante, introduce el tema del Tren Maya y los demás proyectos prioritarios de su administración:

“(...) Vamos a impulsar proyectos productivos con inversión pública y privada, nacional y extranjera. Estos proyectos se crearán como cortinas de desarrollo de sur a norte del país, para retener a los mexicanos en sus lugares de origen. Queremos que la migración sea optativa, no obligatoria. Vamos a lograr que los mexicanos tengan trabajo, prosperen y sean felices donde nacieron, donde están sus familiares, sus costumbres y sus culturas.

Por ello, se construirá el Tren Maya, se sembrarán un millón de hectáreas de árboles frutales y maderables en el Sur-Sureste. Se rehabilitarán, como ya lo expresé, las refinerías existentes y haremos una nueva refinería en Dos Bocas, Paraíso, Tabasco, para dejar de comprar la gasolina en el extranjero. En el Istmo de Tehuantepec se promoverá la creación de una vía férrea para un tren 
de contenedores de carga y se ampliarán los puertos de Salina Cruz y Coatzacoalcos, para comunicar en menos tiempo a los países de Asia con la costa este de Estados Unidos. En este corredor habrá energía eléctrica y gas a precios bajos, así como subsidios fiscales para la instalación de fábricas y la creación de empleos".

Después comenta -desde una lógica pretendidamente no neoliberal pero sí económica- sobre el aprovechamiento de los recursos y el papel del Estado:

“(...) México no es el cuerno de la abundancia que su silueta en el mapa pareciera evocar, pero aun así tenemos muchos recursos naturales: agua, petróleo, gas, yacimientos minerales, vientos, sol, playas, contamos con bosques y selvas, con buenas tierras para la producción agropecuaria y forestal, y somos de los países con mayor biodiversidad en el mundo.

(...) Son tres cosas las que necesitamos para enfrentar la crisis de México y dos de ellas están aseguradas de antemano. Lo reitero, un pueblo trabajador y suficientes riquezas naturales. Pronto, muy pronto, tendremos lo tercero, un buen gobierno, y en ese compromiso empeño mi honor y mi palabra".

Finaliza el discurso reiterando la figura de Benito Juárez como símbolo dominante y la intención de avanzar lo más que pueda en la Cuarta Transformación:

“(...) Por último, así como soy juarista y cardenista, también soy maderista y partidario del sufragio efectivo y de la no reelección. Trabajaré 16 horas diarias para dejar en seis años muy avanzada la obra de transformación, haré cuanto pueda para obstaculizar las regresiones en las que conservadores y corruptos estarán empeñados. Por eso aplicaremos rápido, muy rápido, los cambios políticos y sociales para que si en el futuro nuestros adversarios, que no nuestros enemigos, nos vencen, les cueste mucho trabajo dar marcha atrás a lo que ya habremos de conseguir. Como dirían los liberales del siglo XIX, los liberales mexicanos, que no sea fácil retrogradar".

Al finalizar la ceremonia de toma de protesta, el nuevo presidente de México se dirigió al Zócalo capitalino para participar en la ceremonia de entrega del bastón de mando de los pueblos indígenas y pronunciar el Primer Discurso a la Nación, en el cual 
presentó los primeros cien compromisos del Gobierno de México a cumplir durante su administración ${ }^{105}$.

La ceremonia, organizada por Adelfo Regino Montes, el nuevo titular del ahora Instituto Nacional de los Pueblos Indígenas (INPI) -antes CDI-, duró aproximadamente media hora. AMLO y Beatriz Gutiérrez Müller, su esposa, recibieron un ritual de purificación previo a la entrega del bastón de mando por parte de sacerdotes, sacerdotisas y médicos tradicionales pertenecientes a 12 grupos indígenas. No obstante, hubo representación de los 68 pueblos indígenas y el pueblo afromexicano del país, más la asistencia de un representante de los pueblos indígenas de Estados Unidos.

Imagen 10. Zócalo de la Ciudad de México el día que AMLO tomó protesta de la presidencia de la república mexicana ${ }^{106}$

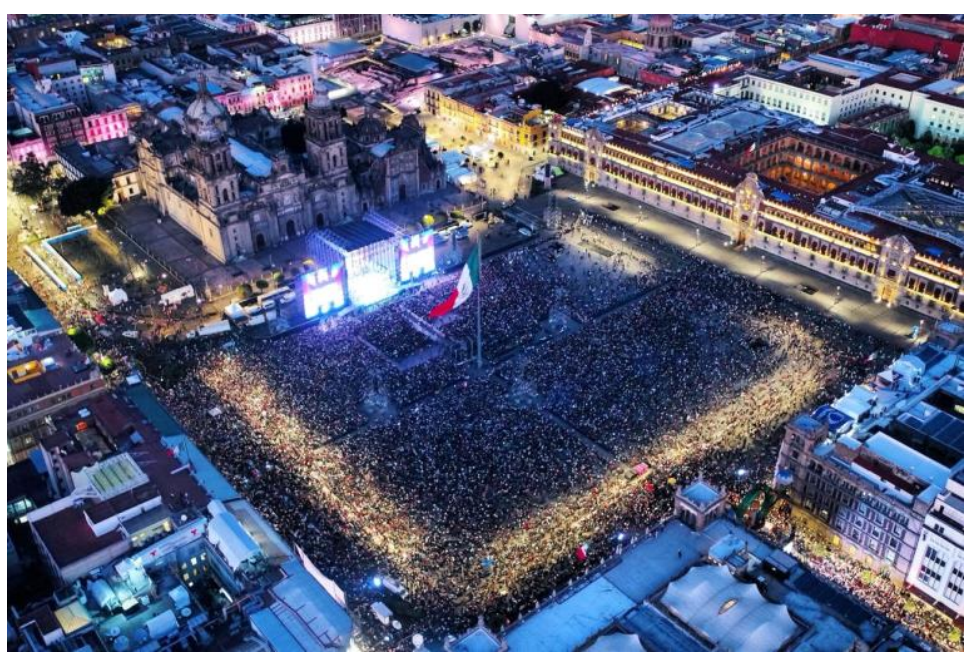

Imagen 11. Saludando a los cuatro vientos durante la ceremonia de entrega del bastón de mando

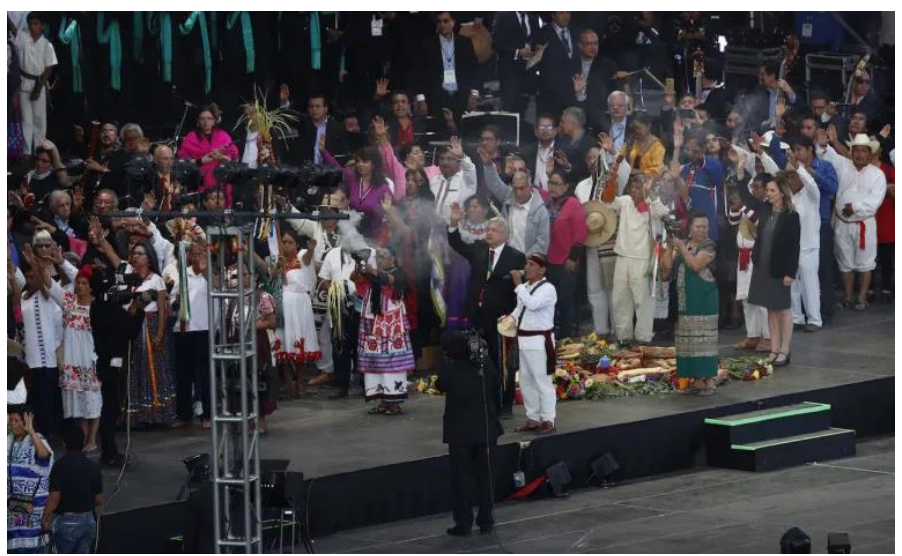

El ritual de purificación constó de varias intervenciones de los representantes de los diversos pueblos. Entre flores, copal e incienso, se sahumó a López Obrador y Beatriz 
Gutiérrez; se realizaron rezos en castellano; se les otorgaron dijes y un crucifijo de madera; un hombre se inclinó ante la pareja expresándose emotivamente en hñähñú ${ }^{107}$ y AMLO se inclinó ante él; se saludó a los cuatro rumbos. Por último, un par de activistas por los derechos de los pueblos indígenas ${ }^{108}$, Carmelina Santiago Alonso, binni zaá (zapoteca) de los valles centrales de Oaxaca, y Longino Julio Hernández Campos, mixteco de Ayutla de los Libres, Guerrero, entregaron a AMLO el bastón de mando. Dicho bastón -se afirmó en entrevista ${ }^{109}$ - representa el establecimiento de una relación de colaboración más que de subordinación, pues supone que quien lo recibe debe mandar obedeciendo. Entre las frases expresadas por los representantes indígenas durante la purificación tenemos:

Carmelina Santiago Alonso: "Queremos todo este pueblo presente aquí en esta gran plaza sagrada, y aquellos hermanos que nos ven a través de los medios de comunicación, conéctese con nosotros porque vamos a consagrar a nuestro presidente de la república, licenciado Andrés Manuel López Obrador, guardemos silencio. Él va a ser consagrado, purificado, por las manos de nuestros hermanos y hermanas de los pueblos indígenas y afromexicanos de los pueblos de México. Gracias por su respeto, gracias por su silencio, la conexión está ahora, su sabiduría viene para acá, su buen deseo viene para acá, su esperanza se va a hacer presente en este momento".

El ritual de purificación fue iniciado por dos médicos tradicionales, María de Lourdes Jiménez Viera, mixteca, y Francisco Martín, náhuatl de Veracruz

María de Lourdes Jiménez Viera: "Buenas tardes, licenciado Andrés Manuel López Obrador, presidente de México, es un honor en verdad estar hoy con ustedes. Los pueblos originarios y afromexicanos nos hacemos presentes y le pedimos respetuosamente, para que usted nos permita hacerle un ritual de purificación para que todos sus deseos, todo lo que usted dijo en todas las comunidades cuando nos visitó, en verdad nos conmovió el corazón como pueblos originarios y afromexicanos. Hoy es una realidad estar en este lugar sagrado, permítanos respetuosamente hacer este ritual de purificación. A ti corazón de la tierra, a ti corazón del agua, a ti corazón del aire, a ti corazón del fuego, le pedimos a los elementos para que liberen y purifiquen al licenciado Andrés Manuel López Obrador, presidente de México" 
Posterior a los pasos del ritual descritos en párrafos anteriores, se procedió a la entrega del bastón de mando. Entre las frases expresadas durante la entrega del bastón de mando tenemos:

Longino Hernández: "A nombre de todos los pueblos indígenas del país, y de Ayutla de los Libres, Guerrero, hacemos entrega, este bastón sagrado que será la guía de usted para gobernar a nuestro país siempre y cuando nosotros primero, los pueblos indígenas."

Carmelina Santiago Alonso: "A nombre de los pueblos indígenas y afromexicanos de México, venimos con todo respeto y con una gran responsabilidad, a depositar en sus manos, licenciado Andrés Manuel López Obrador, el bastón de mando, que como lo ha dicho el hermano, sirva para usted mandar obedeciendo al pueblo. Tenemos mucha esperanza de que México vivirá a partir de hoy una transformación, en la que los pueblos presentes en este momento, y mis hermanos indígenas de los 6 pueblos y el pueblo afromexicano, venimos a decirle, aquí está el bastón de mando, aquí está el símbolo con el que usted conducirá a nuestro pueblo, siempre y cuando, queremos recordarle, que queremos ser tomadas y tomados en cuenta en los planes que usted tenga en los planes de estos 6 años. Queremos manifestar a usted nuestro compromiso, invitamos a todos los hermanos y hermanas presentes en esta gran plaza, esta mañana, este bastón fue consagrado, a las 5 de la mañana, en el centro ceremonial (el Templo Mayor) que guarda la sabiduría de nuestros ancestros, de aquellos hombres y mujeres que llegaron a este lugar a poblar Tenochtitlán, el primer pueblo que hoy le llamamos México. Señor presidente, reciba de nuestras manos y a nombre de nuestro pueblo este símbolo que lo guiará, y recuerde, los pueblos indígenas y el pueblo afromexicano le entrega nuestra confianza y nuestro compromiso". 
Imagen 12. AMLO recibe el bastón de mando de los pueblos indígenas ${ }^{110}$

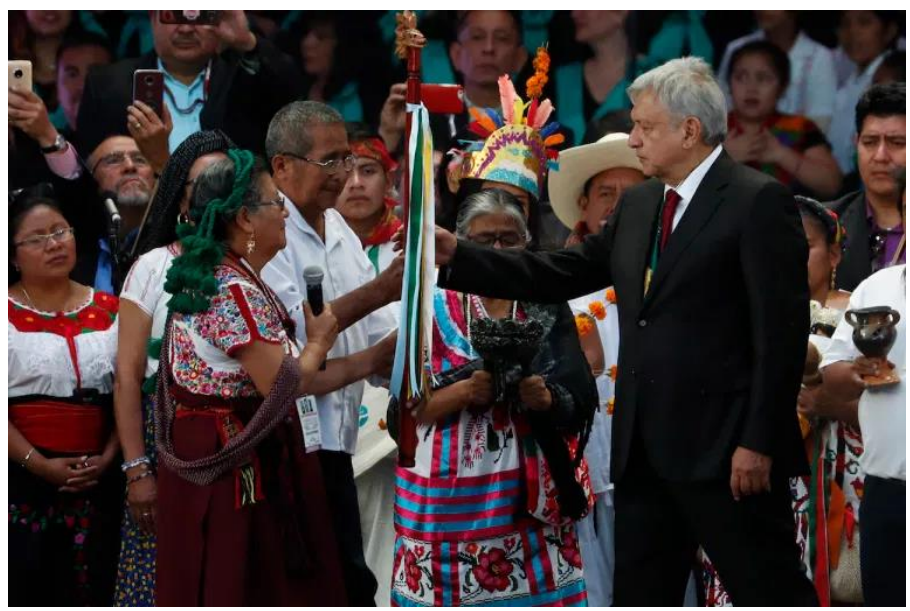

De este modo, el actual presidente se convirtió en el primero en la historia del país en recibir un bastón de mando indígena en el Zócalo capitalino el mismo día de la toma de protesta ${ }^{111}$, otorgado por representantes de los pueblos indígenas convocados por el INPI. Esto no sin polémica interna y entre facciones de grupos indígenas. Hay que destacar el conflicto suscitado con la asociación civil priísta Gubernatura Nacional Indígena (GNI), la cual días antes del evento se presentó ante los medios asegurando que sería la encargada de entregar el bastón de mando. Abordo el tema párrafos más adelante.

Imagen 13. AMLO ostentando el bastón de mando entregado por representantes de organizaciones indígenas

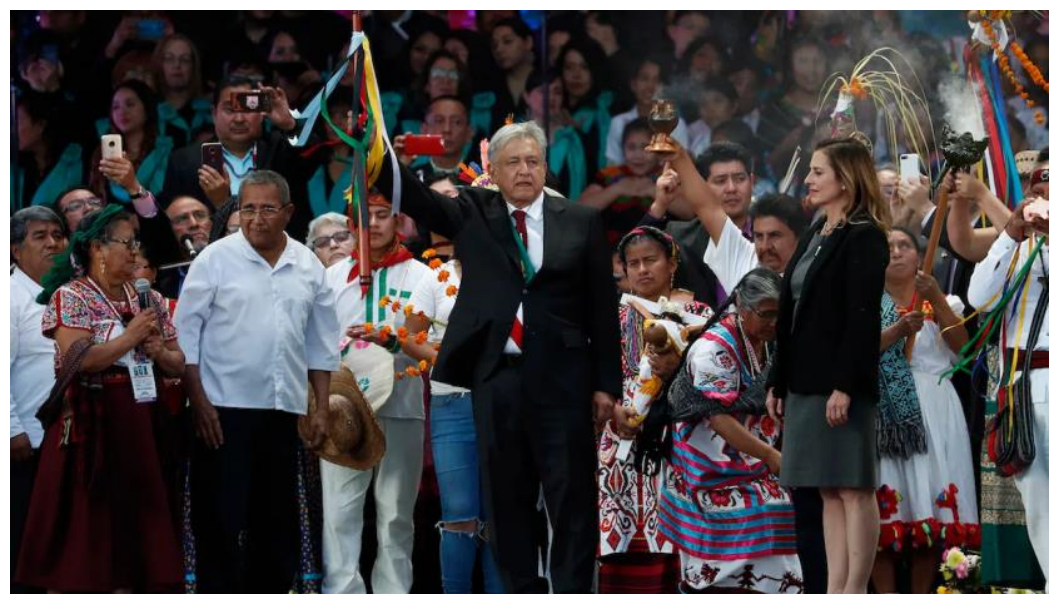

Terminada la ceremonia de entrega del bastón de mando, López Obrador dio un discurso de hora y media de duración ${ }^{112}$, portando la banda presidencial y el bastón de mando, del cual rescato fragmentos relacionados al Drama Social del Proyecto Tren Maya: 
"Hoy hablé en el Congreso sobre el antiguo régimen y de la nueva política para llevar a cabo la Cuarta Transformación de la vida pública de México; ahora quiero expresar lo que ya hemos hecho y estamos por iniciar; lo que bien podríamos llamar, una modernidad forjada desde abajo y para todos. Reafirmo nuestros compromisos, puntualmente:

1) En primer lugar, vamos a darle atención especial a los pueblos indígenas de México; es una ignominia que nuestros pueblos originarios vivan desde hace siglos bajo la opresión y el racismo, con la pobreza y la marginación a cuestas. Todos los programas del gobierno tendrán como población preferente a los pueblos indígenas de las diversas culturas del país.

(...) 51) Las compras del gobierno se harán de manera consolidada; mediante convocatoria y con observación ciudadana y de la oficina de transparencia de la ONU.

52) Los contratos de obra del gobierno se llevarán a cabo con la participación de ciudadanos y de observadores de la ONU.

(...) 67) Se fomentará el turismo para impulsar el desarrollo y crear empleos

68) Se construirá el Tren Maya para comunicar por este medio de transporte rápido y moderno a turistas y pasajeros nacionales en los estados de Chiapas, Tabasco, Campeche, Yucatán y Quintana Roo.

"También va a haber un tren de carga, se va a utilizar esa misma vía nueva para tres cosas, para un tren rápido con un desplazamiento de hasta $160 \mathrm{~km} / \mathrm{h}$ para el turismo, porque se trata de la región con más potencial turístico del país, porque es la región con más importancia arqueológica en el mundo y queremos aprovechar que nuestros antepasados nos dejaron esa herencia cultural para fomentar el turismo y que haya empleos en el sureste, que es una de las regiones más abandonadas de México. Van a llegar muchos turistas, todos los que lleguen ahora a Cancún van a poder entrar, introducirse a estados como Yucatán, Campeche, Tabasco, Chiapas, esto va a significar muchos empleos, pero también el pueblo va a tener este medio de transporte, van a haber trenes de pasajeros, con más estaciones en toda esta región porque son $1500 \mathrm{~km}$ de vías que se tienen proyectadas y se le va a dar también 
el uso para la carga para que de esta manera se trasladen las mercancías en Chiapas, Tabasco, Campeche, Yucatán y Quintana Roo"113.

69) Se creará un corredor económico y comercial en el Istmo de Tehuantepec que comunicará Asia y la costa este de EU. Se construirá una vía ferroviaria para contenedores; se ampliará la carretera; se rehabilitarán los puertos de Salina Cruz y Coatzacoalcos; se aprovecharán petróleo, gas, agua, viento y electricidad de la región; se instalarán plantas de ensamblaje y manufactureras, y habrá subsidios fiscales para promover la inversión y crear empleos.

(...) 74) Protegeremos la diversidad biológica y cultural de México. Impulsaremos prácticas agroecológicas que aumenten la productividad sin dañar a la naturaleza. No se permitirá la introducción y el uso de semillas transgénicas.

(...) 81) Se reformará el Artículo 35 de la Constitución para quitar todos los obstáculos y candados en la celebración de consultas ciudadanas, a fin de que el pueblo tenga siempre el derecho a participar en las decisiones de interés público.

(...) 100) Asimismo, vamos a preservar nuestra memoria histórica. Se promoverá la lectura en general y particularmente de la historia, el civismo, la ética; nunca se olvidará de dónde venimos; por eso se exaltarán nuestras culturas originarias, las transformaciones históricas y el sacrificio de nuestros héroes; por ejemplo, el año próximo que se cumplen 100 años del asesinato de Emiliano Zapata, en toda la papelería del gobierno se recordará su nombre y su lema "Tierra y Libertad".

(...) No dejemos de encontrarnos: mantengamos siempre la comunicación. No habrá divorcio entre pueblo y gobierno. Yo les necesito, porque como decía Juárez "con el pueblo todo, sin el pueblo nada". No me dejen solo porque sin ustedes no valgo nada o casi nada; sin ustedes, los conservadores me avasallarían fácilmente. Yo les pido apoyo, porque reitero el compromiso de no fallarles; primero muerto que traicionarles. Pero por encima de todo, actuemos con optimismo y alegría porque tenemos la dicha enorme de vivir tiempos 
interesantes; estamos ante un momento estelar de la historia porque entre todos empezamos a construir la justicia y la felicidad que nuestro pueblo se merece y una nueva vida a nuestra gran nación".

Hasta aquí se han expuesto los rituales políticos de la toma de protesta de la presidencia de la república y la entrega del bastón de mando. Con ellos se inviste y presenta a López Obrador como presidente de la república y líder moral en el combate al neoliberalismo, la corrupción, el clasismo y el racismo desde la agenda política de la Cuarta Transformación; muestran también la aprobación y respaldo de las clases populares y la población indígena. En cierto modo es en este momento donde se introducen en el campo político del Proyecto Tren Maya las polémicas sobre las desigualdades raciales y de clase. Es el momento en que se sientan las bases para las acusaciones de racismo y clasismo entre diversos actores.

Igualmente, se sugiere que la actividad política indígena debe pasar por la vía estatal, a la vez que propone transformar al Estado, llevándolo del neoliberalismo a una combinación del liberalismo mexicano decimonónico y del Estado de bienestar de la primera mitad del siglo $\mathrm{XX}$, que funcione en el contexto del capitalismo tardío globalizado. También enfatiza la atención al sur-sureste del país, mediante la activación económica con programas prioritarios entre los que se encuentran el Corredor Multimodal Interoceánico en el Istmo de Tehuantepec y el Proyecto Tren Maya. Se recurre nuevamente al símbolo dominante de Benito Juárez, al igual que a Lázaro Cárdenas y a Emiliano Zapata, siendo este último un símbolo dominante frecuentemente utilizado por la izquierda radical representada en el neozapatismo.

Ahora bien, estos rituales tuvieron reacciones en el CPPTM, particularmente la entrega del bastón de mando. Antes de comentar las reacciones es necesario abordar un conflicto previo. Días antes de la ceremonia, un grupo autodenominado Gubernatura Nacional Indígena (GNI), presidido por Hipólito Arriaga Pote, manifestó ante los medios de comunicación que GNI entregaría el bastón de mando ${ }^{114}$. Aseguró haber realizado la propuesta en la casa de transición del nuevo gobierno en CDMX y que esta había sido aprobada por el mismo AMLO. 
Imagen 14. Hipólito Arriaga Pote, presidente de Gubernatura Nacional Indígena A.C. presentando el bastón de mando no entregado a AMLO115

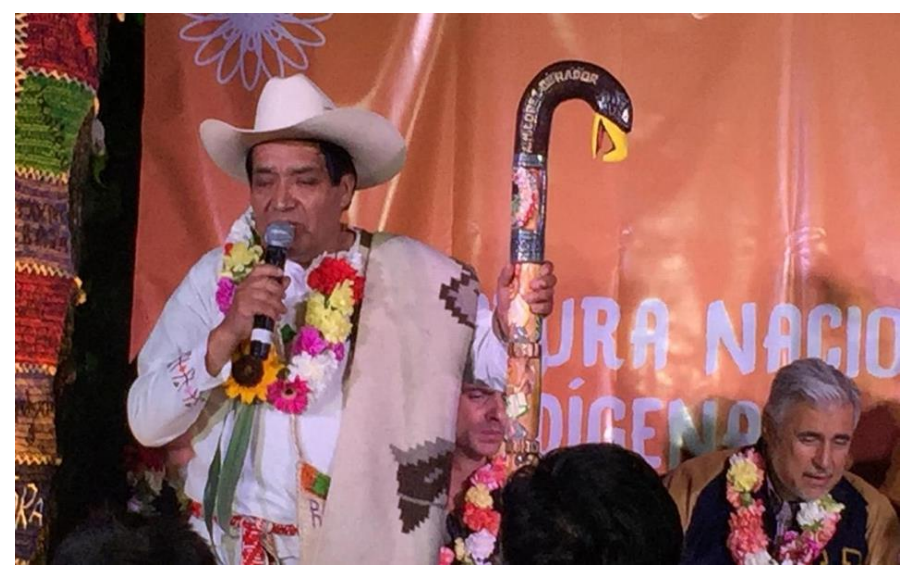

Sin embargo, el primero de diciembre fue otro grupo, convocado por Adelfo Regino nuevo titular del recién creado INPI- el que entregó el bastón de mando, a pesar de que miembros de GNI se presentaron al Zócalo con un bastón de más de un metro de largo y vestidos con trajes típicos. El equipo de transición les impidió a los miembros de GNI acercarse al escenario, dejándolos "vestidos y alborotados" y estos acusaron al gobierno entrante de discriminación ${ }^{116}$. A pesar de haber sido descartados, la GNI ha insistido en sacarle provecho a la 4T y al Tren Maya mediante Filiberto Ku Chan, el autoproclamado "líder supremo nacional indígena”.

Imagen 15. Miembros de Gubernatura Nacional Indígena tras serles negado acercarse al escenario para la entrega del bastón de mando ${ }^{117}$

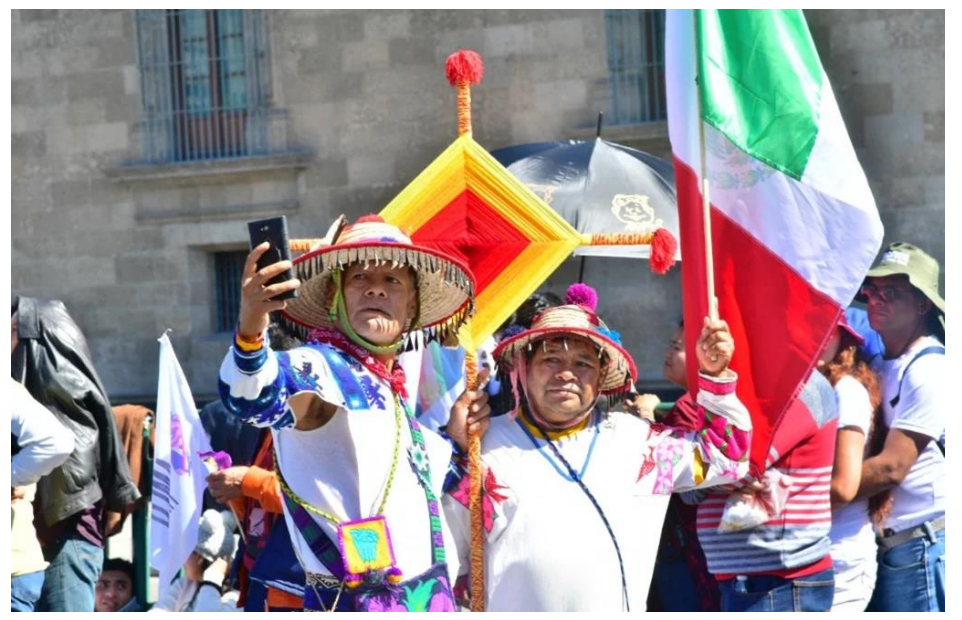

Ahora bien, ¿qué es la GNI (o GIN, como también firman)? Marcos Matías Alonso, académico del CIESAS -quien hizo una investigación sobre esta organización basándose en actas notariales ${ }^{118}$ - asegura que se trata de una organización priísta creada en 2014 para restarle votos en la elección presidencial a AMLO. Igualmente, 
afirma que el presidente de esta organización, Hipólito Arriaga Pote, es un líder del Estado de México ligado por muchos años a la Confederación Nacional Campesina $(\mathrm{CNC})$, una instancia priísta involucrada en múltiples casos de corrupción. En una entrevista ${ }^{119}$ realizada por Daniel Blancas Madrigal, publicada el 29 de noviembre del 2019 en el medio digital Crónica, Marcos Matías Alonso señala:

"GNI es un engendro creado desde el PRI, lo pensaron como una estrategia de campaña para restarle votos al movimiento de AMLO (en 2014) y no tiene ninguna representación de los pueblos indígenas (...) A gente que estaba perdida entre los pueblos indígenas, le dijeron: 'vente, serás gobernador estatal', y así han venido creciendo, pero en la mayoría de los casos son individuos, no hay colectividad ni representación fuerte en ningún estado".

Con respecto a las reacciones inmediatas ante la ceremonia de entrega del bastón de mando a AMLO, el 8 de diciembre fue degradado a soldado el líder maya José Isabel Sulub Cimá ${ }^{120}$, quien fungía como general del Centro Ceremonial de la Cruz Parlante de Felipe Carrillo Puerto y presidente del Gran Consejo Maya. El motivo fue haber asistido a la ceremonia de entrega del bastón de mando sin el consenso de los demás dignatarios mayas. Cornelio Puc Jiménez lo reemplazó como general del Centro Ceremonial de la Cruz Parlante de Felipe Carrillo Puerto y presidente del Gran Consejo Maya.

Imagen 16. José Isabel Sulub Cimá (arriba a la derecha, con sombrero) en la ceremonia de entrega del bastón de mando a AMLO

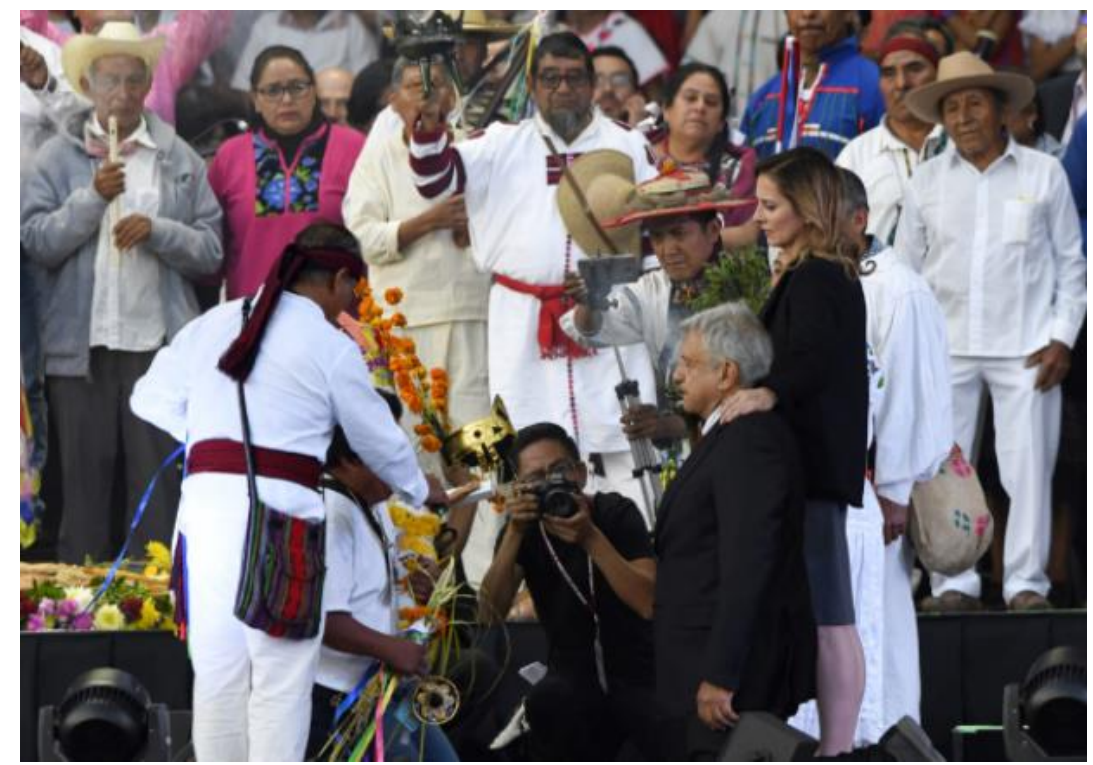


Cabe mencionar que los dignatarios mayas y los centros ceremoniales son herencia de la Guerra de Castas que inició 1847 y terminó en 1901, con la toma de lo que hoy es Felipe Carrillo Puerto, que fue fundada por los rebeldes mayas en $1850 \mathrm{con}$ el nombre de Noj Kaj Santa Cruz Balam Naj Kampokolche, en torno al culto de la Cruz Parlante. Actualmente, en torno al culto de la Cruz Parlante hay 482 dignatarios, entre generales, sacerdotes, comandantes, capitanes, tenientes, sargentos, cabos y rezadores que se encargan de cuidar cinco centros ceremoniales, ubicados en Felipe Carrillo Puerto, Tixcacal Guardia, Chancá-Veracruz, Chumpón y Tulum; así como las iglesias tradicionales de Kantunilkín, San Martiniano, X-Yaxley, X-Yatil, X-Hazil Sur, X-Pichil, Tihosuco, Sabán, Sacalaca, Señor, Tuzik, Kampokolche' Nuevo y Dzulá ${ }^{121}$.

\subsection{Ritual de los Pueblos Originarios a la Madre Tierra para anuencia del Tren Maya}

El 16 de diciembre del 2018 se llevó a cabo en la antigua pista aérea de Palenque, Chiapas, el evento denominado "Ritual de los Pueblos Originarios a la Madre Tierra para anuencia del Tren Maya"122, mediante el cual iniciaron simbólicamente las obras para la construcción del PTM. El evento fue coordinado por la Secretaría para el Desarrollo Sustentable de los Pueblos Indígenas (SEDESPI), del Gobierno de Chiapas. Asistieron representantes de los 12 Pueblos Indígenas de Chiapas. Cabe mencionar que simultáneamente se llevaron a cabo rituales de permiso a la Madre Tierra en Edzná y Becán, Campeche; Chichén Itzá, Yucatán; Tenosique, Tabasco; y en Tulum, Quintana Roo. Cada ritual fue diferente y participaron representantes de los pueblos maya, tseltal, tsotsil, ch'ol, zoque, tojolabal, mam, mochó, kaqchikel, jakalteco, chuj, q'anjobal, lacandón, tojolabal y chontal.

Entre los principales actores del sector gubernamental presentes en Palenque tenemos a AMLO, los gobernadores de Chiapas, Rutilio Escandón; de Tabasco, Arturo Núñez; de Campeche, Alejandro Moreno; de Yucatán, Mauricio Vila, de Quintana Roo, Carlos Joaquín González, así como el gobernador electo de Tabasco, Adán Augusto López Hernández, Carlos Morales Rodríguez, presidente municipal de Palenque, Miguel Torruco Marqués, Secretario de Turismo del Gobierno Federal, y Rogelio Jiménez Pons, titular de FONATUR y encargado del Proyecto Tren Maya y Emilio Ramón Ramírez Guzmán (presentado como Gutiérrez) Secretario para el desarrollo sustentable de los pueblos indígenas de Chiapas. 
Imagen 17. Actores del sector gubernamental durante el ritual de los Pueblos Originarios a la Madre Tierra para anuencia del Tren Maya ${ }^{123}$

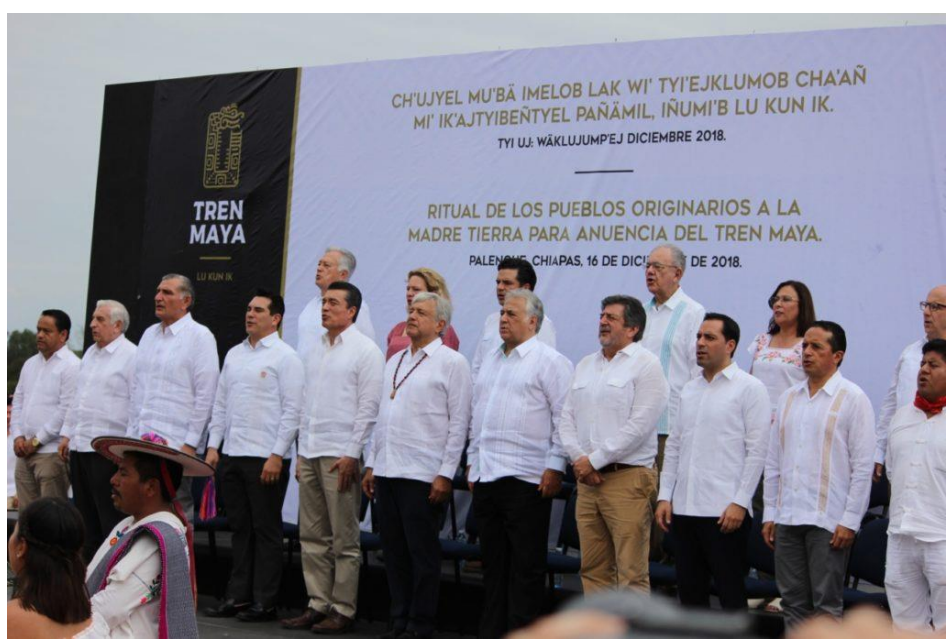

La ceremonia, de una hora de duración, estaba programada a las 10:00 am pero se retrasó media hora, porque en su camino al escenario AMLO se detuvo a saludar y conversar con el público y los realizadores del ritual. También porque Jiménez Pons le mostró a AMLO unas mamparas donde se expone el proyecto de reordenamiento territorial de Palenque, el cual contempla la creación de la estación y el nuevo centro urbano del municipio en el lugar donde se realizó este evento.

El evento tuvo el siguiente orden: 1) palabras del gobernador de Chiapas desde el escenario; 2) palabras del titular de SEDESPI (ch'ol, único indígena en el gabinete de Escandón); 3) el ritual de permiso a la Madre Tierra; 4) palabras del titular de FONATUR; 4) discurso de AMLO. A continuación presento fragmentos de los discursos y algunos datos sobre la ceremonia de permiso a la Madre Tierra.

Rutilio Escandón Cadenas, nuevo gobernador morenista de Chiapas, recurrió a figuras folclorizadas de los mayas arqueológicos y de la relación de los pueblos indígenas con la naturaleza como elementos retóricos en su discurso ${ }^{124}$; igualmente enfatizó el potencial económico y turístico del sur-sureste de México. A continuación algunos fragmentos del discurso:

“(...) La riqueza ancestral de la cultura maya es también la riqueza cultural y turística de todos. Nuestras selvas y el colorido de las aves han trascendido desde el reinado de Pakal, hasta nuestros días (...) Esta magna obra de infraestructura, como todos sabemos, es una inversión que generará fuentes 
de empleo y mayores ingresos, conectando, a la vez, a las comunidades de los pueblos originarios. Cabe aclarar y resaltar que esta rehabilitación de las vías férreas está proyectada para realizarse con estricto respeto al ecosistema y con estudios de impacto ambiental, por lo que la vida silvestre de los bosques y selvas no correrán ningún peligro. Al contrario, se protegerá el majestuoso vuelo del quetzal y la sagrada figura del jaguar para los mayas.

(...) Ya era urgente y necesario, señor presidente, que el gobierno federal volteara a ver a los estados del sur, como una región segura y fértil para invertir; para que su población alcance mayores niveles de bienestar, no solo con apoyos sociales directos, sino con empleos formales, dignos, con seguridad social y bien remunerados, lo que se traducirá en un mayor índice de desarrollo humano. El sureste, como todos sabemos, es un imán que atrae turismo e inversiones. Somos, por eso, la punta de lanza de la Cuarta Transformación de la vida pública del país".

Posteriormente, se le cedió la palabra a Emilio Ramón Ramírez Guzmán, funcionario ch'ol a cargo de la SEDESPI. El funcionario, vestido con un traje típico, leyó su discurso abajo del escenario, frente al espacio dispuesto para el ritual, con AMLO y Escandón a su derecha, y a su izquierda estuvieron los dos hombres que oficiaron la ceremonia. Su intervención difirió de la de Escandón al enfatizar la vigencia y vitalidad de las culturas mayas, las cuales han sido vistas como piezas de museo, pero que han sabido resistir al desprecio y las carencias; igualmente señaló que los pueblos mayas, en tanto mexicanos, apoyan al presidente y al Tren Maya, agradeciendo ser tomados en cuenta en tanto indígenas en la entrante administración, a diferencia de las anteriores. A continuación algunos fragmentos:

“(...) Uno de los rasgos más significativos del mundo maya sigue siendo esa devoción por la sabiduría, por la protección a la Madre Tierra; por el conocimiento y uso medicinal de más de cuatro mil 500 plantas, y porque desde el flagelo de nuestras carencias nos hemos acostumbrado a resistir. Tengan la seguridad, hermanas y hermanos, que sabremos velar por el futuro y destino de nuestros pueblos, sin restar un ápice en la construcción de esta gran nación que es México, y este hermoso estado llamado Chiapas. Hoy nos encontramos las 12 etnias de origen maya aquí presentes en esta ceremonia, en esta 
ceremonia sagrada, a quien pedimos respeto, los medios de comunicación a veces tergiversan el significado de esto.

Esta ceremonia, señor presidente, lleva un proceso, ya caminamos la combinación con lo divino y con la Madre Tierra, ofrecimos ya la luz de las velas, el olor a incienso, la comida que vamos a ofrecer a la Madre Tierra porque nosotros, como hermanos y hermanas indígenas, nuestros usos y costumbres, tenemos que pedir permiso a la tierra, porque de ella comemos y en ella caminamos. Por tal razón, nosotros vamos a ofrecer este alimento que está aquí, a la vista, con aguardiente, con el pozol de cacao, con la tortilla, con lo que comemos los campesinos de esta región. Nosotros comemos lo que hay y lo que está aquí presente.

Al olor del incienso, con el aguardiente y al son de la música, aquí nuestros rezadores pedirán este permiso para la construcción, para la modernización de nuestra región. Es algo histórico, es algo histórico en nuestra tierra, en nuestra nación, con usted, señor presidente, que nos está tomando en cuenta.

Al pueblo indígena lo han tenido en el olvido, aquellos que han pasado, aquellos que han maltratado nuestra nación, aquellos que han maltratado nuestra tierra. Somos considerados los más pequeños, pero la voz sale de nuestro corazón. Todo lo que estamos haciendo aquí, señor presidente, es porque también respaldamos su gobierno, respaldamos el gobierno de nuestro gobernador, para el bienestar de nuestros pueblos.

La construcción del Tren Maya, sea para el bien y por el bien de nuestros pueblos y hermanos indígenas. Respaldamos esta construcción, pero antes los rezadores van a pedir, van a ofrecer la comida, que es la costumbre entre todos los representantes, hasta para sembrar nuestra milpa, sembrar los frijoles; lo que da la tierra, nosotros lo ofrecemos siempre una comida y aguardiente a la tierra para que dé frutos, y el Tren Maya tiene que correr, correr para el bienestar y para el desarrollo de México.

Hoy, señor presidente Andrés Manuel López Obrador, señor gobernador Rutilio Escandón Cadenas, por mi voz habla la voz de muchos hermanos y hermanas indígenas, porque es el mismo sentimiento, el sentimiento de la justicia social, 
porque muchos nos han considerado nada más como museo. No somos museo, señor presidente. Gracias a usted nos están dando esta oportunidad. Gracias a nuestro señor gobernador Rutilio Escandón, el pueblo maya aquí está presente y no nos hemos extinguido.

Queremos recordarles que el glorioso pasado de los pueblos indígenas es también nuestro presente y que la cultura que representan es la llave para una mejor comprensión entre mexicanas y mexicanos, indígenas y no indígenas. Decirles también que no somos museos, ni mucho menos extranjeros en nuestra propia tierra. Somos mexicanos. No nos importa si nos dicen indios, indígenas, pueblos originarios, eso no nos importa; lo que nos importa es que somos de esta patria, por una patria nueva. Chiapas, de corazón, muchas gracias. Vamos a guardar silencio, por favor. Vamos a entrar a la ceremonia".

Durante la ceremonia entre el humo del copal, música y oraciones le ofrecieron a la Madre Tierra, tostadas, pozol, pollo y aguardiente. En un hoyo en la tierra, dos personas vestidas con trajes típicos, vaciaron licor y depositaron las demás ofrendas mientras rezaban en voz alta en ch'ol.

Imagen 18. Ritual de permiso a la Madre Tierra en Palenque para construcción del Tren Maya ${ }^{125}$

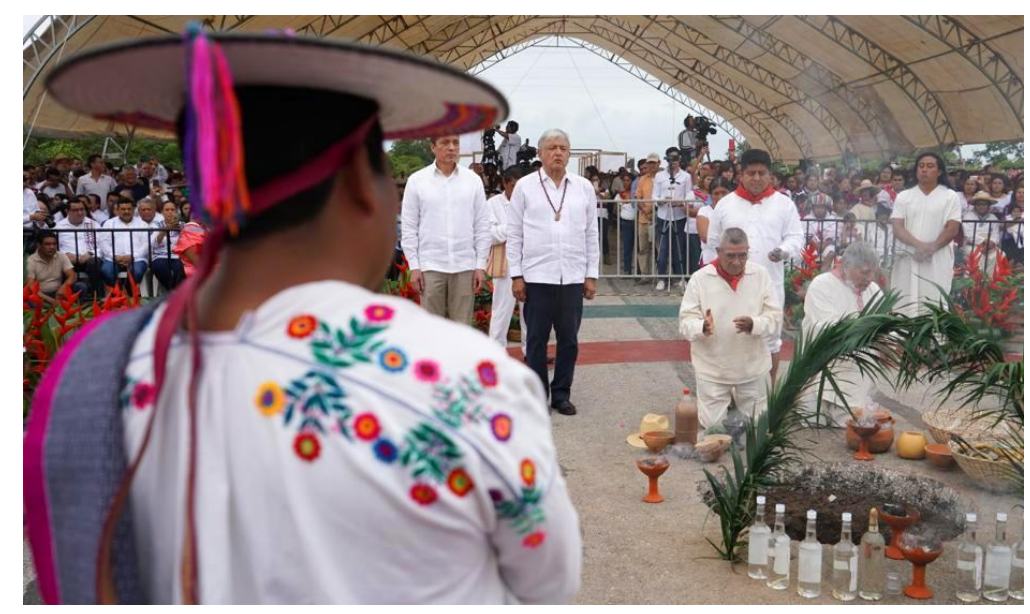

Después de la ceremonia se cedió -de improviso por petición de AMLO- la palabra al titular de FONATUR, Rogelio Jiménez Pons, quien dio un breve discurso:

“(...) Al rato que ya se termine el evento, los invitamos a que vean las láminas, pero les describo rápidamente dónde estamos. Esto va a ser la nueva Plaza Cívica de Palenque. 
(...) La característica fundamental de todos los nuevos desarrollos que emanen del Tren Maya, en términos territoriales, de ordenamiento territorial, es que van a predominar las áreas verdes. La proporción será 70 por ciento de área verde, contra un 30 por ciento de área urbanizada. Esto debe ser prevaleciente en toda la región del Tren Maya. El interés fundamental es dar el acento particular de respeto al medio ambiente y preservación del contexto, como ustedes podrán ver, verde que tenemos".

Por último, AMLO dió un discurso ${ }^{126}$ en el que abordó brevemente la historia de la comunicación entre el centro y la región sur-sureste del país durante los siglos XIX y $\mathrm{XX}$, por barco, ferrocarril y carretera; comentó sobre el potencial económico del turismo en la región; sobre los programas y proyectos prioritarios de su administración; aspectos técnicos del PTM y cómo el Tren Maya puede ser el dinamizador de una modernidad desde abajo. A continuación algunos fragmentos:

“(...) la comunicación del centro hacia el sureste era por barco. Posteriormente, se construyó el ferrocarril del sureste, antes de la carretera. Primero por barco, luego el ferrocarril del sureste. Ya existía desde la época de Porfirio Díaz el ferrocarril, del Istmo hasta Coatzacoalcos, porque Porfirio Díaz construyó 20 mil kilómetros de vías férreas. Por eso, cuando dicen ahora que no se va a poder terminar el Tren Maya, sí él hizo 20 mil kilómetros, claro, tardó 34 años en la presidencia, por qué nosotros, que vamos a estar seis años, no vamos a construir mil 500 kilómetros de tren, de vía férrea.

Después del porfiriato, luego de la revolución, se construyeron más líneas férreas y se construyó el tren del sureste. Se inició allá, por los años 30, cuando era presidente el general Lázaro Cárdenas del Río. Se empezó la construcción del ferrocarril del sureste, era secretario de Comunicaciones el general Francisco J. Múgica. Y se hizo poco a poco porque era una gran obra. Se inició con el general Cárdenas, lo continuó el general Ávila Camacho y lo inauguró el presidente Miguel Alemán, que vino aquí, a Palenque, a inaugurar el Tren del Sureste.

(...) Este es un proyecto para reactivar la economía en el sureste del país. Para tener una idea, llegan alrededor de 10 millones de turistas a Cancún, pero sólo se dedican a disfrutar de las playas del Mar Caribe y no se introducen hacia 
los estados del sureste, donde se tiene esta riqueza extraordinaria, cultural. Las zonas arqueológicas de esta región son las zonas arqueológicas más bellas del mundo. Poseemos esta gran riqueza cultural y, por eso, el proyecto tiene que ver con impulsar el turismo, que los que llegan a Cancún puedan visitar Yucatán y Campeche y Tabasco y Chiapas, para que se aproveche esa afluencia turística; que ya no estén sólo disfrutando del Mar Caribe, sino que también conozcan toda la riqueza cultural ecológica de los estados del sureste.

(...) Y es un programa, también, de reordenamiento urbano, porque por donde va a pasar el tren, en las estaciones, se va a poner orden en cuanto al desarrollo urbano, para que no haya tanto desorden, tanta anarquía. Que, así como nuestros antepasados, los antiguos mayas hicieron sus ciudades con mucha planeación, con arquitectura, con sistemas hidráulicos... la zona arqueológica de Palenque tiene un acueducto, desviaron los arroyos para que no les faltara agua. Tenían mucho conocimiento técnico-científico en muchos campos, en muchas disciplinas, ¿por qué nosotros no vamos a hacer lo mismo que en las antiguas ciudades mayas o cerca de donde florecieron las culturas indígenas?, en este caso, la cultura maya, podamos construir las nuevas ciudades. Me canso ganso.

(...) Ya estamos viendo con el arquitecto Rogelio Jiménez Pons, que es el encargado, coordinador de esta obra, es el director de Fonatur. Fonatur es una dependencia de la Secretaría de Turismo que dirige Torruco, que está aquí, con nosotros, secretario de Turismo. También su papá era chiapaneco y de aquí, de Palenque, y luego en San Cristóbal. Es el secretario de Turismo. Hablábamos, les comento, porque estamos definiendo todo el procedimiento que vamos a seguir para terminar, a más tardar en cuatro años, los mil 500 kilómetros, porque es Palenque, es Tenosique, es Escárcega, Campeche, es Mérida, es Chichen Itzá, es Cancún, es por el Caribe, Playa del Carmen, Tulum, Carrillo Puerto, Bacalar, Calakmul y otra vez Escárcega. Es todo un circuito. Entonces, se ha dividido este circuito en siete grandes tramos. Por ejemplo, un tramo es de Palenque a Escárcega, otro de Escárcega a Campeche, otro de Campeche a Mérida y otro de Mérida a Cancún, por el Golfo; y los otros tres tramos, de Cancún, pasando por Bacalar, Calakmul, de nuevo a Escárcega. Siete tramos. 
En el presupuesto que les comentaba, se entregó ayer, ya hay seis mil millones de pesos para empezar. Pero no alcanza con eso, esa es inversión pública y necesitamos hacer una mezcla de recursos, necesitamos también inversión privada. $Y$ aprovecho para convocar a empresarios a que participen en esta obra. Estamos pensando que, si se hacen cargo de un tramo, previa licitación, gana una empresa, un consorcio. Estamos hablando de que un tramo puede significar una inversión de 15 a 18 mil millones de pesos. Las vías, porque se calcula entre 50, 60 millones por kilómetro, más lo que son los trenes, el material rodante.

¿Qué vamos nosotros a hacer? Primero, garantizarles el derecho de vía, que ya se tiene en todo el tramo hasta Cancún, porque la vía llega a Valladolid y de ahí a Cancún por el Golfo, existe una concesión que tiene ICA, de la carretera de Mérida a Cancún. Tenemos ya ese derecho de vía, lo que se invierta por parte de las empresas que acepten la concesión, van estas empresas a contar con un estímulo, con una subvención del gobierno. Por cada kilómetro que construyan, un porcentaje de apoyo por parte del gobierno a las empresas, una subvención. Entonces así sí nos va a alcanzar el presupuesto público, porque no todo va a ser inversión del gobierno, la mayor parte va a ser inversión del sector privado, se le entrega la concesión y se les da un estímulo por kilómetro construido de línea férrea su apoyo.

(...) La concesión va a ser para tres tipos de trenes: tren de carga, que esto es muy importante, porque ahora se mueve mucha mercancía por camiones y cuesta mucho el transporte de carga. Cuesta más barata la transportación de carga por tren, la concesión es para eso. Dos, concesión para tren turístico, es decir, ese es el tren que se va a desplazar a más velocidad para estar pronto en los centros turísticos, en las zonas arqueológicas. $Y$ tercero, tren de pasajeros para los pueblos. La subvención va a tener, como requisito, o la contraprestación va a consistir en que el pasaje para los habitantes de toda la región sea barato.

(...) También, como contraprestación, le va a quedar a los gobiernos estatales, municipales, al gobierno federal, el manejo de las estaciones. Por ejemplo, esta estación va a estar administrada por el gobierno, para que aquí lo que se haga 
de edificios públicos pueda ser autofinanciable y que participen también los dueños de la tierra.

Ese es el planteamiento en lo general, pero no sólo es el Tren Maya. Por eso me da mucho gusto que estén aquí los pueblos originarios, la verdad más íntima de México; que no vamos nada más a estar pensando, como aquí se afirmó, que los pueblos indígenas son museos, como decía Fernando Benítez, que se respetaba, admiraba al indio muerto y se despreciaba al indio vivo. No, eso no. La modernidad nuestra es una modernidad surgida desde abajo, a partir de nuestras culturas y para todos. No es modernidad nada más para beneficio de una minoría. Todos podemos participar en el desarrollo de México. Todos tenemos derecho a una vida mejor. Se tiene derecho al bienestar, es un derecho que se debe de cumplir. Todos van a tener participación en este proyecto. Si lo analizamos bien, la construcción de estos mil 500 kilómetros va a generar muchísimos empleos, va a haber mucho trabajo.

(...) Y tiene esto un efecto multiplicador, porque es crear empleos. Ya no van a tener que irse los jóvenes a buscarse la vida a otras partes. Ya la migración va a ser optativa, no va a ser obligatoria, porque va a haber trabajo en las comunidades, va a haber trabajo en los pueblos.

(...) ¿Qué vamos a hacer ahora? Vamos a sembrar de nuevo para dejar esa riqueza a las nuevas generaciones y, en el corto plazo, poder vivir con los cultivos que requieren menos tiempo: el café, el cacao, a los tres años y hay producción, y eso va a permitir que esperen los 20 o 30 años del cedro o de la caoba para las nuevas generaciones. ¿Pero qué otra cosa ganamos con esto? Reforestamos. Cuidamos nuestro medio ambiente. Como nunca vamos a sembrar árboles en el sureste. Esto lo digo, también, porque ahora que hablamos del Tren Maya surgieron algunos que protestaron diciendo que se iba a afectar el medio ambiente. No. No se va a tirar un solo árbol. Al contrario. Vamos a sembrar millones de árboles en el sureste. Vamos a cuidar el medio ambiente. $Y$ van a haber otras acciones, porque es un programa integral.

(...) Ésta es la transformación de México. Esto es lo que significa la Cuarta Transformación de la vida pública de nuestro país. Es progreso con justicia, porque progreso sin justicia es retroceso. Es que haya crecimiento económico, 
pero que también haya bienestar. Repito, modernidad forjada desde abajo y para todos. Esto es lo que significa, paisanas y paisanos, la Cuarta Transformación de la vida pública de nuestro país (...)".

El evento finalizó con la entonación del himno nacional mexicano. Este evento es un ritual político en la medida que sirvió para mostrar en la región la nueva jerarquía en la estructura del Estado, con la participación de los gobernadores electos y al ejecutarse simultáneamente en diferentes localidades del sur-sureste. También es un ritual político porque inauguró un proyecto que pretende cambiar la realidad socioeconómica de la región. Con este ritual, más que la anuencia de la Madre Tierra, se busca la aceptación y/o reiteración del respaldo de la población indígena.

Este uso de la indigeneidad recuerda al indigenismo folklorista del Estado mexicano posrevolucionario, no obstante la afirmación del presidente de no considerar a los indígenas como piezas de museo, sino como la base de una "modernidad desde abajo". Cabe preguntarse ¿estamos ante la propuesta de un neokeynesianismo neoindigenista? ¿Es posible el Estado de bienestar en el México del capitalismo tardío en el contexto de la globalización neoliberal?

La idea de una modernidad desde abajo y centralizada estatalmente es polémica. Desde la narrativa del despojo por megaproyectos/resistencia territorial indígena esta propuesta puede parecer absurda, pues se considera que la modernidad es esencialmente occidental, capitalista y desde arriba, contra las clases de abajo y no occidentales. Algunas variedades incluso descartan las modernidades alternativas, pues toda modernidad es considerada colonialista. En cambio, promulgan las alternativas a la modernidad que sólo pueden ser de origen indígena y proletario, como el Buen Vivir.

Este ritual político mostró parte de los significados que tienen los recursos materiales e inmateriales en disputa en el DSPTM para los actores del sector gubernamental, un sector que, como otros, no es homogéneo pero tiene una jerarquía clara, lo que implica desigualdades en la diversidad de perspectivas: no tienen la misma influencia la perspectiva sobre lo maya de AMLO, Rutilio Escandón y Emilio Ramírez, aunque éste último sea el único con ascendencia mayence. 
En cuanto a los usos y significados de los recursos materiales e inmateriales, se aludió a las tierras, el reordenamiento territorial, la conservación y explotación de la naturaleza, al pasado histórico y arqueológico, a la indigeneidad y la mayanidad, a la posibilidad de una "modernidad desde abajo" centralizada por el Estado. Quedó en evidencia la polisemia del recurso inmaterial indigeneidad-mayanidad, pues fueron asociadas con lo arqueológico, con el desprecio y la resistencia, con el patrimonio cultural y el potencial económico turístico que conlleva su uso.

En síntesis, en este ritual político se explicitan los recursos en disputa en el CPPTM y sus significados, al mismo tiempo que se busca fijar significados particulares en la opinión pública a través de una dramatización emotiva, simbólicamente cargada, en un lugar simbólicamente relevante, y en transmisión audiovisual a nivel nacional e internacional vía internet.

Esta puesta en escena, con un aire celebratorio y optimista debido a la reciente toma de posesión de la presidencia, tuvo diversas recepciones en la opinión pública $y$ en los sectores del CPPTM. En el siguiente apartado se aborda un evento del sector del activismo étnico ambientalista, desde el cual se responde a este evento con otra puesta en escena con gran carga emotiva, la cual puede ser considerada como una ceremonia definicional, pues se reiteran posiciones previas del EZLN en contra de AMLO y sus propuestas. Cabe recordar el llamado del EZLN a no votar por él en las elecciones presidenciales de $2006^{127}$, como posible resultado de conflictos anteriores, entre ellos, cuando AMLO militaba en el PRD este partido fue cómplice en la traición estatal a los Acuerdos de San Andrés en $2001^{128}$.

\subsection{Aniversario del inicio de la guerra contra el olvido (EZLN)}

Del 31 de diciembre del 2018 al 1 de enero de 2019, en el caracol zapatista de La Realidad $^{129}$, se celebró el 25 aniversario del levantamiento armado del EZLN. Se conmemoró la aparición pública del movimiento del 1 de enero de 1994, cuando tomaron las cabeceras municipales de San Cristóbal de las Casas, Altamirano, Las Margaritas, Ocosingo y Oxchuc, el día que entraba en vigor el Tratado de Libre Comercio de América del Norte (TLCAN), con el cual se insertaría a los campesinos mexicanos de manera desigual, exógena y vertical en el libre mercado con los agroproductores de las potencias económicas de Estados Unidos y Canadá. 
Imagen 19. Jóvenes neozapatistas en evento artístico en la celebración del 25 aniversario ${ }^{130}$

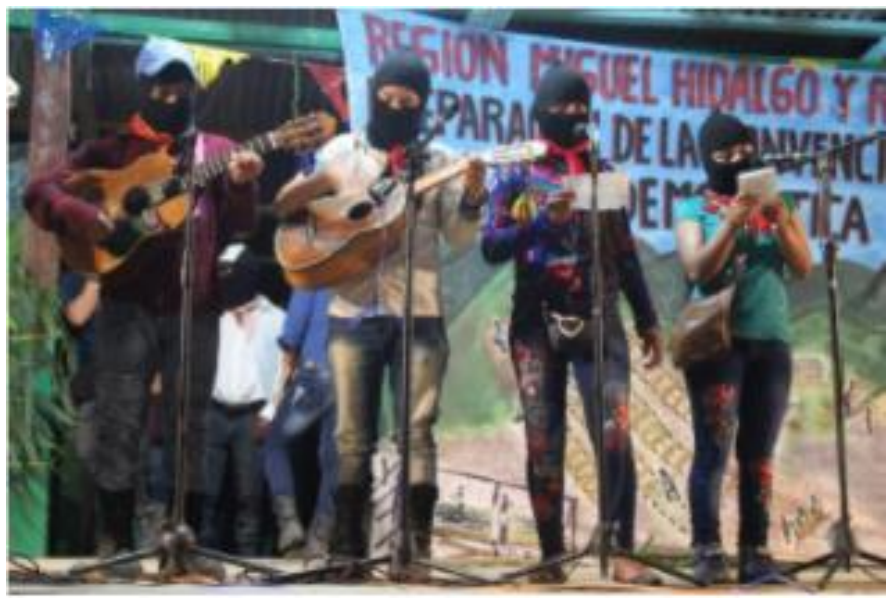

En el contexto de la celebración ${ }^{131}$, prepararon foros y conversatorios denominados "Análisis y valoración de la situación actual de sus mundos” y “¿Qué sigue?”, en los que representantes de los cinco caracoles, decidirían la agenda de los próximos años. Igualmente, hubo un amplio programa cultural con música, recitales de poesía, dramatizaciones teatrales, etc. Hubo también un desfile militar en el que soldados del EZLN Ilenaron la plaza cívica de La Realidad, ante la vista de locales y visitantes, indígenas y no indígenas.

Imagen 20. Soldados del EZLN en la plaza cívica de La Realidad durante la celebración del 25 aniversario $^{132}$

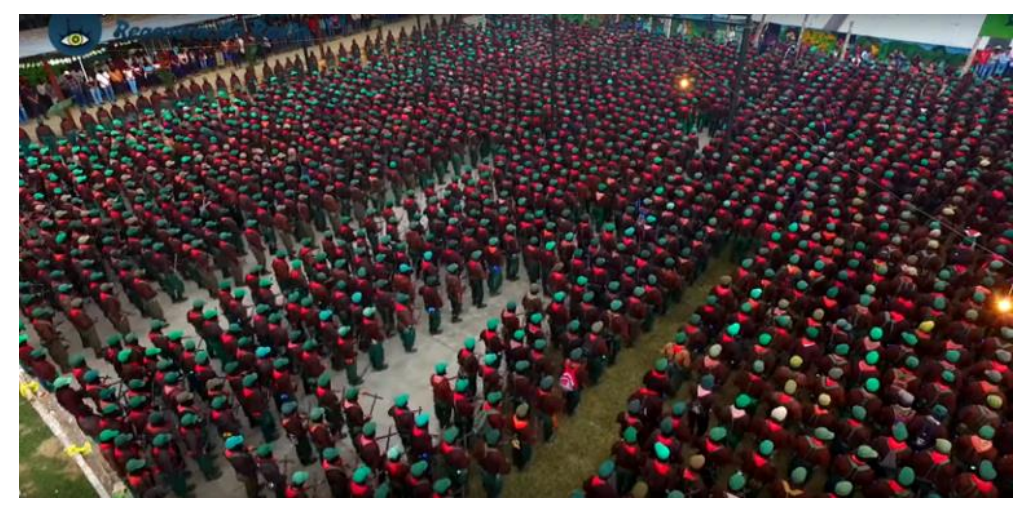

Alrededor de la medianoche, para recibir el año nuevo, en la plaza cívica se realizaron tres discursos ${ }^{133}$. El primero por parte del Subcomandante Insurgente Moisés; el segundo por la Compañera Berenice a nombre de la Junta de Buen Gobierno "Hacia la Esperanza"; el tercero por la Comandanta Everilda, por el Comité Clandestino Revolucionario Indígena, Comandancia General del EZLN. Expongo a continuación los fragmentos de los mismos relacionados con el DSPTM. 
El primer discurso fue el del Subcomandante Insurgente Moisés. En síntesis, estas fueron las ideas expuestas: 1) señala que los zapatistas están solos como hace 25 años; 2) califica a AMLO, sin mencionarlo, como mentiroso, mañoso, tramposo, loco, que no piensa por el pueblo, capataz del capitalismo que quiere destruir a los pueblos indígenas; 3) señala que se opondrán al proyecto de AMLO y defenderán lo que han construido; 4) califica como simulación el ritual de permiso a la madre tierra de AMLO para el PTM; 5) señala que los actores del sector gubernamental no saben que es la madre tierra, la pobreza, el sudor ni el sufrimiento, por lo que no saben legislar para los pueblos originarios, a diferencia del EZLN; 6) aseguró que la consulta nacional sobre el PTM sirvió para manipular a la población nacional y convencerla de que se destruya a los pueblos originarios y al EZLN; 7) desaprobó el uso del etnónimo "maya" para el PTM; 8) afirmó que AMLO está equivocado, no se puede gobernar para ricos y pobres, porque no se puede apoyar al mismo tiempo al explotador y al explotado; 9) afirmó que nadie va a luchar por los pueblos del campo y la ciudad, por lo que se necesita la organización; 10) reiteró que no le tienen miedo a AMLO, "al capitalismo, al finquero, al nuevo finquero". A continuación los principales fragmentos:

“(...) Por mi voz habla la voz del Ejército Zapatista de Liberación Nacional. Les hablo como vocero de todos ustedes, es mi trabajo ser su voz y ser su mirada. Llegó la hora para nosotros los pueblos zapatistas y lo miramos que estamos solos. Se los digo claro compañeras y compañeros bases de apoyo, compañeros y compañeras milicianos y milicianas, así lo vemos, estamos solos como hace veinticinco años.

(...) Nos quieren mentir, nos quieren engañar, empezando por que hay pueblo que cree eso que se dice la virgen Morena (cursivas propias). Es un loco el que dice eso, no sabe pensar, no piensa por el pueblo. Nosotros, compañeros, estamos trabajando con nuestra experiencia, con nuestro trabajo, y con nuestro esfuerzo y lo vamos a seguir haciendo. $Y$ lo vamos a seguir construyendo y lo vamos a ganar. Todo lo que hemos construido lo tenemos cargado nosotros, hay algunos hermanos, hermanas solidarias, algunos y algunas que nos han ayudado, pero todo el peso lo hemos cargado, nosotras, nosotros, porque no es fácil enfrentar a esos partidos políticos, a esos malos gobiernos y hoy al que está actual tramposo, mañoso. 
No es fácil enfrentar los veinticinco años aquí a miles de soldados protectores del capitalismo, y aquí están, aquí donde estamos, pasamos en sus narices estos días. No es fácil enfrentar a los paramilitares, no es fácil enfrentar a los chiquitos líderes que los tienen comprado todos los partidos políticos hoy, especialmente el que está en el poder y el partido que está en el poder. Pero no le tenemos miedo. ¿O sí le tenemos miedo, compañeras y compañeros?

[se oye al unísono "No"] No les escuché [se escucha más fuerte "No"]

(...) Compañeros, compañeras, ése que está en el poder lo va a destruir al pueblo de México pero principalmente a los pueblos originarios, viene por nosotros, y especialmente a nosotros al Ejército Zapatista de Liberación Nacional. ¿Por qué? Porque aquí estamos diciéndole claro no le tenemos miedo ¿o sí, compañeros y compañeras?

[suena fuerte "No"]

Vamos a enfrentar, no vamos a permitir que pase aquí ése su proyecto de destrucción, no le tenemos miedo a su guardia nacional que lo cambió de nombre para no decir ejército, que son los mismos, lo sabemos. Vamos a defender lo que hemos construido y que lo estamos demostrándole al pueblo de México y del mundo que somos nosotros los que estamos construyendo, mujeres y hombres, no vamos a permitir a que vengan a destruirnos ¿O sí?

[suena fuerte "No"]

Aquel que está en el poder, es mañoso, ¿y cuál es la maña que hace? Que hace de que está con el pueblo de México y engañando a los pueblos originarios y demostrando que se hinca en la tierra pidiéndole permiso como creyendo de que todos los pueblos originarios lo creen y aquí nosotros le decimos, no lo creemos eso, al contrario. ¿Cómo es eso que al contrario? Eso de que disimula que agarra nuestros modos, nuestras costumbres, que pide permiso a nuestra madre tierra; nos está diciendo, dame permiso madre tierra para destruir a los pueblos originarios, eso es lo que dice eso, le hace falta entender a esos otros hermanos pueblos originarios. Eso es lo que está haciendo ese señor, nosotros no lo creemos. Sólo porque la madre tierra no 
habla, si no se lo dijera ¡Chinga tu madre! Porque la tierra no habla, si fuera, ¡No, vete a la chingada!

Nosotros sabemos lo que es la madre tierra, tenemos quinientos veintitantos años de estar conviviendo con ella, sabemos nosotros, no aquellos que no saben ni han sentido cómo es el sudor, que se creen que lo saben, como esos babosos, babosas de los diputados y senadores, no saben ni lo que es pobreza, no saben lo que es sudor, nosotros sí. Por lo tanto no saben hacer ley para el pueblo de los pueblos originarios, nosotros sí, porque sabemos cómo es el sufrimiento y sabemos cómo queremos la ley que queremos, no a ellos y a ellas.

(...) Ahora estamos viendo que viene por nosotros, los pueblos originarios. Esa consulta que hacen, tenemos que decirlo claro, cómo manipulan al pueblo, esa consulta le está pidiéndole permiso, a través de voto, para que nos vengan a atacar a nosotros los pueblos originarios.

(...) Eso es lo que hace el nuevo gobierno que está ahora, está consultando a que nos vengan a enfrentarnos, nosotros los pueblos originarios y en especial a nosotros, al Ejército Zapatista de Liberación Nacional con ese su porquería Tren Maya y todavía ponen su nombre de nuestros anteriores. No lo aceptamos. Que le ponga su nombre, no tiene nada que ver, si quiere así como no nos preguntó, que le ponga su nombre de su mamá.

(...) la cosa que le estamos diciendo ése, el que está en el poder, fíjese cómo está de loco, dice, yo voy a gobernar para pobres y para ricos, solamente a un loco al que está mal en su cabeza eso lo puede decir, porque entonces no trabaja su mente, es descerebrado, solamente aquel lo dice eso porque nosotros sencillamente, un terrateniente, el porquería de Absalón Castellanos Domínguez, que por fin ya está en el infierno ahorita, no vamos a convencer que nos dejen de explotar, porque ese loco dice que gobierna para rico y para pobre, no sabe lo que dice, ni lo entiende lo que dice. Y estamos seguros que no lo entiende porque es dictado por su patrón, así lo tienes que decirlo a huevos, está obedeciendo, se lo estamos diciendo, para que lo sigan creyendo los ciudadanos y a las ciudadanas. Simplemente es muy sencillo, no se puede apoyar al que está explotado y al que es explotador, se tiene que escoger una 
de dos, estás con el explotador o estás con el explotado, pero de dos no se puede. Así lo vemos nosotros, y así lo entendemos nosotros y así lo estamos haciendo nosotros.

(...) No hay nadie que va a luchar por nosotros a los pueblos explotados del campo y la ciudad, nadie. Nadie va a venir, ni un hombre, ni una mujer; ni un grupo, sino que se necesita que haya mujeres y hombres que van organizándose y organizándose y organizándose, el pueblo es la que se tiene que organizarse para liberarse ¿o creen que va a venir el Papa?

(...) No le tenemos miedo al capitalismo, al finquero, al nuevo finquero ¿O sí le tenemos miedo?

[Se escucha al unísono NO].

Posteriormente, tomó la palabra la Compañera Berenice a nombre de la Junta de Buen Gobierno "Hacia La Esperanza". Las principales ideas expuestas son: 1) los indígenas son los más olvidados, marginados y explotados por el sistema capitalista neoliberal; 2) rememora los motivos del levantamiento armado de 1994, entre ellos la esclavitud de ellos y sus antepasados por parte de los finqueros; 3) afirmó que los programas y proyectos del nuevo gobierno son para acabar la organización, pero no lo lograrán porque existe la organización; 4) llamó a los pueblos del mundo a organizarse según su modo para resistir al sistema capitalista neoliberal; 5) señaló a los gobiernos como capataces del capitalismo que es el patrón que quiere convertir a los países en fincas. A continuación algunos fragmentos:

“(...) Hoy cumple ya 25 años que estamos en pie de lucha, somos los más olvidados, marginados, explotados por el sistema capitalista neoliberal. En esos años atrás, no nos veían si existimos los pueblos indígenas, pero en 1994, dijimos ¡Ya Basta! declarándonos en guerra contra el mal gobierno. Tomando cinco cabeceras municipales. Las margaritas, San Cristóbal de las Casas, Ocosingo, Altamirano y Oxchuc. Porque hace más de 500 años nuestros abuelos y abuelas no eran tomados en cuenta por el sistema capitalista, porque para ellos no valemos. Solo eran esclavos de los patrones, trabajaban mucho y no les pagaban y les maltrataban como animales, sin importar la vida de la humanidad, todos esos maltratos nuestros abuelos lo sufrieron. Ya estaban 
cansados, de tantos maltratos e injusticia y por eso decidieron organizarse, para luchar contra la explotación.

(...) Enfrentando los diferentes ataques del mal gobierno, porque nos quiere acabar y ha creado diferentes proyectos y programas para que nos confundan y no nos demos cuenta, y así acabar a nuestra organización, pero nosotros estamos organizados, no nos podrán acabar. Porque cada vez más estamos trabajando con nuestra autonomía para enfrentar al sistema capitalista neoliberal. Pero como pueblos en resistencia y en rebeldía hemos entendido que no queda otro camino: el organizarnos, desde cualquier rincón del mundo, cada organización tenemos nuestros diferentes modos y costumbres, de organizarnos, pero sí, todas y todos en contra de un mismo enemigo que es el sistema capitalista neoliberal.

(...) Este sistema a los países los quiere convertir en fincas y los gobiernos serán los capataces, y para nosotros los malos gobiernos ya no son gobiernos del pueblo, porque están al servicio de su patrón. Por eso nosotros como EZLN ya no les creemos porque son los mismos rateros y asesinos vendepatria. Les decimos que aquí estaremos con nuestra autonomía, resistencia y rebeldía en nuestro territorio zapatista.

Por último, tomó la palabra la Comandanta Everilda, en representación del Comité Clandestino Revolucionario Indígena-Comandancia General del EZLN (CCRICGEZLN). Las principales ideas expuestas son: 1) EI EZLN no permitirá proyectos capitalistas que destruyan la vida humana y de la Madre Tierra; 2) afirma que la tierra es suya porque en ella nacieron y en ella morirán; 3) señaló que no traicionarán la sangre, vida y muerte de los compañeros caídos en la lucha; 4) afirmó que a pesar de las consultas no se van a rendir; 5) señaló que desde 1492 comenzó la resistencia de "los de sangre morena, color de la madre tierra" reiterando que aquí siguen. Es destacable la presencia de los elementos de sangre, vida y muerte, propicios para generar el clímax de la ceremonia definicional. A continuación los principales fragmentos:

“(...) no permitiremos ningún proyecto que destruya la vida de la humanidad y la muerte de nuestra madre tierra, porque detrás de todo esto están los intereses de los grandes capitalistas nacionales y trasnacionales. Por más que 
intenten humillarnos con todas las fuerzas represivas, como es la guardia nacional, no descansaremos en defender nuestra madre tierra, porque en ella nacimos, porque en ella vivimos y en ella moriremos. En estas tierras de hombres y mujeres rebeldes, deben saber que no nos rendimos, no nos vendemos y no claudicamos, ni mucho menos traicionaremos la sangre, la vida y la muerte de nuestros compañeros caídos en nuestra lucha. Aunque consulten a mil millones, no nos vamos a rendir. $\mathrm{O}$ aunque le pidan permiso a su chingada madre, no nos van a doblegar. Desde 1492 a este 2018, han pasado 525 años de resistencia y rebeldía contra las grandes humillaciones extranjeras y mexicanas; nunca nos pudieron exterminar. Nosotros, los de la sangre morena, color de la madre tierra, reiteramos que aquí estamos y aquí seguiremos".

Como se podrá notar, hay muchas concordancias entre las ideas expuestas por el subcomandante insurgente Moisés, la Compañera Berenice y la Comandanta Everilda: 1) remembranza del inicio del levantamiento armado en 1994 y de los combatientes; 2) descalificación y rechazo del EZLN hacia AMLO y sus proyectos neoliberales, especialmente el PTM; 3) la narrativa del Mundo-Finca, basada en la metáfora de la organización social de la finca chiapaneca de los siglos XIX y XX (patrón, capataz, esclavo) para explicar la geopolítica neoliberal, sus desigualdades y violencias étnicas, raciales y de clase; 4) la reiteración de que se opondrán al capitalismo neoliberal y sus proyectos en el territorio indígena, sumada a la invitación a los pueblos del mundo a resistir a su modo; 5) la disputa por el significado y control de recursos inmateriales como las categorías "maya", "morena" (virgen, sangre, tierra, alusión al partido político) y "madre tierra", las cuales tienden a convertirse en símbolos dominantes.

La concordancia discursiva puede deberse -especulativamente- a que todos los discursos son resultado de reflexiones colectivas; a que pasan por un corrector de estilo; o a que la ideología -nutrida de narrativas concretas, uso de símbolos dominantes reiterados, la apropiación de una retórica particular sostenida, etc.- ha tenido un papel pedagógico exitoso al interior del movimiento y espontáneamente se generan ideas individuales coincidentes, acaso como expresión del sentipensar colectivo. 
Imagen 21. Mural en el caracol de La Realidad: Sobre las narrativas contrapuestas ${ }^{134}$

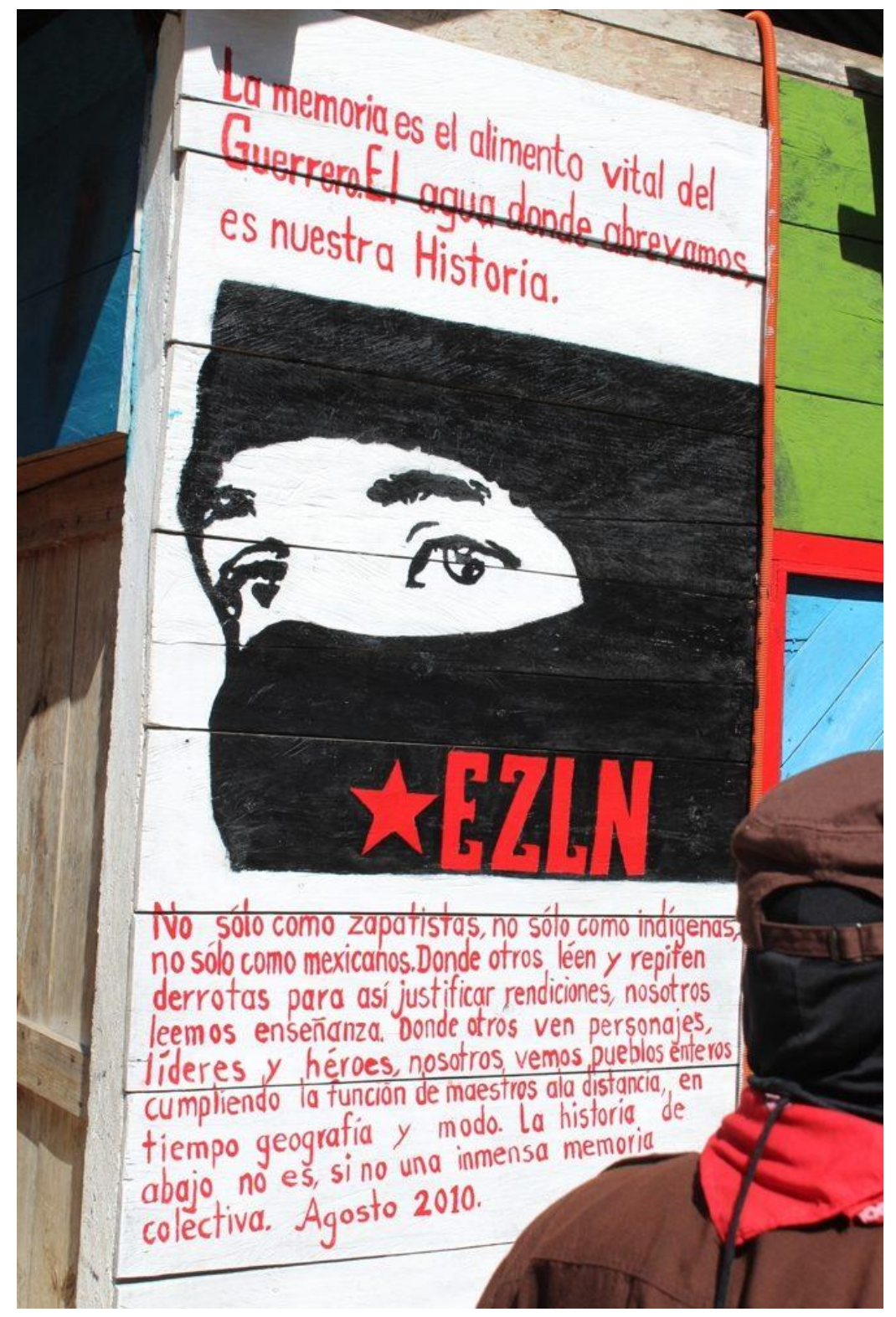

Otro dato a considerar es que quienes tomaron la palabra tienen orígenes étnicos, culturales y de clase similares y trayectorias de vida ligadas al mismo movimiento social, por lo que resulta más probable que haya cierta homogeneidad en las subjetividades. Esto contrasta con la heterogeneidad interna de los discursos del sector gubernamental durante el ritual de permiso a la madre tierra, en el cual quienes tomaron la palabra tienen orígenes y trayectorias de vida diversas.

Asimismo, como la directora de este trabajo comentó atinadamente, es posible que la narrativa neozapatista constituya una indianidad de clase, es decir, antepone en sus discursos elementos ligados a la explotación (económica y política) por un Otro. A su vez, la narrativa vislumbrada en el discurso del director del SEDESPI 
durante el ritual de permiso a la Madre Tierra en Palenque, destaca la opresión y dominación (cultural y social) y no tanto la explotación.

Igualmente hay que considerar los elementos del indigenismo institucional retomados por el director de SEDESPI, como lo fueron la alusión a la ancestralidad milenaria y la cultura antigua; a diferencia de los zapatistas que mencionaron "estamos aquí desde hace 525 años" (en alusión a los albores de la llegada de los europeos), enfatizando la relación de explotación surgida de este encuentro. Así, se sugiere que -al menos en lo concerniente a los discursos analizados- el indigenismoindígena-institucional del SEDESPI enfatiza la reivindicación cultural y social a través de la etnicidad; y la propuesta neozapatista reivindica lo económico y político a través de lo que podría denominarse como indianidad de clase.

Ahora bien, siguiendo a Turner, este evento -el de los neozapatistas- es una ceremonia definicional, ya que fue desplegado durante una crisis de invisibilidad del grupo al ser desdeñado por un grupo más poderoso, en este caso el sector gubernamental. Igualmente, mantuvo una "subjetividad organizada en relatos más o menos consistentes, con un simbolismo tendiente a erigir un mundo convincente e incuestionable, alentando el pensamiento, acciones y clasificaciones esquemáticas y simplificadoras" (Díaz Cruz, 2005:108), en este caso la idea del neoliberalismo contra pueblos indígenas de la narrativa del Mundo-Finca, en sintonía con la narrativa del despojo por megaproyectos/resistencia territorial indígena, que en conjunto conforman la narrativa del altermundismo-anticapitalista-antiestado. Pero sobre todo, es una ceremonia definicional porque los actores externaron lo que quieren, lo que aspiran a ser y su compromiso.

Las reacciones desde otros sectores del campo político no se hicieron esperar. El 2 de enero del 2019 se preguntó a AMLO sobre el pronunciamiento del EZLN en la conferencia matutina. Igualmente, se pronunciaron en apoyo y solidaridad a los zapatistas -mediante respectivas cartas públicas- actores del sector académico y artístico, y actores del activismo étnico ambientalista.

En la conferencia matutina del 2 de enero del 2019135, Alfredo Páez, reportero de la revista El BigDataMx, preguntó a López Obrador: "el EZLN dijo que no va a permitir que se construya el Tren Maya en la zona que pasa por Chiapas, ¿qué va a 
responder a ellos?, ¿va a haber algún tipo de negociación con ellos?, ¿se va a mediar de algún modo?" Al lo que el presidente respondió:

"Acerca de las declaraciones de ayer, o de antier del movimiento zapatista, expreso mi respeto a sus planes, programas, a sus decisiones. Vivimos en un país libre, no hay represión, no hay censura. ¿Quién califica? El ciudadano. No vamos nosotros a enfrentarnos a ningún grupo. Nosotros queremos la paz y la reconciliación, puede haber diferencias, las hay, pero eso no significa que se vaya a caer en una confrontación o en un pleito. Tenemos ahora ya a un adversario que queremos vencer, que vamos a enfrentar todos los días. Ese adversario ni siquiera, ahí sí yo creo ese enemigo es la crisis de México y a eso estoy ocupado.

Ahora sí que, aunque quieran confrontarnos no va a haber respuesta. Amor y paz, pero claro que vamos a estar aquí hablando de cosas interesantes, debate sobre la situación del país, por qué los proyectos productivos, por qué se apuesta al desarrollo sustentable, por qué los programas del nuevo gobierno. Porque queremos sacar de la pobreza al pueblo. ¿Por qué hay inconformidad de los conservadores? Porque se dieron los cambios, tardó este régimen de injusticias, de privilegios, 36 años, y es natural que haya cuestionamientos y críticas y puntos de vista distintos. Los entiendo y además vamos a garantizar siempre el derecho a disentir."

Posteriormente, Arturo Páramo de Grupo Imagen cuestionó:

"Insistir un poco en el asunto del Ejército Zapatista, ¿por qué? Porque no se trata solamente de debatir, es un ejército. Entonces, quisiera saber si usted o el secretario de la Defensa o el secretario de Seguridad Pública tienen alguna idea de si el Ejército Zapatista se ha reforzado, tiene mayor despliegue, tiene una verdadera capacidad de poder hacer algo más allá de una declaración. Y si de verdad no le inquieta la posición que tiene el Ejército sobre el Tren Maya, porque es uno de sus proyectos más importantes, y ellos fueron específicos al decir que no van a permitir la construcción de este proyecto".

A lo que López Obrador respondió: 
"Están en su derecho de expresarse, de manifestarse. No veo por qué deba preocuparnos. Somos libres. Siempre he dicho que en la democracia hay pluralidad; en la dictadura es pensamiento único, nadie puede hablar, nadie discrepa. Nosotros tenemos afortunadamente el respaldo de los ciudadanos, el apoyo de la gente. No le hacemos mal a nadie. Al contrario, vamos a atender a todos, a escuchar a todos, y se le va a dar preferencia a los pobres, a los humildes. Eso es todo lo que puedo decir".

Seguidamente se dió la palabra a Yanet López Ponce, de Milenio. Quien realizó unas afirmaciones que parecían buscar una respuesta desmesurada a su pregunta. Cabe mencionar que la respuesta fue tergiversada en la prensa ${ }^{136}$, pues el señalamiento de AMLO de "nadie me va a cucar" iba dirigido a la reportera, no al EZLN, como se puede ver a continuación:

YLP: “¿Entendí bien?, está llamando al EZLN de este grupo de conservadores, los está calificando a ellos también en este grupo de oposición conservadora. Y sí insistir en el tema de realmente no tiene por qué preocuparle. Es un grupo con bastante fuerza en esa zona, incluso, ayer lo calificaban a usted como un mañoso. Dicen que usted asegura estar con el pueblo, pero que no es así. Y que no van a permitir que sus proyectos entren en esta zona. Sabiendo que son un grupo armado, ¿realmente no le preocupa que se opongan a sus proyectos?"

AMLO: "No, no, no. Y tampoco me va a cucar. Nadie me va a cucar. ¿Se acuerdan como era en la escuela?, bueno, antes, ahora ya no se permite eso, y que bueno que ya no se permita. Pero en el recreo: "Ya ves cómo te dijo. A que no le quitas la basurita". Te ponían una basurita aquí [toca su hombro]. No, últimamente se comentaba, "eso sí calienta". Pues no, hay mucho frío ahorita. No vamos a caer en ninguna provocación, o sea, esa es mi respuesta, y añado para que no vayan a decir: 'Ah, le es igual, es soberbio, es indiferente'. Sencillamente todos tenemos derecho a manifestarnos y somos respetuosos del derecho a disentir".

Dos turnos después se le dio la palabra a Misael Zavala, de El Universal, quien comentó: "Yo quisiera reiterar este tema del EZLN, ¿buscará el gobierno federal, 
buscará su gobierno, algún tipo de reunión con el Ejército Zapatista? Tal vez amenacen ellos con detener la obra, con frenar algunas obras".

A lo que AMLO respondió: "Nosotros estamos abiertos al diálogo en todos los casos. Todo el que solicite una audiencia, tiene derecho a ser atendido. Es un derecho constitucional".

Algunos turnos después Agustín Velasco de Uno TV retomó el tema del EZLN: "dice usted que en este asunto con el EZLN todo mundo tiene derecho a una audiencia si la solicita, esto quiere decir que el gobierno federal no va a buscar al EZLN para entablar un diálogo; es decir, si quieren un diálogo, ellos se tienen que acercar al gobierno federal." La respuesta de López Obrador fue: "Estamos abiertos al diálogo, y amor y paz, esto es lo que puedo comentar".

Se mencionó párrafos atrás que hubo un par más de reacciones al evento del EZLN manifiestos en cartas públicas. La primera carta ${ }^{137}$ fue publicada el 9 de enero de 2019 por un colectivo denominado Coordinadora Metropolitana Anticapitalista. La misiva intitulada "L@S ZAPATISTAS NO ESTÁN SOL@S. ESTAMOS JUNT@S CONTRA EL CAPITALISMO Y LOS PROYECTOS DE MUERTE COMO EL TREN MAYA Y EL CORREDOR TRANSÍSTMICO", fue firmada por alrededor de 60 actores individuales y colectivos. En ella se incorporan los elementos discursivos, retórica y símbolos dominantes manifiestos en el evento de celebración del 25 aniversario, en concordancia con las narrativas del Mundo-Finca, la del despojo por megaproyectos/resistencia territorial indígena y la del altermundismo-anticapitalistaantiestado. Cito algunos fragmentos relativos al PTM:

“(...) Una ceguera moral y política, mezcla de desmemoria, mentira, mala fe y deliberada calumnia, ha exhibido la ignorancia y fanatismo, lleno de odio irracional y racista por parte de militantes y simpatizantes de Morena en contra del EZLN; sobre todo, después de las declaraciones que hiciera Andrés Manuel López Obrador (el nuevo Finquero), respecto a que el Ejército Zapatista de Liberación Nacional no me va a "cucar" (provocar). Como si declararse en contra del despojo, la explotación, la represión, el desprecio y en defensa del derecho a la vida, a la tierra, al territorio y a su autonomía, fuera una provocación. Es un ¡YA BASTA! 
Denunciamos, que la imposición del Tren Maya, el Corredor Transístmico, la Extensión de las Zonas Económicas Especiales, la Iniciativa de Ley para el Desarrollo Agrario y la velada decisión, de convertir a México en "un Paraíso de la Inversión"; representa un PLAN DE CONTRAINSURGENCIA en contra de los pueblos y comunidades indígenas zapatistas, y que más allá de la simulación de la consulta, el "nuevo gobierno" impone políticas neoliberales y capitalistas. Frente a ello, nosotros no sólo declaramos sino que asumimos, que nuestr@s herman@s Zapatistas, nuestr@s herman@s del EZLN, jNO ESTÁN SOL@S!, pues en México y el mundo, muchas miradas, pensamientos y palabras, pero sobretodo, Resistencias y Rebeldías, caminamos con la palabra digna y los pasos rebeldes de nuestr@s herma@s zapatistas, en una apuesta de lucha mundial contra el capitalismo y el patriarcado.

(...) El mercenario de José Manuel Mireles, quien lanzó una amenaza al EZLN, señalando que tiene "autodefensas en 28 estados a favor de AMLO" para responder por el proyecto del nuevo gobierno federal, se suma a las declaraciones de Alejandro Solalinde, quien también en la defensa de AMLO, declaró que "30 millones no se equivocan", esto, en respuesta a la declaración del EZLN, cuando advertía, que habrá "desilusión" con López Obrador. Así mismo, la complicidad de Morena con el gobernador Velasco, el Partido Verde en Chiapas y sus paramilitares, son una muestra clara de elementos militares de contrainsurgencia, que se suman a elementos de propaganda contrainsurgente, y que en estos días han saturado las redes sociales, mediante bots y trolles que operan desde la IV transformación.

Los zapatistas se bastan a sí mismos para decir su palabra y defenderse. Sin embargo es nuestro deber ético y moral, salir al paso de las mentiras, las calumnias y amenazas contrainsurgentes para decir que $@ s$ herman@s zapatistas, que I@s herman@s del CNI-CIG, jNO ESTÁN SOL@S!"

La segunda carta pública fue firmada por alrededor de 800 intelectuales, artistas, asociaciones, académicos y activistas mexicanos y extranjeros. La misiva intitulada "Carta de solidaridad y apoyo a la resistencia y la autonomía zapatista" ${ }^{138}$ fue publicada el 16 de diciembre y circuló a través de múltiples medios digitales nacionales y extranjeros. En ella se expresa: 
"Nosotros, nosotras, intelectuales, académicos, artistas, activistas y personas de buena voluntad, así como organizaciones, asociaciones y colectivos de varios países manifestamos nuestra solidaridad con el Ejército Zapatista de Liberación Nacional (EZLN) en este momento crucial de su historia y rechazamos tajantemente la actual campaña de desinformación, mentiras y calumnias dirigida en contra del zapatismo.

(...) Por eso, expresamos nuestra preocupación por la situación que enfrentan las comunidades zapatistas y los pueblos indígenas de México, al ser atacados sus territorios y comunidades por proyectos mineros, turísticos, agroindustriales, de infraestructura, etc., tal como lo ha denunciado el Congreso Nacional Indígena (CNI) y el Concejo Indígena de Gobierno (CIG). En este momento, nos preocupa especialmente los grandes proyectos impulsados por el nuevo gobierno mexicano, como el Corredor Transístmico, el millón de hectáreas de árboles comerciales y el llamado "Tren Maya", recientemente denunciado como una humillación y una provocación por el subcomandante Moisés, vocero del EZLN, ya que afecta gravemente los territorios de los pueblos mayas que habitan en el sureste mexicano.

Además de los devastadores efectos ambientales de este proyecto y del desarrollo turístico masivo que pretende detonar, nos preocupa la premura en iniciar las obras del "Tren Maya”, encubriéndola con un pseudo ritual a la Madre Tierra, denunciado por el vocero zapatista como una burla inaceptable. Nos indigna que de esta manera se prepare un ataque más en contra de los territorios zapatistas y que se hayan ninguneado los derechos de los pueblos originarios, evadiendo la obligatoriedad de la consulta real, previa, libre e informada, tal como lo establecen el Convenio 169 de la OIT y la Declaración de la ONU sobre los pueblos originarios. Nos parece muy grave que así se violen los compromisos internacionales asumidos por México.

Compartimos el rechazo total expresado por el EZLN frente a estos y otros grandes proyectos que afectan gravemente a los territorios autónomos y a las formas de vida de los pueblos. Denunciamos de antemano cualquier agresión en contra de las comunidades zapatistas, sea directamente por parte del 
Estado mexicano o a través de grupos y organizaciones de "civiles" armados o no armados.

Responsabilizamos al gobierno mexicano de cualquier confrontación que pueda surgir en el marco de la implementación de estos megaproyectos, que corresponden a un modelo ya rebasado de "desarrollo", insostenible y devastador, decidido desde las cúpulas del poder y violando descaradamente los derechos de los pueblos originarios".

Como era de esperarse, tanto las respuestas de AMLO a la prensa como las cartas (sobre todo la de los intelectuales) resonaron de modos diversos. En redes sociales se desataron batallas campales donde hubo discursos apologéticos hacia todas direcciones, descalificaciones altisonantes no argumentadas de actores del DSPTM, ataques ad hominem y otras formas de catarsis propias del ágora virtual, canal de la opinión pública, la cual es un recurso inmaterial en disputa en el DSPTM.

Con el tiempo estos eventos fueron desplazados por nuevos eventos correspondientes al DSPTM y otros temas de actualidad nacional o internacional. Con el tiempo se confrontarían nuevamente los actores aludidos en este apartado y la opinión pública revisaría lo suscitado en los episodios anteriores, dotando progresivamente -desde distintas narrativas- de personalidades específicas a los diferentes actores individuales y colectivos.

Hasta aquí se ha podido observar que las descalificaciones entre el sector gubernamental y el sector del activismo étnico-ambientalista han sido de orden ontológico: se le ha dicho conservadores a los que se asumen revolucionarios, se le ha dicho neoliberal al que se presenta como opositor del neoliberalismo y la corrupción. No obstante, hay que recordar que el DSPTM no se limita a los lances entre estos dos sectores. En los siguientes apartados se abordan, eventos protagonizados por otros actores del Campo Político del Proyecto Tren Maya.

\subsection{FONATUR inicia búsqueda de alianzas intersectoriales}

FONATUR inició la búsqueda de alianzas con actores clave para la realización del PTM en febrero del 2019, manteniendo una actividad constante en cuanto a firma de convenios de colaboración y contratos de prestación de servicios hasta diciembre del 2019139. Durante este periodo la firma de convenios y contratos fue intensiva, se 
realizaron 26 con días de distancia entre una y otra. Entre los actores llamados a establecer alianzas con FONATUR tenemos universidades e instancias de investigación, colegios profesionales, organizaciones de la sociedad civil y empresas nacionales e internacionales. Para ver una relación de instancias y su papel en el PTM se sugiere revisar las tablas 3, 4 y 5 presentadas en el capítulo 1 de este trabajo.

Esta búsqueda de alianzas y la publicación de las mismas en la prensa y comunicados oficiales significa varias cosas: 1) la nueva administración federal y FONATUR están interesados en iniciar las obras con el respaldo moral de diferentes sectores de la sociedad, lo cual tiene peso en la opinión pública; 2) este respaldo multisectorial es capital político que el sector gubernamental acumula usando su posición privilegiada en la estructura de poder, consolidándose como el interlocutor obligado u objeto de crítica insalvable en el CPPTM; 3) es una forma de subordinar y restar capital político y simbólico a las facciones oponentes al interior de instancias clave; 4) es una forma de asegurarse y mostrar la colaboración de actores regionales clave en los aspectos técnicos, operativos, políticos y científicos.

\subsection{Foro Maya Peninsular convocado por Gubernatura Nacional Indígena}

El 25 de febrero del 2019 reapareció Gubernatura Nacional indígena (GNI), tras haber sido plantados para la entrega del bastón de mando. Esta vez en Mérida, Yucatán, durante una rueda de prensa sobre el "Primer Foro Peninsular Indígena Maya" a realizarse el 2 de marzo. Participaron en esta rueda de prensa un personaje autoproclamado "líder supremo índígena maya" o "líder supremo nacional indígena" Ilamado Filiberto Ku Chan; los profesores Jorge Lizama Góngora, Alberto Casanova Martín y Cornelio Mena Ku; y la Dra. Carla Gruintal Lugo de la Universidad Intercultural Maya de Quintana Roo (UIMQROO).

En esta rueda de prensa ${ }^{140}$ los actores respaldaron la construcción del PTM, debido a que perciben un daño ambiental mínimo, argumentando -erróneamente- que sólo se requiere de aproximadamente 10 metros de ancho para las vías férreas. Filiberto Ku Chan afirmó que el daño ambiental "será mínimo, debido a que no se puede evitar porque además no estamos peleados con la modernidad"141, además "hay más daño a la ecología por la deforestación de Calakmul, pues hay una tala inmoderada"142. Esta idea ha sido expresada por FONATUR y AMLO en el marco de 
la propuesta de reordenamiento territorial del PTM. Podemos ver aquí una intención de adherirse al sector promovente del Tren Maya

Imagen 22. Filiberto Ku Chan cuando se presentaba como "dignatario maya" de GNI (derecha) e Hipólito Arriaga (con sombrero), presidente de GNI ${ }^{143}$

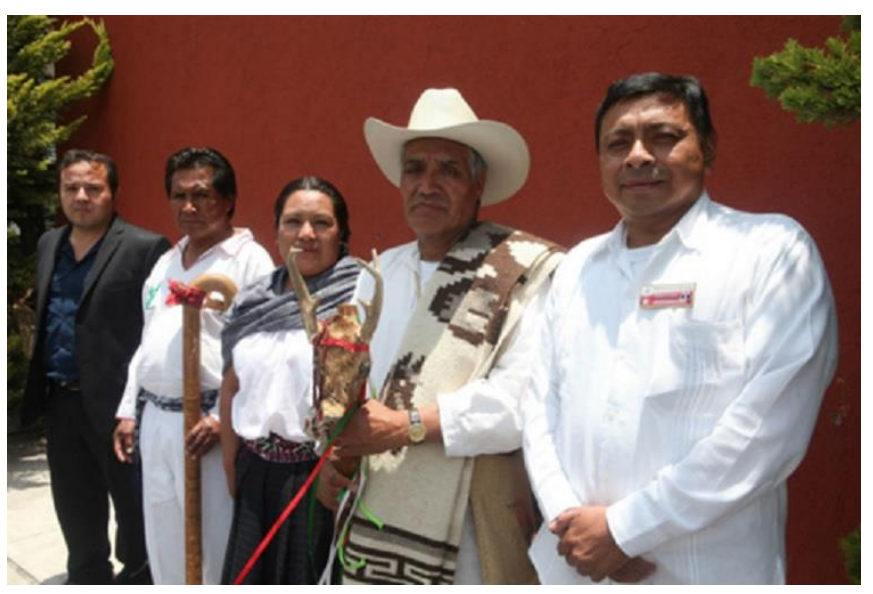

Imagen 23. Organizadores del Primer Foro Peninsular Indígena Maya. Ku Chan al centro ${ }^{144}$

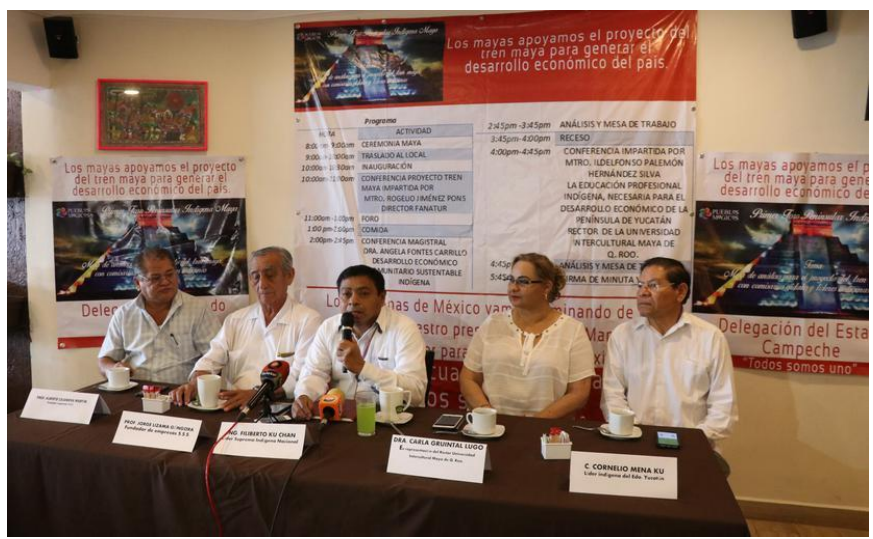

Ku Chan señaló que el foro se organiza para que 400 comisarios ejidales de comunidades de Quintana Roo, Campeche y Yucatán analicen los beneficios o perjuicios del PTM en una "Mesa de análisis para el Proyecto del Tren Maya", porque parte de ellos son propietarios de las tierras ejidales que tendrán que negociar para su venta al gobierno federal. Comunicó también que RJP había sido invitado al evento como conferencista para exponer el proyecto a los ejidatarios, aunque no había confirmado su asistencia. Expresó también:

"Nosotros no estamos contra el progreso por eso apoyamos la construcción del Tren Maya, proyecto que contribuirá a la economía de los pueblos por donde transitará, debido a que fomentará el turismo, por lo que tenemos fe que con 
el nuevo gobierno de Andrés Manuel López Obrador las cosas van a cambiar para bien ${ }^{145 " .}$

"Los verdaderos indígenas aprobamos el proyecto de nuestro presidente, Andrés Manuel López Obrador, por el desarrollo que representa al sureste y todo el país ${ }^{146 " .}$

Ahora bien, la cita para el Foro fue el 2 de marzo del 2019 a las 10:00 am en el local de la Sección 95 de la Confederación Revolucionaria de Obreros y Campesinos (CROC), ubicado en la calle 30 Lote 4 entre 23 y 25 de la colonia Manuel Crescencio Rejón, cerca del aeropuerto de Mérida. Cabe mencionar que la CROC fue abiertamente simpatizante del candidato del PRI a la presidencia en las elecciones del $2018^{147}$. Igualmente, durante el evento apoyaron en la logística estudiantes de la licenciatura en derecho del Centro de Estudios Superiores CTM, instancia educativa de la Confederación de Trabajadores de México (CTM), emanada también del PRI. En este sentido, este evento puede considerarse un esfuerzo de los militantes de dicho partido político por incluirse mediante las vías indigenista, campesina y obrera a la disputa por recursos en torno al Tren Maya.

Imagen 24. Tiburcio Can realizando una "ceremonia maya" antes del Foro Indígena Maya Peninsular ${ }^{148}$

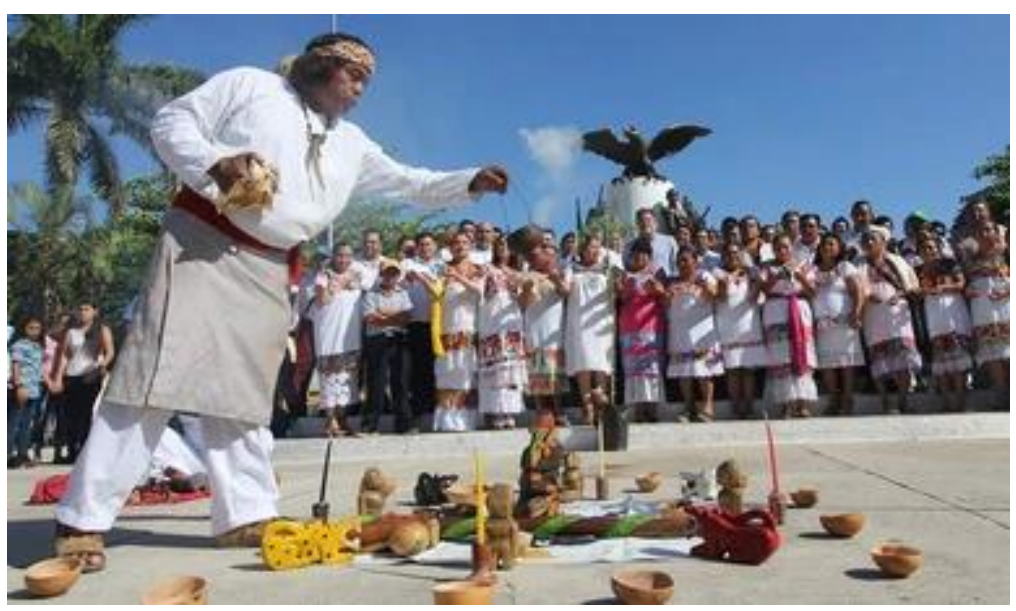

Previo a las actividades en la sede referida, hubo una "ceremonia maya" oficiada por el j'meen Tiburcio Can May en el Parque de la Mejorada en el centro histórico de la ciudad, ante la vista de los ejidatarios invitados al Foro. Cabe mencionar que Can May ofició la ceremonia de permiso a la Madre Tierra en Chichén Itzáa ${ }^{149}$ el 16 de diciembre anterior, evento al cual asistió también el "líder supremo". Aquí podemos notar cómo 
GNI ha persistido en el intento de estar en el CPPTM, pues a pesar de negársele entregar el bastón de mando y aparecer en la ceremonia de permiso a la Madre Tierra en Palenque, logró realizar la ceremonia en Yucatán con la presencia de personal de FONATUR e invitar al titular de dicha instancia a un evento organizado por GNI en Mérida.

Después de la ceremonia maya, los asistentes se trasladaron al local de la CROC. Los aproximadamente 400 ejidatarios provenientes de los tres estados de la península fueron recogidos por autobuses durante la madrugada para llegar en la mañana al parque de la Mejorada en Mérida, presenciar la ceremonia maya y posteriormente ser trasladados en los mismos autobuses al local de la CROC.

La cita era a las 10:00 am, pero la inauguración se atrasó hora y media pues el traslado y la repartición de desayunos fue tardada. Además no había llegado al lugar el titular de FONATUR, quien tenía programada una intervención para comentar a los presentes las características generales del Tren Maya

A grandes rasgos, el local se divide en dos partes, una techada y otra al aire libre. Al fondo de la parte techada estaba la mesa que ocuparían los funcionarios municipales, estatales y federales invitados y el organizador del evento. Delante de esta mesa larga se reservó un espacio para que el j'meen Tiburcio Can realizara otra "ceremonia maya", que a observación de un par de antropólogas con amplia experiencia en el tema parecía algo inventado para este tipo de eventos que poco tienen que ver con los rituales que se llevan a cabo en las localidades mayas.

La directora de este trabajo -quien tiene una amplia trayectoria en la investigación antropológica con población maya de Yucatán- señala que nunca ha visto o leído sobre rituales de permiso a la Madre Tierra en comunidades mayas yucatecas, señala que lo más cercano sería la solicitud de permiso a los dueños y los vientos, y el ritual de jets lu'um (inaugurar, asentar la tierra). No obstante, en estos rituales no se utilizan jaguares de madera, ni velas acomodadas en el orden cromático de los vientos, ni se realizan en el suelo. Adicionalmente, debe notarse que en el centro de la disposición de objetos para el ritual se muestra la imagen del New Age (creada por José Argüelles) asociada a Hunab Ku (Dios único), siendo este último un invento de los evangelizadores durante la colonia (Cruz Cortés, 2019). Así, esta ceremonia podría tener mayor relación con los "mayas galácticos" del New Age - 
narrativa extendida entre los turistas extranjeros en la Riviera Maya ${ }^{150}$ (Elbez, 2017)que con las ceremonias mayas realizadas en algunas localidades de la Península de Yucatán en la actualidad.

Imagen 25. Mesa de funcionarios durante el Foro Indígena Maya Peninsular ${ }^{151}$

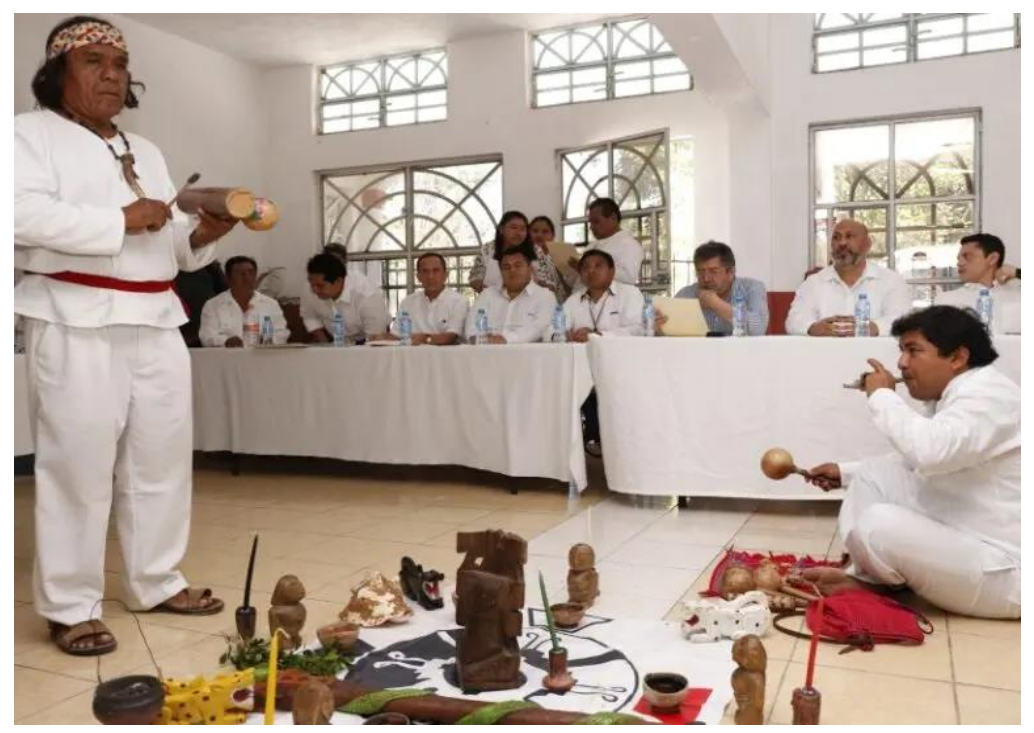

Después del espacio para el ritual, se encontraban las mesas más cercanas a la mesa de funcionarios. Eran 6 y en cada una había capacidad para 10 personas. Estaban ocupadas por los organizadores del evento, líderes de la CROC, acompañantes de los funcionarios invitados, profesores de la UIMQROO, "líderes indígenas" y comisarios municipales de los tres estados de la península. El equipo de sonido fue ineficiente en cuanto a potencia y nitidez, por lo que lo dicho en la mesa principal solo fue escuchado por estas primeras mesas. Durante todo el evento se escuchó el barullo de quienes no alcanzaban a escuchar a los conferencistas principalmente de los ejidatarios- a pesar de que hubo traducción a la lengua maya.

Atrás de las primeras mesas estaban las de los ejidatarios, algunas en la parte con sombra y otras en la parte soleada. Los estudiantes de la licenciatura en derecho de la CTM se encargaron de acomodarlos y servirles el desayuno. Escuché de una de las organizadoras -una mujer alta, de piel blanca, vestida con un huipil yucateco y un collar rarámuri-: “isi no se sientan no comen!”, dirigiéndose a los ejidatarios y estudiantes.

Las actividades fueron: 1) inauguración del Foro a cargo de Filiberto Ku Chan; 2) conferencia sobre el Proyecto Tren Maya por parte del titular de FONATUR Rogelio 
Jiménez Pons; 3) intervenciones de otros funcionarios invitados; 4) comida; 5) mesas de análisis sobre el PTM en las que participarían los ejidatarios invitados; 6) conferencia magistral sobre desarrollo económico comunitario sustentable indígena a cargo de la Dra. Ángela Fontes Carrillo; 7) conferencia sobre educación profesional indígena y su necesidad para el desarrollo económico de la Península de Yucatán a cargo del Mtro Idelfonso Palemón Hernández Silva, rector de la UIMQROO; 8) mesas de análisis sobre el Proyecto Tren Maya en las que participarían los ejidatarios invitados; 9) firma de minuta de clausura. A las 11:30 Filiberto Ku Chan realizó el discurso inaugural del Foro, transcribo literalmente:

"Muy buenos días hermanos y hermanas mayas de la Península de Yucatán. El objetivo de este primer Foro Peninsular Indígena Maya, mesa de análisis del tren maya. Como invitado especial tenemos al arquitecto Rogelio Jiménez Pons, que viene a platicar cómo se va a construir el Tren Maya. Todos nosotros, como hemos declarado públicamente, estamos con el señor de que vamos a apoyar la construcción del Tren Maya. ¿por qué? porque el Tren Maya va a generar autorriqueza de las comunidades indígenas, nos va a beneficiar no solo a los mayas de la Península de Yucatán, a los hermanos del sureste y de todo el país.

Este proyecto tiene muchas aristas, los que están hablando de que va a ocasionar un daño ecológico son gentes que no son mayas, en cambio hoy estamos reunidos, somos orgullosamente mayas, y los más importante, compañeros, que aquí estamos los comisarios ejidales y líderes indígenas de la Península de Yucatán que somos los dueños de estas tierras. Nosotros no somos de México, somos dueños de México. Y creo que este es el momento, mucho ha hablado la gente que no es maya, que no es indígena, que nosotros alcemos la voz de lo que queremos con el Tren Maya, pacíficamente y con hermandad, porque los indígenas es lo que nos distingue, porque lo que nos sobra es educación, cultura, una lengua materna y conocimiento ancestral, que no sólo tenemos para presumir, hermanos, nos sobra hasta para aventar al cielo.

Y hoy es la oportunidad como cultura maya de aportar a la humanidad no solamente, lo que tenemos en la península de Yucatán sobre turismo de 
playas, hoy en la Península de Yucatán tenemos la oportunidad de compartirle a todo el mundo nuestro conocimiento ancestral, nuestra cultura, nuestra educación, nuestro conocimiento ancestral, como nuestro hermano jmeen Tiburcio Can que es un conocimiento ancestral que también mis ancestros me legaron a mí. Tenemos tanto que ofrecerle a la humanidad en la Península de Yucatán y al sureste de México con el Tren Maya en el tema turístico y hoy día esto que estamos haciendo aquí reunidos es un legado que le vamos a dejar a las nuevas generaciones porque les va a generar su autorriqueza sin necesidad de salir de sus comunidades.

Después de la intervención de los hermanos Rogelio Jiménez Pons, vamos a seguir trabajando aquí con nuestra compañera indígena tarahumara de Chihuahua, una catedrática de la Universidad de Chapingo, una especialista en cooperativas, las famosas empresas triple $s$, sociedades con interés social y les vamos a contar las ventajas que tienen. Vamos con una demora de más de una hora y media. Mis bendiciones, Nib óolal.

¡Perdón! y el día de hoy el primer foro, hoy lo declaramos un foro permanente de los indígenas de Yucatán para que nosotros mismos, los descendientes mayas hablemos nosotros, ya no queremos héroes prestados, ya no queremos los ambientalistas que están hablando por nosotros, o los indigenistas, o los mayas de Miami, no, eso ya no queremos, nosotros queremos alzar la voz y decir lo que queremos, queremos ser copartícipes del Tren Maya, por eso estamos reunidos acá mis hermanas y hermanos. Queremos que nos incluyan, nosotros los indígenas mayas no estamos peleados con la modernidad y el desarrollo tampoco lo podemos parar, así que vamos adelante, vamos adelante y no podemos agarrar empuje echando para atrás, para adelante.

Y esto es una gran oportunidad que nos está dando el presidente Andrés Manuel López Obrador, que siempre lo ha dicho a gritos, el sureste, la Península de Yucatán siempre nos han segregado y de eso se trata el foro, de que ustedes hablen, no de que alguien hable por ustedes, por eso están ustedes acá, los comisarios ejidales y líderes indígenas mayas, repito, mayas, los dueños de estas tierras. Y repito este día declaramos que este foro va a ser permanente abierto para discutir todo lo que les aqueje, lo que es el coyotaje, 
esto tiene que cambiar, pero esto lo vemos en los foros de análisis. In laak ech' todos somos uno ${ }^{152}$. Nib óolal' (transcripción propia).

Posteriormente se le dio la palabra a Jiménez Pons, quien dijo que el proyecto abriría programas educativos y de capacitación para las comunidades, los cuales generarían oportunidades de empleo mejor pagado. Igualmente, comentó que los trenes son cerca de cien veces menos contaminantes que una carretera y que el proyecto del Tren Maya liberaría a las carreteras del peso de la carga que llega del resto del país, además de incluir pasos de fauna y otros avances de infraestructura que debieron hacerse hace varias décadas. Igualmente señaló que el apego a la ley sería un eje rector del proyecto, tanto en lo que respecta al medio ambiente, como a las comunidades en la zona de influencia del Tren Maya; incluyendo la elaboración de las Manifestaciones de Impacto Ambiental (MIA). Una vez obtenidos los resultados de los estudios, se aplicarían las medidas de contención y mitigación correspondientes. Asimismo, comentó que se realizarían consultas a los pueblos originarios con apego a la ley y en observancia del Convenio 169 de la OIT.

Cabe destacar que la participación de Jiménez Pons fue traducida al maya yucateco por Julia Chan, conductora del noticiero en lengua maya del Canal 13 de Yucatán, de corte oficialista. Después de la participación de Jiménez Pons, se le dio la palabra a los demás funcionarios invitados, quienes de manera breve respaldaron el proyecto y agradecieron la invitación al Foro. En todo momento se escuchaba el barullo de las conversaciones en maya y castellano de los ejidatarios que no alcanzaban a escuchar lo que decían en la mesa de funcionarios.

Al declararse terminada esta primera parte del evento, algunas personas comenzaron a pedir a los comisarios ejidales que formaran filas para entregar documentos. Me acerqué para conversar. Al preguntarle a uno de ellos para qué era la fila, me dijo que era para entregar papeles para entrar al programa Sembrando Vida y solicitar apoyos. Inmediatamente llegó una de las organizadoras, les clavó una mirada a los comisarios ejidales con quienes empezaba a conversar y ellos comenzaron a evadirme y alejarse. Después de esta entrega de documentos para solicitar apoyos gubernamentales los comisarios ejidales volvieron a sus mesas y los estudiantes de derecho de la CTM repartieron los alimentos. 
Posteriormente fue la primera mesa de análisis del PTM, la cual fue coordinada por la Dra. Ángela Fontes Carrillo, quien pidió a los ejidatarios que formaran grupos con personas que no son de sus comunidades de origen para la actividad. Me senté en una de las mesas donde había ejidatarios de los tres estados de la península. Las mesas de trabajo fueron coordinadas por estudiantes de derecho de la CTM, quienes entregaron a cada persona una hoja donde se presentaba información sobre los retos y soluciones ambientales y socioeconómicos del PTM en castellano y maya yucateco. Dicha hoja presentaba el logotipo del Proyecto Tren Maya utilizado por FONATUR, pero no tenía logotipos de ninguna instancia gubernamental.

Los dos estudiantes de la CTM presentes en la mesa donde participé -al igual que en las demás por instrucción de sus profesores- procedieron a dar lectura a la parte en castellano de la hoja referida:

"EI TREN MAYA se concibe como un proyecto integral de infraestructura, orientado primordialmente a promover el bienestar y las condiciones socioeconómicas de los habitantes de la región, y al mismo tiempo, a promover acciones para salvaguardar y preservar su invaluable patrimonio ambiental, histórico y cultural.

Retos y soluciones ambientales:

- Pasos de fauna adecuados a lo largo de la vía

- Promoción de la reforestación y la remediación de espacios perturbados y erosionados por actividades humanas

- Disminución de la contaminación originada por el transporte carretero de carga

- Identificación, prevención y remediación de accidentes geológicos (subsuelo, ríos y cenotes)

- Promoción del turismo ecológico responsable en las zonas ambientalmente sensibles

Retos y soluciones sociales:

- EI TREN MAYA fomentará la capacitación y el empleo para habitantes interesados de las comunidades 
- El TREN MAYA apoyará con orientación y capacitación a los productores y artesanos locales para fomentar la innovación y la competitividad

- El apego a la ley será un eje rector del proyecto, tanto en lo que respecta al medio ambiente como a las comunidades en la zona de influencia del Tren Maya

- Esto incluye la elaboración de las Manifestaciones de Impacto Ambiental (MIA). Una vez que se obtengan los resultados de los estudios se aplicarán las medidas de contención y mitigación correspondientes

- Asimismo el Tren Maya realizará las consultas a los pueblos originarios con apego a la ley y en completa observancia del Convenio Número 169 de la Organización Internacional del Trabajo sobre pueblos indígenas"

Después preguntaron: “¿están de acuerdo en que se construya el Tren Maya?”, a lo que cada miembro de la mesa -éramos 6- contestó. En síntesis, dos ejidatarios de Quintana Roo comentaron que estaban de acuerdo sólo si primero se atendían otras necesidades de las localidades, como la falta de buenos caminos, trabajo y apoyos monetarios. Por parte de Yucatán participó una mujer que es ejidataria del municipio de Muna y afiliada a la $\mathrm{CROC}$, quien dijo que era una buena idea y estaba de acuerdo; yo, meridano, mestizo-blanco e hispanohablante dije que era una propuesta interesante, que podría ser muy buena o muy mala para quienes vivimos en la península y todo dependía de cómo se realizara, por lo que era bueno que los ejidatarios supieran más del proyecto y decidieran por su cuenta en sus localidades. Por parte de Campeche, dos ejidatarios dijeron que estaban de acuerdo con el proyecto si era para beneficio de la gente de los pueblos y no sólo para los ricos.

Después, los estudiantes hicieron otra pregunta: “¿qué necesitan para que se haga el Tren Maya?". Esta pregunta no fue respondida por turnos como la anterior, detonó una conversación entre los presentes en la mesa que en varias ocasiones devino en anécdotas sobre las localidades de origen, en la que los ejidatarios de Campeche y Quintana Roo enfatizaban las carencias de infraestructura, servicios deficientes, falta de trabajo y apoyos gubernamentales; y la ejidataria yucateca y los estudiantes de la CTM enfatizaron lo bonito, natural, simple y bello que es vivir en el 
campo, lejos de las presiones de la ciudad. Yo me limité a comentar que se necesitaría realizar la MIA y la Consulta Indígena de manera adecuada.

Los estudiantes recopilaron algunos puntos que les parecieron esenciales para resumir lo expresado en la mesa en torno a las dos preguntas hechas y entregaron las hojas a sus profesores sin dar una lectura final de las mismas a los participantes. Los profesores entregaron las hojas de todas las mesas a la coordinadora de la actividad, quien procedió a leer algunas respuestas al azar -las cuales en su mayoría señalaban el apoyo condicionado al proyecto- y dio por terminada la primera mesa de análisis.

Terminada la primera mesa de análisis tuve que retirarme del Foro, por lo que no presencié la conferencia magistral sobre desarrollo económico comunitario sustentable indígena a cargo de la Dra. Ángela Fontes Carrillo ni la conferencia sobre educación profesional indígena y su necesidad para el desarrollo económico de la Península de Yucatán a cargo del Mtro. Idelfonso Palemón Hernández Silva, rector de la UIMQROO; así como la segunda mesa de análisis sobre el PTM.

Ahora bien, este evento puede interpretarse como una ceremonia definicional, debido a que GNI muestra a funcionarios públicos de los tres niveles su capacidad de convocatoria y organización, el modo en que quiere ser visto por los ejidatarios al proponer una instancia de articulación y mediación con el Estado, y sus intenciones de adherirse al PTM ofreciendo sus servicios de mediación con los ejidatarios y población indígena a FONATUR. Esta propuesta no fue desestimada por Jiménez Pons ni por Aarón Rosado -enlace territorial de FONATUR en Yucatán- ese día, pero posteriormente no se requirieron los servicios del "líder supremo", acaso porque el respaldo social de base que ofrecía fue logrado por el nuevo gobierno a través del aparato estatal con los múltiples apoyos directos a la población rural; acaso por el desprestigio de GNI y el partido político que lo originó; o por las múltiples críticas y el desconocimiento del que fueron objeto el "líder supremo" y los "gobernadores indígenas" 153 nombrados por GNI.

La vía indigenista de los aparatos del PRI para participar en el PTM no se consolidó. No obstante, el "líder supremo" no dejaría de intentar obtener beneficios del PTM mediante la organización ejidal y obrera en su natal Campeche, donde incluso amenazaría en junio del 2020 a Grupo Carso (ganador de la licitación del 
tramo 3) con incendiar sus máquinas si no le concedían a su organización el contrato exclusivo para proveer mano de obra y materiales locales ${ }^{154}$.

El Foro Indígena Maya Peninsular y el "líder supremo" fueron desconocidos por múltiples actores. El caso más relevante es el del colectivo Úuchben Ch'i'ibal Túumben T'aan conformado por reconocidos intelectuales, artistas y activistas mayas de Yucatán, algunos son funcionarios públicos, otros participaron en el ya referido Cha'anil Kaaj Festival Independiente de la Cultura Maya, otros son miembros del colectivo Múuch Xíinbal. Durante una rueda de prensa ${ }^{155}$ el día 7 de marzo del 2019 en el Restaurante Amaro, ubicado en el centro histórico de Mérida, hicieron público un comunicado sobre el Proyecto Tren Maya y la pretensión de Gubernatura Nacional Indígena de representar a los mayas.

Imagen 26. Miembros del colectivo Úuchben Ch'i'ibal Túumben T'aan: Feliciano Sánchez Chan, Fidencio Briceño Chel, Marbella Casanova Calam, Elisa Chavarrea Chim y Pedro Uc Be

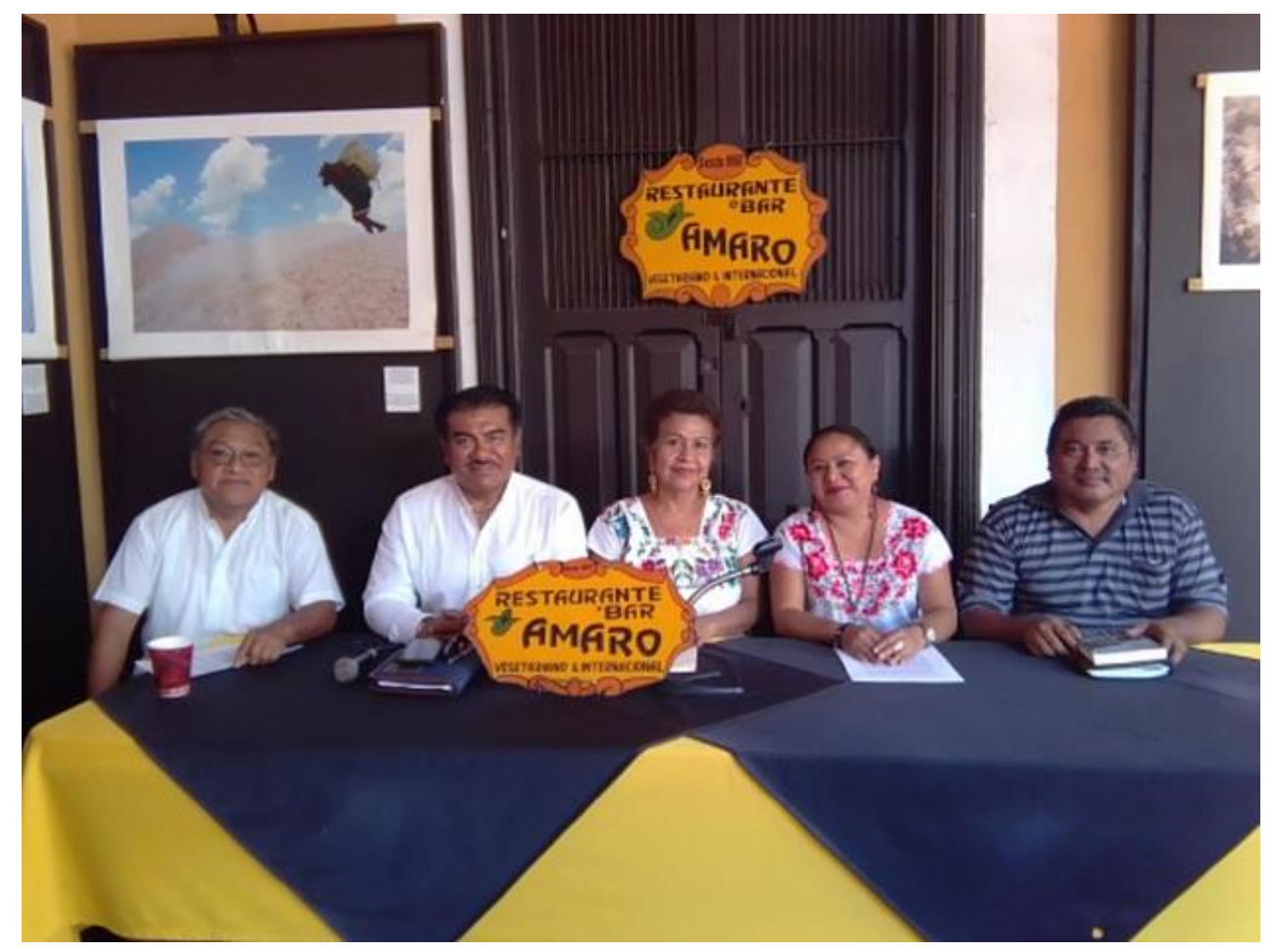

A continuación unos fragmentos del comunicado:

"Rechazamos la existencia de líderes, supremos, gobernadores indígenas mayas, o cualquier otra figura ilegítima que no tenga el poder ni la facultad de representar las decisiones ni la voz de las comunidades mayas, pues no se 
han realizado los mecanismos establecidos ni para la determinación de dicha autoridad ni para realizar negociaciones relacionadas con el tren maya.

(...) Nos deslindamos de las declaraciones realizadas por el Sr. Filiberto Ku, pues en ningún momento fue elegido por las comunidades mayas de la península y mucho menos existió algún procedimiento legítimo para dar legalidad a su nombramiento como líder indígena, por lo tanto, NO representa nuestros intereses comunitarios, ni a nuestras comunidades y mucho menos nuestras formas de organización y decisión comunitaria, ya que las afirmaciones hechas ante los medio sólo pertenecen a una asociación civil llamada Gubernatura Indígena Nacional.

Dejamos en claro que no estamos de acuerdo con este proyecto, debido a que carecemos de información que permita conocer todas las implicaciones, afectaciones, consecuencias y/o beneficios que el proyecto pudiera ocasionar directa e indirectamente al pueblo maya, en lo relacionado a lo ambiental, social, económico y cultural. Asimismo, reiteramos que todas las decisiones para llevar a cabo proyectos que impacten a las comunidades deberán de realizarse mediante toma de decisiones en asambleas comunitarias, por lo tanto quienes se ostenten como representantes supremos, no nos representan y por lo tanto toda declaración, foro, asamblea o acuerdo al que se llegue con estas personas carece de validez jurídica. Como colectivos mayas ocupados por que se garanticen los derechos colectivos e individuales de los pueblos indígenas, instamos a las instituciones del Estado, a los medios de comunicación y a la sociedad yucateca en general a lo siguiente:

Primero. Respetar el derecho a la autodeterminación del pueblo y las comunidades mayas, para lo cual se exige que se realicen los procedimientos de consulta de acuerdo a los lineamientos establecidos en el convenio 169 de la Organización Internacional del Trabajo, la Declaración de la ONU sobre los Derechos de los Pueblos Indígenas y el artículo segundo de la Constitución política de los Estados Unidos Mexicanos sobre los derechos de los pueblos indígenas. Bajo estas leyes, exigimos se escuche la voz del pueblo maya en la toma de decisiones sobre su devenir, y por ello, de NINGUNA MANERA el proyecto del Tren Maya deberá reducirse a un tema agrario y económico, pues 
no todos los ejidatarios pertenecen al pueblo maya, ni todos los mayas son ejidatarios, además de que, por lo general, las mujeres mayas no detentan títulos ejidales por prácticas de discriminación, por lo que, como consecuencia quedarían fuera de la discusión, dejándolas en una situación contraria a lo establecido en la constitución política en la materia.

Segundo. Se solicita a los medios de comunicación informar a la ciudadanía sobre los derechos de los pueblos mayas, y no prestarse a distorsiones políticas sobre la información que se brinda.

Tercero. Exigimos que se realice la Consulta previa, libre, informada de manera pacífica y culturalmente adecuada, de acuerdo a los estándares internacionales más altos, tales como los de la Corte Interamericana de Derechos Humanos; que cuente con estudios del impacto ambiental y con estrategias conjuntas para aminorar, en su caso, los efectos negativos de estos proyectos. A través de la consulta se garantizan nuestros derechos humanos a la autodeterminación, a la ejecución de un proyecto de vida colectivo, al desarrollo con identidad, a mantener el medio ambiente sano, entre otros. Rechazamos aquellas visiones de desarrollo que no provengan de nosotros los pueblos. ¡Basta de imposiciones!

Cuarto. El mejor patrimonio del pueblo maya, es su gente viva y que resiste, invitamos al pueblo maya a estar atento y a sumarse a la exigencia de nuestros derechos. Nosotros los pueblos indígenas no nos oponemos al desarrollo, nos oponemos al despojo, a la contaminación de nuestros recursos y al daño de nuestra selva, a la eliminación de nuestra forma tranquila de vivir. Sí queremos trabajo, pero queremos que sea en los términos que nosotros mismos decidamos y no lo que se decida para nosotros. ¡no más explotación!"

Esta rueda de prensa congregó a personalidades del ámbito intelectual, artístico y activista maya, quienes desde distintas instancias, ya sean académicas, gubernamentales u organizaciones activistas sin fines de lucro, sumaron esfuerzos para mostrar a la opinión pública lo que no son los mayas, quiénes no los representan y cuáles no son los modos para obtener el derecho de ostentarse como representante del Pueblo Maya. A pesar de las diferencias que existen entre los miembros del colectivo, coincidieron en la necesidad de cortar de tajo la propuesta de mayanidad y 
de relación intersectorial que proponía $\mathrm{GNI}$ a través del autoproclamado "líder supremo". Igualmente coincidieron en que el Pueblo Maya no puede apoyar el PTM si no se conocen los efectos positivos y negativos, por lo que se necesitaría realizar las MIAs y la consulta indígena de manera adecuada.

Estamos ante un sector -diverso y fluído- que ha construido narrativas particulares sobre la mayanidad como identidad étnica y como recurso inmaterial para disputar otros recursos. Este proceso de construcción negociada de universos simbólicos compartidos ha generado una ética más o menos común, sensible y comprometida con las necesidades y realidades de la población maya (aunque con matices y diferencias en las prioridades, agendas y acciones) desde la cual la propuesta de GNI resulta inaceptable, ofensiva y deshonesta. Este colectivo no siguió trabajando después de la descalificación pública de GNI y Ku Chan, sino que sus miembros generaron (o no) críticas, propuestas y acciones divergentes con respecto al PTM. O sea, actores con intereses más o menos compartidos pero con agendas y modos heterogéneos unieron capitales simbólicos y sociales de sus diversos ámbitos de operación, para ponerle un alto a una propuesta que atentaba contra sus intereses a mediano y largo plazo, pues amenazaba la hegemonía de las narrativas sobre la mayanidad que han construido a lo largo de los años, con mucho trabajo, empeño, compromiso y buenas intenciones.

El "líder supremo" emitió algunos comentarios sobre la declaración del colectivo, en entrevista con el poco conocido medio digital Noticias Contrapunto. Según este medio ${ }^{156}$, Ku Chan afirmó: "ni caso hacerles (...) Yo los voy a tomar como el borracho, que se ahoguen con su propio vómito. A mí no me van a provocar". Igualmente, según el referido medio, Ku Chan aseguró que él no es un empleado de gobierno y sí es un líder porque trabaja desde las 4 de la mañana y en acciones filantrópicas para los mayas, para los que fundó empresas socialmente sustentables. A diferencia de los indigenistas -nunca ha especificado a quiénes se refiere como "indigenistas"- a quienes tildó de "hijos de la gran puta que se aprovecharon de la causa indígena", él como indígena habla una lengua materna (sic) y tiene apellidos mayas.

Antes de finalizar este último capítulo de la tesina, quisiera señalar que durante el trabajo de campo realizado en el oriente de Yucatán durante 2019, al conversar 
sobre el Tren Maya y la disputa entre el "líder supremo" y los intelectuales mayas, con personas que se asumen como mayas -hablan la lengua, tienen apellidos mayas, ellos o sus padres trabajan la milpa y también son miembros de cooperativas de turismo comunitario- era recurrente la idea de que "es su opinión y está bien que crean lo que quieran pero que no hablen por los demás", en referencia tanto a Ku Chan como a los intelectuales mayas. No obstante, el rechazo y desaprobación al proceder de Ku Chan fue unánime también en este sector. Esto hace pensar que no todos los que se asumen a sí mismos como mayas quieren lo mismo. En este sentido nadie está capacitado para hablar por todos los mayas; lo más cercano sería un representante elegido mediante democracia directa asamblearia o representativa a escala estatal, peninsular o sur-sureste, pero no existe en la actualidad un proyecto de este tipo.

Con respecto a la postura de los intelectuales mayas sobre el PTM, opinaron que estaban de acuerdo en que se hicieran las consultas y las MIAs para que el proyecto se hiciera bien y porque es su derecho como mayas ser tomados en cuenta para este tipo de obras. No obstante, a pesar de los temores que les causaba la incertidumbre y la falta de información sobre los efectos negativos que podría tener el Proyecto Tren Maya en lo ambiental, cultural y social, se mostraban expectantes sobre la promesa de dinamización económica en la zona, sobre todo para que los jóvenes pudieran conseguir trabajo en su localidad y no tuvieran que migrar forzosamente a Cancún o la denominada Riviera Maya. En una ocasión se le preguntó a una de estas personas si estaba de acuerdo con el Tren Maya, al afirmar que sí, alguien más le preguntó si estaría dispuesto a dar parte de su tierra si fuera necesario, ante la sorpresa de varios de los ahí presentes dijo que sí, pero con la condición de que fuera para el bien de toda su comunidad. Agregó, por último, que él podía estar dispuesto a dar su tierra, pero que no estaba en sus manos, pues la tierra no es sólo suya, sino que pertenece al ejido y a través de este a toda la población de la localidad.

Si bien la fase de ruptura significó la formación de las facciones promovente y oponente del Tren Maya, la fase de crisis se caracterizó por el engrosamiento de las filas de ambas facciones. Los distintos actores intentaron persuadir a otros de adoptar sus narrativas mediante rituales políticos, ceremonias definicionales, convenios de colaboración, contratación o propaganda. Esto con el fin último de ajustar la voluntad del Otro a sus agendas políticas, ya sea de modo solidario, colaborativo o 
subordinado. Los diversos actores sociales hicieron despliegues de las capacidades de convocatoria, los capitales políticos, sociales, culturales y económicos de los que disponen. En este sentido, se generaron las primeras alianzas y se declararon los primeros antagonismos.

La facción promovente buscó aliarse con actores colectivos estratégicos en la región sur-sureste y a nivel nacional, firmando convenios de colaboración con universidades, colegios profesionales, empresas, organizaciones de la sociedad civil e instancias de la ONU. Esto con el fin de lograr la aprobación del proyecto y garantizar la colaboración de actores que pudieran nutrir la iniciativa.

Quedó en evidencia también la exigencia de lealtad y el poco espacio para la crítica, pues de manera estratégica el sector gubernamental calificó como oposición a aquellos actores que se acercaron con una propuesta en sus propios términos. La lealtad que demanda entonces la facción promovente se basa en la aceptación de la narrativa de la Cuarta Transformación, la aceptación en lo general del Proyecto Tren Maya, y la disposición para colaborar en aspectos particulares del mismo en los términos del sector gubernamental. Esta situación, surgida de la necesidad política de afianzar la nueva administración y sus proyectos, probablemente influya en el establecimiento de los márgenes y posibilidades de incidencia de los ejercicios de participación comunitaria promovidos posteriormente a través del área de vinculación social del Tren Maya, ONU-Habitat, etc.

Esta situación recuerda a lo señalado por Pereda en Díaz Cruz (2014) sobre la "razón arrogante", aquella que busca autoconfirmarse sin límites y descalificar también sin límites, buscando constantemente más de lo mismo y nada de lo otro. En este momento inicial de la fase de crisis del drama social, la narrativa de la Cuarta Transformación tuvo que ser sostenida por sus promotores de manera "arrogante", pues de no haberlo hecho sus oponentes hubieran aprovechado la ventaja política para cuestionar constantemente con la intención de desvanecerla y convertir en un absurdo el Proyecto Tren Maya ante la opinión pública. No había lugar para titubeos. Como se mencionó antes, lamentablemente los "abajofirmantes" fueron el sacrificio simbólico que realizó el sector gubernamental para decir "conmigo o en mi contra", generando la ruptura y sentando las bases para la crisis en el drama social del Proyecto Tren Maya. 
Del mismo modo, la facción oponente hizo despliegues de razones arrogantes mediante las narrativas del despojo por megaproyectos/resistencia territorial indígena, la del Mundo-Finca y la del altermundismo-anticapitalista-antiestado. Al igual que la facción promovente, la facción oponente se valió de estas herramientas y estrategias para posicionar su agenda política y negar la del sector gubernamental. También excluía en todo momento la posibilidad de crítica y proporcionaba explicaciones esquemáticas de la realidad social orientadas a la movilización social.

Tenemos pues que el patrón de despliegue de narrativas es similar en ambas facciones, las dos incurrieron en "razones arrogantes", pero con una diferencia fundamental: el Estado tiene abismalmente más recursos a su disposición para patrocinarse la hegemonía en el campo político mediante convenios, contrataciones, vinculación social; aunado a que la publicidad y propaganda del Proyecto Tren Maya es hecha por expertos para ganar terreno en la opinión pública.

Por el contrario, la facción oponente se vio disminuida, pues una parte de los actores que hubieran podido posicionarse en contra del Proyecto Tren Maya fueron invitados a colaborar con FONATUR, lo que pudiera ser percibido por dichos actores -pero cuestionado por otros- como un modo de incidir en la optimización de beneficios y en la disminución de impactos negativos. Esto último responde a un episodio del drama social de la Cuarta Transformación, cuando una parte considerable de los académicos, intelectuales, artistas, activistas y oeseceros de izquierdas se vieron en la situación de elegir entre el EZLN y AMLO, optando por este segundo, pues vieron revitalizada en su agenda la posibilidad de generar cambios sociales positivos desde el Estado, aprovechando los recursos que éste tiene a su disposición y que al final son bienes públicos. Algunos de estos actores mudaron de narrativas y se ideologizaron, otros aspiran a operar estratégicamente para incidir en aspectos particulares.

En buena medida, esta fase se ha tratado de la confrontación de perspectivas y agendas políticas que no estaban dispuestas a ceder en ningún aspecto, pero con capacidades y recursos muy desiguales para conseguir sus objetivos. El clima de violencia fue en aumento durante esta fase de crisis. Se multiplicaron los episodios de hostilidad, afrenta y descalificación hacia múltiples direcciones. El Gobierno Federal prescindió de Gubernatura Nacional Indígena el día de la entrega del bastón 
de mando, después de haberle dejado anunciar que sería la instancia encargada de la ceremonia. EI EZLN reforzó su desaprobación hacia López Obrador, su agenda política de la Cuarta Transformación y el Proyecto Tren Maya. Un colectivo intersectorial de actores mayas desconoció al autoproclamado "líder supremo nacional indígena" y su intento de hablar por todos los mayas ante FONATUR.

Es de resaltar la alianza de los actores mayas pertenecientes a diversos sectores del campo político del PTM -gubernamental, académico, activismo étnico ambientalista- para desconocer al "líder supremo nacional indígena", su narrativa y agenda política, pues los actores aliados, aunque no estuvieran de acuerdo en lo concerniente a la Cuarta Transformación y al Tren Maya, coincidían en la necesidad de desaparecer del campo político a la polémica Gubernatura Nacional Indígena, su narrativa de la indigeneidad/mayanidad folklorizante y clientelar y sus prácticas éticamente cuestionables.

Después de marzo del 2019, fecha de corte de este trabajo, la fase de crisis del drama social del Proyecto Tren Maya ha seguido su curso. La facción promovente ha realizado más rituales políticos como la Caravana Informativa "EI Tren que nos une" en diversos municipios a lo largo de la ruta del proyecto durante junio y julio del 2019. También ha llevado a cabo ceremonias definicionales, como los banderazos de inicio de obras del Tren Maya en localidades de la Península en junio del 2020, en el contexto de la pandemia de COVID-19, momento en que la facción oponente aprovechó para cuestionar la prioridad nacional de este proyecto ante la emergencia sanitaria y la desaceleración económica consecuente.

De igual forma, la facción oponente ha realizado ceremonias definicionales como el $5^{\circ}$ Festival de Arte Independiente de Bacalar Deba-Tren Maya en Bacalar del 3 al 6 de abril de 2019; la 4 ${ }^{\text {a }}$ Asamblea Nacional del CNI-CIG y el Foro en Defensa del Territorio y la Madre Tierra del 18 al 22 de diciembre de 2019, en los que el EZLN y el CNI-CIG reiteraron el rechazo al PTM; y los múltiples posicionamientos de organizaciones del activismo étnico ambientalista de la Península de Yucatán en contra del Tren Maya, protagonizados por Múuch Xínbal, CRIPX, U kúuchil k Ch'i'ibalo'on e Indignación, entre los que destaca la reiteración del rechazo al PTM por parte de Múuch Xíinbal en el edificio del INPI a casi un mes de que fuera tomado por parte de la Comunidad Indígena Otomí alineada al CNI el 12 de octubre del 2020. 
Como era previsible, los distintos actores han continuado impulsando las narrativas analizadas en este estudio a través de comunicados, propaganda, publicidad, encuentros, seminarios, rituales y ceremonias políticas de diversa índole. Entre las acciones más importantes del sector promovente en este sentido, tenemos el inicio de informes semanales -el 24 de agosto del 2020- sobre los avances del Proyecto Tren Maya durante las conferencias matutinas de López Obrador, a cargo de Jiménez Pons, estableciendo la meta de concluir el proyecto en 157 semanas, por lo que cada informe abona a la impresión de avance, independientemente de lo acelerados o modestos que sean los progresos.

También se han dado nuevos momentos de confrontación, como es el caso de los múltiples amparos por parte de actores del sector OSC que lograron por un momento la suspensión del tramo 1 del Tren Maya por orden judicial en junio del 2020. Igualmente, cuenta al respecto la acusación de López Obrador hacia diversas OSC que presuntamente reciben dinero de instancias extranjeras para oponerse al Tren Maya, el 28 de agosto del 2020 durante una conferencia matutina.

De igual modo, tenemos la sorpresiva reaparición del "líder supremo nacional indígena" Filiberto Ku Chan, transmutado en líder ejidal a través de la Unión de Ejidos Autónomos de la Península. Mediante esta instancia amenazó a Grupo CARSO ganador de la licitación del tramo 2- con incendiar sus maquinarias si no ofrecía un contrato colectivo exclusivo para la mano de obra y dotación de materiales. Al final esta amenaza fue desoída y grupo CARSO firmó un convenio con el sindicato de la CTM, ocurriendo todo esto en junio del 2020. Así pues, tenemos que un sindicato priísta logró conseguir el contrato colectivo en vez del brazo indigenista en decadencia del PRI.

Por otra parte, también se han dado momentos de diálogo como la realización de Foros Legislativo-Académicos sobre el Proyecto Tren Maya entre marzo y agosto del 2019; el Diálogo INAH Yucatán-FONATUR los días 26 y 27 de septiembre del 2019; la Consulta indígena en noviembre y diciembre del 2019; los Talleres de visión con apoyo de ONU-Habitat para definir el rol de las estaciones y comunidades sostenibles en el entorno durante enero y febrero 2020.

Como ya se ha mencionado, las obras del Tren Maya iniciaron el 1 de mayo del 2020. Posteriormente se presentó ante SEMARNAT la Manifestación de Impacto 
Ambiental del Proyecto Tren Maya Fase 1, el 16 de junio del 2020, abriéndose a consulta pública durante julio del mismo año. Asimismo, la realización de seminarios, mesas panel, webinarios y publicaciones oficiales, académicas y de divulgación sobre el Tren Maya han ido en aumento (ver anexo). A continuación se ofrecen las consideraciones finales de este trabajo. 


\section{Conclusiones}

A continuación se aborda cómo las diversas narrativas desplegadas en el drama social del Proyecto Tren Maya han servido para disputar el control y significado de los recursos espacio geográfico, indigenidad-mayanidad y opinión pública. Se presta particular atención a las narrativas sobre la mayanidad y se presenta una clasificación de las mismas. El análisis y categorización de las narrativas de la mayanidad propuesto es un hilo conductor que permite ofrecer una síntesis de las posiciones de los actores principales del proceso político, en función de las desigualdades interétnicas alrededor del Proyecto Tren Maya. Asimismo, con base en el análisis de los resultados obtenidos, se brindan recomendaciones para que el Proyecto Tren Maya pueda reducir y no reproducir o profundizar las desigualdades interétnicas existentes en la región sur-sureste de México. Por último, se señalan posibles rutas de estudio para la investigación doctoral en ciencias antropológicas.

A lo largo de este trabajo se mostró como las facciones promovente y oponente en el campo político del Proyecto Tren Maya se valieron de múltiples narrativas con el objetivo de lograr la hegemonía en la opinión pública, ampliar los capitales políticos y el respaldo social de agendas políticas en torno al Tren Maya, para así obtener el control sobre los recursos espacio geográfico e indigenidad-mayanidad. En momentos de confrontación, estas narrativas se presentaron estratégica 0 inconscientemente como "razones arrogantes" que buscaban autoafirmarse sin límites y descalificar a las otras perspectivas también sin límites. Los grados de aceptación popular de estas narrativas dependieron en buena medida de la capacidad de proveer seguridad ontológica y/o material a quienes las aceptan y propagan. En este sentido, el éxito de las narrativas en su lucha por el sentido común -en función de respaldar agendas políticas- dependió de la adecuada activación de los capitales sociales, económicos y políticos de los que disponían los actores. Asimismo, influyó en su éxito la adecuada ejecución de acciones simbólicas, como rituales políticos, ceremonias definicionales, sacrificios simbólicos y el uso oportuno de símbolos dominantes.

A lo largo de este trabajo estuvieron presentes varias pequeñas narrativas que en última instancia corresponden a cuatro grandes narrativas. La primera de ellas es la de la Cuarta Transformación, promovida desde el sector gubernamental, siendo la 
punta de lanza de la facción promovente del Tren Maya. La segunda es la de altermundismo-anticapitalista-antiestado, vinculada al sector del activismo étnico ambientalista y a facciones de la academia, el sector OSC y el sector periodístico, que en suma conformaron la facción oponente.

La tercera, fue la narrativa de la turistificación-mayanización que operó de manera velada en los sectores gubernamental y empresarial al interior de la facción promovente, y de manera quizás inconsciente en facciones del sector académico, OSC y dueños legales de las tierras, que a través de estos elementos compartidos con la facción promovente han establecido canales de diálogo y tal vez colaboración, incluso si inicialmente tenían sus reservas ante el Proyecto Tren Maya.

En última instancia, quienes han aceptado el diálogo o la colaboración con FONATUR es porque están familiarizados con la cuarta gran narrativa que operó en este proceso político de manera subyacente y omnipresente: la narrativa del desarrollo -sin adjetivar o adjetivado- que es un componente fundamental de las narrativas de la turistificación-mayanización y de la Cuarta Transformación. Como la narrativa del desarrollo está presente a nivel institucional en los sectores académico, OSC, empresarial y gubernamental, se explica el éxito obtenido por FONATUR en el establecimiento de alianzas con dichos sectores.

Por otra parte, dado que la narrativa del desarrollo surgió en Occidente y no puede entenderse sin la participación del Estado y del Capital, esta es rechazada por una porción importante de la facción oponente del PTM. En este sentido, los actores de las izquierdas institucionalizadas tuvieron que elegir en algún momento si se sumarían a la facción promovente o a la oponente, resultando que una parte considerable optó por la opción política que representa la Cuarta Transformación, y a través de dicha lectura, les haya sido atractivo entablar diálogos para generar posibles rutas de incidencia para minimizar perjuicios y optimizar beneficios. Esta es una posible explicación del engrosamiento de la facción promovente y de la disminución de la facción oponente.

Es llamativo también en este sentido que las facciones de los sectores académico y OSC cercanos a la narrativa del altermundismo-anticapitalistaantiestado, y consecuentemente críticos a la narrativa del desarrollo, no hayan querido o no hayan tolerado los diálogos con la facción promovente, pues la oposición 
entre las perspectivas puede llegar a ser, en cierta forma, hasta ontológica si los actores se identifican personalmente con la narrativa.

Resulta interesante que quienes fueron en algún momento aculturados con la narrativa del desarrollo no percibieron negación o choque ontológico alguno a raíz de las acciones y declaraciones de la facción promovente. Más bien se vieron intrigados sobre la ejecución del proyecto y, si acaso, buscaron formas de incidir para llevar a buen término los procesos.

En contraste, los actores críticos a la narrativa del desarrollo -como resultado de una formación particular en ciencias sociales y del acompañamientos a los movimientos sociales- sí percibieron un choque ontológico. Sin embargo, sólo desde ese desfase fue posible ver que la narrativa del desarrollo es una construcción social y no es algo dado, natural ni de sentido común, por lo que la aceptación del Tren Maya no debería darse a la ligera. No obstante, las narrativas que permitieron observar esto también pueden ser vistas externamente como construcciones sociales, no dadas ni naturales ni cuestión de sentido común.

En última instancia las facciones promovente y oponente operan con los mismos patrones de uso de narrativas, la diferencia entre ambas posturas es una diferencia de poder, de suma de capitales económicos, políticos, sociales, culturales; de control sobre las instituciones, los medios de comunicación, los presupuestos, las políticas públicas.

¿Es la Cuarta Transformación una agenda política en torno al desarrollo o utiliza la narrativa del desarrollo como parte de una agenda política? Sólo atendiendo a los detalles a lo largo del proceso político se podrá saber si la balanza se inclina hacia alguna de las opciones o si en realidad se trata de las dos caras de una moneda.

Ahora bien, al interior de estas cuatro grandes narrativas presentes en el drama social del Proyecto Tren Maya, encontramos diferentes usos y significados conferidos al recurso inmaterial en disputa de la indigenidad-mayanidad. Sostengo que estos usos y significaciones constituyen diversas narrativas sobre la mayanidad. A continuación ofrezco una categorización de las mismas que permite también sintetizar las posiciones de los actores principales del drama social del Tren Maya. 
Sugiero que el proceso político del Proyecto Tren Maya debe considerarse a la luz del proceso de "etnogénesis maya" iniciado en la década de 1970 -tanto por la formación de intelectuales mayas como por la creación de la noción de "Mundo Maya" por el Estado mexicano- y que la "mayanización" tiene diversas manifestaciones simultáneas en el drama social. Inspirándome en los Comaroff y Rodríguez Garavito, citados en Llanes (2016), propongo la siguiente clasificación etic de narrativas sobre la mayanidad:

- mayanidad.gob: Abreva de la narrativa de la "modernidad desde abajo centralizada estatalmente" de la Cuarta Transformación. Concibe a la población maya como circunstancialmente pobre y rezagada a la vez que culturalmente valiosa y rentable. Incluye a los mayas del pasado arqueológico y los del presente, pero no menciona a los mayas históricos, que han habitado la región en condiciones de explotación y dominación desde la Conquista. Considera la mayanidad simultáneamente como capital simbólico-político para la legitimación de agendas políticas; como capital simbólico-económico para la generación de valor agregado; y como patrimonio cultural a conservar y promocionar. Desde esta narrativa la población maya es simultáneamente objeto de políticas públicas, capital político y sujeto de derecho. En este trabajo fue representada por Andrés Manuel López Obrador, Rogelio Jiménez Pons y Emilio Ramírez de la SEDESPI (Chiapas);

- mayanidad.old: Reminiscencia del indigenismo posrevolucionario desvirtuado por los antiguos partidos políticos hegemónicos en combinación con discursos racistas sobre la otredad. Concibe a la población maya como esencialmente pobre y rezagada a la cual hay que usar y transformar, aún sea en contra de su voluntad o con engaños. Exalta a los mayas arqueológicos, ignora a los mayas históricos y concibe a los mayas actuales principalmente como capital político y económico, secundariamente como objeto de políticas públicas y residualmente como sujetos de derecho. En este trabajo fue representada por Filiberto Ku Chan alias "Iíder supremo" y su asociación civil Gubernatura Nacional Indígena;

- mayanidad.com: Esta narrativa abreva de la creación de la noción de Mundo Maya por parte del Estado mexicano en la década de 1970, en combinación con el éxito turístico del CIP Cancún iniciado en 1972, cuyo modelo se replicó 
a lo largo de la costa quintanarroense en lo que se denominaría "Riviera Maya". Esta narrativa enfatiza la mayanidad como marca comercial, valorando su uso como capital simbólico-económico generador de valor agregado para productos turísticos y de otra índole. Con fines comerciales exalta a los mayas arqueológicos y puede no desestimar a los "mayas galácticos"; actualmente no da mayor importancia a los mayas históricos, aunque recientemente se ha vuelto polémica la oferta turística del "sueño del hacendado" en Yucatán (por ejemplo, baño "maya" en cerveza ${ }^{157}$ ) y la disneyzación de la esclavitud de los mayas durante la Guerra de Castas ${ }^{158}$. Considera a los mayas actuales como capital humano barato que sin embargo es dueño de su propio destino, pues no considera la complejidad de las desigualdades estructurales. En este trabajo no fue suficientemente representada por ninguno de los actores;

- mayanidad.age: Esta narrativa se nutre de las ideas del New Age sobre el origen extraterrestre de los mayas arqueológicos y del movimiento aztequista o de la mexicanidad. Desde esta narrativa los mayas actuales son descendientes de los antiguos mayas que no fueron dignos de emprender el viaje fuera del planeta en un momento de colapso, por lo que no son herederos de lo maya original, como sí lo son los aprendices de las enseñanzas del fundador del New Age José Argüelles y sus discípulos. Exalta al maya arqueológico en función de las narrativas del New Age e ignora al maya histórico, incluso puede llegar a justificar las violencias que han sufrido y sufren los pueblos mayas con el argumento de que están pagando una deuda kármica. Considera a la población maya actual como no realmente o no lo suficientemente maya. Desde esta narrativa la población maya actual no es relevante, salvo los individuos que performan el misticismo de esta mayanidad y ofician falsas ceremonias, rituales, sanaciones, temazcales y bodas mayas, así como los "danzantes prehispánicos" en entornos turísticos. En torno a esta narrativa, aunque no es primordialmente económica, se ha creado un mercado pujante y elitista, cuyos consumidores principales son mayormente turistas temporales o residentes- de Europa y Estados Unidos. En la región se focaliza esta oferta y demanda de servicios esotéricos y sus derivados en Palenque, Tulum y a lo largo de la denominada Riviera Maya. Esta narrativa es popular entre quienes demandan estos servicios y quienes los ofrecen. En este trabajo esta narrativa fue representada por el supuesto j'meen Tiburcio Can; 
- mayanidad.omm: Se basa en la narrativa de la turistificación-mayanización iniciada por el Estado mexicano en la década de 1970 con la creación de la noción Mundo Maya y en la consolidación de esta mediante la conformación de la Organización Mundo Maya (OMM) en 1988, compuesta por las secretarías de turismo o equivalentes de México, Guatemala, Belice, Honduras y El Salvador. Esta narrativa combina circunstancial y estratégicamente elementos de la mayanidad.gob, mayanidad.old, mayanidad.com y mayanidad.age. Es una narrativa amplia, ambigua, adaptable, con fines primordialmente económicos, secundariamente políticos y consecuentemente culturales y sociales, por tal motivo se ha instalado como narrativa hegemónica y es posible encontrar vínculos entre esta y cualquier otro tipo de mayanidad aquí expuesta, ya sea por afinidad o por esmero en la detracción. Se utiliza la mayanidad como capital simbólico-político legitimador, como capital simbólicoeconómico generador de valor agregado y como patrimonio cultural para conservar y promover. Desde esta perspectiva la población maya actual es simultáneamente objeto de políticas públicas, capital político, capital humano y sujeto de derecho. En este trabajo fue representada por la OMM y el ex presidente mexicano Felipe Calderón;

- mayanidad.osc: Abreva principalmente de las narrativas del desarrollo y la de los Derechos de los Pueblos Indígenas, impulsadas por organismos internacionales como la ONU y la OIT con el Convenio 169. Esta narrativa considera a la población maya como diversa internamente pero diacrónica y estructuralmente empobrecida, a la vez que culturalmente valiosa. No ignora a los mayas arqueológicos e históricos pero prioriza a los mayas actuales y la atención a sus problemáticas vigentes en los ámbitos económico, social y cultural. Desde esta narrativa se valoran los conocimientos y capacidades locales a la vez que se intenta transferir conocimientos y capacidades exógenas; igualmente se valora la colaboración intersectorial -gobierno, empresa, academia, OSC- para atender las problemáticas socialmente sentidas o externamente detectadas en las poblaciones mayas. Desde esta narrativa la mayanidad es simultáneamente una identidad étnica que sirve como capital simbólico-político para el empoderamiento local; una marca comercial que como capital simbólico-económico puede generar valor agregado a los emprendimientos locales; y como patrimonio cultural a 
conservar y promover. Desde esta narrativa la población maya es primordialmente sujeto de derechos y secundariamente objeto de programas de desarrollo y políticas públicas. Esta narrativa suele ser sostenida por actores mayas y no mayas que operan como intermediarios y/o mediadores entre las localidades mayas, el sector gubernamental, el empresarial y el sector OSC. Fue parcialmente representada en este trabajo por ONU-Habitat y la Alianza Peninsular de Turismo Comunitario;

- mayanidad.soc: Esta narrativa es propia de las discusiones académicas y los académicos de las ciencias sociales, se nutre de los temas de investigación sostenidos en el tiempo que han generado narrativas como la del "despojo por megaproyectos y resistencia territorial indígena", la cual a su vez abreva de (re)elaboraciones mayoritariamente de la segunda mitad del siglo XX latinoamericano como el marxismo, el etnomarxismo, la teología, pedagogía y filosofía de la liberación, la Investigación Acción participativa, la teoría de la dependencia, la crítica al desarrollo, la teoría poscolonial y decolonial, la antropología comprometida y/o nativa, las distintas olas de estudios indigenistas y del racismo, y considera sumamente relevante las experiencias y narrativas de las organizaciones indígenas de izquierda como el CNI y el EZLN. En buena medida, esta narrativa de la mayanidad es una particularización de la narrativa más amplia sobre los Pueblos Indígenas generada en Latinoamérica, de la cual México ha sido referencia sostenidamente desde su etapa indigenista posrevolucionaria. Debido a la multiplicidad de fuentes de las cuales se nutre esta vasta narrativa, las posibilidades de elaboración sobre la mayanidad en particular (y de la indigenidad en general) pueden ser tantas como investigadores sobre el tema. No obstante, hay ciertas constantes que se han vuelto una especie de sentido común, como que la población maya ha sido sistemáticamente explotada y sometida a través del tiempo por los no-mayas de la región y del país; que las causas de su pobreza pueden hallarse tanto en el primer contacto con los europeos, como en la historia de dominación colonial de los siglos posteriores y en la colonialidad que impera en el sentido común de la sociedad nacional y peninsular actuales, misma que se ve reflejada en la planeación e implementación de las políticas públicas para la población maya. Igualmente, es una constante en esta narrativa compleja el concebir la mayanidad 
principalmente como una identidad étnica, la cual los sujetos de estudio, el investigador comprometido y/o el investigador nativo, pueden activar como capital simbólico-político para empoderar a un grupo, legitimar una propuesta política y llamar a la movilización social. Contempla también la mayanidad como patrimonio cultural a conservar y promover, pero desdeña todo intento de mercantilizar la mayanidad, ya sea considerar a los mayas actuales como capital humano o al etnónimo como una marca comercial. Desde esta narrativa es una constante considerar a la población maya como un Pueblo vivo sujeto de derecho, a los mayas como conciudadanos y sujetos de estudio. Esta narrativa fue parcialmente representada en este trabajo por Giovanna Gasparello y Felipe Echenique;

- mayanidad.cni: Esta narrativa es desplegada mayormente por actores que se asumen reivindicativamente como mayas y por sus aliados activistas, académicos y oeseceros no mayas. Se nutre de narrativas creadas en conjunto con el sector académico, como la del "despojo por megaproyectos y resistencia territorial indígena", y también recupera las narrativas de organizaciones indígenas de izquierda como el EZLN y el CNI, como la del "Mundo-Finca" y "neoliberalismo contra los pueblos del mundo" y la del "altermundismoanticapitalista-antiestado". Concibe a la población maya como sistemática e intencionalmente empobrecida a través de la explotación económica y la dominación política y cultural por los Estados Capitalistas Occidentales. También percibe a la población maya como un Pueblo -incluso como una Nación- que ha resistido la colonialidad por más de 500 años desde la llegada de los europeos a la Península hasta la globalización neoliberal actual. Reconoce la ancestría de los mayas arqueológicos, pero enfatiza la dominación y explotación de los mayas históricos y del presente. Desde esta narrativa la mayanidad es la identidad étnica que da sentido a la existencia de quien la asume y que permite enseñar a quien no se asume como maya y esté dispuesto a escuchar. Es concebida la mayanidad como una identidad étnica que activada como capital simbólico-político permite la movilización social; estratégicamente y en situaciones particulares se considerará la mayanidad como patrimonio cultural a conservar y promover; se desdeña toda intención de mercantilizar la mayanidad, ya sea a través de concebir a la población maya actual como capital humano o mediante el uso del etnónimo maya como marca 
comercial. Desde esta narrativa la población maya es simultáneamente un Pueblo en resistencia, sujeto de derecho y capital político. En este trabajo fue representada por el EZLN, CRIPX, Múuch Xínbal y U kúuchil k Ch'ỉibalo'on.

Como se podrá notar, en función de cada una de estas narrativas sobre la mayanidad hay una propuesta ideológica de fondo con una particular forma de significar el espacio geográfico, ya sea como territorio maya, sur-sureste de México, Península de Yucatán, Mundo Maya. Cada una de estas significaciones representa modos de percibir las relaciones interculturales y la relación del humano con el medio natural.

Ahora bien, en términos políticos, no es relevante si los contenidos de las narrativas son "verdad", importa su verosimilitud, su impacto en la opinión pública y en el ordenamiento material del mundo, es decir, que haya quienes lo crean, difundan y pongan en práctica para lograr la distribución de recursos del modo que consideran conveniente, ya sea únicamente para sí mismos o para capas más amplias de la sociedad.

Considero que explorar las vetas de investigación abiertas por la clasificación de las narrativas aquí propuestas abonaría a superar los esencialismos y maniqueísmos en torno al Proyecto Tren Maya, lo cual aportaría tal vez a generar espacios de diálogo -intersectorial, intercultural, interclase, intergeneracional y transdisciplinario- más fructíferos para la población maya y no maya de la Península de Yucatán. Opino que si se quiere comprender y/o atender alguna desigualdad como la étnica- no basta con mirar al sujeto en desventaja, hay que mirar el conjunto de las relaciones con otros sectores, los valores, recursos y significados en juego. Mientras no haya conciencia de la integralidad e interdependencia de los múltiples sectores sociales y de la complementariedad de sus narrativas, poco se podrá hacer para reducir las desigualdades.

Quizá sin el referente abierto por las posiciones utópicas más radicales de la izquierda -como el sector del activismo étnico ambientalista- no habría un horizonte pragmático más modesto pero viable para los objetivos de la centroizquierda al interior de los aparatos gubernamentales, intergubernamentales, el sector OSC y la academia. Igualmente, quizá sin la injerencia de estos últimos en las agendas y asignación de presupuestos, los actores más radicales no podrían subsistir económicamente. Del mismo modo, la academia simpatizante-acompañante de la 
izquierda radical -a veces duramente crítica con el sector OSC- no podría existir sin el financiamiento del Estado o de algún Engels, por lo que no habría tiempo ni recursos para la implementación de investigaciones aplicadas o implicadas ni para la reflexión. Asimismo, sin la labor de investigación académica no existirían ni las narrativas del desarrollo, ni los instrumentos para diseñar y medir proyectos sociales y política públicas, ni buena parte de los fundamentos de la narrativa del altermundismo-anticapitalista-antiestado. Estos sectores y sus narrativas están íntimamente interconectados y se influyen mutuamente. Todos abonan a la producción, reproducción y transformación del sentido común, todos abonan a la construcción material del mundo y a la distribución de los recursos.

Una ventaja de la generación nacida en las décadas de 1980 y 1990 es que hemos metido las manos y la cabeza en más de uno de los sectores mencionados, como resultado de la inestabilidad laboral y de la mayor oferta ontológica que nos fue legada. Hemos tenido la oportunidad de aprender desde varias perspectivas del legado de las generaciones que nos anteceden, tanto de sus aciertos como de sus desaciertos, de sus compromisos e incongruencias, de sus posibilidades y limitaciones, de sus erudiciones y puntos ciegos.

Como resultado imprevisto del actuar de las generaciones anteriores, nuestra reflexión es necesariamente transectorial y transdisciplinaria, y en algunos casos también intercultural, pues nuestra generación cuenta con muchos profesionistas, académicos, intelectuales y artistas indígenas de primera y segunda generación con formación occidental. Si podemos sacarle provecho a estas circunstancias es creando una síntesis de las lecciones aprendidas en cada sector para generar propuestas integrales, así el migrar entre sectores -por decisión u obligación- no sería un impedimento para la consecución de una agenda compartida orientada al bien común. ¿Cómo empezamos? como lo han hecho todas y cada una de las generaciones que nos han precedido y enseñado: conversando en busca de acuerdos correspondientes a las necesidades de nuestra época.

La competencia intersectorial es estéril y en la suma cero se reproducen las desigualdades. Los maniqueísmos, las ideologías cerradas, la negación de lo diferente, las arrogancias y resentimientos ya no deben tener cabida. Es necesario articular esfuerzos transdisciplinariamente manteniendo una vigilancia ética y 
epistemológica constante, sin ignorar las múltiples asimetrías de poder y privilegio. Nos toca plasmar nuestras propias líneas en la carta de amor para el futuro que se escribe de una generación a otra.

Este proceso de creación de posibilidades implica también la cancelación progresiva de las posibilidades de un retorno o recrudecimiento de los aspectos perniciosos de la cultura política que arrastramos hasta la actualidad, como el clientelismo, el asistencialismo, el individualismo neoliberal como premisa de la convivencia, el sexismo, el racismo y el clasismo. Si este momento de la vida pública de México en general -la Cuarta Transformación- y el Proyecto Tren Maya en particular son una oportunidad o un último clavo al ataúd del país y la región sursureste, depende de la coordinación de voluntades intersectoriales y, en buena medida, de la activa participación de la sociedad civil.

En este sentido, expongo algunas recomendaciones a consideración de todos los actores del campo político del Proyecto Tren Maya, para que este pueda reducir y no reproducir o profundizar las desigualdades existentes en la región sur-sureste de México:

1. Realizar los estudios ambientales pertinentes para garantizar la sostenibilidad de los servicios ambientales que brindan los ecosistemas de la Península;

2. Revisar que los indicadores de pobreza de los programas de vivienda y planeación urbana no estén culturalmente sesgados y consideren como signos de pobreza características de la cotidianidad de las poblaciones locales, vulnerando la reproducción cultural y/o la libre elección del estilo de vida;

3. Garantizar las condiciones para que vincularse a las Comunidades Sustentables sea una opción y no la única opción para las poblaciones cercanas;

4. Generar las condiciones para que la inserción de la población maya en las Comunidades Sustentables no se limite a garantizar la mera subsistencia, sino que siente las bases para la creación de una sociedad maya peninsular con movilidad social ascendente;

5. Promover el respeto a las poblaciones locales y su empoderamiento sin folklorizar -incluso penando la folklorización- para evitar que se reproduzca el 
clasi-racismo estructural ante la llegada de colonos y turistas de otras regiones del país y el extranjero, como ocurrió en la costa quintanarroense;

6. Garantizar la comunicación intercultural mediante la participación de traductores en los eventos y actividades en torno al PTM;

7. Generar canales de diálogo intersectorial eficientes e incluyentes;

8. Incentivar la producción agroecológica, pesquera, acuícola, artesanal, etc. y generar cadenas de valor ligadas a la actividad turística;

9. Crear un Fondo Maya para la atención de problemáticas sociales de las localidades mayas así como para la revitalización de la lengua, promoción, producción y difusión artística de creadores mayas;

10. Crear un Impuesto Maya para todas las empresas, programas y proyectos lucrativos que usen el etnónimo maya en su marca, productos y servicios, destinado al Fondo Maya;

Con el Proyecto Tren Maya, si se concreta, iniciará un momento interesante en la historia social, económica, cultural y política de la región sur-sureste de México/Península de Yucatán. Tal vez se trate del detonante de cambios profundos, quizá observemos en el futuro cercano la proletarización y desindianización masiva de la población mayahablante o la mayanización generalizada de la población como proyecto de Estado o como consecuencia imprevista de la actividad turística. Quizá veamos la profundización de las desigualdades interétnicas a raíz del turismo o se logre aprovechar esta actividad para fortalecer económica y políticamente a las poblaciones locales y reivindicar la identidad maya. Quizá las poblaciones locales ya no tengan que migrar de sus lugares de origen para subsistir o tal vez sean desplazadas legal y sistemáticamente.

El objetivo trazado para este trabajo fue ofrecer un balance de la disputa por recursos materiales e inmateriales significativos en torno a la construcción del PTM, de agosto del 2018 a marzo del 2019, analizando las acciones, alianzas, antagonismos, narrativas y usos simbólicos desplegados por diversos sectores sociales, como son el gubernamental, empresarial, dueños legales de las tierras, académico, Organizaciones de la Sociedad Civil (OSC), activismo étnicoambientalista y periodístico. 
El balance tuvo resultados razonables puesto que se identificaron y analizaron las acciones, reacciones, discursos, alianzas y antagonismos de los actores del Campo Político del Proyecto Tren Maya que tuvieron lugar durante las fases de ruptura y crisis del drama social del PTM; se estableció un criterio útil de clasificación de la diversidad de actores; se propuso una ruta para la comprensión y análisis de los recursos materiales e inmateriales en disputa para este proceso político que puede ser replicado; se identificaron, analizaron, explicaron y se reflexionó sobre las narrativas que se presentaron a lo largo de las dos fases del drama social abordadas; se creó una clasificación etic de las narrativas de la mayanidad vigentes actualmente en la Península de Yucatán; y se generó una serie de propuestas a los actores del campo político del Proyecto Tren Maya para que este, de realizarse, pueda reducir y no reproducir o profundizar las desigualdades interétnicas existentes en la región sursureste de México/Península de Yucatán.

En la tesis doctoral planeo seguir el desenvolvimiento del proceso político del Tren Maya en la Península de Yucatán, con un trabajo de campo amplio que permita dar cuenta de las percepciones locales en diferentes lugares de la Península, atendiendo en buena medida a las acciones que los diversos actores llevan a cabo para intentar disminuir las desigualdades sociales, ya sea mitigando efectos negativos previstos del Tren Maya o planeando rutas para la optimización de los posibles beneficios. 


\section{Bibliografía}

Augé, Marc y Jean Paul Colleyn. 2004."La antropología de lo político" en Marc Augé y Jean Paul Colleyn ¿Qué es la antropología? Paidós básica.

BID. 2000. "Programa de Desarrollo Sostenible. Resumen del Proyecto presentado en el Seminario de Preservación del Patrimonio Cultural. Reunión anual de Gobernadores del BID”. Disponible en: https://cedocvirtual.sectur.gob.mx/janium/Documentos/004212Pri0000.pdf Pp.31-33.

Brysk. 2009. De la tribu a la aldea global. Derechos de los pueblos indígenas, redes transnacionales y relaciones internacionales en América Latina. Barcelona: Ediciones Bellaterra.

CAFS-CD. 2019. Ficha Técnica del Tren Maya: Aspectos legislativos, ambientales, económicos $y$ socio-culturales. Disponible en: https://www.trenmaya.gob.mx/repositorio-de-documentos-oficiales/ (24/jul/20)

Cruz Cortés, Noemí. 2019. "Hunab Ku, revisión de una deidad en la Historia de Yucatán de fray Diego López Cogolludo", en Estudios de Cultura Maya. Vol. 53 Pp.239-260

De la Peña, Francisco. 2012. "Profecías de la mexicanidad: entre el milenarismo nacionalista y la new age" en Cuicuilco, vol. 19, núm. 55, septiembre-diciembre, Pp. 127-143

Diamond, Jared. 2007. Colapso. Por qué unas sociedades perduran y otras desaparecen. México: Random House Mondadori

Díaz Cruz, Rodrigo. 2005. "El persuasivo espectáculo del poder. Rituales políticos y ritualización de la política" en Pablo Castro (Coord.) Cultura política, participación y relaciones de poder. El Colegio Mexiquense, UAM-I, México.

Díaz Cruz, Rodrigo. 2014. Los lugares de lo político, los desplazamientos del símbolo. Poder y simbolismo en la obra de Victor W. Turner. México: UAM-Gedisa.

Dirección General de Transporte Ferroviario y Multimodal. 2012. Manifestación de Impacto Ambiental modalidad regional para el proyecto denominado Tren Transpeninsular Mérida-Punta Venado. México. Disponible en: 
https://apps1.semarnat.gob.mx:8443/dgiraDocs/documentos/yuc/estudios/2014/31Y U2014V0001.pdf

Elbez, Melissa. 2017. “¿Quién es maya en un entorno turístico? Patrimonialización y cosmopolitización de la identidad maya en Tulum, Quintana Roo, México", en Cultura y representaciones sociales, vol. 11, núm. 22. Pp. 34-64.

FONATUR. 2020. Manifestación de Impacto Ambiental del Proyecto Tren Maya Fase

1. Disponible en: https://www.trenmaya.gob.mx/repositorio-de-documentos-oficiales/ $(24 / j u l / 20)$

FONATUR. s/f. “Información del Proyecto Tren Maya. Anexo Técnico”. Disponible en: https://www.gob.mx/cms/uploads/attachment/file/513993/TM ANEXO TECNICO V F2 1 .pdf $(24 / j u l / 20)$

Gasparello, Giovanna et al. 2019. “ ¿Sabías que el tren maya...? Proyecto de investigación. Producción de territorialidades y resistencia a los megaproyectos en la región maya". Disponible en: https://www.ccmss.org.mx/wp-content/uploads/trenmaya-colores.pdf $(23 / j u l / 20)$

Gasparello, Giovanna. 2020. ¡Que no te lleve el Tren! Regiones indígenas en contra del Tren Maya. Cuaderno 1. Km. 0: desigualdad, despojos y violencias. Contexto social y territorial, antecedentes y escenarios en la Zona Selva-Norte y Palenque, Chiapas. México: Pez en el árbol. Disponible en: https://kehuelga.net/IMG/pdf/quenotelleveeltren_web_print_062020.pdf

Giménez, Gilberto. 2005. "Territorio e identidad. Breve introducción a la geografía cultural”. En Trayectorias, vol. VII, núm. 17, enero-abril, Universidad Autónoma de Nuevo León, México, Pp. 8-24.

Gledhill, John. 2000. El poder y sus disfraces. Barcelona: Ediciones Bellaterra.

INEGI. 2019. Cuenta satélite de turismo de México, 2018. Comunicado de prensa núm. 700/19. Disponible en: http://datatur.sectur.gob.mx/Documentos\%20compartidos/CSTM_2018_Anexo.pdf 
Llanes Salazar, Rodrigo. 2016. Las reivindicaciones del Pueblo Maya: etnicidad y poder en Yucatán. Tesis doctoral en ciencias antropológicas por la Universidad Autónoma Metropolitana-Iztapalapa.

Llanes Salazar, Rodrigo. 2018. "Etnicidad maya en Yucatán: balances y nuevas rutas de investigación" en Estudios de Cultura Maya, LI, pp. 257-282.

Medina Domínguez, Alejandra. 2020. Destejiendo la acción colectiva: el movimiento social de oposición al nuevo aeropuerto de la ciudad de México en la región nororiente del Edomex (2014-2018). Tesis para optar al grado de Maestra en desarrollo rural por la

UAM-Xochimilco.

Disponible

en:

http://dcsh.xoc.uam.mx/podr/images/Tesis/Maestria/Medina Dominguez Alejandra. pdf

Moreno Acevedo, Elda. 2018. "Inventando el Mundo Maya. Los inicios de la aviación y el turismo en Yucatán, 1929-1969" en Norois. Environnement, aménagement, société. Recherche touristique: perspectives latino-américaines. Núm. 247, Pp. 95106. Disponible en: https://www.cairn.info/revue-norois-2018-2-page-95.htm

Naciones Unidas México. 2020. El trabajo de la ONU en relación con el Proyecto Tren Maya. Disponible en: https://onuhabitat.org.mx/images/Tren-Maya/ONU-en-el-TrenMaya.pdf $(23 / \mathrm{jul} / 20)$

Núñez Rodríguez. 2019. “¿El Tren Maya beneficiará a los ejidatarios de la Península de Yucatán mediante su incorporación al proyecto?" en Gasparello et al. IMPACTOS SOCIALES Y TERRITORIALES DEL TREN MAYA Miradas multidisciplinarias. Disponible en: https://www.academia.edu/40054725/IMPACTOS SOCIALES Y TERRITORIALES DEL TREN MAYA Miradas multidisciplinarias (24/jul/20)

Oslender, Ulrich. 1999. "Espacializando resistencia: perspectivas de 'espacio' y 'lugar' en las investigaciones de movimientos sociales". En Cuadernos de geografía, VIII, pp. 1-35.

Quintal Avilés, Ella Fanny. 2005. "Way yano’one: aquí estamos. La fuerza silenciosa de los mayas excluidos", en Miguel Bartolomé (ed.) Visiones de la diversidad: 
relaciones interétnicas e identidades indígenas en el México actual. México: Instituto Nacional de Antropología e Historia. Pp. 291-371,

Reygadas, Luis. 2008. La apropiación: Destejiendo las redes de la desigualdad. Barcelona. Anthropos/UAM-Iztapalapa.

Secretaría Ejecutiva OMM. 1996. Organización Mundo Maya. México.Disponible en: https://cedocvirtual.sectur.gob.mx/janium/Documentos/004212Pri0000.pdf

SHCP. 2020. Proyecto de presupuesto de egresos de la Federación 2021. Disponible en:

https://es.scribd.com/document/475326309/EM-Documento-

\section{Completo\#download\&from embed}

Subsecretaría de Planeación y Política Turística. 2019. Cuenta satélite del turismo de México 2018. Principales resultados. Disponible en: http://datatur.sectur.gob.mx/SitePages/ProductoDestacado3.aspx

Velázquez Ramírez, Adrián. 2013. "La producción política del espacio: el problema de la praxis". En Utopía y praxis latinoamericana. Revista internacional de filosofía iberoamericana y teoría social, año 18, núm. 63, octubre-diciembre, Pp. 63-74.

Villalobos Cavazos, Oswaldo. 2016. Del lacandón a la selva lacandona. La construcción de una región a través de sus representaciones y narrativas. UNAM: México.

Wieviorka, Michel. 2009. "¿A dónde va el debate sobre los nuevos movimientos sociales?", en Mestries,Francis, Pleyers, Geoffrey y Sergio Zermeño Los movimientos sociales: de lo local a lo global, Anthropos UAM-Azcapotzalco, Barcelona, México.

Zárate Vidal, Margarita. 2008. "Resistencias, sujetos y agencia. Comunidad, etnicidad y resistencia" $3^{a}$ versión (febrero 2008) para Rethinking histories of resistance in Brazil and Mexico project.

Zárate Vidal, Margarita. 2012. Resistencias en movimiento de dignidad, deseo y emociones. Una mirada antropológica. UAM-Iztapalapa: México. 


\section{ANEXO \\ Publicaciones escritas por académicos sobre el Proyecto Tren Maya}

Azamar Alonso, Aleida y Carlos Rodríguez Wallenius. 2020. Conflictos sociales por megaproyectos extractivos, de infraestructura y energéticos en la cuarta transformación. México: Rosa Luxemburg-Stiftung, Oficina Regional para México, Centroamérica y el Caribe. (48 págs.). Disponible en: http://www.rosalux.org.mx/sites/default/files/conflictos-megaproyectos-4t.pdf

Benítez, Jorge y Shelley Alexander. 2019. "Elementos de evaluación ambiental estratégica para el Proyecto Tren maya" (preliminar), (39 págs.). Disponible en: https://www.researchgate.net/profile/Jorge Benitez4/publication/331558425 Evalua cion Ambiental Estraregica preliminar del Proyecto Tren Maya/links/5c80063529 9bf1268d40456c/Evaluacion-Ambiental-Estraregica-preliminar-del-Proyecto-TrenMaya.pdf

Benítez, Jorge et al. 2019. "Impacto de la vía férrea y del crecimiento turístico asociado al Tren Maya; medidas de mitigación y cambios al diseño para las reservas de Calakmul y Balam Kú” (preliminar), (48 págs.) Disponible en: https://www.researchgate.net/publication/330994315 Impacto de la Via Ferrea y del Crecimiento Turistico Asociado al Tren Maya medidas de mitigacion y ca mbios al diseno para las reservas de Calakmul y Balam-ku

Ceceña, Ana Esther. 2019. "Geopolítica de los estrechos: Canales, trenes y conexiones catastróficas", en Panamá en Tehuantepec, colonización ferroviaria del sureste, en América Latina en Movimiento, núm. 547, Pp. 1-4. Disponible en: http://geopolitica.iiec.unam.mx/sites/default/files/2020-05/alem-547 0.pdf

Ceceña, Ana Esther et al. 2020. Observaciones a la Manifestación de Impacto Ambiental Tren Maya. México: UNAM-OLAG (25 págs.). Disponible en: http://geopolitica.iiec.unam.mx/node/848

Ceceña, Ana Esther y Alberto Hidalgo. 2019. "Turismo colonizador: la larga historia bajo amenaza", en Panamá en Tehuantepec, colonización ferroviaria del sureste, en América Latina en Movimiento, núm. 547, Pp. 13-14. Disponible en: http://geopolitica.iiec.unam.mx/sites/default/files/2020-05/alem-547 0. pdf 
Ceceña, Ana Esther y Josué Veiga. 2019. Avances de investigación. Tren Maya. México: UNAM-Observatorio Latinoamericano de Geopolítica. (52 págs.) Disponible en:

http://geopolitica.iiec.unam.mx/sites/default/files/202003/Tren\%20Maya.\%20Avances\%20de\%20investigacio\%CC\%81n\%202.pdf

Echenique March, Felipe. 2020. "El Tren Maya y la falsa aporía de la 4T" (34 págs.). Disponible en: https://www.snp-inahinvestigadores.org/wpcontent/uploads/2020/08/BB2La-apor\%C3\%ADa-del-Tren-Maya-y-la-4T-1.pdf

Escalante Gonzalbo, Paloma et al. 2019. Diagnóstico, observaciones $y$ recomendaciones sobre el Tren Maya en Quintana Roo (18 págs.). Disponible en: https://www.trenmayaenquintanaroo.com/2020/01/resumen-del-proyecto.html

Espadas Manrique et al. 2019. Perspectiva de los territorios del norte de la Península de Yucatán de cara al Tren Maya: Una visión integral de sus condiciones socioeconómicas, socioambientales y socioculturales al 2019. Mérida, México: CICY, UADY-Colectivo Popol Vuh, ITM, CIESAS-Peninsular, CIEA-Mérida, Articulación Yucatán. págs.)

Disponible

en: https://articulacionyucatan.files.wordpress.com/2020/04/gc-ttm-2-2019.pdf

GC-TTM. 2019. "Territorios mayas en el paso del tren: situación actual y riesgos previsibles" (resumen ejecutivo de un documento extenso en proceso de edición). México: CONACYT. (26 págs) Disponible en: http://geopolitica.iiec.unam.mx/sites/default/files/2020-03/RESUMEN-EJECUTIVO-

\section{GCTTM-ok.pdf}

Gasparello, Giovanna. 2019. "Mercantilización de la cultura: turismo y reordenamiento territorial", en Panamá en Tehuantepec, colonización ferroviaria del sureste, en América Latina en Movimiento, núm. 547, Pp. 21-23. Disponible en: http://geopolitica.iiec.unam.mx/sites/default/files/2020-05/alem-547 $0 . p d f$

Gasparello, Giovanna (coord.). 2019. Impactos sociales y territoriales del Tren Maya. Miradas multidisciplinarias. México: DEAS-INAH, DPE-UAM-X, Altépetl Desarrollo Comunitario Productivo y Ambiental A. C. (60 págs.). Disponible en: https://www.researchgate.net/publication/336699874 IMPACTOS SOCIALES Y T ERRITORIALES DEL TREN MAYA Miradas multidisciplinarias 
Gasparello, Giovanna (coord.). 2019a. “ ¿Sabías que el tren maya...? Proyecto de investigación. Producción de territorialidades y resistencia a los megaproyectos en la región maya" (23 págs.). Disponible en: https://www.ccmss.org.mx/wpcontent/uploads/tren-maya-colores.pdf

Núñez, Violeta. 2019. "El despojo financiero: los campesinos como "socios" del Tren Maya", en Panamá en Tehuantepec, colonización ferroviaria del sureste, en América Latina en Movimiento, núm. 547, Pp. 9-12. Disponible en: http://geopolitica.iiec.unam.mx/sites/default/files/2020-05/alem-547 $0 . p d f$

Núñez Rodríguez. 2019. “¿El Tren Maya beneficiará a los ejidatarios de la Península de Yucatán mediante su incorporación al proyecto?" en Gasparello et al. IMPACTOS SOCIALES Y TERRITORIALES DEL TREN MAYA Miradas multidisciplinarias. Disponible en: https://www.academia.edu/40054725/IMPACTOS SOCIALES Y TERRITORIALES DEL TREN MAYA Miradas multidisciplinarias

Prieto, Sergio. 2019. "(In)movilidades y megaproyectos: El Tren Maya y las nuevas Fronteras del Sur de México", en Panamá en Tehuantepec, colonización ferroviaria del sureste, en América Latina en Movimiento, núm. 547, Pp. 17-20. Disponible en: http://geopolitica.iiec.unam.mx/sites/default/files/2020-05/alem-547 $0 . p d f$

Ramírez Carrillo, Luis Alfonso. 2019. "Diez retos para un ferrocarril. El Tren Maya y el desarrollo social y económico del sureste mexicano", en Desarrollo Regional, núm. 274, Pp. 3-17. Disponible en: http://www.revistauniversitaria.uady.mx/pdf/274/ru2742.pdf

Ramírez Gutiérrez, Sandy y Josué Veiga. 2019. "Tren Maya: Máquina imparable de despojo empresarial", en Panamá en Tehuantepec, colonización ferroviaria del sureste, en América Latina en Movimiento, núm. 547, Pp. 24-27. Disponible en: http://geopolitica.iiec.unam.mx/sites/default/files/2020-05/alem-547 0.pdf

Reyes García, Casandra et al. 2019. "El tren maya ¿por qué están tan preocupados los biólogos?", Mérida, México: CICY, (7 págs.). Disponible en: https://www.cicy.mx/Documentos/CICY/Desde Herbario/2019/2019-06-20-Reyes-etal.-El-Tren-maya.pdf 


\section{Notas y referencias a pie de página}

\footnotetext{
${ }^{1}$ http://www.datatur.sectur.gob.mx/SitePages/RankingOMT.aspx

${ }^{2} \mathrm{https}$ ://www.elfinanciero.com.mx/mercados/estas-son-las-principales-fuentes-y-salidas-de-dolaresen-mexico-al-inicio-del-2018

${ }^{3}$ Miguel de la Madrid (1982-1988), Carlos Salinas de Gortari (1988-1994), Ernesto Zedillo Ponce de León (1994-2000), Vicente Fox Quesada (2000-2006), Felipe Calderón Hinojosa (2006-2012), Enrique Peña Nieto (2012-2018), Andrés Manuel López Obrador (2018-2024).

${ }^{4}$ Los objetivos dell Programa Mundo Maya de la OMM fueron: 1) Recuperación de Monumentos Arqueológicos e Históricos; 2) Transporte e Infraestructura Básica de Bajo Impacto; 3) Desarrollo de Microempresas y Adiestramiento; 4) Protección Ambiental y Promoción; 5) Participación Indígena y Consulta; 6) Desarrollo de Estrategia de Mercado (BID, 2000:3)

${ }^{5}$ es la unidad más larga del sistema calendárico maya conocido como cuenta larga. Equivale a 144,000 días, aproximadamente unos 394 años

${ }^{6} \mathrm{https}$ ://www.animalpolitico.com/2012/12/el-fin-del-mundo-segun-los-mayas-galacticos/

${ }^{7}$ Las profecías asociadas a la espera de un cambio radical de la sociedad son un componente destacado dentro del sistema de creencias de los grupos que integran el movimiento de la mexicanidad. A grandes rasgos, estas creencias se dividen en dos tipos: aquellas vinculadas a una ideología nacionalista nativista y revitalista, y aquellas asociadas al universo pararreligioso de la new age. Si las primeras corresponden a las corrientes más radicales y populares del neoindianismo mexicanista, las segundas son compartidas por las agrupaciones más elitistas y eclécticas. En ambos casos, la llegada de una nueva época histórica, dominada por el ethos civilizatorio prehispánico o por una espiritualidad autóctona, es prevista bajo diferentes formas (De la Peña, 2012:127)

${ }^{8}$ https://www.eleconomista.com.mx/estados/Programa-Mundo-Maya-fue-un-fracaso-CNT-201303040068.html

${ }^{9}$ https://cedocvirtual.sectur.gob.mx/janium/Documentos/004171Pri0000.pdf

${ }^{10}$ (Dirección General de Transporte Ferroviario y Multimodal, 2012:12)

${ }^{11} \mathrm{http}: / / \mathrm{www} . f c c m . c o m . m x / c h i a p a s . h t m l$

${ }^{12}$ https://aristeguinoticias.com/3001/mexico/videgaray-cancela-presupuesto-para-el-tren-mexicoqueretaro/

${ }^{13} \mathrm{https}: / /$ sipse.com/novedades-yucatan/cancelacion-tren-transpeninsular-bola-cantada-empresariosyucatecos-135248.html

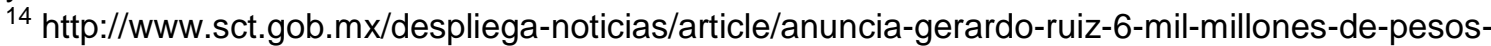
para-rehabilitar-la-via-ferrea-chiapas-mayab/

${ }^{15}$ https://www.jornada.com.mx/2010/11/14/politica/019n1pol

${ }^{16} \mathrm{https}: / /$ www.proceso.com.mx/318070/ciudades-rurales-sustentables-fracaso-de-sabines

${ }^{17}$ En 2017, la economía de dicha ciudad dependía fuertemente del turismo, pues el $49.6 \%$ del PIB de Cancún provino de las actividades turísticas y el $37.7 \%$ de los empleos se vinculan a dicha actividad. Fuente: https://qroo.gob.mx/qroo/cancun-lidera-con-el-pib-y-los-empleos-por-turismo-nivel-mundial

${ }^{18} \mathrm{https}$ ://qroo.gob.mx/qroo/cancun-lidera-con-el-pib-y-los-empleos-por-turismo-nivel-mundial

19 https://www.forbes.com.mx/quintana-roo-paraiso-perdido-por-laviolencia/\#: : :text=Esto\%20es\%20a\%C3\%BAn\%20m\%C3\%A1s\%20grave,por\%20cada\%20100\%20m il\%20habitantes.

${ }^{20} \mathrm{https}: / /$ www.dof.gob.mx/nota_detalle.php?codigo=5565599\&fecha=12/07/2019

$21 \mathrm{https}: / /$ www.trenmaya.gob.mx/

22 Tras un ejercicio de respaldo de la actualización referida, el contenido ocupó cien cuartillas usando el mismo formato de este escrito.

${ }^{23} \mathrm{https}: / /$ www.trenmaya.gob.mx/repositorio-de-documentos-oficiales/

${ }^{24}$ Al citar la MIA-TMF1 se señala el capítulo en números romanos y la página en números arábigos, ya que cada capítulo tiene su propia numeración.

${ }_{25}$ https://www.trenmaya.gob.mx/wp-content/uploads/2020/05/POLOS-TM 20200116-2.pdf

26 https://www.gob.mx/sre/prensa/firma-mexico-y-onu-habitat-convenio-para-dar-asistencia-tecnica-alproyecto-de-tren-maya?state=published

${ }^{27}$ https://onuhabitat.org.mx/index.php/fonatur-y-onu-habitat-firman-acuerdo-de-colaboracion
} 
${ }^{28}$ En la MIA-TMF1 aparece como "Objetivo 11. Ciudades y comunidades sustentables" (FONATUR, 2020:III:33), probablemente para homologar con el resto del archivo y demás documentos.

${ }^{29}$ https://www.trenmaya.gob.mx/comunidades-sustentables/

${ }^{30}$ Zona, no territorio como en la definición de polo de desarrollo

${ }^{31} \mathrm{https}$ ://www.yucatan.com.mx/mexico/el-tren-maya-tendria-un-serio-costo-social-en-la-peninsula-deyucatan

https://www.eleconomista.com.mx/estados/Comunidades-se-organizan-para-discutir-el-Tren-Maya20181202-0090.htm

${ }^{32}$ https://www.elfinanciero.com.mx/peninsula/estas-son-las-2-nuevas-estaciones-que-tendra-el-trenmaya

${ }^{33}$ https://www.bnamericas.com/es/noticias/ruta-de-tren-maya-cambia-tras-controversial-estudio

34 https://www.trenmaya.gob.mx/trazo/

35 Elaboración propia con información de: https://www.trenmaya.gob.mx/trazo/

${ }^{36}$ Para más información sobre el proceso de licitaciones ver el apartado 1.2.6

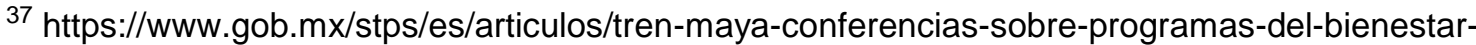
253122?idiom=es

${ }^{38}$ Aunque no aparece en la página oficial, AMLO ha declarado públicamente que la construcción de los tramos VI y VII estarán a cargo de la SEDENA:

https://www.eleconomista.com.mx/empresas/Construccion-por-Sedena-de-tramos-6-y-7-del-TrenMaya-ahorrara-25-fonatur-20200512-0010.html

39 Tabla de Gasparello et al. 2019:4, complementada con información de FONATUR, 2020:III:181

40 https://www.gob.mx/fonatur/prensa/el-tren-maya-presenta-modelo-financiero?idiom=es

${ }^{41}$ https://www.jornada.com.mx/2020/03/07/opinion/016a1pol

42 Es un Derecho de Visitante sin permiso para realizar actividades remuneradas que se cobra a los extranjeros que ingresan al país. En 2019 costaba $\$ 558.00 \mathrm{MN}$.

https://www.gob.mx/paisano/es/articulos/que-documentos-necesitas-para-ingresar-a-

mexico?idiom=es

${ }^{43}$ https://www.cmic.org/prepara-fonatur-plan-b-del-proyecto-tren-maya/

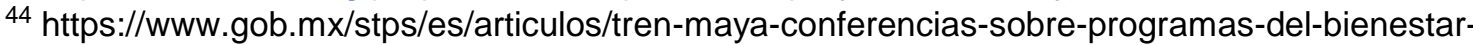
253122? idiom=es

${ }^{45} \mathrm{https}: / /$ www.elfinanciero.com.mx/economia/tren-maya-recibiria-48-mas-presupuesto-segunpaquete-economico-2021

${ }^{46} \mathrm{https}: / /$ www.forbes.com.mx/negocios-tren-maya-36-mil-mdp-2021-mas/

47 https://www.gob.mx/fonatur/prensa/el-tren-maya-un-proyecto-transparente

${ }^{48}$ https://www.elfinanciero.com.mx/empresas/invitaciones-y-adjudicaciones-directas-la-ruta-del-trenmaya

$49 \mathrm{https}: / /$ piedepagina.mx/tren-maya-no-habra-fideicomisos-sino-algo-semejante-dice-fonatur/

${ }^{50} \mathrm{https}: / /$ lopezobrador.org.mx/2020/09/07/version-estenografica-de-la-conferencia-de-prensa-

matutina-del-presidente-andres-manuel-lopez-obrador-370/

51 https://www.proceso.com.mx/nacional/2020/10/21/trasnacionales-opositoras-las-empresas-

ganonas-en-fideicomisos-del-conacyt-251300.html

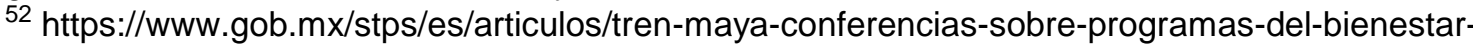

253122? idiom=es

${ }^{53}$ https://www.trenmaya.gob.mx/academia/

54 Elaboración propia con información de Naciones Unidas México, 2020

${ }^{55} \mathrm{https}$ ://www.trenmaya.gob.mx/asesores-tecnicos/

56 https://www.trenmaya.gob.mx/empresas-constructoras/

${ }^{57}$ Elaboración propia, fuentes al interior del cuadro

58 https://lopezobrador.org.mx/2018/08/13/nombra-lopez-obrador-a-rogelio-jimenez-en-fonatur-y-agabriela-camara-en-promocion-turistical

59 https://lopezobrador.org.mx/2018/11/12/encabeza-amlo-reunion-de-trabajo-en-yucatan-por-trenmayal

$\overline{60}$ https://lopezobrador.org.mx/2018/11/16/presenta-gobierno-electo-boleta-para-consulta-nacionalde-programas-prioritarios/

61 https://lopezobrador.org.mx/temas/toma-de-protesta/

62 https://www.gob.mx/presidencia/articulos/mensaje-del-presidente-andres-manuel-lopez-obradordurante-ceremonia-de-pueblos-originarios-para-construccion-del-trenmaya 
${ }^{63}$ https://www.gob.mx/fonatur/prensa/fonatur-aclara-nuevos-nombramientos-para-sus-empresasfiliales?idiom=es

${ }^{64} \mathrm{https}: / /$ www.megafonocampeche.com/2019/06/el-tren-que-nos-une-lleva-informacion.html

65 https://www.trenmaya.gob.mx/consulta-indigena/

66 https://www.animalpolitico.com/wp-content/uploads/2020/01/version-P\%C3\%BAblica-ACB-TrenMaya-08012020-VFI-vF-4.pdf

67 https://onuhabitat.org.mx/index.php/talleres-de-vision

$68 \mathrm{https}: / /$ www.dof.gob.mx/nota detalle.php?codigo=5591971\&fecha=21/04/2020

69 https://www.gob.mx/fonatur/prensa/fonatur-anuncia-empresa-ganadora-de-licitacion-del-tramo-1del-tren-maya-palenque-escarcega-240854

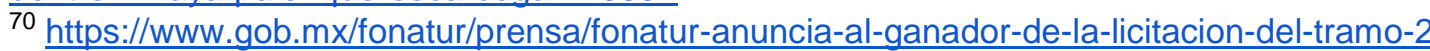

71 https://www.gob.mx/fonatur/prensa/fonatur-anuncia-al-ganador-de-la-licitacion-del-tramo-3-del-trenmaya

72 https://www.jornada.com.mx/2020/05/19/politica/008n1pol

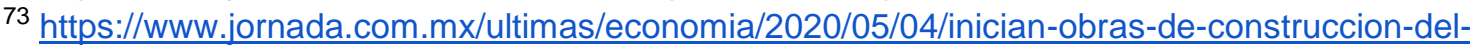
tramo-1-del-tren-maya-fonatur-2285.html

${ }^{74}$ https://presidente.gob.mx/01-06-20-version-estenografica-banderazo-de-inicio-de-obra-del-trenmaya-desde-lazaro-cardenas-quintana-roo/

${ }^{75} \mathrm{https}: / /$ presidente.gob.mx/02-06-20-version-estenografica-banderazo-de-inicio-de-obra-del-trenmaya-desde-maxcanu-yucatan/

${ }^{76} \mathrm{https}$ ://presidente.gob.mx/03-06-20-version-estenografica-banderazo-de-inicio-de-obra-del-trenmaya-desde-escarcega-campeche/

77 https://presidente.gob.mx/04-06-20-version-estenografica-banderazo-de-inicio-de-obra-del-trenmaya-en-palenque-chiapas/

78 https://www.gob.mx/fonatur/prensa/tren-maya-presenta-estudios-ambientales-para-los-tramos-1-2y-3-ante-semarnat

${ }^{79} \mathrm{http}: / /$ consultaspublicas.semarnat.gob.mx/proyectopublico/

80 https://www.jornada.com.mx/2020/07/07/politica/011n2pol

${ }^{81} \mathrm{https}: / /$ tabasco.gob.mx/noticias/firma-tabasco-convenio-de-colaboracion-alianza-mundo-mayamexico

82 La ONU como tal no es una OSC, es una organización de Estados nacionales de la que México forma parte. No obstante, tampoco es una instancia del Estado mexicano. Aunque los Estados nacionales aportan recursos para la subsistencia del organismo internacional, estos no se dan a modo de nómina y la ONU conserva cierta autonomía con respecto a los Estados miembros. Paralelamente las determinaciones de la ONU no son vinculantes y no puede condicionar ni determinar las acciones de ningún Estado. Sumado a esto, suele operar en los territorios nacionales en colaboración con OSCs locales e internacionales, en coordinación -o no interferencia- con las instancias de gobierno y sus agendas, al igual que las OSC de diversos tamaños. En este sentido, la ONU opera como una OSC sin serlo formalmente, más bien como La OSC que ordena las agendas, lenguajes y modos de operación de las OSC locales e internacionales mediante diseños como la Agenda 2030, los Objetivos del Desarrollo Sostenible (ODS), los Objetivos del Milenio, etc. Por esto, con fines analíticos, en este estudio se considera a la ONU como una OSC, aunque no lo sea formalmente.

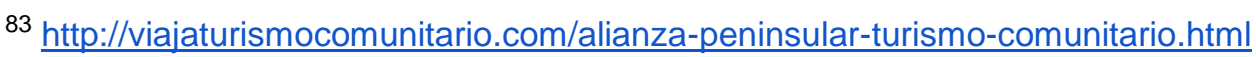

${ }^{84}$ Cabe mencionar que Llanes Salazar recurre también al método del drama social para analizar el proceso del Cha'anil Kaaj.

85 https://computos2018.ine.mx/\#/presidencia/nacional/1/1/1/1

${ }^{86} \mathrm{https}$ ://lopezobrador.org.mx/2018/08/13/nombra-lopez-obrador-a-rogelio-jimenez-en-fonatur-y-agabriela-camara-en-promocion-turistical

87 https://lopezobrador.org.mx/2018/08/13/nombra-lopez-obrador-a-rogelio-jimenez-en-fonatur-y-agabriela-camara-en-promocion-turistical

88 En 2018 hubo dos consultas nacionales promovidas por el presidente electo, para los fines de este estudio sólo la segunda es relevante. La primera Consulta Nacional, realizada del 25 al 28 de octubre, fue sobre la continuación o cancelación del Nuevo Aeropuerto Internacional de México (NAIM) en Texcoco, impulsado por el entonces presidente Enrique Peña Nieto del PRI; el resultado fue la cancelación de este y la opción por ampliar el aeropuerto existente y adaptar la base aérea militar de Santa Lucía. Para un análisis de este proceso se recomienda revisar el trabajo de Alejandra Medina Domínguez (2019). 
${ }^{89}$ https://lopezobrador.org.mx/2018/11/12/encabeza-amlo-reunion-de-trabajo-en-yucatan-por-trenmayal

${ }^{90} \mathrm{https}: / /$ www.uccs.mx/prensa/comunicados/carta-tren-maya-y-corredor-tehuantepec

${ }^{91}$ https://territoriosypatrimonio.wordpress.com/

92 Sobre el tema del colapso de la civilización maya y de otras es recomendable la obra Colapso del historiador Jared Diamond (2007).

${ }^{93}$ https://aristeguinoticias.com/2311/mexico/por-si-te-la-perdiste-entrevista-de-carmen-aristegui-aamlo-transcripcion/

94 https://issuu.com/pajaropolitico/docs/manifiesto sobre el tren maya

${ }^{95}$ (Consejo Regional Indígena y Popular de Xpujil S. C.-Romel Rubén González Díaz), Prodiversa A. C., Red de Productores de Servicios Ambientales Ya'ax Sot' Ot' Yook'ol Kaab A. C.-Humberto Vázquez León, Colectivo de Comunidades Mayas de los Chenes, Muuch Kambal A. C., Consejo Indígena de Atasta-Francisca Heredia Córdoba, Cladem Yucatán-Karen Montiel Cime, Movimiento de Resistencia Civil-Sara López González, Candelaria Campeche, Sociedad Cooperativa Turística Repobladores de Chiquila-David Valerio Espinoza y Ejido de Conhuas en Calakmul-Israel Oliveros López.

${ }^{96} \mathrm{Al}$ estar fuera de la temporalidad contemplada para este estudio, estos dos eventos no fueron incluidos en el análisis.

${ }^{97}$ Revisar el Anexo 1 donde se comparten referencias bibliográficas académicas sobre el PTM, revisadas pero no necesariamente analizadas en este trabajo. La mayoría fueron publicados después del corte temporal establecido para este estudio.

$98 \mathrm{https}: / /$ lopezobrador.org.mx/temas/consulta-nacional/

99 https://www.eleconomista.com.mx/politica/Resultados-de-la-segunda-consulta-un-89.9-voto-por-elsi-para-el-Tren-Maya-20181126-0027.html

100 https://lopezobrador.org.mx/2018/11/16/presenta-gobierno-electo-boleta-para-consulta-nacionalde-programas-prioritarios/

101 https://asambleamaya.wixsite.com/muuchxiinbal/single-post/2018/12/08/El-tren-maya-Rodandoentre-celdas-solares-y-aerogeneradores 102

https://twitter.com/gdehoyoswalther/status/1067171586820595712?ref src=twsrc\%5Etfw\%7Ctwcamp \%5Etweetembed\%7Ctwterm\%5E1067171586820595712\%7Ctwgr\%5E\&ref url=https\%3A\%2F\%2Fw ww.eluniversal.com.mx\%2Fcartera\%2Fun-fraude-la-segunda-consulta-de-amlo-coparmex

103 https://www.reporteindigo.com/reporte/tatiana-clouthier-responde-a-coparmex/

$104 \mathrm{https}$ ://lopezobrador.org.mx/2018/12/01/andres-manuel-lopez-obrador-rinde-protesta-comopresidente-constitucional-de-mexico/

${ }^{105}$ Video completo de la ceremonia y el discurso: https://www.youtube.com/watch?v=QR-JWPTp-T0

$106 \mathrm{https}$ ://lopezobrador.org.mx/2018/12/01/ceremonia-de-entrega-del-baston-de-mando-y-primerdiscurso-a-la-nacion/

107 "Los saludo en este día, le damos la bienvenida,

todos estamos aquí, mucho pedimos que le vaya bien, porque aquí es difícil, porque aquí es de los mestizos,

por eso estamos aquí, por eso estamos aquí con nuestro hermano, que no le sea difícil hermano nuestro, estamos contigo hermano,

iqué será de nuestro hermano!,

¡qué será de nuestro hermano el gran maestro!" (Fuente: https://www.eluniversal.com.mx/nacion/quele-dijo-amlo-el-indigena-que-se-le-hinco)

${ }^{108}$ https://www.eluniversal.com.mx/nacion/politica/ellos-son-quienes-entregaron-el-baston-de-mandoamlo

$\overline{109}$ http://www.cronica.com.mx/notas/2018/1102414.html

$110 \mathrm{https} / / /$ noticieros.televisa.com/ultimas-noticias/indigenas-entregan-amlo-baston-mando-zocalo/

111 Otros presidentes de México como Vicente Fox, Felipe Calderón y Enrique Peña; aligual que candidatos del PRI como Adolfo López Mateos, Luis Donaldo Colosio, José Antonio Meade han recibido bastones de mando indígenas (Fuente:

https://twitter.com/i/events/1069048868761976832?lang=es) pero no el día de la toma de protesta ni en el Zócalo capitalino. Igualmente, otros presidentes de Latinoamérica han recibido bastones de mando de los pueblos indígenas como Andrés Pastrana, Álvaro Uribe y Juan Manuel Santos en Colombia (Fuente: https://www.elmundo.es/america/2010/08/07/colombia/1281191714.html); Evo Morales en Bolivia (Fuente: https://eldeber.com.bo/bolivia/evo-recibe-baston-de-mando-en- 
tiahuanaco 66986); y Rafael Correa en Ecuador

(Fuente:https://www.jornada.com.mx/2007/01/15/index.php?section=mundo\&article=034n1mun)

112 https://www.animalpolitico.com/2018/12/discurso-amlo-zocalo/

$113 \mathrm{https://www.youtube.com/watch?v=QR-JWPTp-T0,} \mathrm{(1:40:00)}$

114 https://www.milenio.com/politica/presentan-baston-de-mando-que-entregaran-a-amlo

$115 \mathrm{https}$ ://www.milenio.com/politica/presentan-baston-de-mando-que-entregaran-a-amlo

116 https://www.eluniversal.com.mx/nacion/politica/impiden-indigenas-pasar-templete-para-entregar-

baston-de-mando-amlo

117 https://www.eluniversal.com.mx/nacion/politica/impiden-indigenas-pasar-templete-para-entregarbaston-de-mando-amlo

${ }^{118}$ https://www.servindi.org/actualidad-noticias/10/10/2017/la-gubernatura-indigena-pantomima-del-

pri

$\frac{019}{119} \mathrm{http} / / /$ www.cronica.com.mx/notas/2018/1102302.html

120 https://www.proceso.com.mx/571463/destituyen-a-lider-maya-por-asistir-a-la-entrega-del-bastonde-mando-a-amlo

${ }^{121}$ https://www.proceso.com.mx/571463/destituyen-a-lider-maya-por-asistir-a-la-entrega-del-bastonde-mando-a-amlo

122 Video completo del evento: https://www.youtube.com/watch?v=HI0oUF-7cZA

${ }^{123} \mathrm{https}$ ://www.proceso.com.mx/564126/amlo-pide-permiso-a-la-madre-tierra-y-ayuda-a-empresariospara-el-tren-maya-video

${ }^{124}$ Discursos de Escandón, Ramírez y Jiménez Pons:

https://www.gob.mx/presidencia/prensa/diversas-intervenciones-durante-la-ceremonia-de-pueblosoriginarios-a-la-madre-tierra-para-anuencia-del-tren-maya

${ }^{125}$ https://www.gob.mx/presidencia/articulos/mensaje-del-presidente-andres-manuel-lopez-obrador-

durante-ceremonia-de-pueblos-originarios-para-construccion-del-trenmaya

${ }^{126}$ https://www.gob.mx/presidencia/articulos/mensaje-del-presidente-andres-manuel-lopez-obrador-

durante-ceremonia-de-pueblos-originarios-para-construccion-del-trenmaya

${ }_{127} \mathrm{https}: / / w w w . j o r n a d a . c o m \cdot m x / 2006 / 03 / 18 /$ index.php? section=politica\&article=013n1pol

$128 \mathrm{https://www.bbc.com/mundo/noticias-america-latina-44979322}$

129 En el Caracol de la Realidad Ilamado "MADRE DE LOS CARACOLES DEL MAR DE NUESTROS SUEÑOS", está ubicada la JUNTA DE BUEN GOBIERNO SELVA FRONTERIZA "HACIA LA ESPERANZA", que comprende los siguientes Municipios Autónomos: General Emiliano Zapata, San Pedro de Michoacán, Libertad de los Pueblos Mayas, Tierra y Libertad. Abarca desde Marqués de Comillas, la región de Montes Azules y todos los municipios fronterizos con Guatemala hasta Tapachula. Sus habitantes son mayoritariamente tojolabales, tseltales y mames (Fuente: http://www.cedoz.org/site/content.php?doc $=481 \&$ cat $=82$ )

130 https://radiozapatista.org/?p=29845

131 https://radiozapatista.org/?p=29845

$132 \mathrm{https://radiozapatista.org/?page} \mathrm{id=30081}$

133 https://radiozapatista.org/?p=29835

134 https://radiozapatista.org/?p=29845

135 https://lopezobrador.org.mx/2019/01/02/version-estenografica-de-la-conferencia-de-prensamatutina-del-presidente-andres-manuel-lopez-obrador-14/

136 1) Reforma:

https://www.reforma.com/aplicacioneslibre/preacceso/articulo/default.aspx? rval=1\&urlredirect=https ://www.reforma.com/nadie-me-va-a-cucar-amlo/ar1575201?referer=--

7d616165662ł3a3a6262623b727a7a7279703b767a783a--

2) El Universal: https://www.youtube.com/watch?v=pCwIT3bU9uQ

3) Proceso: https://www.proceso.com.mx/565910/sobre-el-ezln-no-me-van-a-cucar-responde-amlo

137 https://enlacezapatista.ezln.org.mx/2019/01/09/carta-de-solidaridad-con-el-ezln-de-lacoordinadora-metropolitana-anticapitalista-colectivos-e-individuos/

138 1) http://comunizar.com.ar/carta-solidaridad-apoyo-la-resistencia-la-autonomia-zapatista/

2) https://blogs.mediapart.fr/les-invites-de-mediapart/blog/170119/carta-internacional-de-solidaridady-apoyo-la-resistencia-y-la-autonomia-zapatista

3) https://www.facebook.com/Resonancias.Radio/posts/1269358713221895

139 https://www.trenmaya.gob.mx/aliados/

140 https://www.yucatan.com.mx/merida/politica/apoyo-indigena-peninsular-al-tren-maya 
${ }^{141} \mathrm{https}: / /$ sipse.com/novedades-yucatan/tren-maya-yucatan-foro-indigena-proyecto-325469.html

142 https://www.yucatan.com.mx/merida/si-al-tren-maya

143 https://www.servindi.org/actualidad-noticias/10/10/2017/la-gubernatura-indigena-pantomima-del-

pri

144 https://sipse.com/novedades-yucatan/tren-maya-yucatan-foro-indigena-proyecto-325469.html

$145 \mathrm{https}: / /$ sipse.com/novedades-yucatan/tren-maya-yucatan-foro-indigena-proyecto-325469.html

146 https://www.yucatan.com.mx/merida/si-al-tren-maya

147 https://pri.org.mx/SomosPRI/SaladePrensa/Nota.aspx?y=31472

148 https://www.gob.mx/fonatur/prensa/fonatur-participo-en-foro-indigena-para-presentar-el-trenmaya?idiom $=$ es

149 http://www.cronica.com.mx/notas/2018/1104250.html

150 Melissa Elbez estudia el caso de Tulum: personas originarias de varias partes del mundo, se autodenominan "mayas" conforme a una teoría según la cual los mayas prehispánicos eran de origen galáctico (extraterrestre), excluyen a los mayas contemporáneos de su ascendencia al considerar que sus herederos legítimos son los depositarios (de todas las procedencias) del saber cósmico que legaron aquellos a la humanidad y que el líder New Age, José Arguelles, ha sido capaz de descifrar y de traducir para sus seguidores (Elbez, 2017:59).

151 https://www.yucatan.com.mx/merida/los-mayas-buscan-consenso

152 El in lak'ech / hala ken es un saludo acuñado por Domingo Martínez Paredes en 1964, en su libro Hunab Ku: síntesis del pensamiento filosófico maya, representando al Hunab Ku con un cuadrado dentro de un círculo o un círculo dentro de un cuadrado. También vinculó al Hunab Ku con la expresión maya "In lak'ech" (dizque Yo soy otro tú ) que se respondía "Hala Ken" (dizque Tú eres otro yo ). Este es un "saludo" que nada tiene que ver con los pueblos mayas, ya que en cada comunidad (ya sea en México, Guatemala, Honduras, Belice o El Salvador) hay una forma diferente de saludar, y la mayoría de los saludos expresan algo sobre el alma, el corazón o el ser (Guillermo Kantún: https://popol-mayab.org/2015/09/06/in-lakech/)

$153 \mathrm{https}: / /$ www.lajornadamaya.mx/yucatan/21041/RUTA YUC CULTURA

$154 \mathrm{https}$ ://www.proceso.com.mx/633864/amenazan-con-quemar-vehiculos-de-grupo-carso-si-nocontrata-a-lugarenos-para-tren-maya

${ }^{155}$ En el siguiente sitio se puede consultar el video de la rueda de prensa y el comunicado en castellano y maya yucateco:

http://www.nuestravoz.maayakaaj.org/?fbclid=IwAR2_UglrVV3G1m2v_j2KqmRdnGIN3_bbTvpxZQxiSmRF7ncxDpUAcKTCkQ

$156 \mathrm{https}$ ://www.noticiascontrapunto.com.mx/ni-caso-hacerles-ku-chan-a-sus-detractores/

$157 \mathrm{http}: / /$ www.uxmalresortmaya.com/spadecerveza

158 http://www.hazruido.mx/reportes/lamentable-tuit-de-fridman-exalta-la-esclavitud-maya/ 


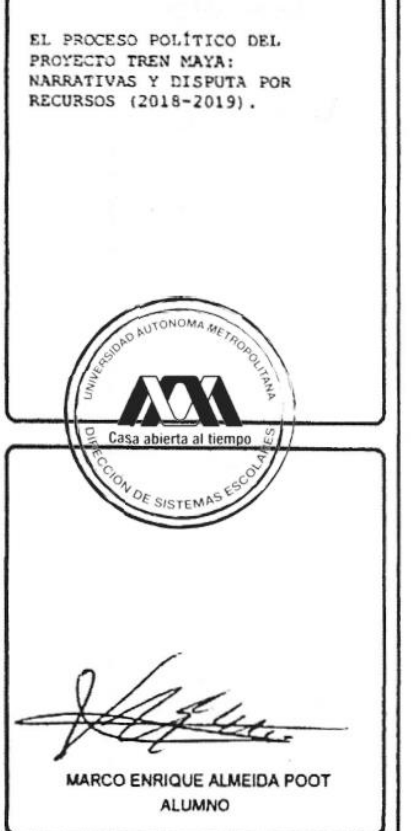

Con base en la Legislación de la Universidad AutGnoma Metropolitana, en la Ciudad de México so presentaron a las

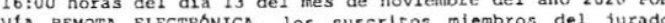

DRA, ELLA FANAYY OUINTAL AVILES

DR. SAMUEL FRANCOIS JOUAULT

DR. LUIS BERNARDO REYGADAS ROBLES GIL

Bajo la Presidencia de la prinera y con carácter de Secretario el úlimo, se reunleron para proceder al Examen de Grado cuya denominacion aparece al margen, para la obtencion del qrado de:

MAESTRO EN CIENCIAS ANTROPOLOGICAS

DE: MARCO EMRIQUE ALMEIDA POOT

$y$ de acuerdo con al articulo 78 fraccion III del Reglamento ce Estudios Supertores de la Universidad Autónoma

\section{APROBAR}

REVSO

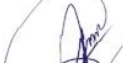

ntinuo, in presidenta del jurado comunicó al interesado el resultado de la evaluación y, en caso aprobatorio, le tue comada ta protesta.

MTRA ROSALL SERRANO DE LA PAZ

DRECTOR DE LA DIVSION DE CSH

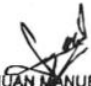

DR. JUAN N NUEL HERRERACABALLERO

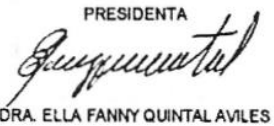

VOCAL

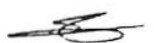

SECRETARIO

Luis Reygadas

DR. LUIS BERNAR OO REYGADAS ROBLES

DR. SAMUEL FRANCOIS JOUAULT

El presente documento cuenta con la firma -autógrafa, escaneada o digital, según corresponda- del funcionario universitario competente, que certifica que las firmas que aparecen en esta acta - Temporal, digital o dictamen- son auténticas y las mismas que usan los c.c. profesores mencionados en ella 